NBSIR 75-783

\title{
Validation of the DELCAP Airport Simulation Model
}

Judith F. Gilsinn

Institute for Basic Standards Applied Mathematics Division Operations Research Section National Bureau of Standards

Washington, D. C. 20234

July 1975

Final Report

Technical Report to:

Systems Research and Development Service Federal Aviation Administration Department of Transportation Washington, D. C. 20590

Report No. FAA-RD-75-154 
Production Section

335027

A-607, Admin. Bldg.

National Bureau of Standards

Washington, D.C. 20234

Re your report: NBSIR-75-783, "Validation of the DELCAP Airport Simulation Model"

We are not able to process your report for the following reasons. Please make the corrections necessary and returm the document and this letter to us. Report format is to conform with the ANSI standard, ANSI Z39.18, entitled "Format and Production for Scientific and Technical Reports" available @ \$4.00 from the American National Standards Institute, Inc., 1430 Broadway, New York, New York 10018 .

$\square$ 1. Pages are missing.

2. All pages are not numbered and some could therefore be missing. We suggest author or editor number the pages consecutively throughout the document, or within chapters if prefixed by the chapter designation.

3. Some pages are not reproducible.

4. A Bibliographic Data Sheet (BDS) must accompany each title. Blank forms are enclosed.

5. This document has copyright or other restrictions. Please furnish written authorization for NTIS to reproduce and sell to the public.

6. An Accession Notice Card must accompany each title. Blank forms are enclosed.

7. We cannot microfiche pages larger than the standard $8 \frac{1}{2} \times 11$ in one frame (see ANSI standard). Please reduce pages exceeding $8 \frac{1}{2} \times 11$ in this document before returning and limit the page size of future documents to standard size.

8 8. The document is not reproducible due to insufficient contrast between the print and paper or broken print. Some pages, but not all, are indicated by blue check. Please examine all pages and fumish at least one clean, clear, reproducible copy.

Sincerely,

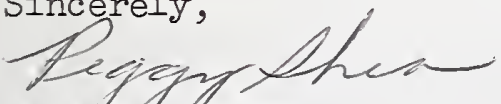

JOHI H. ASHTEY, Chief

Input Branch

Phone: 703-321-8517

IES/mdj

Form NTIS-63 (Rev. $7-74$ ) 
NBS-I14A (REV. T-73)

\begin{tabular}{|c|c|c|c|}
\hline $\begin{array}{l}\text { U.S. DEPT. OF COMM. } \\
\text { BIBLIOGRAPHIC DATA } \\
\text { SHEET }\end{array}$ & $\begin{array}{l}\text { 1. PUBLIL ATION OR REYORT NO. } \\
\text { NBSIR-75-783 }\end{array}$ & $\begin{array}{l}\text { 2. (iov't Accession } \\
\text { No. }\end{array}$ & 3. Recipient's Accession No. \\
\hline \multirow{2}{*}{\multicolumn{3}{|c|}{$\begin{array}{l}\text { 4. TITI.E AND SUBTITI. } \\
\text { Valditation of the DELCAP Airport Simulation Model }\end{array}$}} & $\begin{array}{r}\text { 5. Publication Date } \\
\text { July } 1975\end{array}$ \\
\hline & & & 6. Performing Organization Code \\
\hline \multicolumn{3}{|l|}{$\begin{array}{l}\text { 7. AUTHOR(S) } \\
\text { Judith F. Gilsinn }\end{array}$} & 8. Performing Organ. Report No. \\
\hline \multirow{2}{*}{\multicolumn{3}{|c|}{$\begin{array}{l}\text { 9. PERFORMING ORGANIZATION NAME AND ADDRESS } \\
\text { NATIONAL BUREAU OF STANDARDS } \\
\text { DEPARTMENT OF COMMERCE } \\
\text { WASHINGTON, D.C. } 20234\end{array}$}} & $\begin{array}{l}\text { 10. Project/Task/Work Unit No. } \\
2050490\end{array}$ \\
\hline & & & 11. Contract/Grant No. \\
\hline \multirow{2}{*}{\multicolumn{3}{|c|}{$\begin{array}{l}\text { 12. Sponsoring Organization Name and Complete Address (Street, City, State, ZIP) } \\
\text { Systems Research and Development Service } \\
\text { Federal Aviation Administration } \\
\text { Department of Transportation } \\
\text { Washingt on, D. C. } 20590\end{array}$}} & $\begin{array}{l}\text { 13. Type of Report \& Period } \\
\text { Covered } \\
\text { Final }\end{array}$ \\
\hline & & & 14. Sponsoring Agency Code \\
\hline
\end{tabular}

\section{SUPPLEMENTARY NOTI:S}

16. ABSTRACT (A 200-word or less factual summary of most significant information. If document includes a significant bibliography or literature survey, mention it here.)

This report documents exercises of the DELCAP airport simulation model performed to validate the outputs of that model. Airport throughput levels were calculated by DELCAP for five runway configurations, with three or four appropriate operating policies chosen for each, and for three different mixes of aircraft types. These estimates from DELCAP agreed well, genera11y within 6 to 8 percent, with current values provided by the FAA. An attempt at validating DELCAP's delay-figure output, using existing data on scheduled and actual times of aircraft departures and arrivals, is also reported. It proved unsuccessful, because available data are not sufficient to isolate that portion of total delay which DELCAP is designed to measure, i.e. terminal area ATC delay. A collection effort to accumulate the necessary data is formulated. Appendices to the report contain program listing, flowcharts, descriptions of program changes from earlier versions, and user instructions for the model's operation.

17. KEY WORDS (six to twelve entries; alphabetical order; capitalize only the first letter of the first key word unless a proper name; separaled by semicolons) Airport; airport capacity; airport simulation; models; model validation; runway capacity; simulation; validation.

18. AVAILABILITY $[\mathrm{x}$ Unlimited

For Official Distribution. Do Not Release to NTIS

[] Order From Sup. of Doc., U.S. Government Printing Office Washington, D.C. 20402, SD Cat. No. C13

XX Order From National Technical Information Service (NTIS) Springfield, Virginia 22151

\begin{tabular}{|l|c|}
\hline $\begin{array}{l}\text { 19. SECURITY CLASS } \\
\text { (THIS REPURT) } \\
\text { UNCL ASSIFIED }\end{array}$ & 21. NO. OF PAGES \\
\hline $\begin{array}{l}\text { 20. SFCURITY (IAASS } \\
\text { (THIS PAGE) }\end{array}$ & 22. Price \\
UNCLASSIFIED & $\$ 6.25$ \\
\hline
\end{tabular}





\section{VALIDATION OF THE DELCAP AIRPORT SIMULATION MODEL}

Judith F. Gilsinn

Institute for Basic Standards

Applied Mathematics Division

Operations Research Section

National Bureau of Standards

Washington, D. C. 20234

July 1975

Final Report

Technical Report to:

Systems Research and Development Service

Federal Aviation Administration

Department of Transportation

Washington, D. C. 20590

Report No. FAA-RD-75-154,

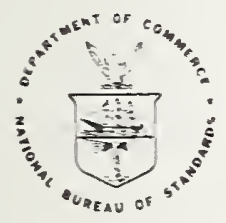

U.S. DEPARTMENT OF COMMERCE, Rogers C.B. Morton, Secretary James A. Baker, III, Under Secretary Dr. Betsy Ancker-Johnson, Assistant Secretary for Science and Technology

NATIONAL BUREAU OF STANDARDS, Ernest Ambler, Acting Director 

.

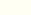




\section{ABSTRACT}

This report documents exercises of the DELCAP airport simulation model performed to validate the outputs (delay and capacity) of that model. Airport throughput levels were calculated by DELCAP for five runway configurations, with three or four appropriate operating policies chosen for each, and for three different mixes of aircraft types. These estimates from DELCAP agreed well, generally within 6 to 8 percent, with current values provided by the FAA. An attempt at validating DELCAP's delay-figure output, using existing data on scheduled and actual times of aricraft departures and arrivals, is also reported. It proved unsuccessful, because available data are not sufficient to isolate that portion of total delay which DELCAP is designed to measure, i.e. terminal area ATC delay. A collection effort to accumulate the necessary data is formulated. Appendices to the report contain program listing, flowcharts, descriptions of program changes from earlier versions, and user instructions for the model's operation.

Key Words: Airport; airport capacity; airport simulation; models; model validation; runway capacity; simulation; validation. 
(1) 


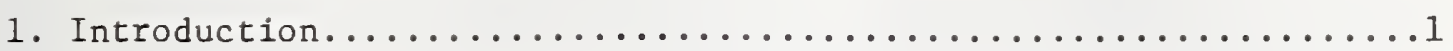

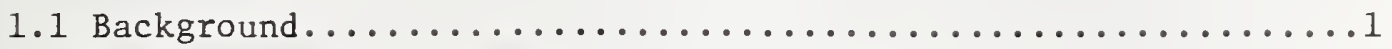

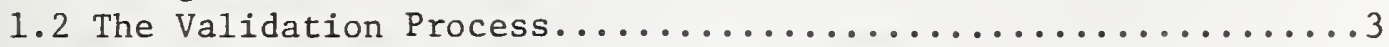

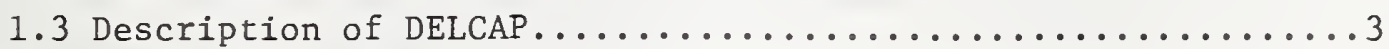

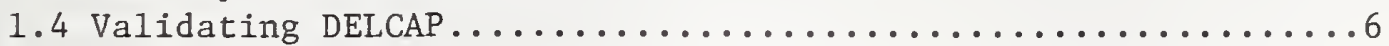

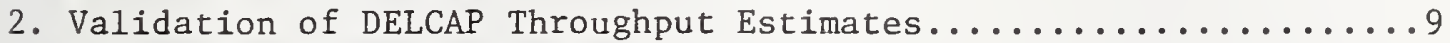

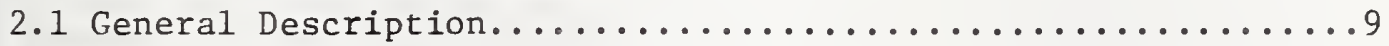

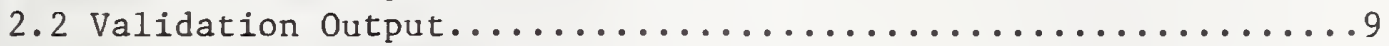

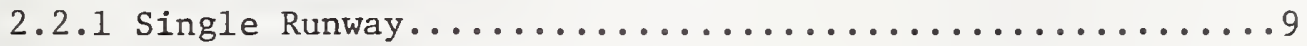

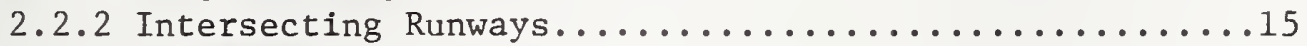

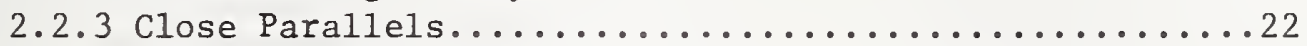

2.2.4 Close Parallels with an Intersecting Runway..........24

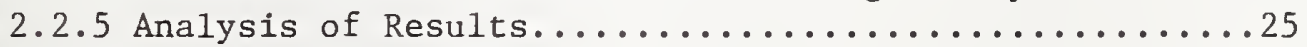

2.3 Comparisons of Model Output with Available Data..........29

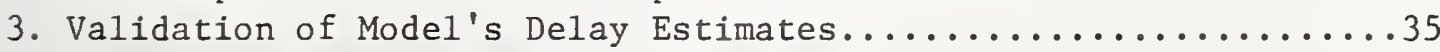

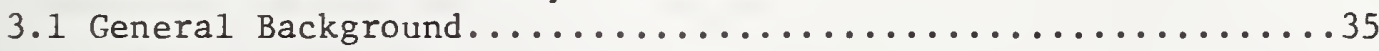

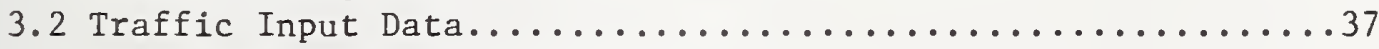

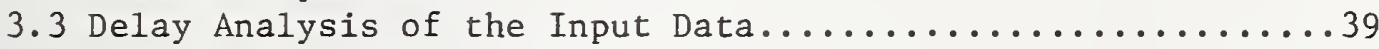

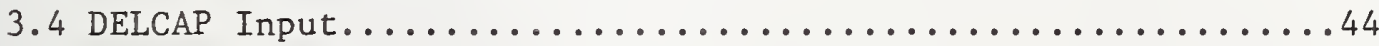

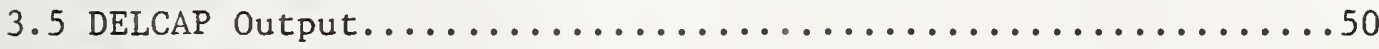

3.6 Data Required for DELCAP Delay Validation..............61

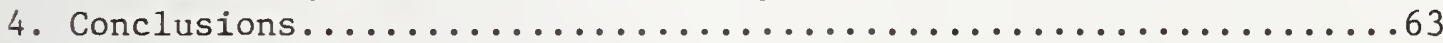

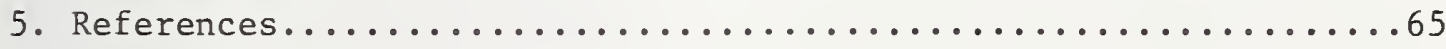

Appendix A. Changes and Additions to DELCAP...............66

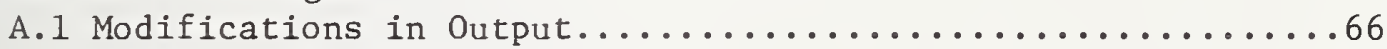

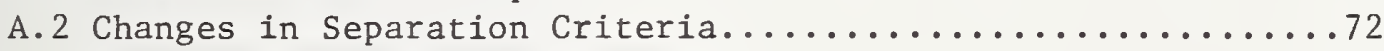

A.3 Improved Random Number Generator................... 72

A.4 Modifications in Operating Policy................... 72

A. 5 Changing Operating Policy During a Computer Run.........75

A. 6 New Preprocessor Standard Values....................... 76

Appendix B. Descriptions and Flowcharts of Simulation Events.....78

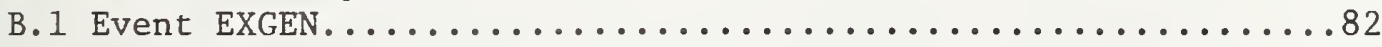

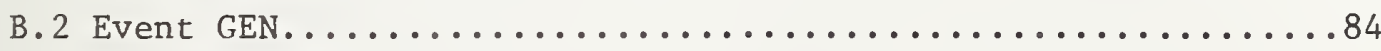

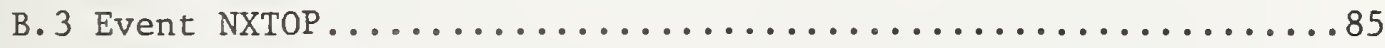

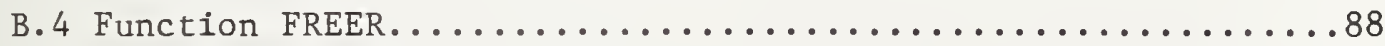

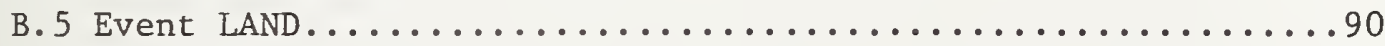

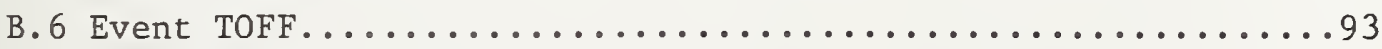

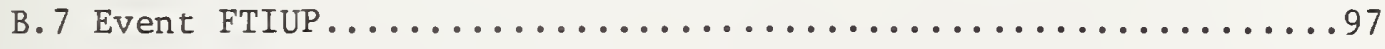

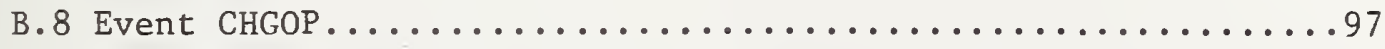

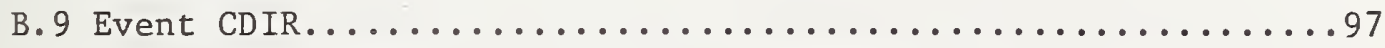

Appendix C. Mode1 Elements: Routines, Variables and Arrays,

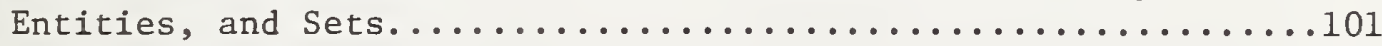

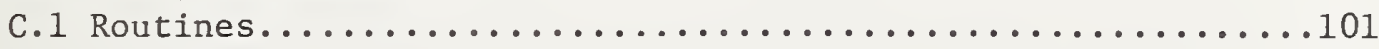

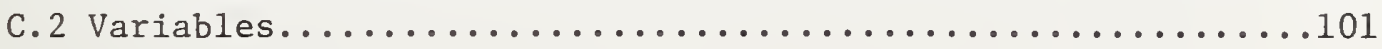




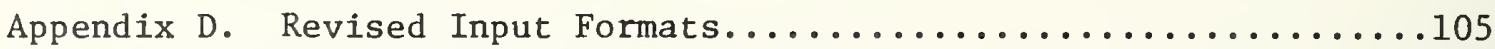

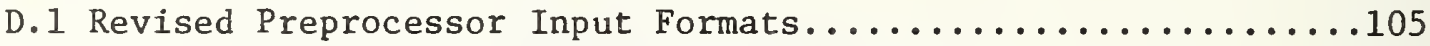

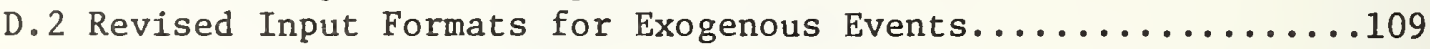

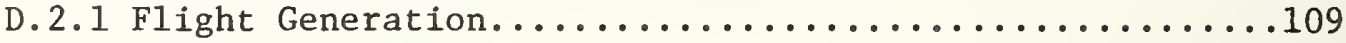

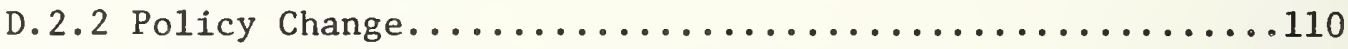

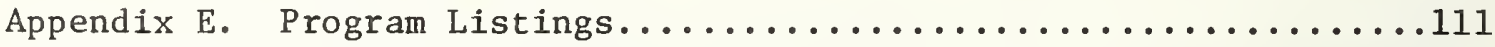

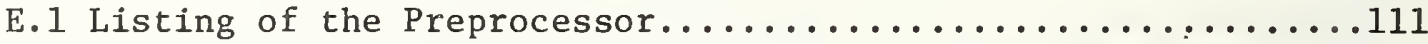

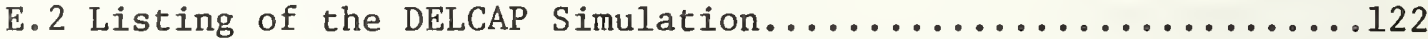

Appendix F. Processing the LGA Traffic Input Data.............142 


\section{LIST OF FIGURES}

page

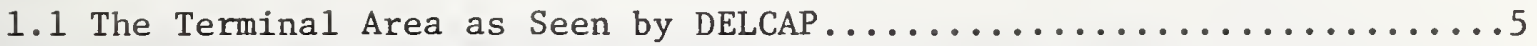

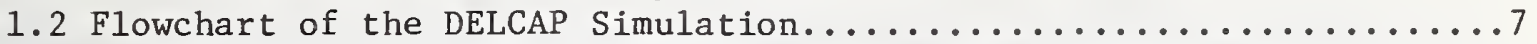

2.1 Hourly Throughput for a Single Runway Handling Only Takeoffs

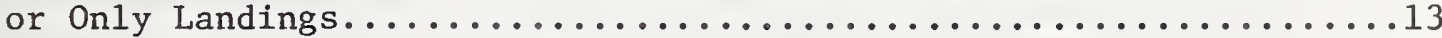

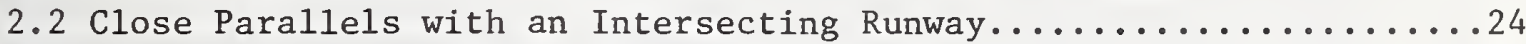

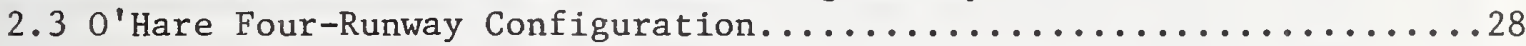

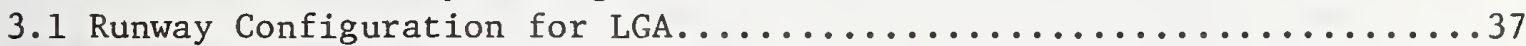

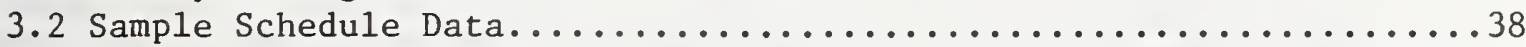

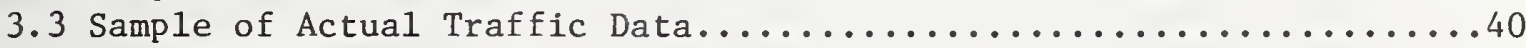

3.4 Delay Profiles Using LGA Input Data.......................

3.5 Preprocessor Output.................................

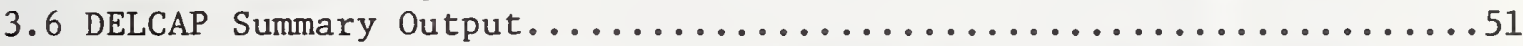

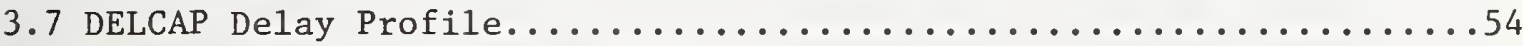

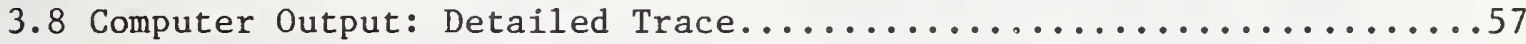

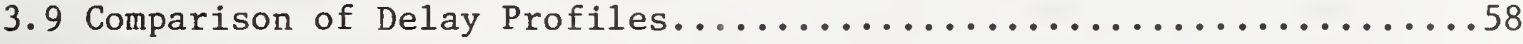

A.1 Sample Preprocessor Output.........................67

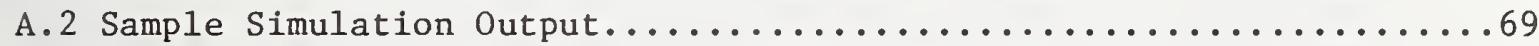

B.1 Flowchart of the DELCAP Simulation Routines..................

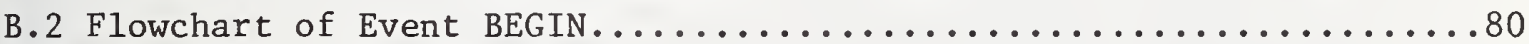

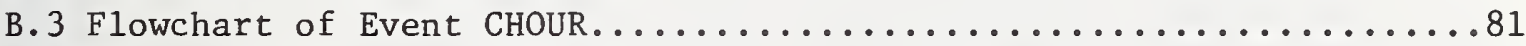

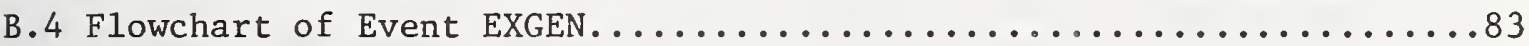

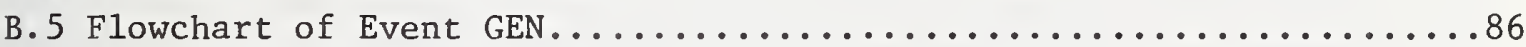

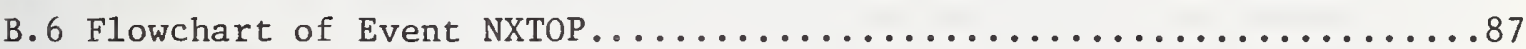

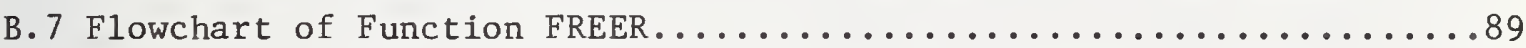

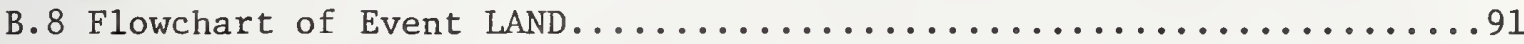

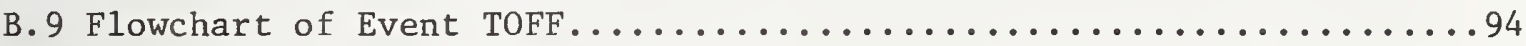

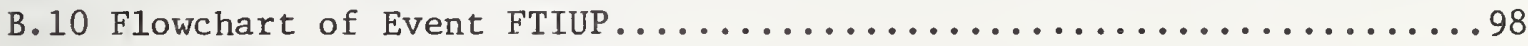

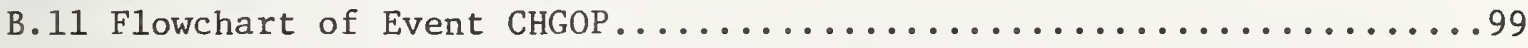

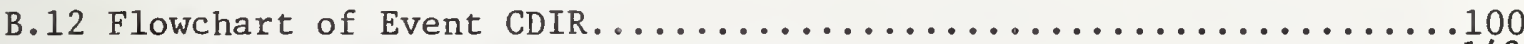

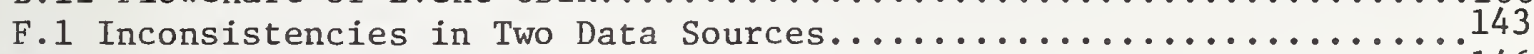

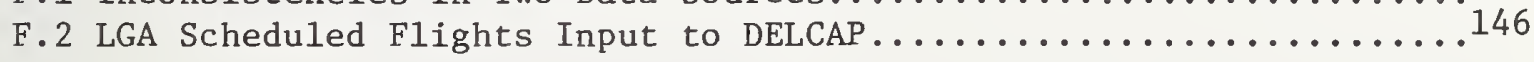


2.1 Aircraft Characteristics for Validation Runs.................

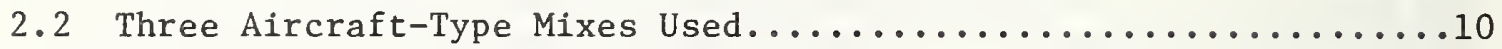

2.3 Configurations and Operating Policies for Validation Runs......11

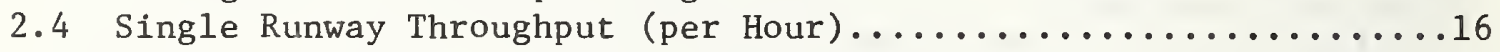

2.5 Hourly Throughput for Near Intersection (V) With Interference...18

2.6 Hourly Throughput for Near Intersection (V) Without

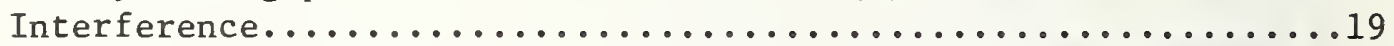

2.7 Hourly Throughput for Far Intersection (X) With Interference....20

2.8 Hourly Throughput for Far Intersection (X) Without

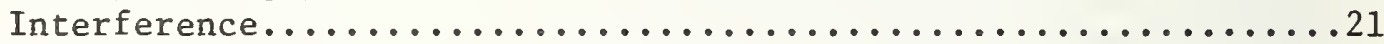

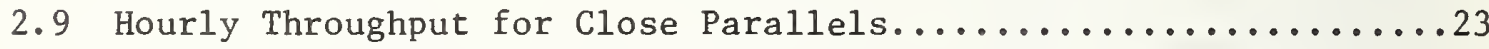

2.10 Hourly Throughput for Close Parallels Plus an Intersecting

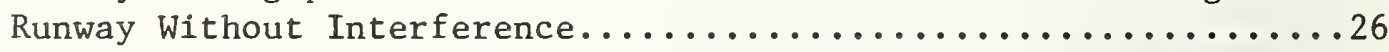

2.11 Hourly Throughput for Close Parallels Plus an Intersecting

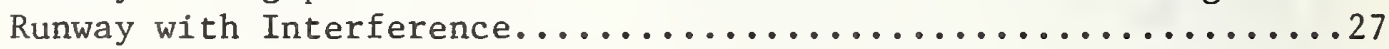

2.12 Throughput for Several Configurations at Selected Airports.....30

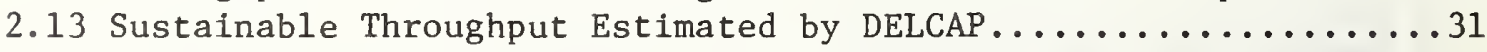

2.14 Comparison fo FAA Theoretical Throughput Estimates With Those

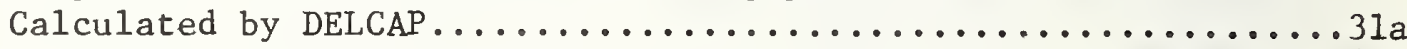

3.1 LGA General Aviation Traffic Levels by Hour................. 45

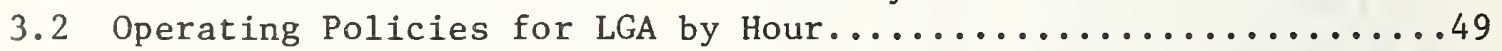

3.3 Example of the Detailed Trace of Simulated Operations........56

3.4 Number of Flights Delayed Excessively in Each Hour..........60

A.1 Sample Operating Policies............................ 74 


\section{INTRODUCTION}

\subsection{Background}

In 1969 the FAA asked the National Bureau of Standards (NBS) to review its Airport Capacity Handbook, developed by Airborne Instruments Laboratory (AIL) in June 1963, and to evaluate the possibility of reapplying or extending that Handbook's airport capacity model so as to account for new aircraft types and mixes of aircraft types. The documentation proved insufficient to permit reconstructing the AIL model, which in effect had been "lost" during the intervening years. Consequently NBS developed an analytical model, for the simple case of a single runway handling landings only, and documented it in [4] and [7]. See also [8] and [9] for similar results. Subsequently XBS extended the analytical model to dual-use runways and multi-runway configurations, in [5] and [6].

In the process of carrying out the extension, it became evident that the analysis for complex configurations was very difficult, and there was a possibility the analytical expressions would prove intractable. To ensure ability to handle a large range of configurations despite possible difficulties in the analytical modeling, it was decided to develop concurrently a simulation model. The DELCAP model, documented in [1], was the result of this effort. Its design principle, described in the first chapter of that documentation, is the "model as little as you can" philosophy under which only those system elements with direct influence on stipulated output measures are included in the model. This philosophy assumes a well-defined set of applications for which a model is to be designed, and recognizes that the resultant model may thus be unsuited for other applications. Specifically, DELCAP was designed to calculate average maximum throughputs and delays resulting from airport airside operations in a terminal area.

Input parameters which were included in the model, and therefore may be varied, include:

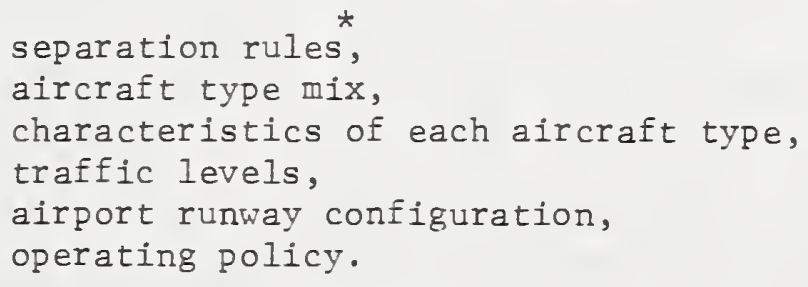

DELCAP was commissioned as a planning tool, and so major criteria in its design were that it be easy to use, have a short computer running time, and be economical enough to encourage its use to answer a variety of "what if" questions concerning airport capacities and airside delays.

* The non-metric units, nautical miles, knots, feet and pounds, used in this report are those customarily employed in aviation. 
The design and development of DELCAP were completed in this first effort, and the documentation was issued in May 1971. However, only illustrative runs designed to demonstrate its versatility and scope were made at that time.

In early 1974 the FAA's Air Traffic Service requested that the DELCAP model be reactivated, some modifications be made in it, and that it be validated for use in their Engineered Performance Standards (EPS) program for calculating target throughput levels at busy airports. This report documents that effort. An interim report [2] described the validation of throughput output from DELCAP; the results reported there have been incorporated in the present document to make it self-contained.

One caveat should be noted at the outset. The validation exercises reported here are aimed at assessing validity of DELCAP for a specific application, that of setting ATC system performance standards. The parameter ranges, configurations, and operating policies involved in the exercises are those to be found in that application. Therefore, although the validity of DELCAP has been established for input values in the ranges required by this one application, validity has not been established for all possible inputs and scenarios. The context of EPS presented a wide range of configurations and operating policies, so that our validation exercises do cover most of today's busy airport scenarios, indicating the model's usefulness in estimating throughputs at these facilities. Still, caution must be exercised if the DELCAP model is to be applied in other contexts, since validity has been established only in the limited sense noted above.

DELCAP is now operating both at NBS on the UNIVAC 1108 computer and on a CDC computer chosen by, and accessible to, the FAA. On both systems it may be operated remotely from a teletype terminal, which allows the analyst to use the model at his desk as "what-if" questions occur. The model has been used as a tool by FAA analysts in establishing EPS's, that is, traffic levels which a facility should be able to handle during busy hours, under a particular configuration and operating policy, with a given mix of aircraft types and a given arrival/departure ratio. Calculations which formerly had to be performed by hand (by FAA analysts) are now done by DELCAP, which, because it is inexpensive, quick and easy to use, can help investigate a wider variety of configurations and operating policies. Runs typically require 15 to 20 seconds to simulate one day's traffic. This speed and flexibility allow the analyst to set performance standards for conditions which occur less frequently as well as for the normal situation, since a large number of alternatives can easily be tried. 


\subsection{The Validation Process}

Once a nathematical model has reached operational status, there is a natural temptation to put it directly to practical use, skipping over any substantial effort to verify that the model does in fact do what it was designed to do. Such an omission, however, courts disaster, since a model which has not been exercised on a variety of data (and had its outputs compared with what is actually observed in the situation being modeled) may contain unsuspected anomalies likely to exhibit themselves at embarrassing moments or (even worse) to remain undetected. To guard responsibly against this, it is necessary to subject the model to a pre-use validation and preliminary sensitivity analysis.

Validation involves two types of analysis. The first is an independent assessment of the appropriateness of the structure and methods used. A second element of validity checking is the comparison of model outputs with what is actually observed in specific instances of the type of situation being modeled. Comparison of model performance with that of other models which are well-based and accepted, for cases to which both apply, could also be part of this type of analysis. Absolute assurance of validity for all possible future uses is, of course, impossible. Replication of reality for a few test cases can only insure that in these particular examples, the model performs as it should, but if the test cases were chosen carefully to be representative of the spectrum of situations to which the model is expected to be applied, then increased confidence in model validity can be obtained.

Beyond the basic validity testing described above, some preliminary sensitivity analyses should be conducted--to identify those parameters having most critical (most sensitive) effect on model outputs, and to ascertain the degree to which model outputs can be expected to vary with input variations. Such sensitivity analyses should also help to determine the limits beyond which application of the model is inappropriate.

\subsection{Descriotion of DELCAP}

DELCAP is a simulation model, written in the SIMSCRIPT 1.5 computer language, of the airport terminal area including terminal airside operations and those ground operations occurring on the runway surface. DELCAP was designed to focus on operations in the terminal area and to measure throughputs and delays associated with this subsegment of the whole Air Traffic Control (ATC) System. Its output consists of throughput and delay figures. Input includes traffic levels (or the explicit schedules of traffic, or both), the mix and characteristics of aircraft types, the separation rules which apply, the airport runway configuration and its runway operating policies.

In accordance with the modeling philosophy under which DELCAP was designed, in which ease of use is a major criterion, a FORTRAN preprocessing program has been written to allow users to provide inputs in a format less 
rigid than that required by SIMSCRIPT programs and to provide a set of nominal input values. The user specifies values for only those input parameters which are to differ from their nominal values. As noted in Appendix A, procedures for selection and values of these nominal inputs have been changed to those most useful for the EPS program.

Figure 1.1 displays the terminal area as seen by the DELCAP model. The aircraft denoted by capital letters are landings; those designated by lower case letters are takeoffs. The landing and takeoff streams are lettered in reverse order of their entrance to the model. (The particular configuration and operating policy shown--a pair of intersecting runways, one handling only takeoffs, the other only landings-is illustrative and should not be taken as a model restriction. Runway configuration is a model input; as will be shown by the exercises reported in Chapters 2 and 3, a wide variety of such configurations can be handled by DELCAP.)

It is convenient to describe DELCAP's treatment of landing and takeoff streams separately, since DELCAP is an event-oriented model (time is incremented to the next "critical event," rather than stepped along at preset intervals) and each critical event in an aircraft's path anticipates the next one along that path. Landings enter the simulation at handoff to tower approach control (A in Figure 1.1). The next critical point along a landing path is the outer marker. DELCAP requires that at least a preset minimum time interval ensue between handoff and the landing ${ }^{\prime} s$ passage of the outer marker. However, the presence of other aircraft in front of A in the landing stream may necessitate that it be placed in a holding pattern or that it fly a longer path to the outer marker, either of which would require extra time. DELCAP does not model the actual route flown by $A$, but this extra time requirement is imposed by the modeling device of "tying up" the outer marker, i.e., prohibiting A from passing it, until all those in front have done so.

$B^{\prime}$ s final approach can be scheduled once the aircraft in front of $B$ ( $C$ in the figure) has passed the outer marker. B must remain separated from $C$ by the required amount (presently 3 miles if $C$ is not a heavy aircraft, 4 miles if both $C$ and $B$ are heavies and 5 miles if $C$ is a heavy but $B$ is not) along the whole final approach path. DELCAP employs the idealization of constant final approach speeds (dependent on aircraft type), and so the acutal separation required between $C$ and $B$ when $B$ crosses the outer marker is either (if $C$ is faster) the minimum required spacing between these aircraft, or (if $B$ is faster) a spacing such that when $C$ touches down $B$ will be at the required minimum separation distance from the end of the runway.* A landing leaves the simulation when it turns off the runway.

* Of course D cannot land as long as $E$ is on the runway surface. That is, in addition to the airborne separation requirements, runway occupancy time also can affect the prescribed separation between D and E. DELCAP includes the "tying up" effects of runway occupancy, though in practice, it is usually the airborne separation which is critical. 
FIGURE 1.1

The Terminal Area as Seen by DELCAP

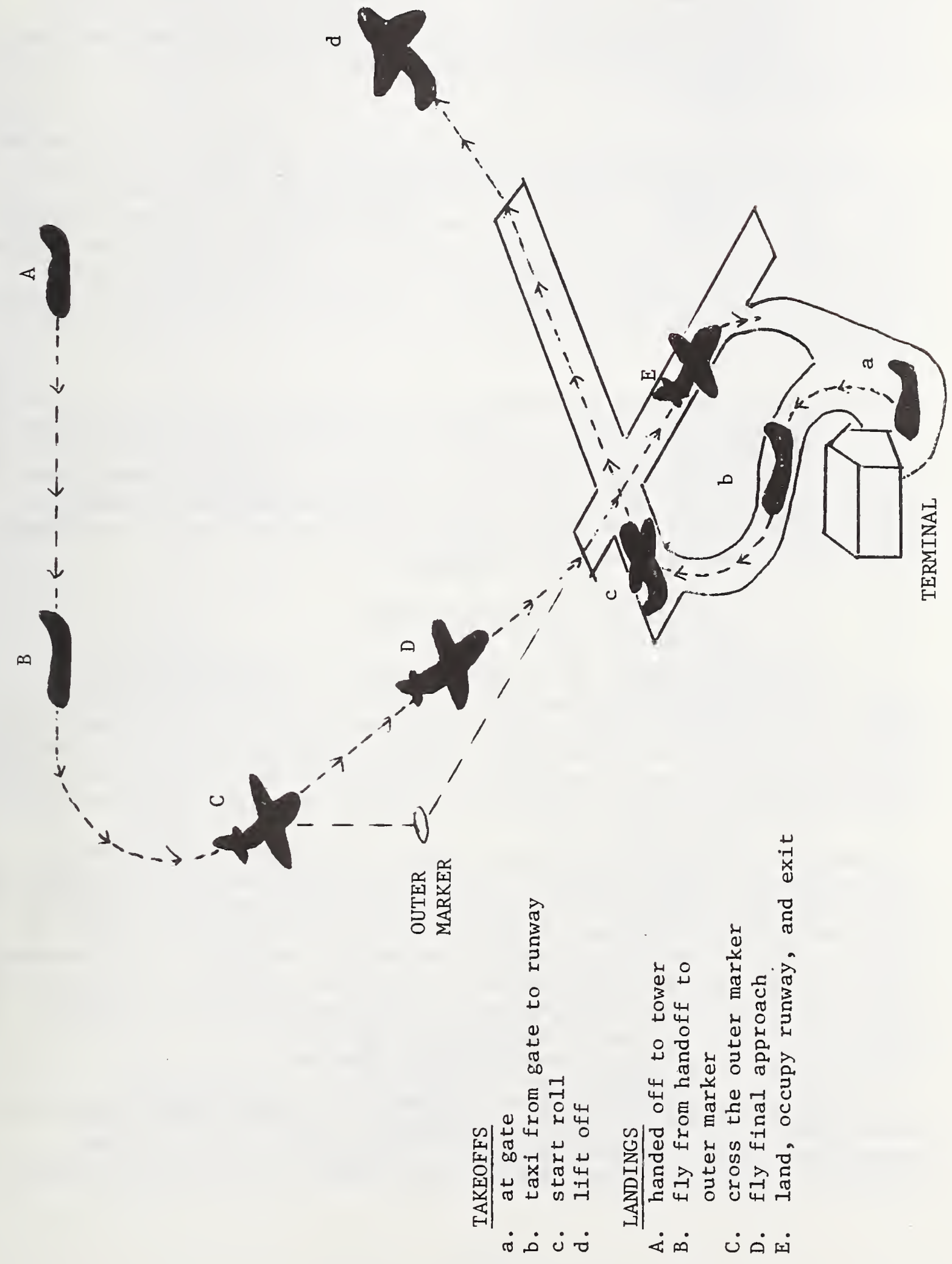


Takeoffs enter the simulation about 15 minutes before scheduled departure time. A minimum taxi time between gate and runway is specified. Since in Figure 1.1, landing $E$ has passed the runway intersection, takeoff $\mathrm{c}$ can be cleared to start its roll, if takeoff $\mathrm{d}$ had sufficient separation from takeoff $\mathrm{c}$; this presently is 2 minutes after $d$ lifts off if $d$ is a heavy and $c$ is not, and is a shorter, constant time interval--approximated as 20 seconds after liftoff--for all other aircrafttype combinations.

Figure 1.2 is a flowchart of the simulation. The bottom box, "choose next operation," represents the implementation of the runway operating policy which determines the sequence of landings and takeoffs on each runway. The two boxes referring to "maintain separation" are implemented in the model by "tying up" critical points in the landing and takeoff paths: the point at which a takeoff starts its roll, the outer marker, and the point at which a landing touches down. A landing or takeoff can be scheduled to take place when no critical point will be tied up when the aircraft reaches it.

The DELCAP model has been designed to provide output of two quantities, namely throughput (the number of operations handled by the facility per time period) and delay. Application of DELCAP is envisaged under two different scenarios. The first is one in which a realistic demand level is stipulated and DELCAP output yields resulting delays and throughputs. In the second scenario, DELCAP is run with high demand levels to estimate the airport's maximum throughput (capacity).

\subsection{Validating DELCAP}

Validation of maximum throughput estimates is reported below in Chapter 2. Testing was concentrated on this case, since the main application which this validation effort supports operates in the second scenario. That application is the computation of EPS's, throughputs which are achievable under heavy traffic conditions, for several of the nation's busiest airports operating under a variety of possible configurations and operating policies.

Chapter 3 recounts an attempt, using currently available data, to validate DELCAP's delay output. This effort, which had to be abandoned for the present because empirical delay figures for that portion of the ATC system modeled by DELCAP were lacking, is reported here as an example of a model exercise, showing the model's versatility and ability to represent actual traffic together with artificially generated traffic. The exercise also illustrates the problems caused by multiple definitions of delay. We do describe (at the end of the chapter) the data collection effort required to support a delay-figure validation analysis.

In Chapter 2, validation exercises employed to test NELCAP under the second scenario above are described in detail, and their results are compared with values obtained from FAA's Air Traffic Service. These tests were designed in consultation with $R$. Scott of FAA's System Research 
FIGURE 1.2

Flowchart of the DELCAP Simulation

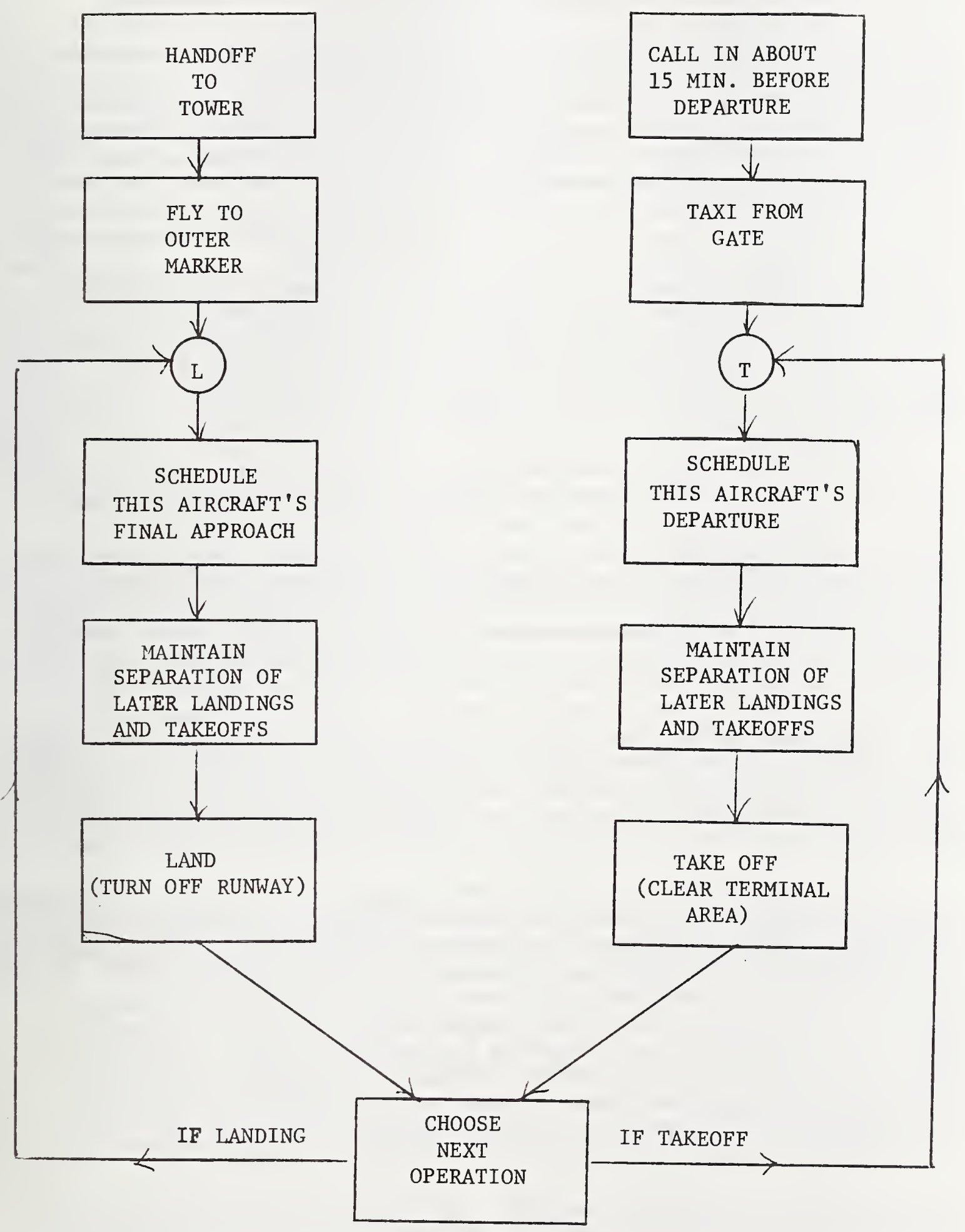


and Development Service and R. Woods and R. Tobiason of the Air Traffic Service, to cover that set of configurations most representative of those encountered at major U.S. terminals, including a single runway, two intersecting runway configurations (differing in the placement of the intersection), a pair of close parallel runways, and a pair of close parallels with a third runway crossing the pair. Wide parallels were not included since they can be modeled as two separate single runways. A variety of operating policies were chosen to approximate those used under different traffic situations: when landings balance takeoffs, when landings predominate, and when takeoffs predominate. This diversity also allows comparison of results, to evaluate the sensitivity of DELCAP throughputs to operating policy. The exercises included different mixes of aircraft types, focusing primarily on the fraction of heavy aircraft in the mix since different, larger separations are required behind heavies because of wake turbulence. Other model inputs (such as aircraft characteristics or the length of the final approach path) could also have been varied, but preliminary tests have led us to believe that the three factors mentioned--configuration, operating policy, and aircraft-type mix--are the ones most critically affecting differences in throughput at major U.S. terminals.

Chapter 3 reports the results of an exercise of the model using actual scheduled traffic data from LaGuardia Airport (LGA) for October 25, 1974, plus general aviation traffic generated in a stochastic manner. Simulated delays were compared with the "real" delays experienced by the scheduled aircraft--calculated as the difference between the actual arrival or departure and the corresponding scheduled time. This comparison proved on closer consideration to be improper, "real" delays necessarily being much greater than the simulated ones because they include the effects of interruptions or slow-ups attributable to other parts of the system (not in the LGA terminal area) and to other sources such as equipment - or crew-induced delays. Simulated delays did, however, agree quite well with the delay level reported by the facility, and the shapes of the distributions, "real" and simulated, were very similar. Chapter 3 also contains a discussion of the data required to do a proper delay-figure validation, and suggests methods of acquiring these data.

Chapter 4 contains a conclusion and summary of the report. Appendices A through $E$ document in detail the current version of the DELCAP model and its preprocessor. Appendix A includes a discussion of changes made to the model since its original documentation [1]. Flowcharts and descriptions of all the simulation routines are included in Appendix $B$. Appendix C lists the variables and arrays used in DELCAP, and Appendix D gives user instructions for preparing preprocessor input. Listings of both programs appear in Appendix E. Appendix F includes a description of the LGA data, together with a discussion of problems encountered in reconciling two data sources for the LGA input. 


\section{VALIDATION OF DELCAP THROUGHPUT ESTIMATES}

\subsection{General Description}

This chapter documents runs of the DELCAP model designed to test the validity of its throughput calculations under a variety of conditions. The characteristics attributed during these runs to each of three aircraft types--heavy aircraft (over 300,000 lbs. gross weight), small aircraft (most single- and two-engine craft), and medium and larger craft (larger piston aircraft and most jets) -- are described in Table 2.1. These values were obtained from data collected by the Air Traffic Service at O'Hare International Airport (ORD).

Five different runway configurations, representative of those most often encountered and described in greater detail below, were investigated: a single runway, two runways intersecting so as to form a $V$, two runways intersecting to form an X, a set of close parallels (3000 to 4300 feet apart), and a set of close parallels with a crossing runway. Configurations involving wide parallels are not included in this analysis since the DELCAP model treats wide parallels as two completely separate runways, and as a result, the maximum throughput of a pair of wide parallels is just the sum of the throughputs available from them independently.

For each configuration, operating policies (displayed in Table 2.3) were chosen as most reasonable for each of three arrival/departure mixes: arrivals balancing departures, departures dominant, and arrivals dominant. Each configuration and operating policy was investigated for three aircrafttype mixes, identified by the percentage of heavy aircraft in the mix and described more fully in Table 2.2.

For each configuration, operating policy and aircraft-type mix, the model was run to simulate 20 hours of traffic. The average hourly throughputs (averaged over the sample of 20 hours) of landings, takeoffs and all operations were recorded for each runway and totaled for all runways to permit comparisons among policies, type mixes and configurations.

In Section 2.2 the model's outputs for these cases are described, and evaluated, including the testing of agreement with analytical models (where available) and with ATC experience about how throughput depends on the factors varied. In Section 2.3, the outputs are compared with FAA-supplied data.

\subsection{Validation Output}

\subsubsection{SINGLE RUNWAY}

The single runway case has been studied extensively ${ }^{*}$, and admits analytical expressions for capacity. Two such expressions, one for

* See for example [4], [5], and [6]. Similar formulas to those appearing below appear in these publications, but are derived here again for completeness. 
TABLE 2.1

\section{Aircraft Characteristics for Validation Runs}

\begin{tabular}{|c|c|c|c|c|c|}
\hline \multirow{2}{*}{$\begin{array}{l}\text { Type } \\
\text { Number } \\
\end{array}$} & \multirow{2}{*}{$\begin{array}{c}\text { Type } \\
\text { Description }\end{array}$} & \multicolumn{2}{|c|}{ Speeds (Knots) } & \multicolumn{2}{|c|}{ Runway Occupancy (Sec) } \\
\hline & & Landing & Liftoff & Landing & Takeoff \\
\hline 1 & Heavy A/C & 124 & 120 & 55 & 33 \\
\hline 2 & Smal1 A/C & 119 & 90 & 40 & 27 \\
\hline 3 & $\begin{array}{l}\text { Category III's } \\
\text { (Larger } \mathrm{A} / \mathrm{C} \text { ) }\end{array}$ & 120 & 120 & 50 & 32 \\
\hline
\end{tabular}

TABLE 2.2

Three Aircraft-Type Mixes Used

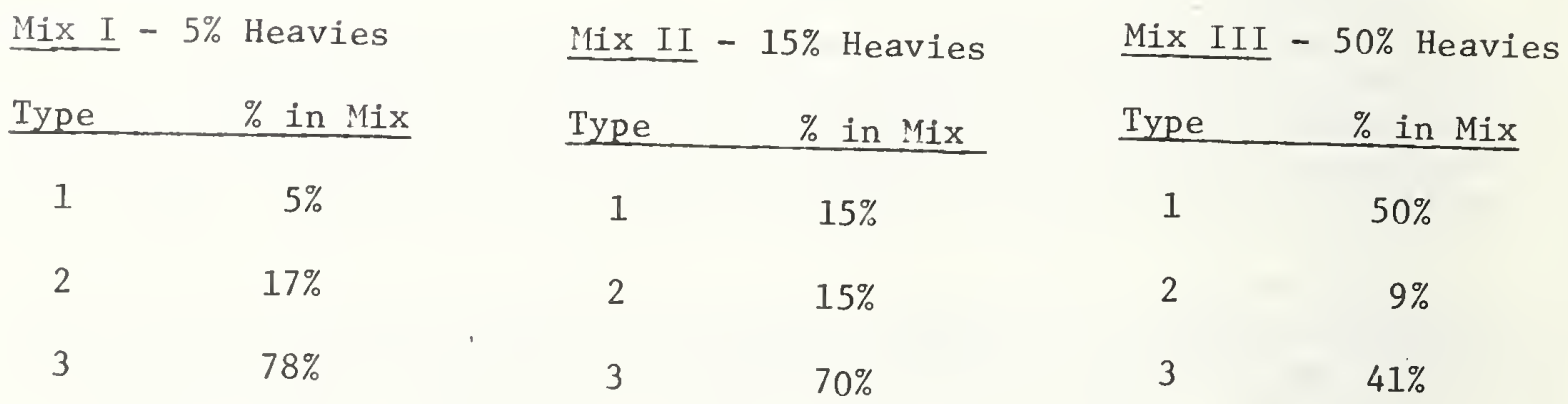




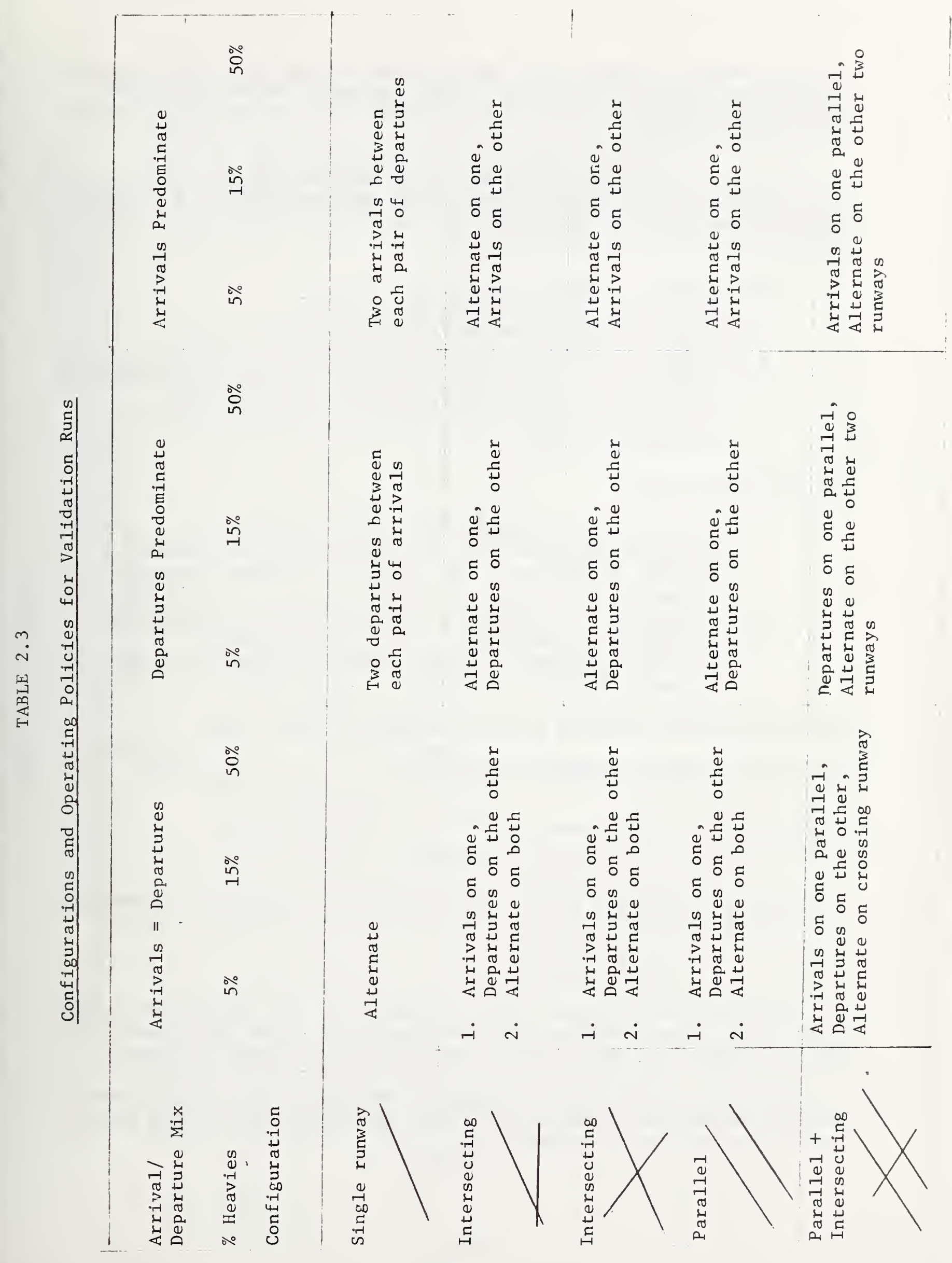


a runway handling takeoffs only and the other for the same runway handling landings only, are derived below. As will be seen, DELCAP outputs for these single-runway situations conform closely (as they should) to these theoretical formulas.

To calculate the expected value of the maximum throughput for a single runway handling takeoffs only, under the assumption of a continuous stream of departures in which heavy aircraft appear randomly and constitute a known fraction of all takeoffs, let

$\mathrm{N}=$ number of takeoffs per hour,

$\mathrm{p}=$ fraction of takeoffs which are heavies,

$r$ = runway occupancy time (hrs.) for heavies,

$\Delta=$ average time (hrs.) between takeoffs for non-heavies

$\delta=$ average time (hrs.) between takeoffs of two successive heavies (Note that separation rules require a non-heavy to wait 2 minutes after a preceding heavy liftoff before starting its rol1.)

Then it follows that:

1. The time between takeoff of a heavy and that of a following non-heavy is $r^{\prime}=r+2 / 60$, the time between takeoffs of heavies is $\delta$, and the time between takeoff of non-heavies is $\Delta$.

2. A fraction $p$ of aircraft following a heavy are heavies; (1 - p) are non-heavies.

3. The expected number of hourly takeoffs by heavies is $\mathrm{pN}$; for non-heavies it is $(1-p) N$.

Thus the following equation (between numbers of hours) holds:

$$
\mathrm{pN}\left[\mathrm{p} \delta+(1-\mathrm{p})\left(\mathrm{r}^{\prime}\right)\right]+(1-\mathrm{p}) \mathrm{N} \Delta=1
$$

or

$$
N=1 /\left[p^{2} \delta+p(1-p) r^{\prime}+(1-p) \Delta\right]
$$

For $r=33$ seconds, $\Delta=54$ seconds, and $\delta=90$ seconds for example, the values in Table 2.1 yield

$$
N=3600 /\left[-64 p^{2}+99 p+54\right] \text {. }
$$

This is plotted as the upper curve in Figure 2.1. The two circled points, at 20 and 30 percent heavies, give the results of actual DELCAP runs and agree well with the corresponding values from the preceding formula.

Similarly, to calculate the expected throughput for a single runway handling landings only, under the further assumption that landing speeds for all aircraft types are equal, let 
FIGURE 2.1

Hourly Throughput for a Single Runway

Handling Only Takeoffs or Only Landings

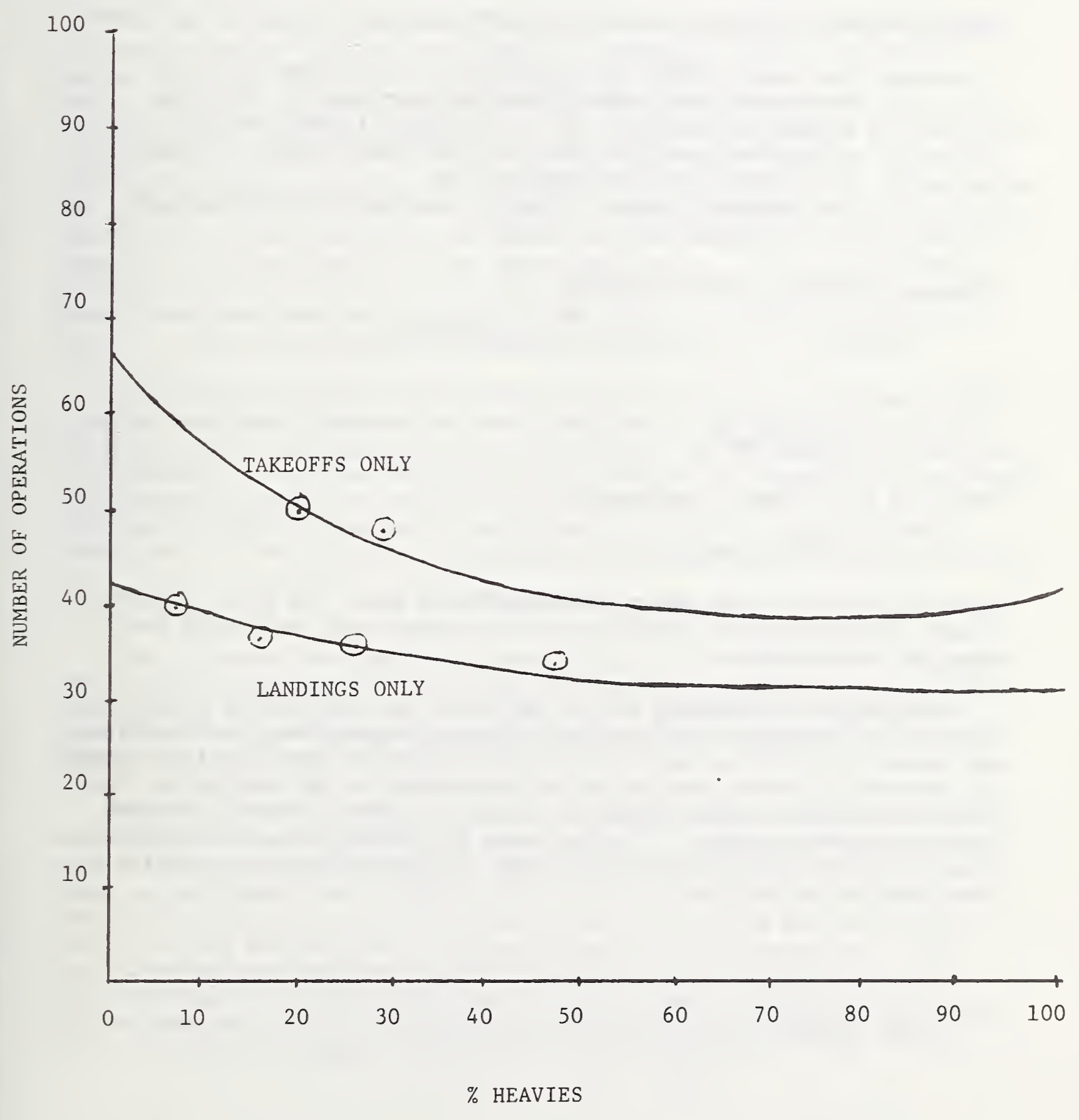


$\mathrm{N}$ = number of landings per hour,

$\mathrm{p}=$ fraction of landings which are heavies,

$s=$ the landing speed (in knots) for all aircraft types. (Although landing speed does vary among aircraft types, the figures in Table 2.1 indicate that using one value is not a great deviation from reality. More complicated formulas can be derived for the case in which speed depends on aircraft type.)

Then it follows (cf. the separation criteria given in section 1.3) that:

1. The time between the landings of two heavies is $4 / \mathrm{s}$, between a heavy and a following non-heavy is $5 / \mathrm{s}$, and between a non-heavy and a following aircraft is $3 / \mathrm{s}$.

2. A fraction $p$ of the aircraft following a heavy are heavies, a fraction (1-p) are non-heavies.

3. The expected number of hourly landings by heavies is $\mathrm{pN}$; for non-heavies it is (1-p)N.

Thus the following equation holds:

$$
\mathrm{pN}[\mathrm{p}(4 / \mathrm{s})+(1-\mathrm{p})(5 / \mathrm{s})]+(1-\mathrm{p}) \mathrm{N}(3 / \mathrm{s})=1
$$

or

$$
N=s /\left(3+2 p-p^{2}\right)
$$

For $\quad s=125$ knots, for example,

$$
N=125 /\left(3+2 p-p^{2}\right) \text {, }
$$

which is plotted on the lower curve in Figure 2.1. The four circled points, output from the DELCAP simulation, agree very well with the expected throughputs.

Analytical expressions can be and have been derived for more complicated operating policies involving dual operations (both landings and takeoffs), * but are much more complex since for some landing aircraft the minimum allowable spacing can be determined by the separation from a preceding landing, rather than the separation from a takeoff occuring between the two landings. In this case, the takeoff is in some sense a "free" contribution to throughput since it does not require an extra interruption in the flow.

* See for example [6]. 
As part of our validation analysis, three operating policies for a dual use single runway were run using DELCAP. The output from these runs is displayed in Table 2.4. For time periods in which the numbers of arrivals and departures are approximately equal, the operating policy chosen for the single runway seeks to alternate landings and takeoffs. During departure-dominant periods, landings are spaced far enough apart to allow two takeoffs between each pair of landings. For arrival-dominant periods, takeoffs are permitted only between every other pair of landings.

As can be seen by comparing Table 2.4 with Figure 2.1 , dual usage of the single runway decreases the takeoff throughput greatly (by about a factor of two). The reason is that landings require more time between operations and dual usage forces some takeoffs to wait for landings. On the other hand, landing throughput is not as greatly degraded by interspersing takeoffs among the landings. Alternation of landings and takeoffs decreased landing throughput by at most 30\% from the pure landing operation, and increased total throughput by $40-60 \%$. This agrees well with operating experience: in the absence of stringent takeoff-airspace restrictions, takeoffs are rarely the limiting throughput factor. On the other hand, spacing between landings is critical, and directions such as "maintain speed" sometimes have to be given by controllers to arriving aircraft in order to ensure that minimum spacing is attained.

Validation for the single-runway case was carried out because it is often an important component of more complicated configurations. Wide parallels may be regarded as two single runways in throughput calculations, for instance. Also, some airports may be reduced to essentially the singlerunway configuration during IFR weather or outages. Still, the primary advantage of DELCAP lies in its applicability to more complex runway situations for which analytic expressions are much more difficult to obtain.

\subsubsection{INTERSECTING RUNWAYS}

Two different configurations consisting of a pair of intersecting runways were investigated: one with the intersection 2000 feet from the ends of each of the runways (representing the near-intersection or " $V$ " case), the second with the intersection 4000 feet from the ends of each runway (a configuration shaped like an " $\mathrm{X}$ ").

During periods in which arrivals and departures are roughly balanced, two different operating policies were chosen as reasonable: the first of them alternates landings and takeoffs on both runways, while the second reserves one runway for landings only and the other just for takeoffs. (The second policy can result in lower capacity, but is easier for the controller and probably more representative of actual practice.) For departure-dominant periods, one of the runways handles takeoffs only, with landings and takeoffs alternated on the other. Similarly, for arrival-dominant periods, one runway is set aside for landings only, while landings and takeoffs alternate on the other. 


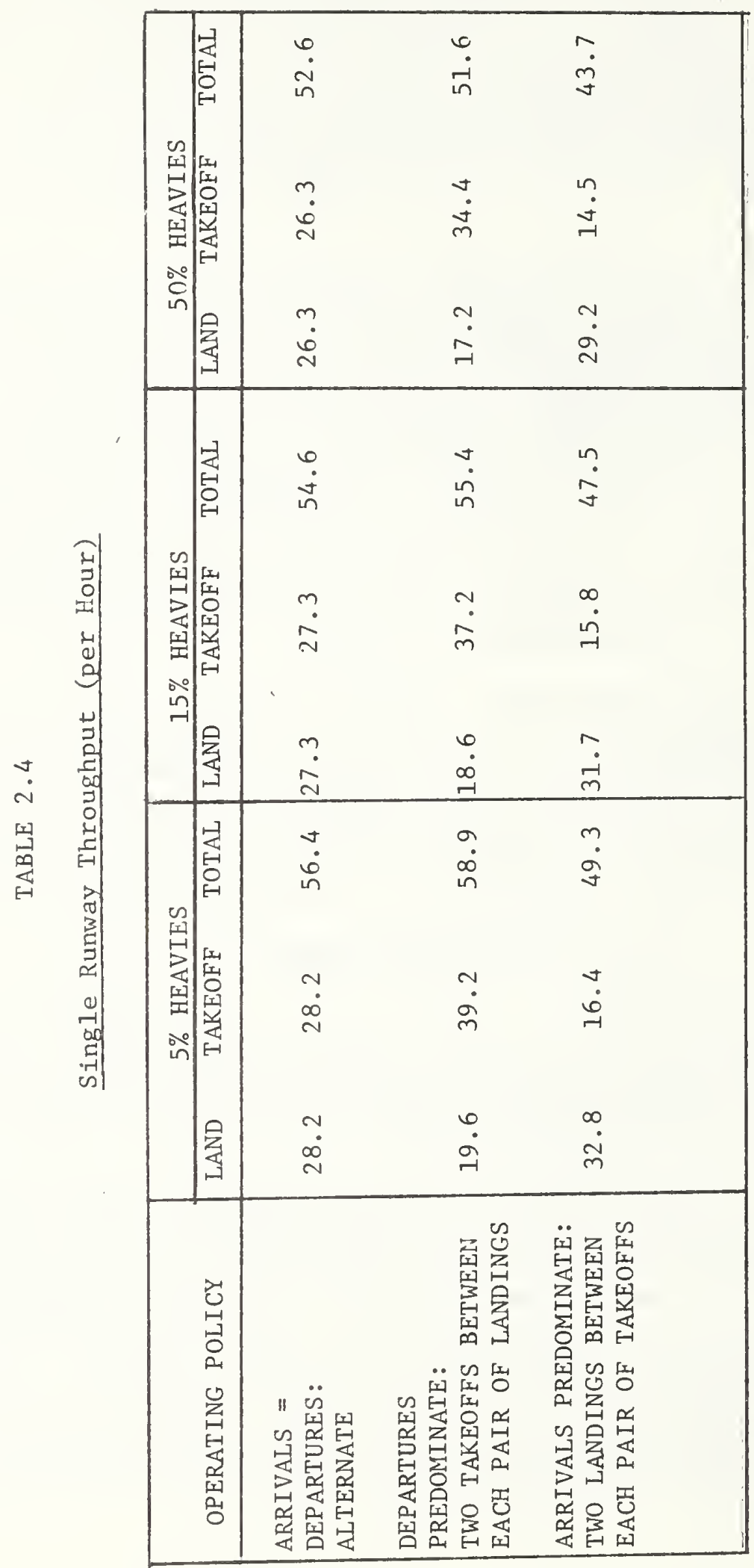


Each intersecting-runway configuration was run both with and without the requirement that operations on one runway be separated from those on the other. In the less restrictive case, the only interaction imposed was that a landing's touchdown or a takeoff's start-of-roll on one runway could not occur in the period between a landing or start-of-roll of an aircraft on the other runway and the time that aircraft passed the intersection. In the other case, in addition to the preceding prohibition, landings on one runway had to be separated by the required 3,4 or 5 miles from landings on the other, and also by 2 miles from preceding takeoffs on the other. Two separate tables are given for each of the $V$ and $X$ intersection cases (see Tables 2.5-2.8), one including the second separation requirement (described as "with interference") and one without.*

The interference requirement reduces throughput by 3 to 45 percent, with the lower reduction occurring when takeoffs are allowed on only one runway (i.e., the middle two operating policies in the Tables). It is probably very unusual for landings to be allowed on both runways of an intersecting pair. In fact, the "landings on one, takeoffs on the other" policy is the one most often employed in practice for an intersecting pair, if the runways are of comparable length. When one is longer than the other, then segregation by aircraft type, rather than by operation, is often employed, and something approaching the policy of alternating operations might be achieved. In this case segregation by type (and thus by landing speed) would tend to decrease actual interlanding separations (by reducing gaps due to a slow plane following a faster one), resulting in slightly higher throughputs than those given in Tables 2.5-2.8. With interference, the maximum number of landings -- which occurs for the near intersection for the policy allowing one runway to handle only landings and the other only takeoffs, and occurs for the far intersection for the policy allowing landings on both runways with takeoffs interspersed on one -- Is actually about the same as the number of landings on the landingsonly runway alone (under the same policles) when there is no interference.

The difference between 5 and 50 percent heavies in the aircraft type mix leads to a decrease of 6 to 24 percent in total throughput, with the larger differences generally occurring for the policy having only landings on one runway and only takeoffs on the other. To explain this, note that with landings spaced at 5 miles (as for a non-heavy aircraft following a heavy), a takeoff can occur between the two landings without affecting either. The pure-landing/pure-takeoff policy does not exploit this, so that the full brunt of the increased separation is felt. Policies employing dual-use runways are in a better position to utilize these extra spaces.

* Output for the "pure arrival, pure departure" case in Tables 2.5 through 2.9 differs from that reported in [2] because of an intervening model modification allowing policies which coordinate operations on different runways. 


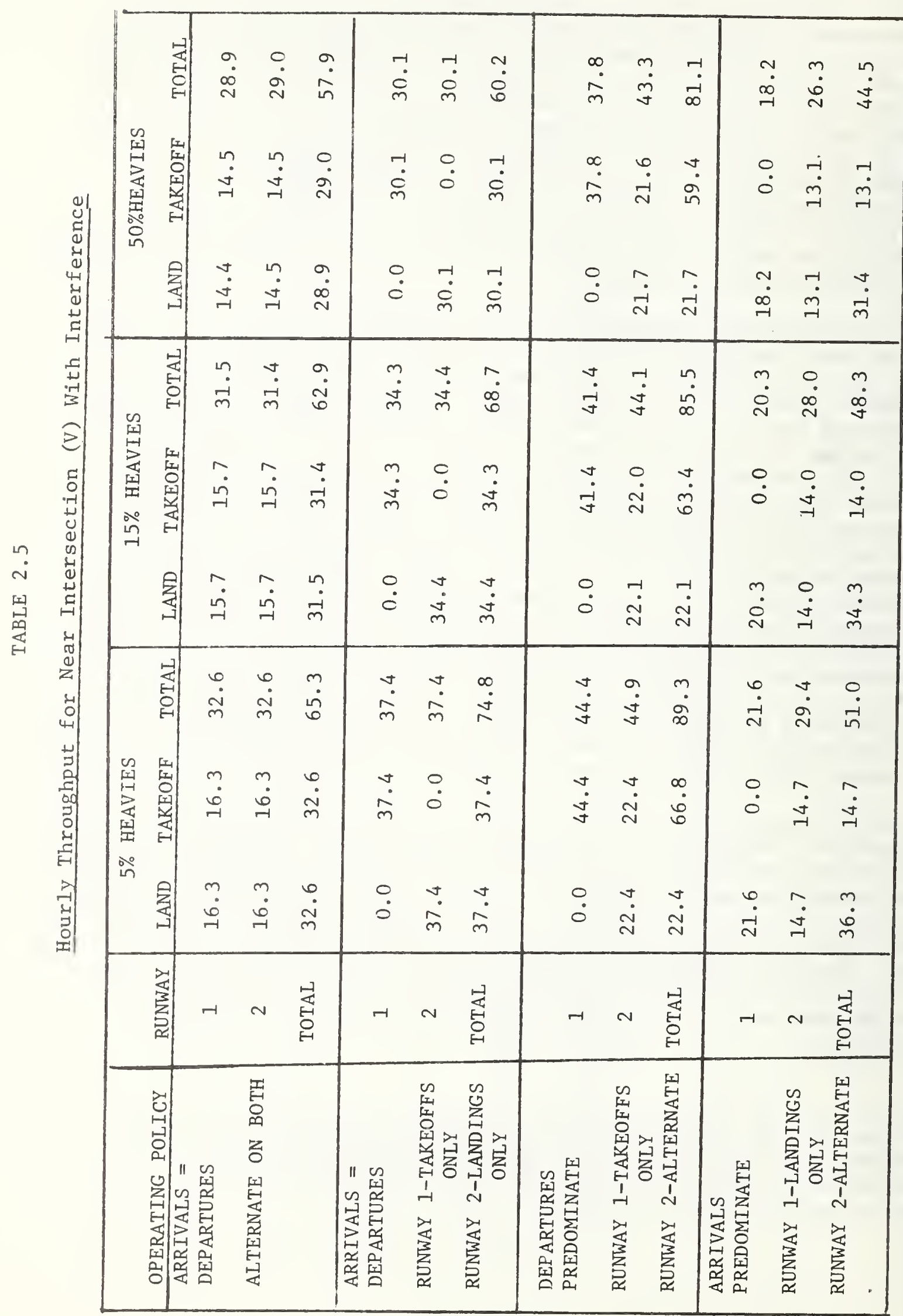




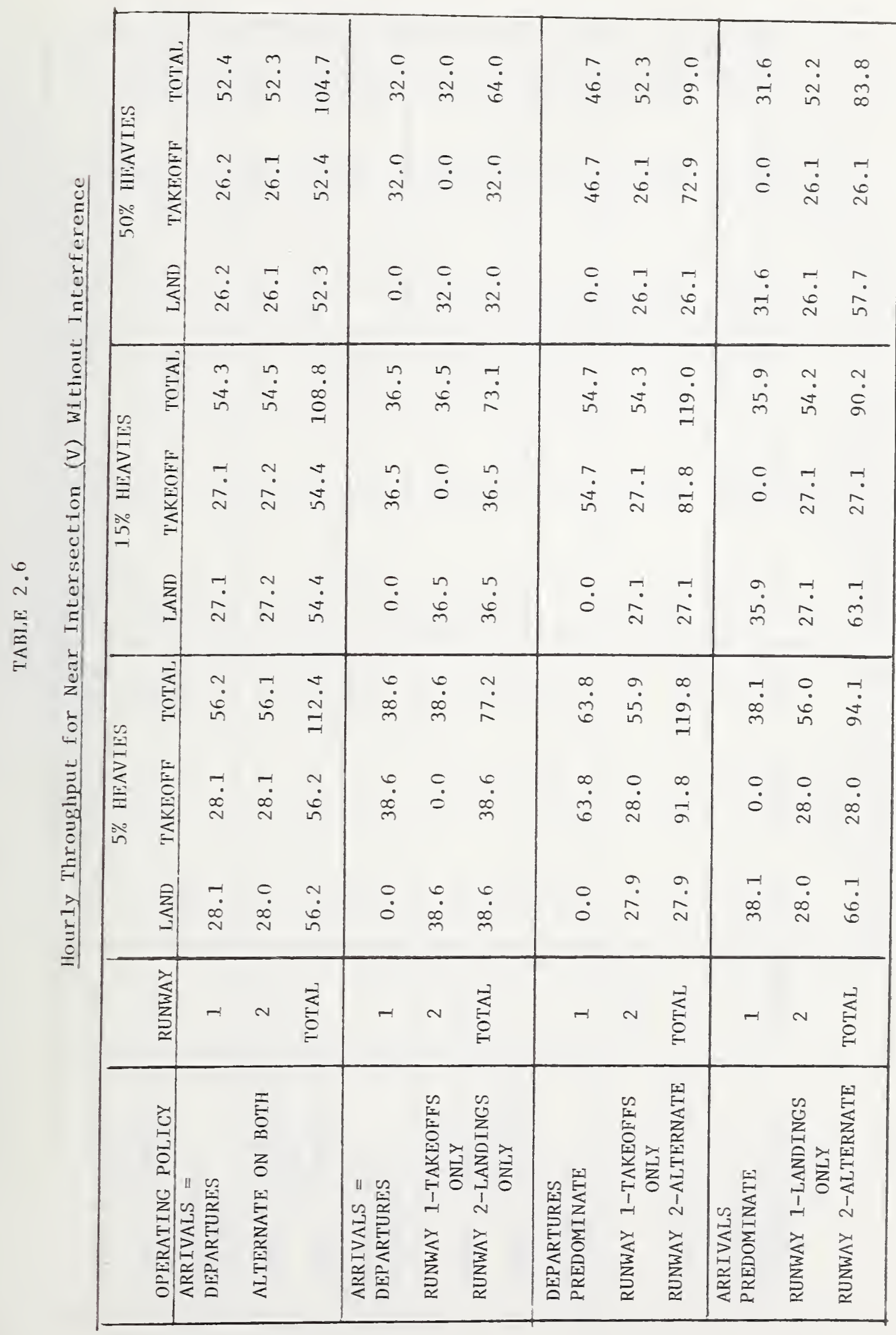




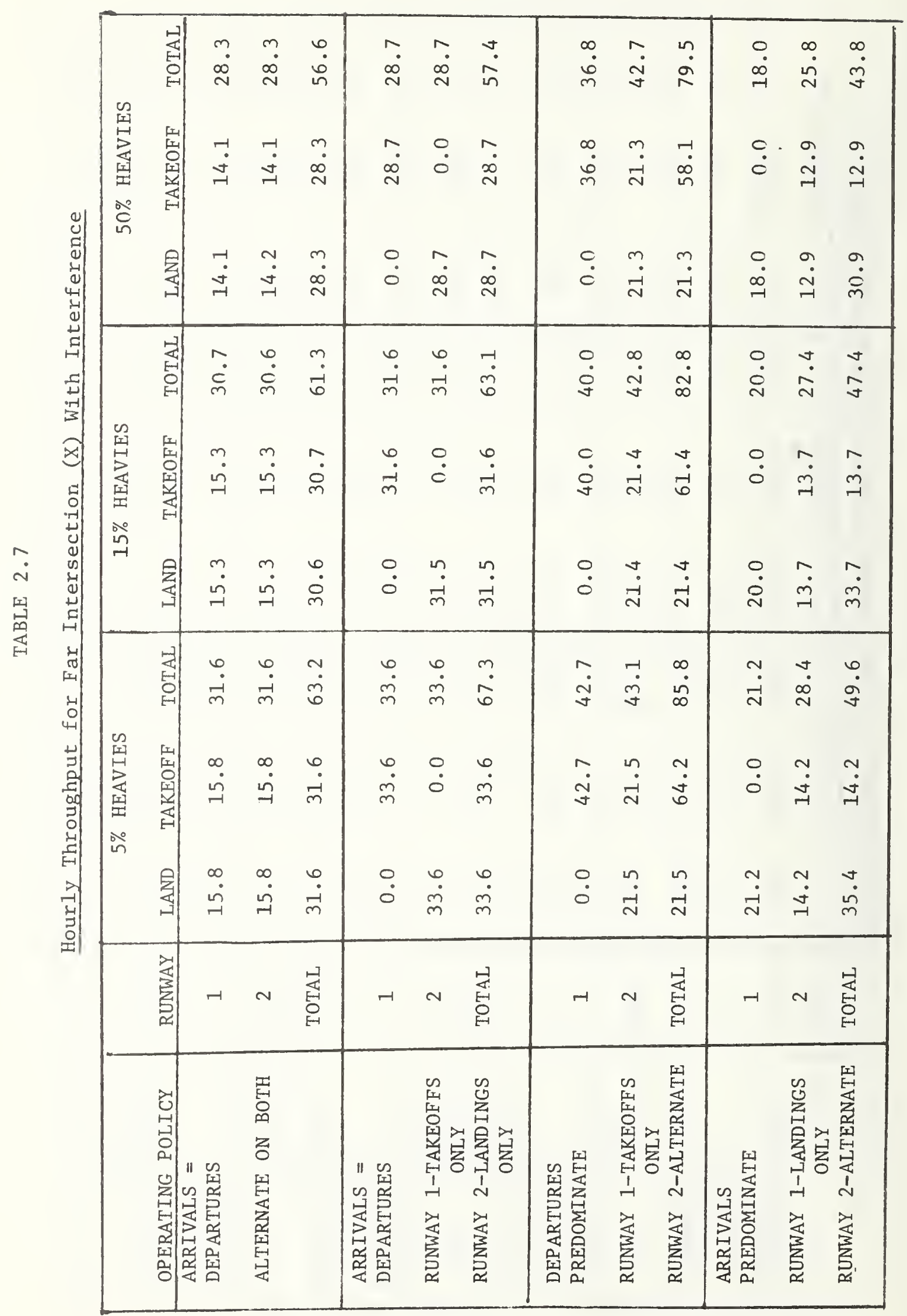




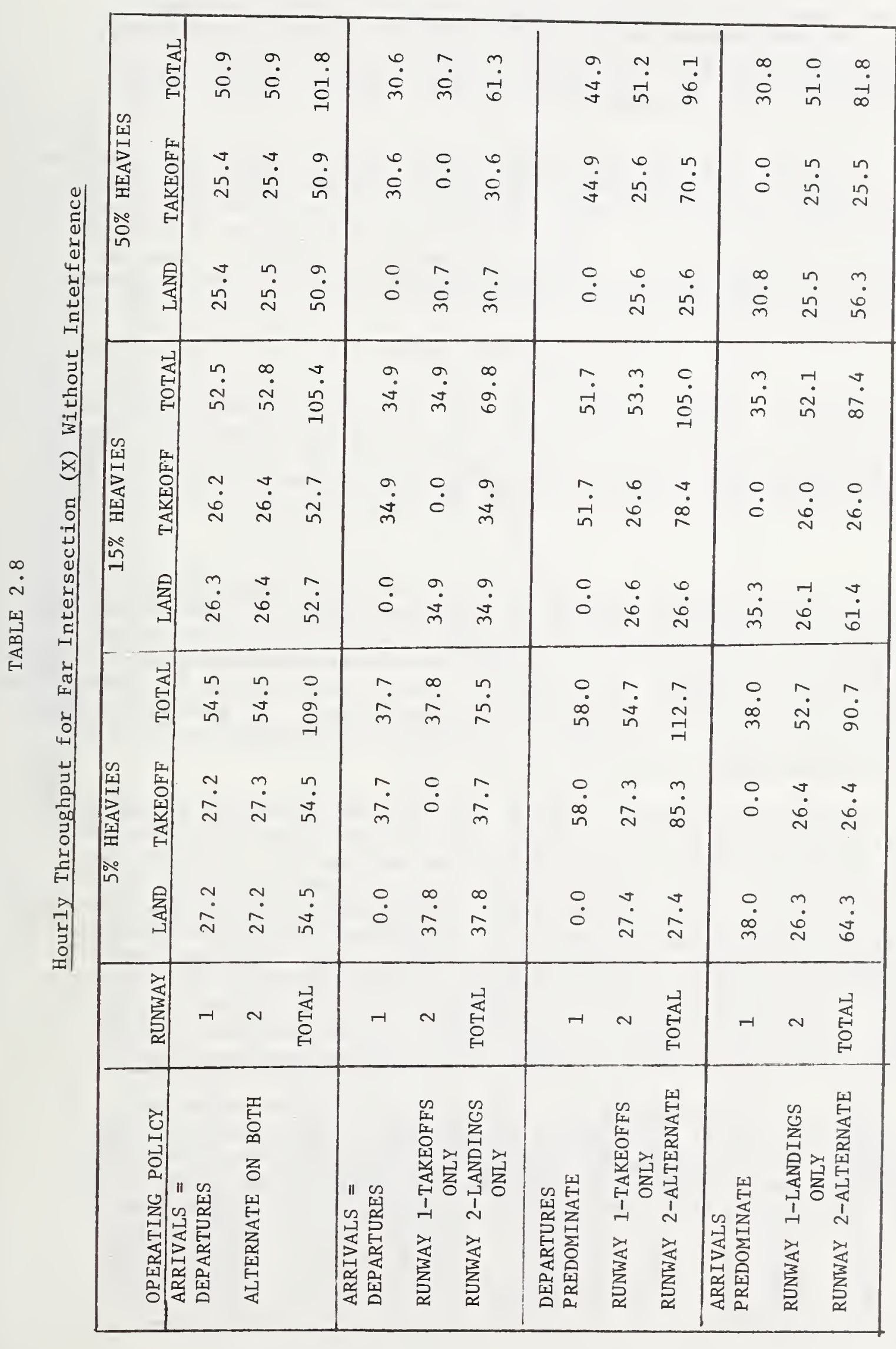


The location of the intersection, far rather than near, causes a greater reduction in takeoff throughput than in landing throughput. This is to be expected, since runway occupancy time is not a critical factor in interlanding spacing, but plays a much greater role in constraining takeoffs. The intersection's location, however, has much less effect than does operating policy.

In summary, the simulated behavior of a pair of intersecting runways is very much as one would expect from logic and real-world experience. The throughput levels produced by DELCAP may be higher than those usually observed because two of the four operating policies simulated allow landings on both runways, a situation atypical in practice. Thus the predicted throughputs for the pure-landing/pure-takeoff strategy perhaps represent the most realistic estimates.

\subsubsection{CLOSE PARALLELS}

A parallel runway configuration was run under the restriction that landings on one runway must be separated by 3,4 or 5 miles from landings on the other, and by 2 miles from preceding takeoffs on the other. (This restriction presently applies to parallels whose center lines are separated by 3000-4300 feet.) The results are given in Table 2.9.

During periods when the numbers of arrivals and departures are about the same, the operating policies of choice are either to alternate landings and takeoffs on both runways or to reserve one runway exclusively for landings and the second just for takeoffs, alternating operations on the two. When departures dominate, one runway is reserved exclusively for them, while landings and takeoffs alternate on the other runway. For periods in which arrivals predominate, one runway is restricted to landings only, while landings and takeoffs alternate on the other.

Comparison with Table 2.6 shows that the performance of a pair of close parallel runways very closely resembles that of a " $V$ " intersection with interference, and many of the remarks made for that earlier case also apply here. Since runway occupancy time is not a critical factor in interlanding spacing and since the required separations between landings on the two runways are the same as for one runway, the maximum landing throughput for a set of parallels is not much larger than that for a single runway with two landings between each pair of takeoffs (see Table 2.4). Alternating landings and takeoffs on both runways yields about a 16 percent improvement over the single runway, gained presumably because runway occupancy time has no effect on the other runway's operations.

When takeoffs predominate, landings are spaced far enough apart to allow extra takeoffs on the other runway, and a comparison with Figure 2.1 shows that the number of takeoffs is at most 11 percent less than a single runway handling only takeoffs. Coordinating operations on the two runways, so that a landing on one alternates with a takeoff on the 


\begin{tabular}{|c|c|c|c|}
\hline 章字妾离 & 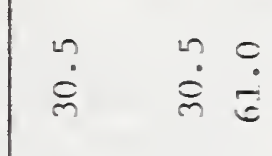 & 粂 & 吾 \\
\hline 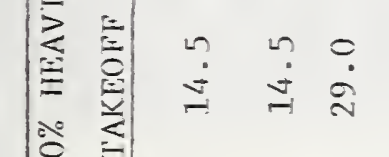 & 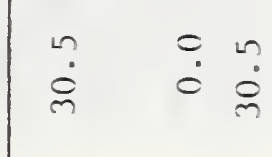 & $\stackrel{8}{\circ}$ & $\stackrel{\infty}{\leftrightarrows}$ \\
\hline 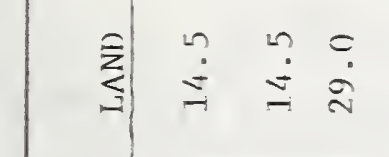 & 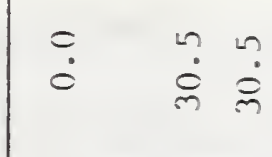 & $\stackrel{8}{\circ}$ & $\stackrel{\infty}{\dot{g}}$ \\
\hline 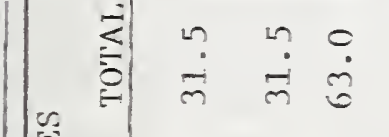 & 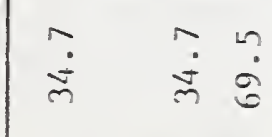 & 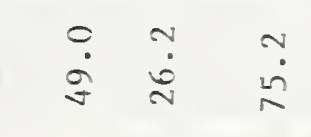 & $\because 8$ \\
\hline 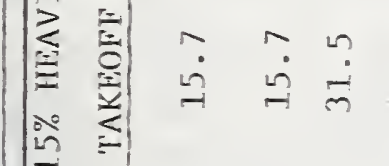 & 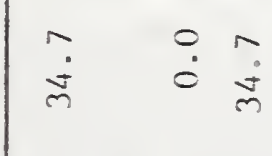 & 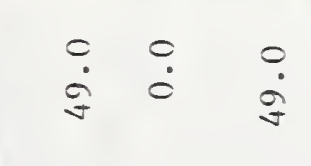 & $\stackrel{\dot{\leftrightarrow}}{-}$ \\
\hline 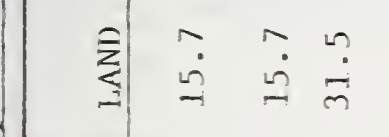 & $\begin{array}{lll}0 \\
\vdots\end{array}$ & 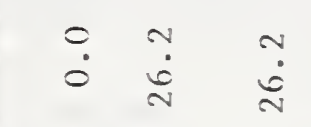 & 蓄 \\
\hline 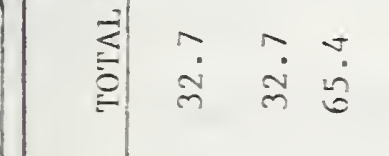 & 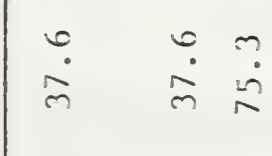 & 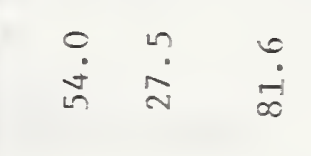 & 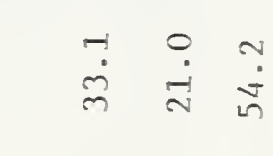 \\
\hline$\underline{\dot{n}}$ & $\stackrel{\circ}{\circ} \stackrel{\circ}{\dot{3}}$ & 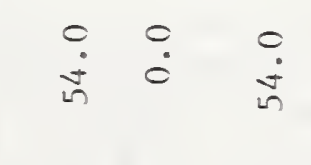 & $\stackrel{9}{9}$ \\
\hline 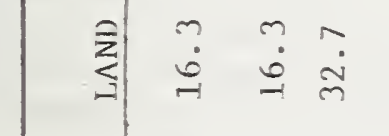 & 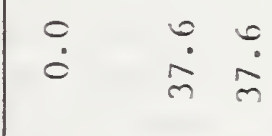 & 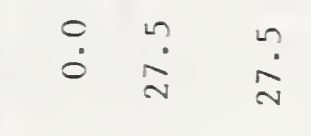 & $\stackrel{g}{g}$ \\
\hline 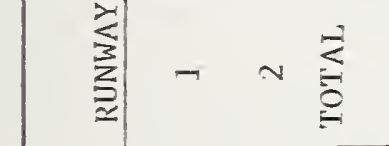 & $-\quad \sim$ & 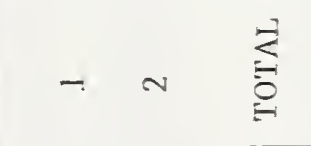 & $-\infty$ \\
\hline 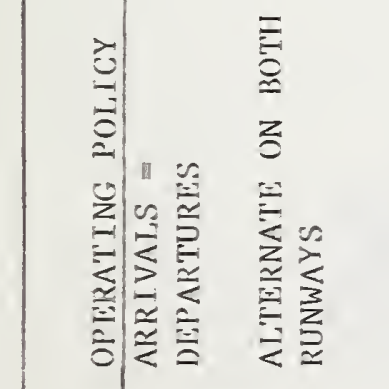 & 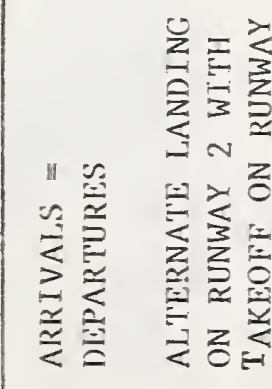 & 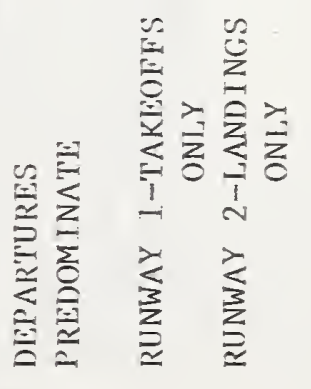 & 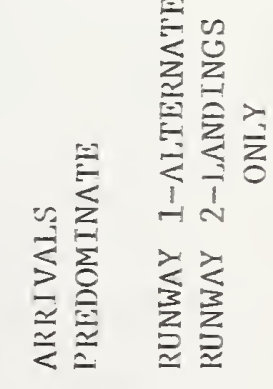 \\
\hline
\end{tabular}


other, results in a decrease of only 8 percent in total throughput but an increase of 28 to 37 percent in the number of landings. In fact the second policy, involving cooperating pure operations, suffers only a 6 to 8 percent reduction in the number of landings from the number operating on a single runway handling landings only. The addition of the second of a close parallel pair of runways thus buys some additional throughput, 16 to 34 percent for periods when the numbers of arrivals and departures balance and 37 percent when departures dominate. During arrival-dominated periods, however, only 9 percent increase in total throughput is observed.

\subsubsection{CLOSE PARALLELS WITH AN INTERSECTING RUNWAY}

The runway configuration for these runs is pictured in Figure 2.2. For time periods in which arrivals and departures are balanced, the operating policy chosen reserves one of the parallel runways (1) for takeoffs, the other parallel (2) for landings and alternates landings and takeoffs on the crossing runway (3). For departure-dominant periods one of the parallels (1) is reserved for takeoffs and landings and takeoffs are alternated on the other two runways. For arrivaldominant periods one of the parallels (1) is reserved for landings, and landings and takeoffs are alternated on the other two. These last two policies are probably unrealistically complicated for a real control situation, but have been simulated to show possible throughput advantages from dual operations.

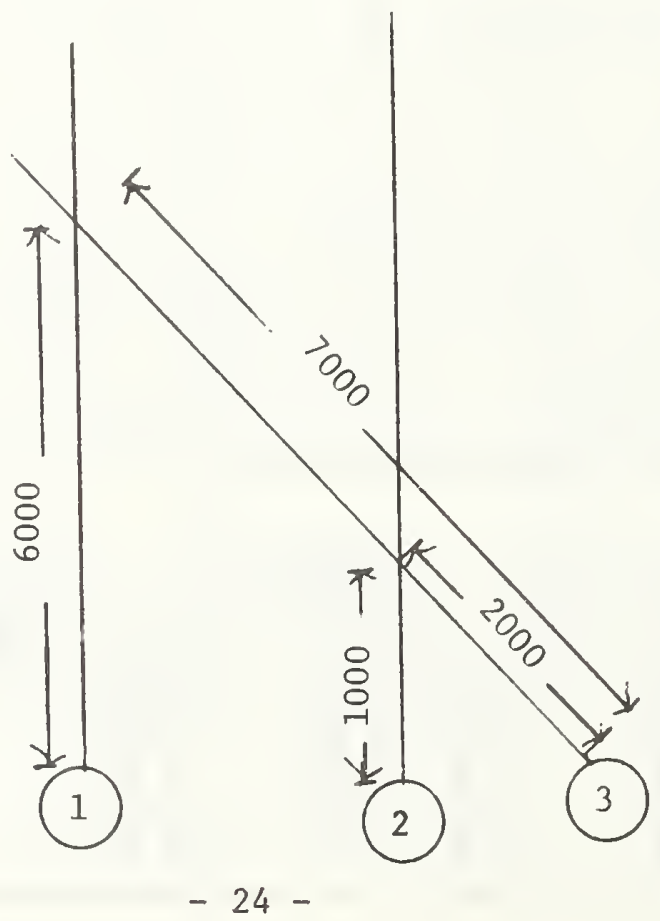


Tables 2.10 and 2.11 summarize the results of these runs. Separation requirements for aircraft on the two parallels are those described in Section 2.2.3 for close parallels. For the runs reported in Table 2.10, no interference requirements were put on the intersecting runway, so that takeoffs and landings on it were restricted only by runway occupancy on the other runways. This, of course, does not represent the real requirement when all runways are operated under IFR conditions, but may be more reflective of actual operating practice if the crossing runway is used primarily for smaller VFR aircraft. The runs reported in Table 2.11 had all interference restrictions in force.

Without the interference requirement in effect, the third runway increases landing throughput by 50 to 79 percent and takeoff throughput by 13 to 33 percent over the levels reported in Table 2.9 for parallel runways operated in the pure landing/pure takeoff mode. This increase does not accrue when the interference requirement is in force, since as noted earlier, that requirement means that maximum landing throughput is effectively that of a single runway.

The three different operating policies chosen differ by 17 to 34 percent in landing throughput, but by a factor of almost 3 in takeoff throughput, again demonstrating that meeting takeoff demand is less difficult and less critical than meeting landing demand, a fact wellrecognized by controllers. This is shown even more dramatically by the observation that the first and second policies displayed in Table 2.10 differ only in that the first one restricts runway 2 to landings only (rather than dual use), but the landing throughput is almost the same in the two cases.

\subsubsection{ANALYSIS OF RESULTS}

The preceding section described output from applications of the DELCAP model to a variety of common runway configurations, demonstrating the model's versatility and its ability to represent those airport facilities for which further computerized throughput analysis is desired. DELCAP has also been run on the Chicago O'Hare (ORD) configuration depicted in Figure 2.3. In addition, the model is capable of handling even more complex configurations than this, with many more runways and more complicated interactions among them. 


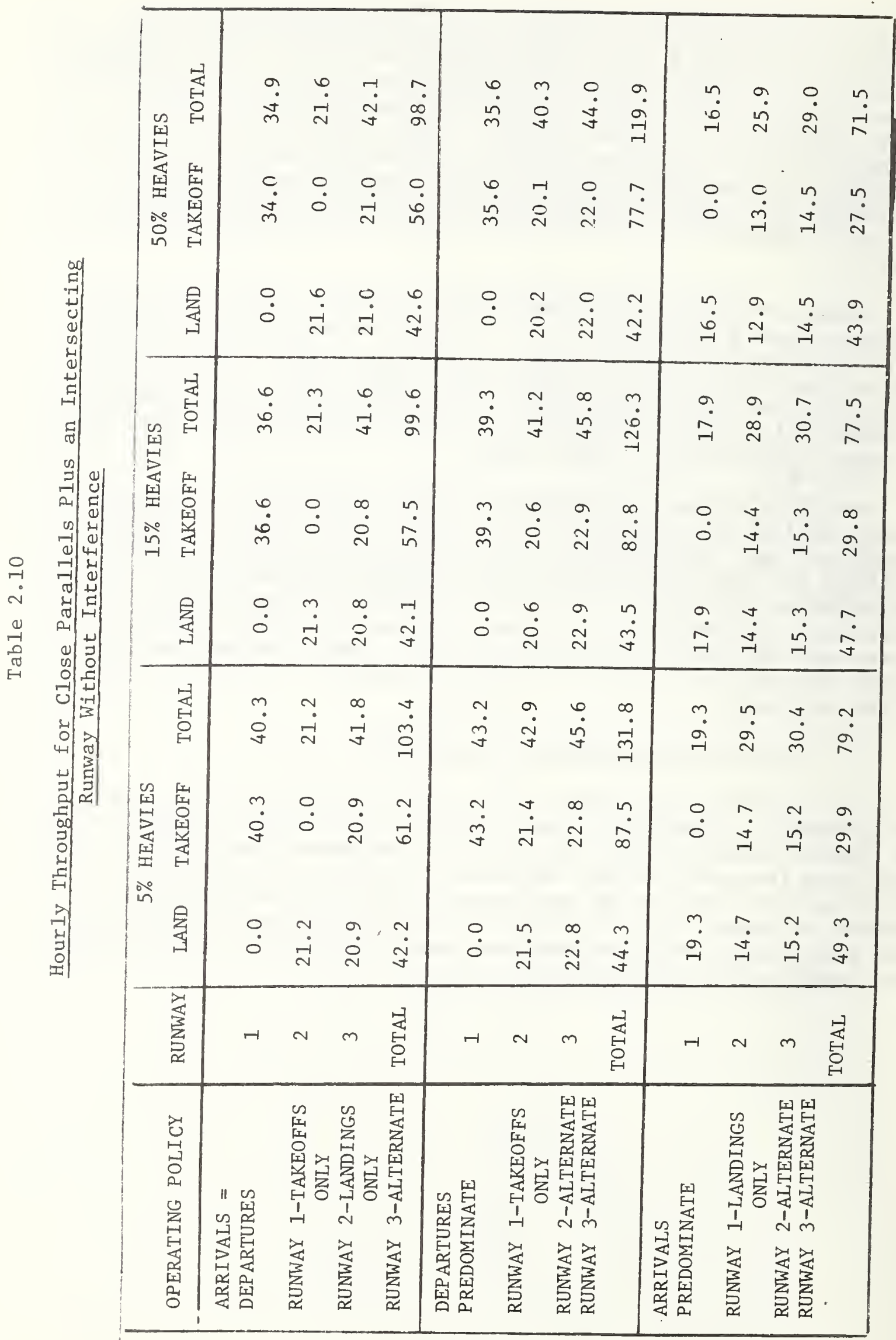




\begin{tabular}{|c|c|c|}
\hline 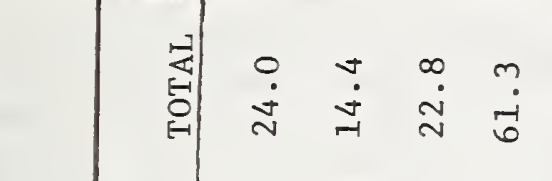 & 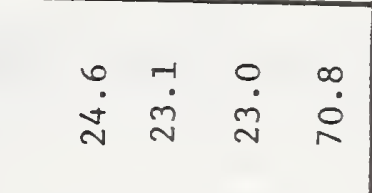 & 罗 \\
\hline 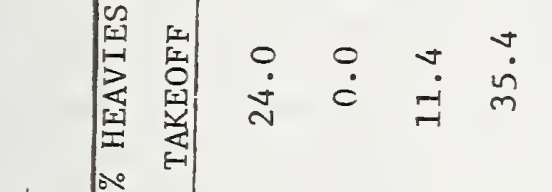 & $\because n_{n}$ & 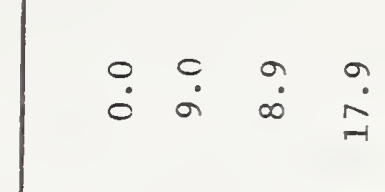 \\
\hline 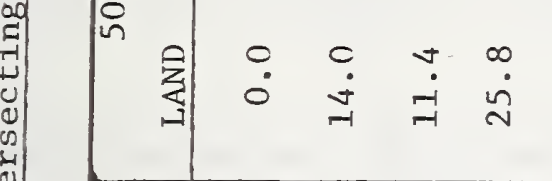 & 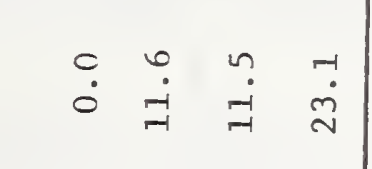 & $\therefore \dot{0}$ \\
\hline 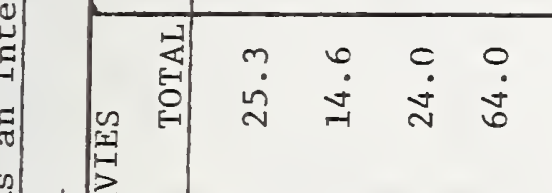 & 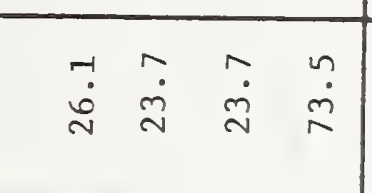 & 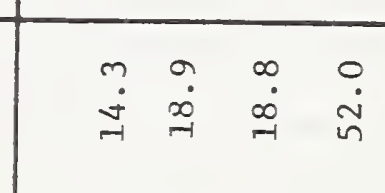 \\
\hline 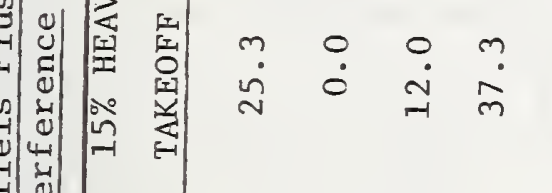 & 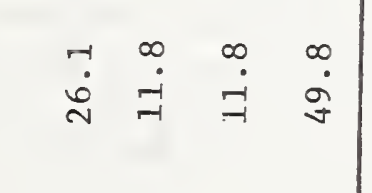 & \\
\hline$\hat{\underline{s}}$ & $\because:$ & $\therefore$ \\
\hline 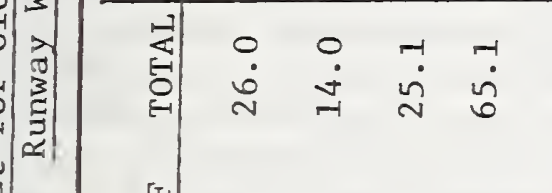 & 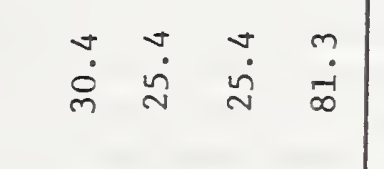 & 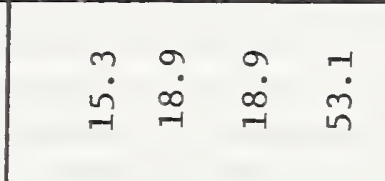 \\
\hline 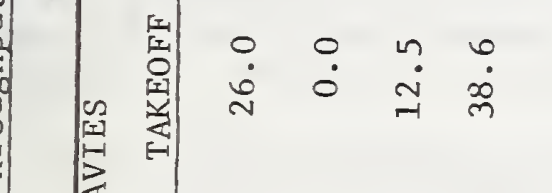 & 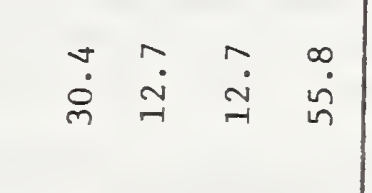 & : \\
\hline 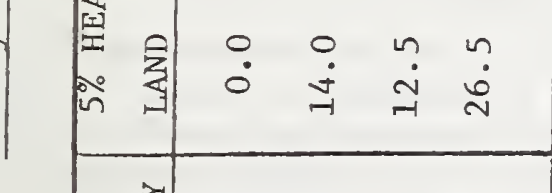 & $\begin{array}{l}0 \\
\dot{\partial}\end{array}$ & 3 \\
\hline 亶 $\cdots \cdots$ & $\because \cdots \infty$ & $\cdots$ \\
\hline 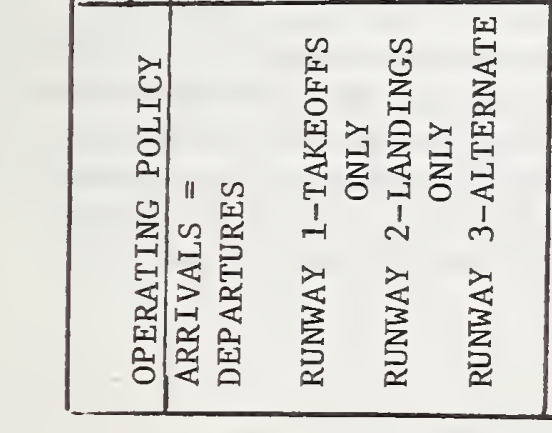 & 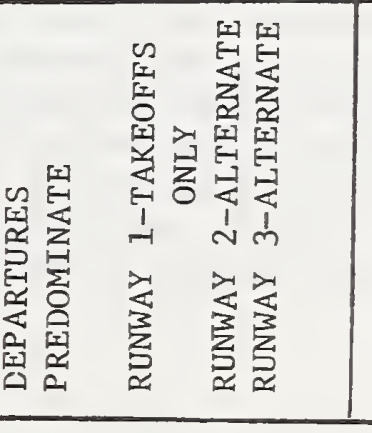 & 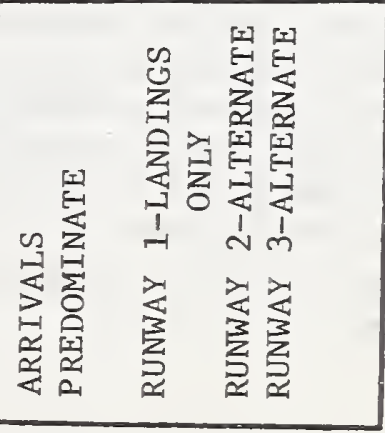 \\
\hline
\end{tabular}




\section{O'Hare Four-Runway Configuration}

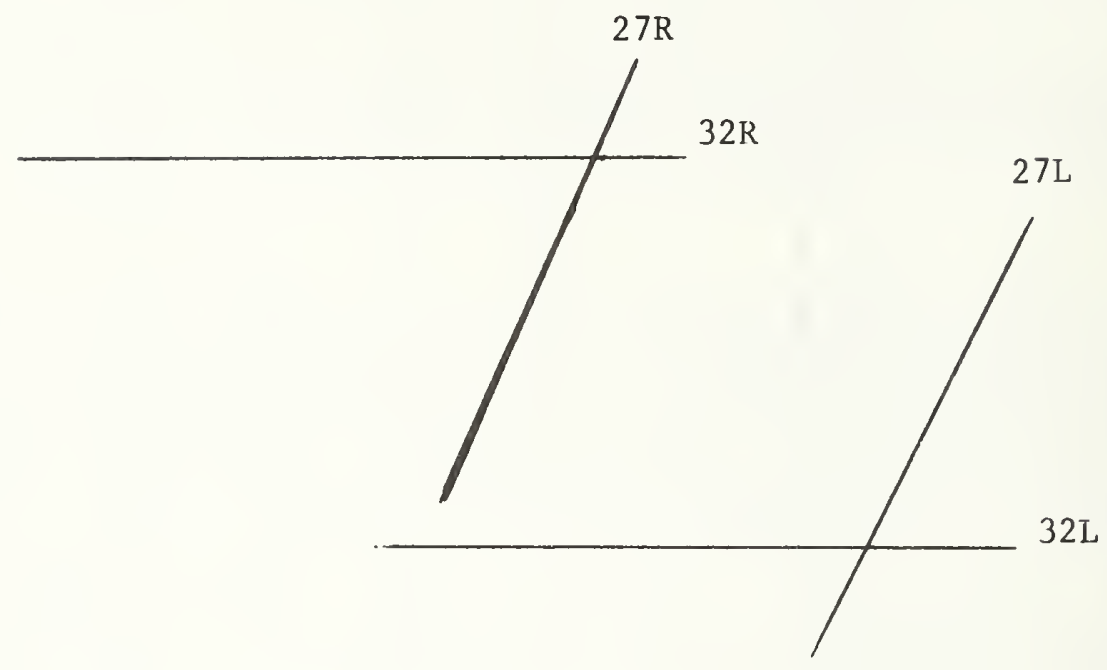

In the analyses reported above, the model was also exercised under different aircraft-type mixes and different arrival/departure ratios to demonstrate its ability to model these variations successfully. Changing the fraction of heavy aircraft from 5 to 50 percent decreases landing throughput (per runway per hour) by from 0 to 20 percent with an average decrease of about 12 percent, representing from 0 to 8 landings per runway and averaging about 4. Hourly takeoff throughput per runway is decreased more severely - from 0 to 28 percent, averaging 12 percent and representing a decrease of from 0 to 19 takeoffs (averaging 7).

As noted above, operating policy has almost as great an effect on throughput as does runway configuration. The influence of policy, a critical factor in actual operations, is probably somewhat exaggerated by the simulation when used to estimate maximum throughputs. In the simulation, operating policy is rigidly imposed. Whereas in a real situation a controller might run overflow takeoffs on a runway normally handling landings only, or divert a landing to a runway generally reserved for takeoffs, the simulation does not have this flexibility. In practice, the controller's extra leeway should allow him to exceed the capacity levels predicted by the model and therefore should allow for contingencies unforeseen by model assumptions, such as more serious bunching of arrivals and departures, or gaps caused by pilot decisions over which the ATC system has little control. The comparative rigidity of the DELCAP model's handling of operating policy should not seriously affect its usefulness as a tool in establishing EPS's, if care is taken in its application to ensure the most appropriate policy is chosen for simulation. 
The DELCAP simulation as now constituted assumes interlanding spacings of exactly 3,4 or 5 miles as well as fixed and constant runway occupancy times, assumptions which are unrealistic. However, since real separations and runway occupancies may be elther less or greater than the nominal values, it is unclear in which direction or to what extent these assumptions bias the resultant throughput values. Although it would be a relatively simple matter to represent these factors in a stochastic manner, it is not at all clear that much additional accuracy in throughput calculations would be gained,particularly since results are averaged over a period of 20 hours.

Throughputs calculated by DELCAP vary with operating policy, configuration and mix in the expected direction and agree quite well in magnitude with observed levels. (A more complete demonstration of this last point follows in the next section.) There are, however, a number of instances in which model outputs are higher than those actually attained at most installations. These involved the simulation of operating policies more complex in their control requirements than the policies in present use, so that empirical data with which to compare these outputs are lacking. For example, it would be unusual for a pair of intersecting or close parallel runways to be operated for any prolonged time with landings on both, unless one runway handled primarily smaller aircraft making visual approaches. This also holds true for the "parallels with crossing runway" configuration; most airports with such a configuration. would use the parallels for landings and takeoffs (on separate runways) of larger aircraft, with the crossing runway allocated to lighter aircraft as required. The DELCAP throughputs reported above, therefore, in part require demand levels and controller capabilities which are unlikely to be sustained over long periods. More practical capacity levels are associated with those policies which reserve main runways for pure operations and shorter crossing runways for mixed operations of lighter aircraft.

\subsection{Comparisons of Model Output With Available Data}

Table 2.12 reports IFR throughput figures for a variety of runway configurations at several airports, as computed by a theoretical procedure now under development by the FAA Air Traffic Service, as estimated by staff at the facility, and finally, as found using a version of the theoretical procedure devised by the FAA to account for local variations. The figures vary from facility to facility for the same configuration because of differences in aircraft-type mix and in other special characteristics such as air space restrictions (at JFK, for example). Differences between the theoretical and the modified standard values range from 4 to 19 percent and average 11 percent, so that one can regard as acceptable similar differences between these values and those produced by the model. 
TABLE 2.12

Throughput for Several Configurations at Selected Airports

\begin{tabular}{|l|ccc|}
\hline $\begin{array}{l}\text { Configuration } \\
\text { Class }\end{array}$ & Theoretical & $\begin{array}{l}\text { Fac1lity } \\
\text { Estimates }\end{array}$ & $\begin{array}{c}\text { Modified } \\
\text { Standard }\end{array}$ \\
\hline Wide Parallels & & & \\
JFK IFR-Pure & 74 & 70 & 71 \\
- MIA - Mixed & 106 & 75 & 100 \\
ATL - Mixed & 114 & 91 & 98 \\
ORD - Mixed & 104 & 90 & 92 \\
C1ose Parallels & & & 52 \\
- JFK IFR-Pure & 60 & 50 & 57 \\
PHL - Pure & 68 & 52 & 137 \\
4 R/W's ORD & & & \\
2 Pure Approach & & 135 & \\
2 Pure Departure & 152 & & \\
\hline
\end{tabular}

* A "pure" operation is one handling only takeoffs or only landings. Parallels operated in a pure policy have one runway only for landings and a second for takeoffs only. "Mlxed" operations refers to a policy allowing both landings and takeoffs on a runway.

In comparing the figures in Table 2.12 with DELCAP outputs, we have modified the latter to take into account the fact that takeoff capacity is rarely restricted and that the numbers in Table 2.12 are those sustainable over an extended period of time during which the total numbers of arrivals and departures are approximately equal. Whenever simulated takeoffs substantially outnumber landings, the maximum total throughput as calculated by DELCAP does not correspond to such a sustainable situation, and a better approximation to realistic total throughput is twice the calculated landing throughput. Table 2.13 reports throughputs thus obtained from DELCAP for configurations similar to those in Table 2.12. (Most of these numbers are taken directly from tables in the previous sections.) Throughput for the 


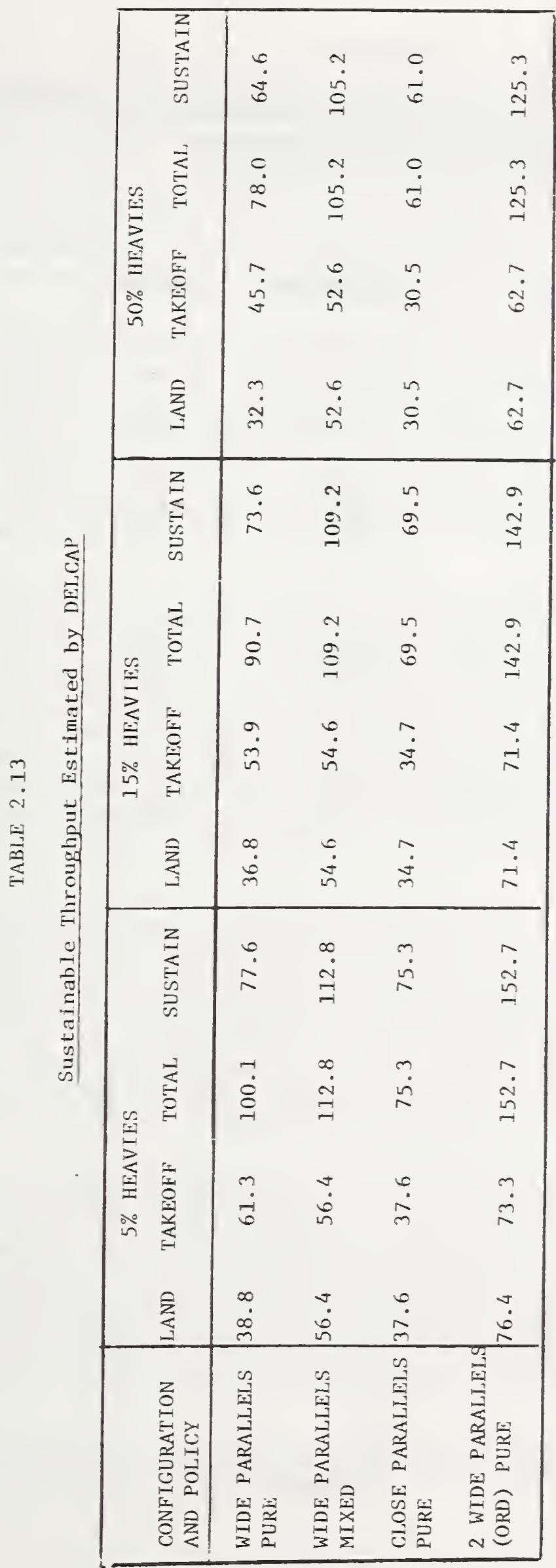


TABLE $\quad 2.14$

Comparison of FAA Theoretical Throughput Estimates With Those Calculated By DELCAP

$\begin{array}{lcc}\begin{array}{l}\text { Configuration } \\ \text { Class }\end{array} & \text { Theoretical } & \text { DELCAP } \\ \text { Wide Parallels } & & \\ & & \\ \text {. JFK IFR-Pure } & 74 & 78 \\ \text {. MIA-Mixed } & 106 & 113 \\ \text { - ATL-Mixed } & 114 & 113 \\ \text { - ORD-Mixed } & 104 & 109 \\ \text { C1ose Parallels } & & \\ & & \\ \text { JFK IFR-Pure } & 60 & 75 \\ \text { PHL-Pure } & 68 & \\ 4 \text { R/W's ORD } & & 143 \\ 2 \text { Pure Approach } & & \\ 2 \text { Pure Departure } & 152 & \end{array}$


wide parallels with pure operations is calculated by adding the throughput for a single runway with only landings, to that for a single runway with only takeoffs.* Throughput for wide parallels used in mixed operations is calculated as twice the throughput for a single runway serving alternating landings and takeoffs. Throughput for the ORD 4-parallels case pictured in Figure 2.3 is estimated as the sum of throughputs for a near-intersection ("V") configuration and a far intersection pair of runways (both pairs without interference). The FAA theoretical values are compared with the DELCAP Estimates for the appropriate aircraft type mixes in Table 2.14.

Differences in throughput among airports depend in part on the aircraft-type mix. The $\mathrm{mix}$ at JFK contains approximately 43 percent heavies, while that at the other airports is much lower. (At ORD, for instance, there are about 16 percent heavies.) For most of the airports of concern here, small aircraft account for a relatively small proportion of traffic (except for PHL where they account for about 40 percent). Therefore, for most airports the throughput figures are more like those reported for 5 and 15 percent heavies.

In the case of wide parallels and pure operations, values in the two tables agree quite well. Whereas the theoretical value of 74 operations per hour agrees exactly with the DELCAP value for 15 percent heavies, the value of 65 from DELCAP for 50 percent heavies is more appropriate since JFK has over 40 percent heavies. Linear interpolation (of 40 percent between 15 and 50 percent) yields about 68, slightly lower than the final figure of 71 (surprisingly, since one would normally expect the model, requiring perfect controllability, to estimate higher than actual values), but still within 5 or 6 percent of the modified performance standard.

In the case of wide parallels under mixed operations, DELCAP maximum throughput values vary from 105 for 50 percent heavies to 113 for 5 percent heavies, agreeing very well with the 104 to 114 theoretical values for the three airports using this operating policy. The most applicable DELCAP values are for the 5 to 15 percent heavies for these three airports, meaning that DELCAP estimates are 5 to 7 operations high for MIA (Miami International) and ORD (Chicago O'Hare International), and one operation low for ATL (Atlanta), but still within 5 to 6 percent of the theoretical values determined by the FAA.

DELCAP values agree very well with the theoretical values for close parallels. The DELCAP throughput of 61 operations at 50 percent heavies matches closely the theoretical value of 60 for JFK, which has a large percent of heavies in its mix. The PHL theoretical value of 68 is closely approximated by the DELCAP-computed value of 69.5 for 15 percent heavies. In both cases the DELCAP values are slightly high ( 1 or 2 percent) but the fraction of heavies at PHL is probably closer to the 5 percent level, in which case the DELCAP figure is 10 percent high.

* The numbers in Table 2.13 for this case are obtained from runs not included among those reported earlier. 

Throughput calculated by DELCAP for the 4-runway ORD case lies between the modified standard and the theoretical value in Table 3.2. Note that the DELCAP throughputs used for this analysis are those without interference. (If values from runs with interference were used, the DELCAP estimates would be somewhat lower.) Discussions with FAA personnel familiar with the ORD operation indicate that the two sets of parallels are treated almost as two independent sets of intersecting runways. For the pure operating policy, takeoffs are cleared once a landing passes the intersection, and occur in such a way that the two mile departure/arrival separation does not limit operations. In this operating situation the "without interference" policy more closely describes the actual situation and therefore is indeed the more appropriate policy choice for comparison purposes.

The exercises described above have incorporated some preliminary investigation of model throughput sensitivity to aircraft $\mathrm{mix}$ and to runway operating policy. Throughput decreases, from 10 to 33 percent (averaging about 16 ), as the percentage of heavy aircraft in the mix increases from 5 to 50 percent. Of much greater effect on throughput are two other factors: runway operating policy, and the interference requirements. The latter are determined by ATC rules, but only apply to IFR traffic. If some crossing runways are used primarily by VFR aircraft, or if many aircraft are able to turn off before an intersection, then throughput obtained from DELCAP runs without interference rules in effect would more closely represent the actual situation. As has been noted above, care must be taken in defining the operating policy. Throughput for a mix containing 5 percent heavies for wide parallels with alternating operations on both runways is 113, while that for wide parallels handling pure operations is 78. Depending on the actual sequencing of operations on the two runways, almost any value between these two extremes can be obtained. Therefore it is necessary to be very careful in defining the operating policy to insure that the DELCAP runs model the particular situation desired, and it is strongly advisable to try a variety of policies if there is any question as to which is most applicable.

The DELCAP simulation as now constituted assumes interlanding spacings of at least 3,4 or 5 miles as well as fixed and constant runway occupancy times, assumptions which are unrealistic. However, the validation indicates that not much additional accuracy in throughput calculations would be gained from (the very easy-to-implement step of) representing these factors in a stochastic manner.

The exercises reported in this chapter have increased our confidence in DELCAP's validity for use as a tool in setting engineered performance standards. In the cases discussed above, DELCAP's throughputs agreed very well with the theoretical values calculated, using a manual process, by the FAA's Air Traffic Service. These theoretical values are the ones with which we would expect greatest agreement, since they are arrived at, 
in the simplest cases, in much the same way as DELCAP simulates events. It was hoped that the validated DELCAP would be able to take over this calculation chore, thus avoiding time-consuming and cumbersome hand operations. These validation exercises have established DELCAP's ability to handle that task. The differences between the theoretical and modified standard values highlight the fact that DELCAP (or any model, for that matter) is only a tool to aid in developing the standards. Other factors not included specifically in the model, such as airport noise restrictions, special approach or departure route requirements, ground configurations, or unusual bunching of the traffic distribution, may further limit the sustainable traffic levels, so that two facilities with the same traffic mix, configuration and operating policy may not be able to sustain the same throughput levels even though the model would output them the same. Use of model outputs without careful scrutiny is never advised in any application, but the validation results reported above indicate that the outputs of the DELCAP model will fit well into the philosophy and process already adopted by the FAA for setting engineered performance standards. 


\section{VALIDATION OF MODEL'S DELAY ESTIMATES}

\subsection{General Background}

In the previous section we reported a successful effort establishing the validation of DELCAP's throughput results. This section will document an effort designed to aid in establishing the validity of DELCAP's delay outputs. Because of problems in the definition of delay and in available data, the approach reported below was unsuccessful. It is described here to provide a further example of the operation of the DELCAP model, as well as a "lesson" in how not to attempt validation of delay output.

Although the effort was unable to establish the validity of DELCAP delay output, it did illustrate how the model can be run with a mixture of scheduled traffic entered explicitly and general aviation traffic generated in a Poisson manner. Whereas model-computed delays were not comparable with actual recorded delay (measured using the difference between actual and scheduled operation times), the model-computed delay figures agree quite well with facility estimates of the delays attributable to facility operations on the day to which the data apply. In addition, the shapes of the delay curves in these two cases as they vary during the day are very similar, with peaks occurring at about the same times. This section ends with suggestions for future delay validation efforts, which would involve the collection of special data referring to that portion of delay attributable to air traffic control procedures in the the terminal areas.

Problems associated with the definitions of capacity and delay are discussed for example in [4]. Intuitively, the definition of "delay" seems clear -- to retard, to slow down, to detain -- but the crux of the problem lies in the question -- retard. slow down, detain relative to what? Presumably there is a faster way to accomplish the activity in question, and delay is experienced because of not being able to do it that way. The commercial air passenger believes he is delayed only if he arrives later than his scheduled arrival time. The pilot may perceive delay whenever he has to wait in a queue on the ground or in a holding pattern. The ATC system seeks to measure ATC delays, those resulting from ATC procedures, but unfortunately it is difficult to separate them from those resulting from schedule bunching. The ATC system does not count those delays occurring on the ground because of airline procedures, including those resulting from gate assignment problems or from crew or equipment shortages. Path stretching procedures are not normally considered by the ATC system to generate "delay" but may be so considered by others.

Thus each party of the air transport system has a different part of the total delay in mind when speaking of delay. The approach to delay calculation also matters, since whether delay occurs only during specific maneuvers or only because of a particular time difference (e.g. actual versus scheduled arrival times) affects the way it should be measured and calculated. The problems arising because of different definitions of delay are further complicated by the need to ascribe portions of delay to different parts of the system. ATC delay must be separated from total delay and then be apportioned to the facilities involved. 
DELCAP is oriented exclusively to the effects of terminal-area ATC, and the "controls" exercised over each aircraft are necessitated predominantly by the presence of other aircraft in the environment. Therefore, the definition adopted for delay in DELCAP is the difference between the time to execute a maneuver in the presence of other aircraft and a nominal value of the time to execute that maneuver with no other aircraft involved. The DELCAP-computed delay includes only that portion of an aircraft's total delay occurring while under control of the terminal facility being modeled. It includes delay caused by airside operations, but not by ground operations, with the exception of those occurring on the runway surface. These restrictions ensure that DELCAP-computed delay refers to only that part of the ATC system, the terminal area, for which it is desired.

While this definition is a quite straightforward way to model delay, is physically meaningful, and corresponds correctly to the "terminal-area ATC" level of analysis for which DELCAP was commissioned, it does not correspond to any current operational definition. Thus, in order to validate DELCAP's delay figures it will be necessary to mount a special data collection effort. The characteristics of such an effort are described below in section 3.6 .

It was recognized early in the DELCAP-delay validation work (and indeed noted earlier when describing future work in [1]) that there would be difficulties in comparing the data on delay available from the scheduled and actual operation times with the delays measured by DELCAP. Despite these anticipated problems, it was decided jointly with the FAA to continue on and to learn as much as possible using these data, which were the only ones available in time without a special data collection effort. Even if the analysis of delay output showed inconsistencies, the exercise would allow testing DELCAP in mode discussed previously but not actually run: mixing scheduled and stochastic types of traffic input.

In the past, DELCAP has been run on a variety of runway configurations representing several of the nation's busiest airports, but each of these efforts used traffic descriptions concocted from general knowledge of the traffic levels expected at the facility. The exercise described below uses actual traffic for LaGuardia Airport (LGA) for Friday, October 25, 1974. The facility reported good weather conditions that day and "no delays" (i.e. no aircraft delayed more than 15 minutes). This includes only delays occurring while aircraft are in a holding pattern or a ground departure queue. Other factors contributing to passenger-experienced longer trips, such as path-stretching, alternate routing, airline gate delays, or equipment problems, are not included in such estimates. Some of these factors, in particular path-stretching, do contribute to the DELCAP-computed delay figures. The LGA facility reports only delays occurring while the arriving or departing aircraft are under its control, specifically while they are in the facility's holding pattern or queues. 
LGA handled 939 operations, of which 715 were air carrier operations and the rest were mainly general aviation, with a few non-scheduled suburban carriers included. The runwav configuration for LFA is denicted in Figure 3.1.

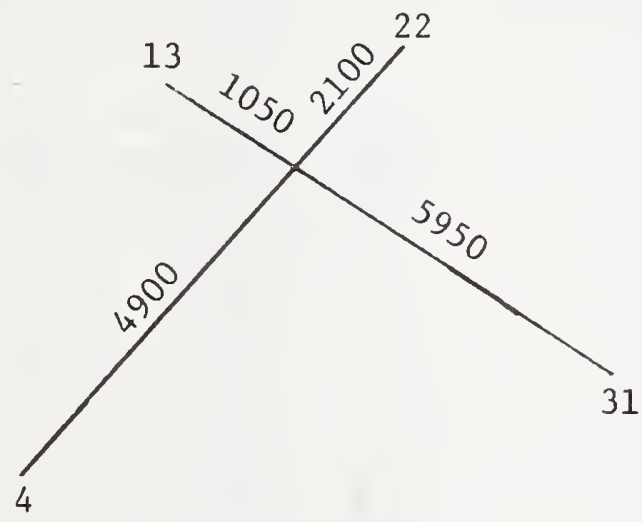

FIGURE 3.1

Runway Configuration for LGA

Most of the time the airport is operated with landings on one of the runways and takeoffs on the other, with runway-directions depending on wind direction. A more detailed description of the input data for the DELCAP run of LGA is given below.

\subsection{Traffic Input Data}

Traffic data for LGA are available from two sources: scheduled operations from the official Airline Guide [3] and actual operations from CATER* data. The Airline Guide schedule data were provided to us by the FAA from a printout of the FAA's Airport Information Retrieval System (AIRS) program, which extracted the data in a form convenient to use in this effort. A sample of this data appears in Figure 3.2. Arrivals and departures were listed separatehy, sorted by departure or arrival time. Ten minutes had been subtracted from arrival time (added to departure time) to allow for the difference between gate time and touchdown (start-of-roll). The data include the flight identification, the operation time (touchdown. or start-of-roll), the aircraft type, and additional data giving origi-

*CATER, Collection and Analysis of Terminal Records, has been instituted at the three large New York airports (LaGuardia, Kennedy and Newark), and under it data are relayed to Washington concerning each operation at any of the airports as well as meteorological conditions. 
FIGURE 3.2

\section{Sample Schedule Data}

IUกก A/C Pח C./A 4

\begin{tabular}{|c|c|c|c|c|}
\hline DI $\cap 19 \cap 5$ & $14 n \cap$ & TFH7 & $n 1 \cap$. & ZRW \\
\hline$A \wedge \cap \cap 564$ & 1405 & J725 & ก 156 & 2013 \\
\hline conntin & $14 n 9$ & JDC 9 & $n \cap 41$ & ZDC \\
\hline MIAnח a? & 1.417 & J727 & ก)17 & $Z M A$ \\
\hline FAnIIRO? & 1424 & J7?S & $0 ?: 24$ & ZMA \\
\hline lwwn 11 : : & 1424 & J72, & 01.39 & $Z A U$ \\
\hline Th:nก.311 & 1427 & 1727 & n14? & $Z A C l$ \\
\hline$A 1, \cap \cap 44 ?$ & 14.38 & J725 & $01 \cap .3$ & \\
\hline NWOn? is & 1440 & 1727 & กว ก & ZMP \\
\hline$\triangle \wedge \cap \cap ว 7\rangle$ & 14113 & .1725 & ก1.58 & ZKC \\
\hline 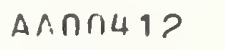 & 1414.3 & 1727 & 0143 & ZAU \\
\hline FAn1ח.3< & 144.3 & JDOS & 0114.3 & $Z R W$ \\
\hline ו' & 1445 & Jis & $n \cap 5$ ' & $20 R$ \\
\hline PIn 172 & 14147 & J7.3, & $n \cap 49$ & ZDC \\
\hline Twחก:17? & $145 n$ & J725 & $n>n: 1$ & $Z K C$ \\
\hline lif $\cap 01115$ & $145 n$ & JDOS & $n 14 n$ & $Z A L$ \\
\hline$F A \cap 24.3<$ & 1450 & JDAS & $0 \cap 511$ & $2 \mathrm{DCC}$ \\
\hline FAnก15! & 14.51 & J727 & $n 148$ & $Z J x$ \\
\hline Al nrt4a? & 1455 & JR 11 & 0055 & $20 R$ \\
\hline IIAกกB4ח & 1459 & $J 7.37$ & $01 \cap 9$ & ZOR \\
\hline
\end{tabular}

\begin{tabular}{|c|c|c|c|c|}
\hline 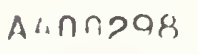 & 1505 & 1727 & ח1:8 & ZOR \\
\hline$A \wedge \cap \cap 14 ?$ & $15 n 5$ & J727 & $n \cap .35$ & $2 D C$ \\
\hline IIAกก451) & 1517 & J727 & ก२1. & ZMP \\
\hline$\triangle \wedge \cap \cap 2: 1$ & 1518 & J72S & 01148 & ZDC \\
\hline Anחती, & 1522 & J725 & 0141 & $Z M E$ \\
\hline$D L \cap 07, a$ & $152 ?$ & JDOS & n:126 & ZRW \\
\hline MAnri144 & 152.3 & J!) & $n>1.3$ & $Z M A$ \\
\hline$T W \cap: .314$ & 1520 & $17 ? 5$ & 0141 & $2 \mathrm{AU}$ \\
\hline 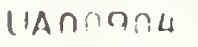 & 15.34 & J72S & 0145 & ZAll \\
\hline Fan 16.3 & 15.38 & J727 & $0 ? 15.3$ & \\
\hline $1119 \cdot 4<$ & $154 n$ & JDOS & ก114: & ZRW \\
\hline $1, \quad, 5,11$ & 1541 & J727 & 0115 & $\mathrm{OK}$ \\
\hline (.7nivanta & 154 ' & Jnas & กก 4? & $20 C$ \\
\hline $7 \mathrm{~V} \cap \mathrm{n} \cdot 12 \mathrm{H}$ & 15,46 & .1727 & $n 1: i$ & ZID \\
\hline AI ก(IR) 1 & 1547 & TrV & $n: 4 ?$ & $7 D C$ \\
\hline A. 0113112 & 1548 & 1725 & ก14H & $Z \wedge U$ \\
\hline$F \wedge \cap 1174 \pi$ & 151,0 & Jnas & กวンก & $Z M A$ \\
\hline$F A n: 1: ?$ & $154, n$ & JD9S & 0151 & ZTL \\
\hline$F A \cap P 411<$ & $15^{\prime} \cdot n$ & JDOS & $n, 1, n$ & $2 D C$ \\
\hline NAח & $15 r: n$ & J72S & 0.145 & $2 D C$ \\
\hline FAn, 611 & 151,0 & J7?7 & ח?:? & 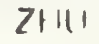 \\
\hline
\end{tabular}


nating (or terminating) air route control center and flight time. Flight ID's with the symbol < as final character belong to Eastern Airline's shuttle flights and may represent several actual aircraft for each flight because of extra sections. Aircraft types represented in the example in Figure 3.2 include Fokker Friendship Turbo-prop F-227 (TFH7), Boeing 727 and Stretch 727 (J727 and J72S), Douglas DC9 and Stretch DC9 (JDC9 and JD9S), Boeing 737 (J737), BAC 111 (JB11), Douglas DC10 (JD10), and the Convair 580 Turbo-prop (TCJ5). Al1 of these, with the exception of the DC10 (a heavy aircraft), are "category 3" aircraft types.

A sample of the CATER data on actual flight operations at LGA appears in Figure 3.3. These data are taken from flight strips and transmitted dally via teletype from New York to Washington. Touchdown and start-of-roll times are recorded for all operations at the three New York airports (LGA), JFK and EWR). Data recorded include the date and time of each operation, the flight identification, the aircraft type, the user category (Air carrier, General aviation, or Suburban), arrival or departure designator, IFR or VFR distinction, the runway on which the operation occurred, and gate departure time for takeoffs. In addition to these traffic data, the CATER printout also indicates operating policy and changes in policy as well as weather conditions (primarily visibility range and wind direction and speed). The traffic recorded in the CATER data includes helicopter operations, designated by aircraft type HELO and an $\mathrm{H}$ associated with the user type (AH is air carrier helicopter, for example), but only fixed-wing operations were included in the simulation input.

Input from the two sources, scheduled operations and actual operations, was matched and discrepancies noted. The discrepancies and efforts to reconcile them are discussed in greater detail in Appendix F, which also contains a listing of the actual traffic input to the model.

\subsection{Delay Analysis of the Input Data}

For each of the 702 flights for which the data contained both a scheduled operation (landing or takeoff) time and an actual operation time, "delay" was computed as the difference between the two times. Figure 3.4 records for each hour the number of aircraft whose delay fell into each delay category (5-minute intervals ranging from no-delay to over one hour's delay). In addition to the hourly delay profile for all aircraft, Figure 3.4 also contains separate profiles for landings and takeoffs. In each case 26-27 precent of all operations are delayed more than 30 minutes and 8-9 percent are delayed over an hour. Since the facility reported good weather with "no delays", these long delays must be the result of problems occuring elsewhere in the air traffic control system. This indicates the difficulties, to be described below, in attempting to use this delay profile for validating DELCAP-computed delays. DELCAP models only the LGA terminal area, and can thus estimate only that subtotal within the total delay which occurs within that terminal area. The delays reported in Figure 3.4, representing the difference between the actual and scheduled operation times, include many delay factors not attributable to conditions in the LGA terminal area. Even departures from LGA can be delayed by late arrival of equipment from elsewhere. 


\section{DATE 10/25/74 LIST OF OPERAIIONS PABE OT}

DIG/OP RI/ID A/C CT AD IV RNY DTR REMARKS/WEATHER/COMMENTS

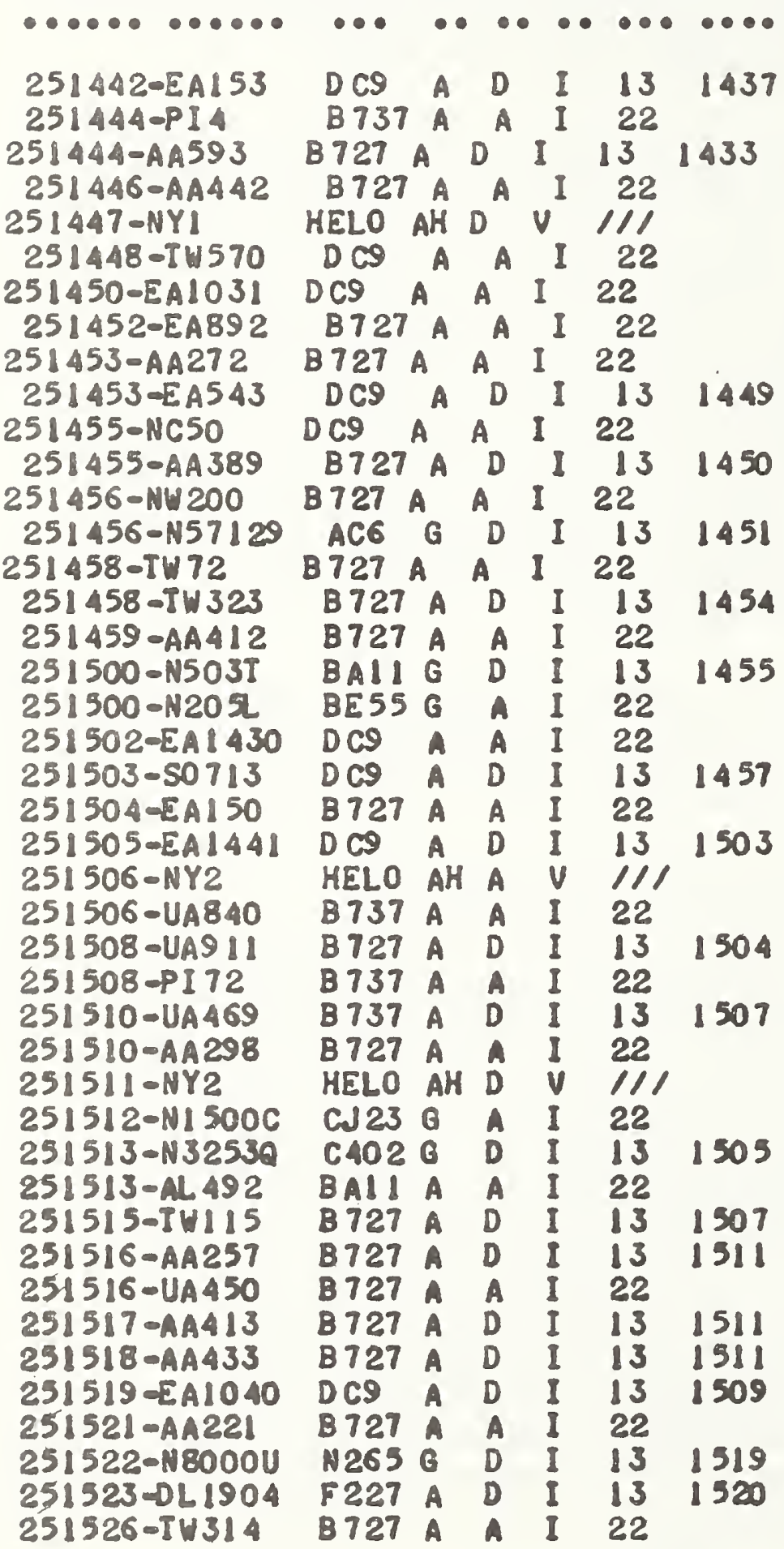




$$
\begin{aligned}
& \text { 至 }
\end{aligned}
$$

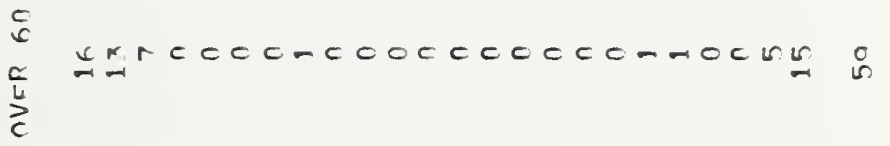

$$
\begin{aligned}
& \text { if } m=m-100000000000000000-n-1 \\
& \prod_{n}^{n} \text { mmo000000000000-000-00Nm m }
\end{aligned}
$$

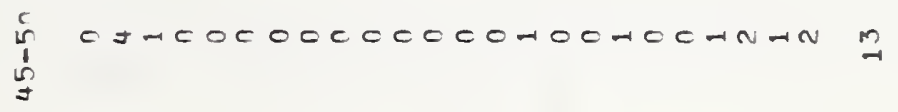

$$
\begin{aligned}
& \sum_{\substack{n \\
n}}^{2}
\end{aligned}
$$

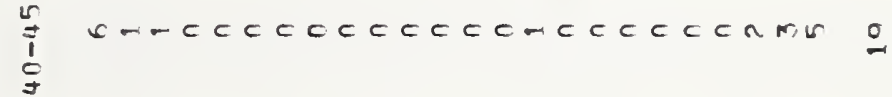

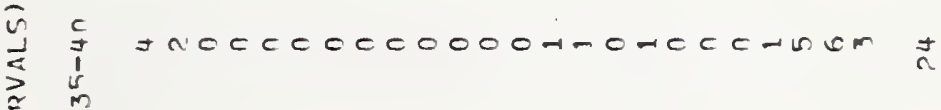

$$
\begin{aligned}
& \text { | }
\end{aligned}
$$

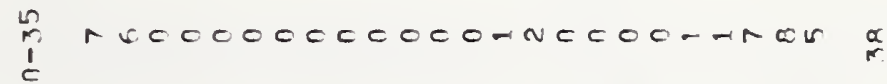

$$
\begin{aligned}
& \text { m DNONOOOOOOOHLNOONOAMNNJ J }
\end{aligned}
$$

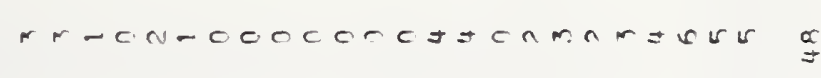

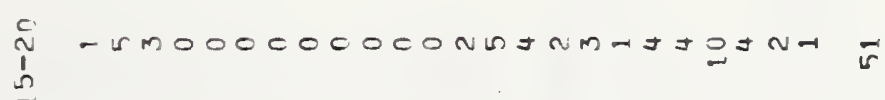

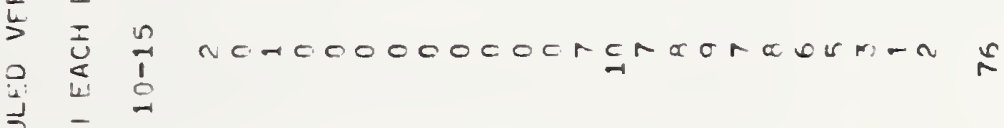

$$
\begin{aligned}
& \text { 三 } \\
& \text { 壳 } \\
& \text { t } \frac{c}{1} \text { - rom-cococoor } \\
& \text { थ } \\
& \text { 岁至台 } \\
& \text { c. }
\end{aligned}
$$

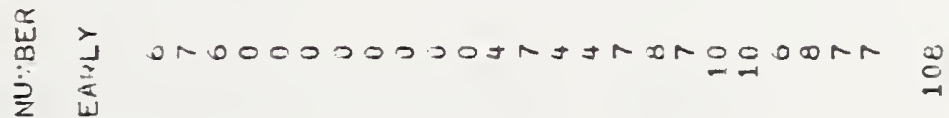

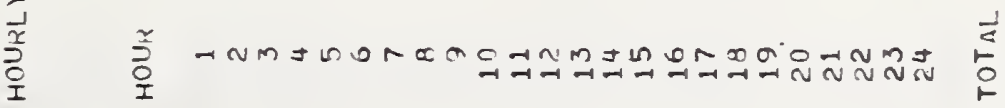




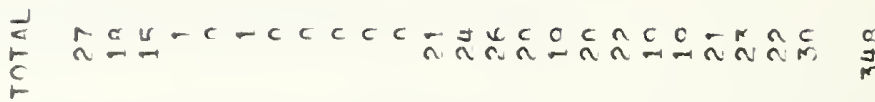




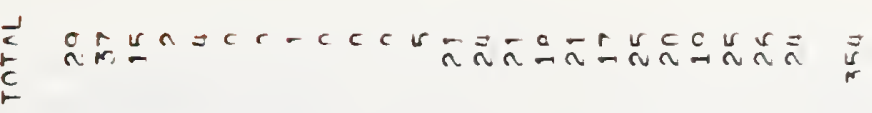
6 $\frac{c}{c}$ ar $r e c c c-c c c c c c c c c c-c c c r u r$

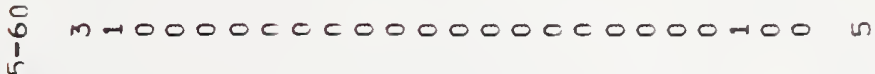

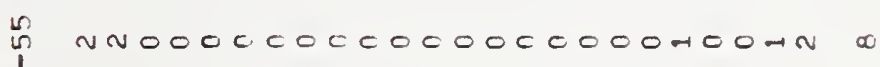

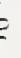

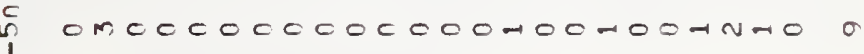
$\stackrel{1}{2}$

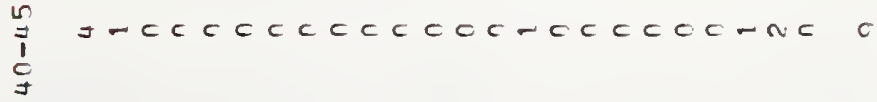

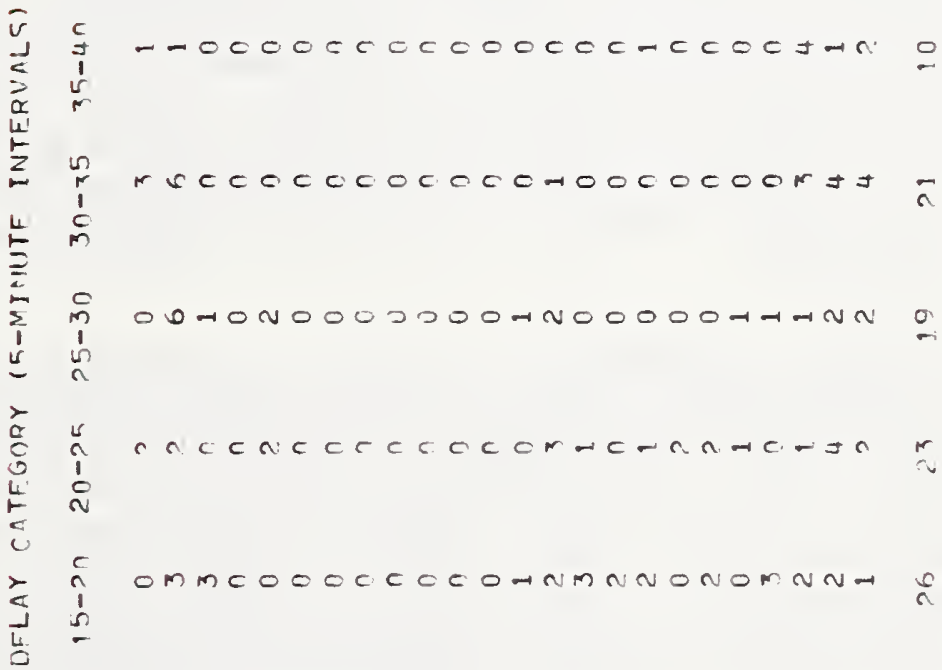

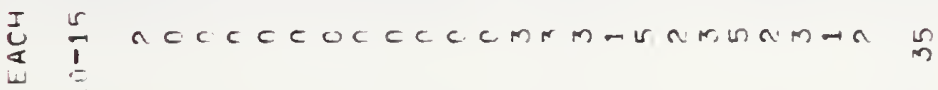

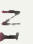

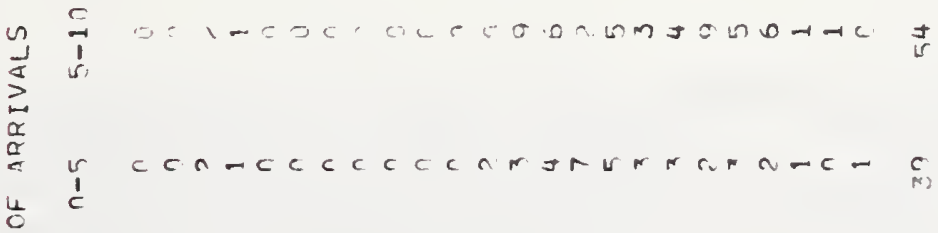

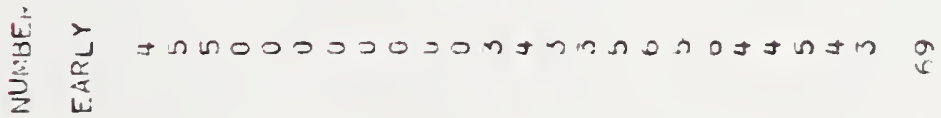
$\frac{i}{5} \quad-N m a n$ a 
Long delays are reported in hours 22 to 24 and 1 to 3 (or 2100 to 300 GMT, which is 5-11 p.m. local time), with about two thirds of the departures and 52 percent of the arrivals scheduled for that period delayed more than half an hour. About 46 percent of all scheduled flights are delayed by more than 15 minutes. On the other hand about 15 percent of the operations were early: 11 percent of the departures and 20 percent of the arrivals. Since no scheduled air carrier can depart early, presumably the early departures occur in the data because of the adjustment of gate time to roll time. Since this adjustment involved a single time increment added to gate time, whereas actual taxiing time depends on gate and taxiway location, actual time may vary from the single nominal value by several minutes. This could cause an aircraft to be listed as departing early if that aircraft actually required less taxiing time than the nominal figure.

\subsection{DELCAP Input}

In addition to the scheduled traffic input to DELCAP shown in Appendix F, general aviation traffic was also included. Table 3.1 displays the hourly general aviation traffic levels actually maintained on October 25 . Scheduled traffic was supplied to the model directly as an exogenous* input through the exogenous event routine XGEN, while a representation of general aviation traffic was generated randomly by event routine GEN according to Poisson distributions with the hourly operation rates from Table 3.1 as means. All general aviation traffic was assumed to be aircraft type 2 (light aircraft).

The runway configuration for LGA is shown in Figure 3.1. Figure 3.5 gives the preprocessor output resulting from the LGA input. "Runway 1 " is runway 04, "runway 2 " is runway 13, "runway 3 " is runway 22, and "runway 4" is runway 31 . The initial operating policy allows landings and takeoffs to alternate on runway 3 (22). Changes in policy are input exogenously through exogenous event routine CHGOP. The operating policies used during the run are given in Table 3.2. The change at 1920 -- from alternating on 3 and 2 to alternating on 3 and 4 -- involves a direction change (runway 2 to runway 4), as does the change at 0250 from 3 and 4 to 1 .

*SIMSCRIPT simulations have two ways of initiating events, exogenously and endogenously. Endogenous events are those initiated by other events in the program while exogenous events are initiated by user-supplied input data. In DELCAP, flights may be generated by either of these mechanisms: stochastically by event GEN which schedules the arrival to the system of the next flight after the previous stochastically-generated one has arrived, or externally by XGEN in which the user inputs the system arrival time of each flight and the characteristics of that flight. 
TABLE 3.1

LGA General Aviation Traffic Levels By Hour

\begin{tabular}{|c|c|c|c|}
\hline Hour & Landings & Takeoffs & Total \\
\hline 1 & 4 & 4 & 8 \\
\hline 2 & 3 & 3 & 6 \\
\hline 3 & 2 & 7 & 9 \\
\hline 4 & 3 & 2 & 5 \\
\hline 5 & 15 & 4 & 19 \\
\hline 6 & 2 & 12 & 14 \\
\hline 7 & 0 & 0 & 0 \\
\hline 8 & 0 & 0 & 0 \\
\hline 9 & 0 & 0 & 0 \\
\hline 10 & 0 & 0 & 0 \\
\hline 11 & 2 & 2 & 4 \\
\hline 12 & 7 & 5 & 12 \\
\hline 13 & 10 & 8 & 18 \\
\hline 14 & 7 & 12 & 19 \\
\hline 15 & 8 & 9 & 17 \\
\hline 16 & 3 & 7 & 10 \\
\hline 17 & 4 & 6 & 10 \\
\hline 18 & 7 & 4 & 11 \\
\hline 19 & 4 & 9 & 13 \\
\hline 20 & 7 & 6 & 13 \\
\hline 21 & 9 & 15 & 14 \\
\hline 22 & 7 & 6 & 13 \\
\hline 23 & 7 & 12 & 19 \\
\hline 24 & 6 & 7 & 13 \\
\hline
\end{tabular}


THIS SIMILATION RUNS FPOM 7.00 TO $7.0 \mathrm{n}$

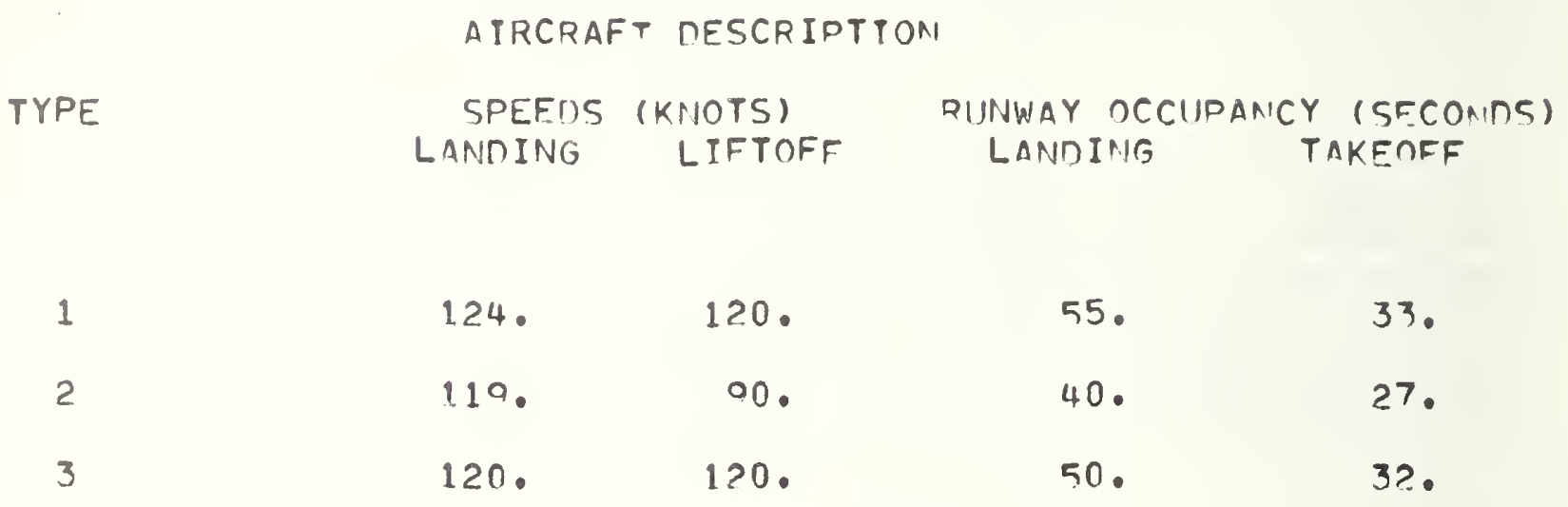

TRAFFIC NESTRIPTTON:

$\begin{array}{ccc}\text { TYPE } & \begin{array}{c}\text { LANDING } \\ \text { MIX }\end{array} & \begin{array}{c}\text { TAKEOFF } \\ \text { MIX }\end{array} \\ 1 & 0 . & 0 . \\ 2 & 10 n \cdot & 10 n \\ 3 & n . & 0 .\end{array}$


AIRPORT CONFIGURATION

NUMBFR OF RUNWIAYS $=4$

RUNWAY $1(4)$ - NO POLICY PROVIDFO! "IOT IISFD INITIALLY

RUNWAY $2(13)$ - IO POLICY PROVIDED/ NOT IISED INITIALLY

RUNIAY $3(22$ ) - DUAL IISE, ALTEPNATTNE OPERATIONS

RUNWAY 4 (31) - NO POLICY PROVIDED/ NIOT USFD INITIALLY

RUNWAYS 4 ANA 13 INTERSECT AT A POINT 4900. FEFT FROM T:-IF END OF RIIIIAY 4 AND 1050. FEET FOOM THE ENC OF RIINWAY 13.

RUNWAYS 4 AND 31 INTERSECT AT A POINT 4900. FEET EROM THF END OF RIINAAY 4 AND 5950. FEET FPON THF FND OF RINWAY 39.

RUNWAYS 13 ANIO 2? IMTERSECT AT A POTMT 1050. FEET FROM THF END OF RUIWIAY 1.3 ANID 2100 . FEET FDOM THF END OF PINWAY ??

RUNHAYS 22 AND 31 INTERSECT AT A POINT 2100 . FFET FRON THF END OF RINNAY 22 AND 5950. FEET FPOM THF ENT OF RINNWAY 31.

RUNIAYS 4 AND 13 ARE SEMI-DEPFNAENT SIMULTANFUISS ARRIVALS ARE DRAHIBITFN

RUNHAYS 4 AND 31 ARE SEMI-DEPFNRENT = SIMULTANEUUS ARRIVALS ARE DROHIBITFD

RUNWAYS 13 AND 22 ARE SEMI-DEPFNINENT SIMULTAMEOIS ARRIVALS ARE DROHIBITFD

RUNINAYS 22 AND 31 APE SEMI-DEPENAENT SIMULTANFOLIS ARRIVALS ARE PROHIBITEN 
FRACTION OF LANDINGS OF EACH TYPE OA FACH DIINWAY

$T Y P$
1
2
3

RUNANAY

$1(4)$

$2(13)$

$3(22)$

$4(31)$

1

2
3

- กnO0

$.0 \cap 00$

.0000

- 0000

.0000

. 0 non

1. $\cap 000$

1. 0000

- onon

1.0000

.0000

. 0000

FRACTION OF TAKEOFFS OF EACH TYPE OA EACH DIINWWY

$\begin{array}{ccccc}\text { RUNWAY } & 1(4) & 2(13) & 3(22) & 4(31) \\ \text { TYPE } & & & \\ 1 & .0000 & .0 n 00 & 1.0000 & .0000 \\ 2 & .0000 & .0 n 00 & 1.0000 & .0000 \\ 3 & .0000 & .0 n 00 & 1.0000 & .0000\end{array}$


TABLE 3.2

Operating Policies for LGA, by Hour

Time

0400-1025

$1025-1920$

$1920-0250$

0250-0400

\section{Policy}

Alternate landings and takeoffs on runway $3(22)$.

Alternate a landing on 3(22) with a takeoff on 2(13).

Alternate a landing on 3(22) with a takeoff on 4(31).

Alternate landings and takeoffs on $1(04)$. 
Standard aircraft-type data as shown in Figure 3.5 were used, with type 1 being heavy jets, type 2 being light aircraft, and type 3 being category 3 aircraft, i.e. medium size jets and large propeller aircraft.

\subsection{DELCAP Output}

Summary output from the DELCAP run of the LGA data is shown in Figure 3.6. Since the general aviation traffic was entered stochastically, it is not surprising that the DELCAP traffic total (934) is slightly lower, by about $0.5 \%$, than the actual total (939). Each average hourly throughput figure is obtained by dividing total throughput for that runway and operation type by the time within the hour during which the runway accepts that operation. If the time period is not a busy one or if it includes a long time during which no operations occur, the average hourly throughput may differ greatly from that for a typical hour with more traffic. The average hourly delay is computed similarly, by dividing the sum of the delays suffered by all aircraft of the appropriate operation type on the runway in question by the time period over which that runway accepts that operation. The delay is thus the hourly average of all the aircraft delays for aircraft that landed (or started to roll) in the time period in question. (Delay is recorded at touchdown or start of roll, so that a delay which actually occurred before a change of policy may be recorded after the change.)

The DELCAP delay profile is given in Figure 3.7. This also is standard DELCAP output whenever the delay output option is selected. Only 66 aircraft, about 7 percent of all operations, had delays of more than fifteen minutes, which agrees fairly well with the facility estimate of "no delay" (since the facility records only delays of more than fifteen minutes). Over half of all operations (57 percent) suffered less than 5 minutes delay. Peak delays occurred during hours 15 (10-11 a.m.) and 22 (5-6 p.m.), which agrees well with the peak traffic hours of 14 and 23 . Regarding LGA as it is operated during busy periods as a pair of V-shaped intersecting runways, operated with landings on one and takeoffs on the other, the capacity of the airport should be about 75 operations per hour (from Table 2.5). Thus the highest traffic input (69 operations in an hour) is less than the airport capacity, but some delay results nonetheless, since the times at which aircraft desire service are bunched instead of being evenly spaced. For instance, 42 percent ( 8 out of 22) of the departures in hour 1 are scheduled to depart at exactly 0000 , clearly a situation making delay inevitable. Arrivals to the terminal area are not as bunched as departures, and even when several have the same scheduled arrival time, their prior processing by the air traffic control system tends to space them apart more than the schedule would indicate. This may explain in part why average takeoff delay per aircraft in Figure 3.6 is greater than the average landing delay, even when the number of landings exceeds the number of takeoffs. 
FIGURE 3.6

DELCAP Sumary Output

HOURLY THROUGHPUT

HOUR RUNif $Y$

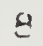

1
2
3
4
1
2
3
4

$1 n$

$\Rightarrow$

4
1

1

3

4

$1 i$

1

2

3

4

1

2

4

13

1

2

4

14

15

1

2

3

4

1

2
3

3
4

1r. 1

2

3

4

17

\section{1}

2

3

4

1

14
LANDINGS TAKEOFFS TOTAL
UIIIRI Y DEI AY PFP. AITCRAFT 1.ANDTAGS TAKFAFFG AI.L

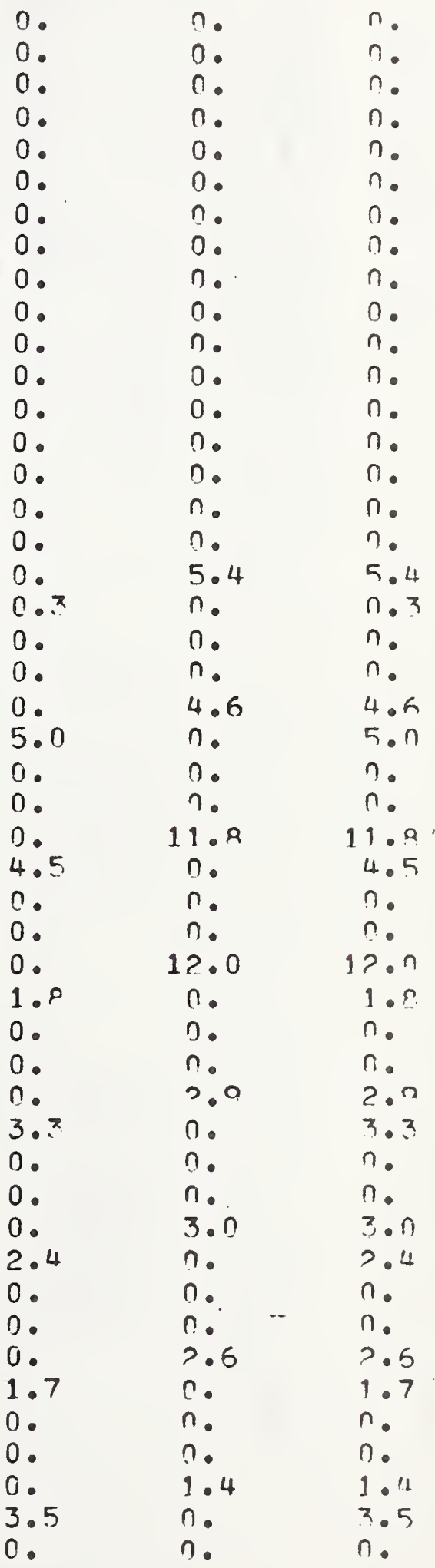




\section{DELCAP Summary Output (Cont'd)}

\begin{tabular}{|c|c|c|c|c|c|c|c|c|}
\hline \multirow[t]{4}{*}{ ci: } & 1 & 0 & & $n$ & $n$ & $n$ & $\cap$. & n. \\
\hline & 2 & 0 & & 15 & 15 & 0. & 2.5 & 2.5 \\
\hline & 3 & 31 & & 0 & 31 & 5.6 & 0. & $5 \cdot 5$ \\
\hline & 4 & 0 & & 14 & 14 & 0. & $1 ? .7$ & $1 ? .7$ \\
\hline \multirow[t]{3}{*}{$2 i$} & 1 & 0 & & 0 & 0 & 0. & $n$. & $n$. \\
\hline & 2 & 0 & & 0 & 0 & 0. & 0. & $n$. \\
\hline & $\begin{array}{l}3 \\
4\end{array}$ & $\begin{array}{r}31 \\
0\end{array}$ & & 37 & $\begin{array}{l}31 \\
37\end{array}$ & $\begin{array}{l}6.4 \\
0 .\end{array}$ & $13 \cdot 5$ & $\begin{array}{r}6.4 \\
13.5\end{array}$ \\
\hline \multirow[t]{4}{*}{$2 ?$} & 1 & 0 & & 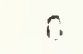 & 0 & 0 & $n$ & $n$ \\
\hline & 2 & 0 & & 0 & 0 & 0 & 0. & 0. \\
\hline & 3 & 38 & & 0 & $3 R$ & 9.1 & 0. & 9.1 \\
\hline & 4 & 0 & - & 38 & 38 & 0 & 17.0 & 17.9 \\
\hline \multirow[t]{4}{*}{23} & 1 & 0 & & ? & 0 & 0 & $n$ & $n$ \\
\hline & 2 & 0 & • & 0 & 0 & 0. & 0. & 0. \\
\hline & 3 & 35 & & $n$ & 35 & 2.0 & $n$. & $? . ?$ \\
\hline & 4 & 0 & & 36 & 35 & 0 & 0.2 & a.? \\
\hline \multirow[t]{4}{*}{$l_{1}$} & 1 & 0 & & $?$ & $n$ & 0. & 0 & $n$. \\
\hline & 2 & 0 & & $r$ & $n$ & 0. & 0. & 0. \\
\hline & 3 & 30 & & is & 20 & 2.5 & 0. & $? .5$ \\
\hline & 4 & 0 & & $3 ?$ & 32 & 0. & 5.0 & $5 . n$ \\
\hline \multirow[t]{4}{*}{1} & 1 & 0 & & 0 & $n$ & 0 . & 0 & $n$. \\
\hline & 2 & 0 & & 0 & 0 & 0 & $n$. & $n$ \\
\hline & 3 & 37 & & $?$ & 37 & 5.4 & $n$. & 5.4 \\
\hline & 4 & 0 & & $2 R$ & 28 & 0 & 6.1 & 6. $?$ \\
\hline \multirow[t]{4}{*}{$?$} & 1 & 0 & & 0 & 0 & 0 & $n$. & $n$. \\
\hline & 2 & 0 & & 0 & 0 & 0. & $n$. & $n$. \\
\hline & 3 & 23 & & $r$ & 23 & $1 . ?$ & 0. & 1.2 \\
\hline & 4 & 0 & & 12 & 18 & 0 & 7.0 & 7.0 \\
\hline \multirow[t]{4}{*}{2} & 1 & 0 & & $n$ & 0 & 0. & $n$. & $n$. \\
\hline & 2 & 0 & & 0 & 0 & 0. & 0. & $n$. \\
\hline & 3 & 1. 1 & & $C^{\prime}$ & 11 & 0.0 & n. & $n . n$ \\
\hline & 4 & 0 & & 9 & 9 & 0. & 2.9 & 3.9 \\
\hline \multirow[t]{4}{*}{ : } & 1 & 5 & & $\hat{\imath}$ & 7 & 0.1 & $n$. & 0.1 \\
\hline & 2 & 0 & & 8 & $n$ & 0 & 0. & $n$ \\
\hline & 3 & 0 & & 0 & 0 & $n$. & n. & 0. \\
\hline & 4 & 0 & & $?$ & 0 & 0. & 0. & 0. \\
\hline \multirow[t]{4}{*}{$\therefore$} & 1 & 1 & & $\because$ & 1 & 0. & 0. & $n$. \\
\hline & 2 & 0 & & 0 & 0 & 0 & ก. & $n$ \\
\hline & 3 & 13 & & $?$ & 19 & 0.8 & 0. & $n . ?$ \\
\hline & 4 & 0 & & $r$ & 0 & $n$ & 0 & $n$. \\
\hline \multirow[t]{4}{*}{$m$} & 1 & 0 & & 0 & 0 & 0. & $n$. & $n$. \\
\hline & 2 & 0 & & 0 & 0 & 0. & 0 & ก. \\
\hline & 3 & 3 & & 7 & 10 & 0. & ก. 9 & $n .1$ \\
\hline & 4 & 0 & & 0 & 0 & 0. & 0. & $n$. \\
\hline \multirow[t]{4}{*}{7} & 1 & 0 & & $n$ & 0 & 0 . & $n$. & $n$. \\
\hline & 2 & 0 & & 0 & $\mathrm{C}$ & 0. & C. & $n$. \\
\hline & 3 & 0 & & 9 & 1 & 0. & $n$. & 0. \\
\hline & 4 & 0 & & 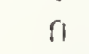 & $c$ & 0. & 0. & $n$. \\
\hline
\end{tabular}


FIGURE 3.6

DELCAP Summary Output (Cont'd)

\section{SUMMARY REDORT FOR THIS RU'.}

TOTAL THROUGHPIJT

\begin{tabular}{|c|c|c|c|}
\hline \multirow[t]{2}{*}{ RUIIAY } & \multicolumn{3}{|c|}{ OPER TIONSS PECFOR 'ET } \\
\hline & LANDINGS & TAKEOFEC & TOTAL \\
\hline 1 & 6 & 2 & 8 \\
\hline 2 & $\eta$ & 251 & 251 \\
\hline 3 & 454 & 9 & 463 \\
\hline 4 & 0 & 212 & 2.12 \\
\hline TOTAL & 460 & 474 & 934 \\
\hline
\end{tabular}

AVERAGF HOURLY THROUGHDIIT

\begin{tabular}{|c|c|c|c|}
\hline \multirow[t]{2}{*}{ RUis, AY } & \multicolumn{3}{|c|}{ OPERATIOH!S PEPFORIAED } \\
\hline & LANDINGS & TAKEOFFS & $T \cap T A I$ \\
\hline 1 & 0.2 & 0.1 & 0.3 \\
\hline ? & 0. & 10.5 & 10.5 \\
\hline 3 & $18.9^{\circ}$ & 0.4 & 10.3 \\
\hline 4 & 0 & 8.8 & 8.8 \\
\hline TOTAL & 19.2 & 19.7 & 38.9 \\
\hline
\end{tabular}

AVERAGT HOURLY DELAY

\begin{tabular}{cccc} 
RUN AY & \multicolumn{3}{c}{ DEI $\cap$ (MINUTTFS) } \\
& LA!NDINES & TAYEOFFS & TOTAL \\
1 & 0.0 & 0.0 & 0.0 \\
2 & 0.0 & 50.6 & 60.6 \\
3 & 72.6 & 0.0 & 72.6 \\
4 & 0.0 & 00.4 & 90.4 \\
TOTAL & 72.6. & 151.0 & $? 23.6$
\end{tabular}




$$
c c c c c c c c c c c c c c c c c c c c, c c c
$$

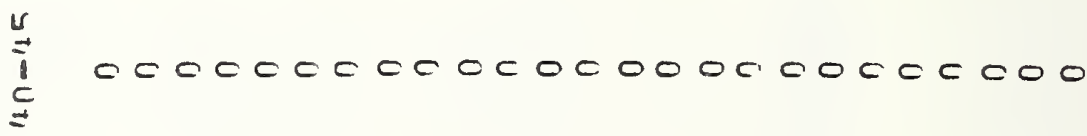

in
I
I

cococectercectcocococtoo

oc $c c c c c c c c c c c c c c c c c=c c=$

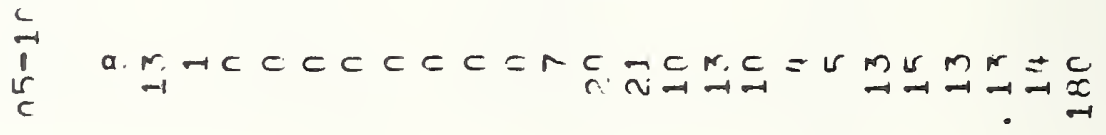

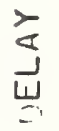


Table 3.3 gives a detailed trace of the various events in the operation of several aircraft. During this time period, landings on runway 3(22) were alternated with takeoffs on runway 2(13) whenever possible. An option in the DELCAP model has been developed which prints out the times of various events in a slightly different format, arranged by time of occurrence rather than flight, and with an internal flight identification number instead of the actual flight number. In Table 3.3 we have arbitrarily assigned the general aviation flights tail numbers N0001 to N0005 for convenience. Figure 3.8 displays the same output (with two additional flights at the end) directly as it comes from the computer. It should be noted that in the computer output flight identification numbers may be repeated after an aircraft lands or takes off, although at any one time the number refers to only one aircraft. ${ }^{*}$ Examples are flight ID's 18199 and 18203 in Figure 3.8. It will also be noted that because of roundoff procedures the times at which flights enter the simulation may be printed. as for instance, 15.09.59 rather than 15.10.00.

These detailed printouts can be used to aid in evaluating the delays given by the DELCAP delay profile as well as to ascertain how the model actually treats the various operations. Such analysis of the internal procedures of the model is itself a valuable step in establishing model validation.

One comparison of the distribution of "total delay" as actually occurring (from Figure 3.4) with DELCAP-computed delay (from Figure 3.7) is given graphically in Figure 3.9, which shows the cumulative frequency distribution for the two sets of "delay" figures. Only a quarter of actual operations experience either no delay or delays of less than 5 minutes, while well over half ( 57 percent) of the simulated operations fall into this category. All simulated aircraft experience less than 25 minutes delay while only 68 percent of the actual operations do so. Thus there is very little agreement between simulated and actual delays.

This discrepancy can mean one of two things: either the model does not correctly model delay and is erroneous, or else the data are inappropriate for this particular analysis. Even before the simulation was run, analysis of the input data delay profile in Figure 3.4 indicated difficulties in using the actual versus schedule operation time data as a basis for terminal delay estimates. The LGA tower facility had reported "no delays" on a day in which over one quarter of the operations were actually delayed more than half an hour, with 8 to 9 percent delayed more than an hour. Clearly this is possible only if the delays occurred elsewhere. The 59 operations delayed over an hour would certainly have complained about incurring such delays at a facility having no problems with runways, weather or unusually high traffic levels, lending further credibility to the supposition that most of this delay did not occur at LGA.

*This is done for efficient computer storage of flight information. 


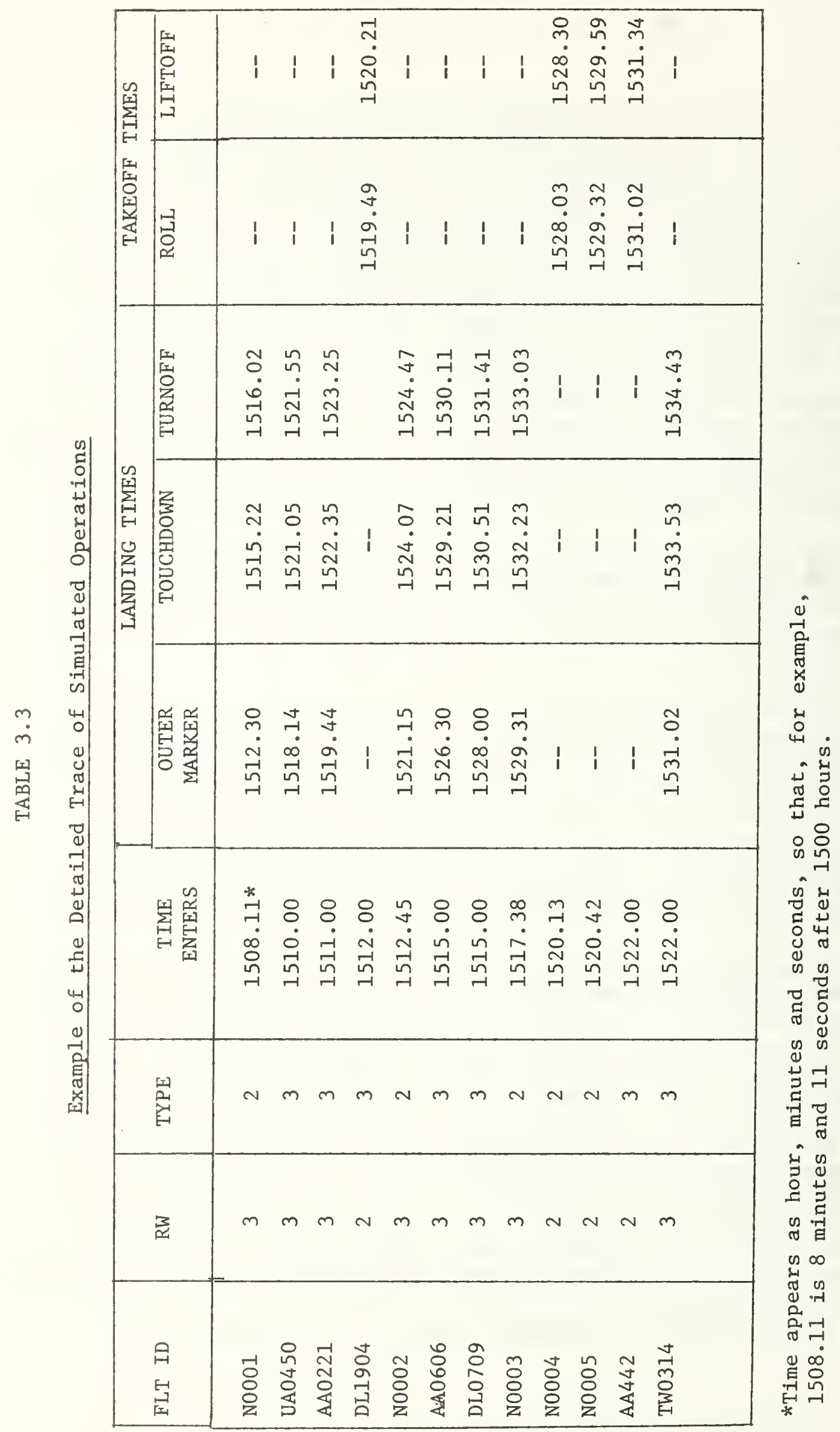



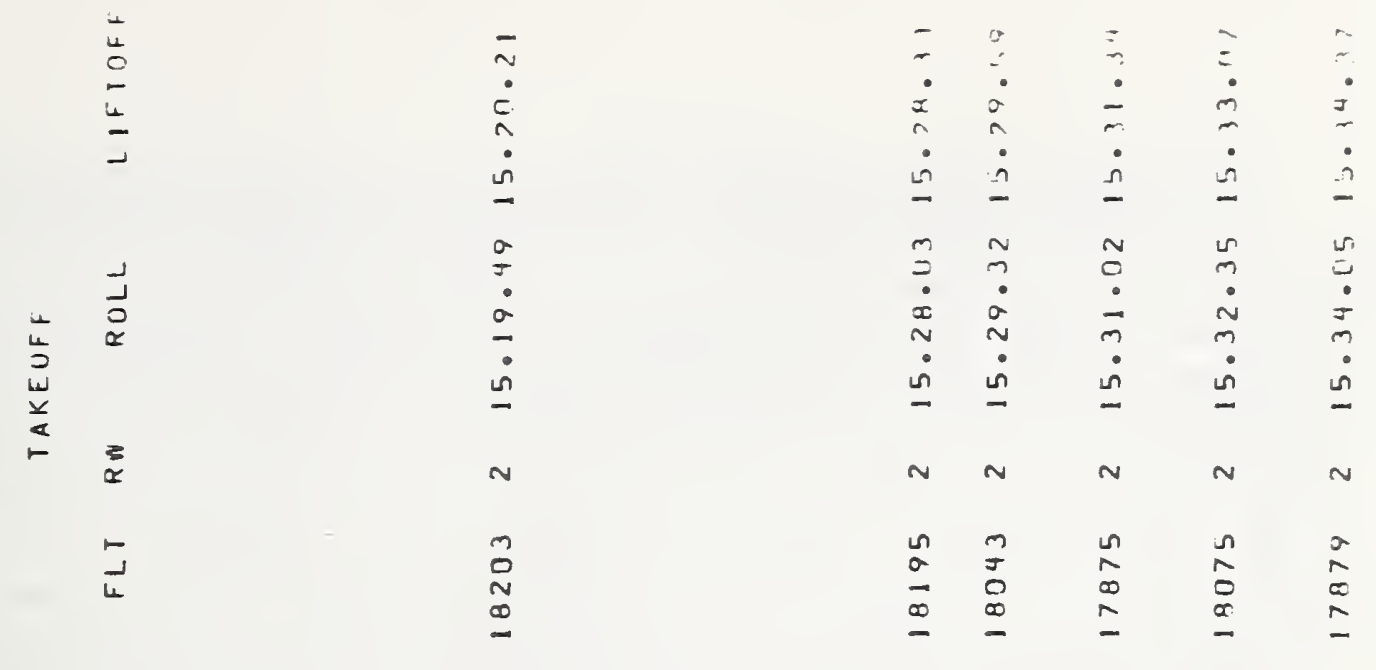

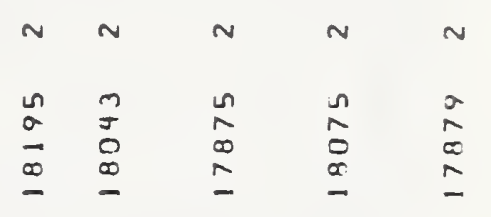
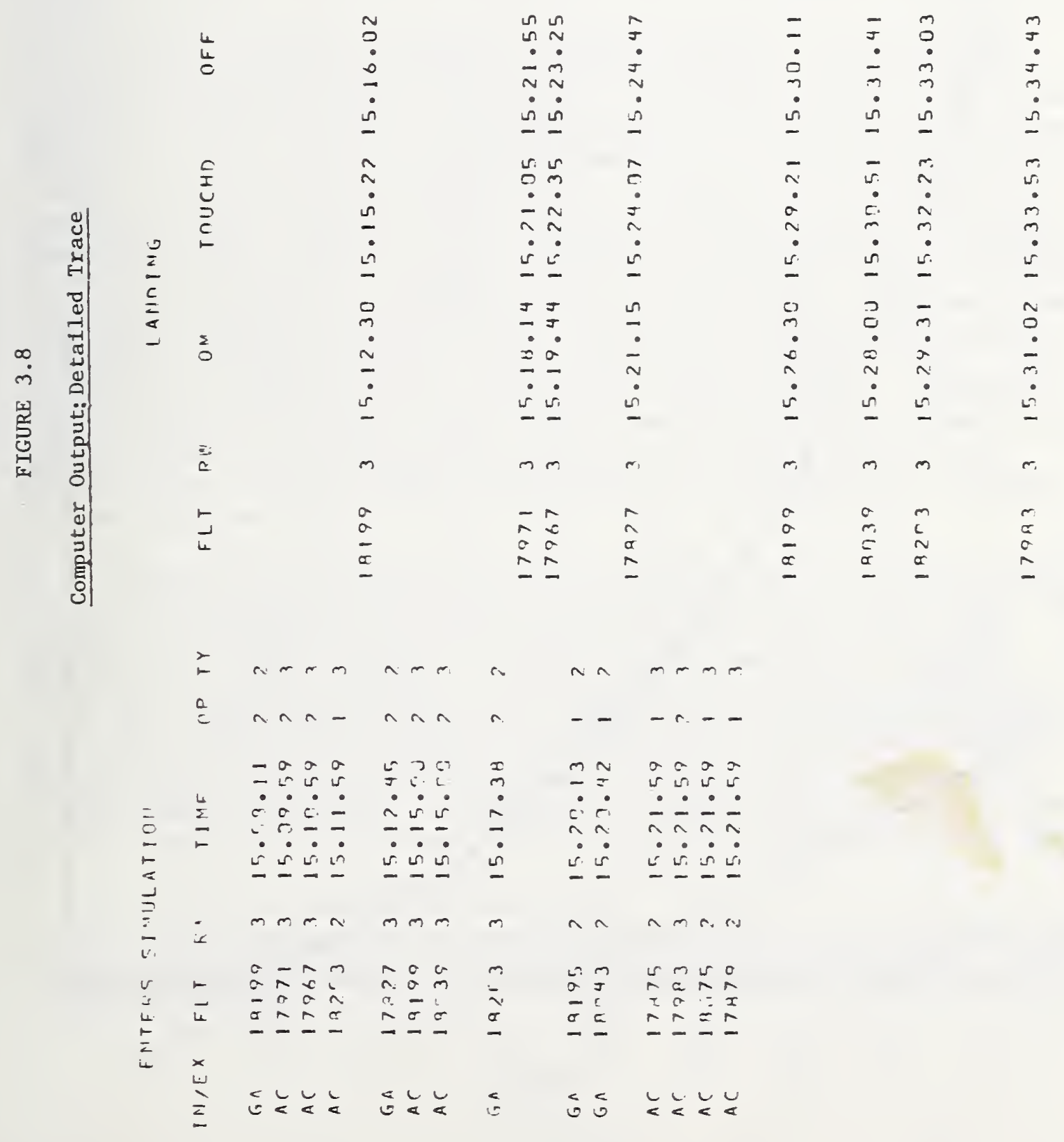


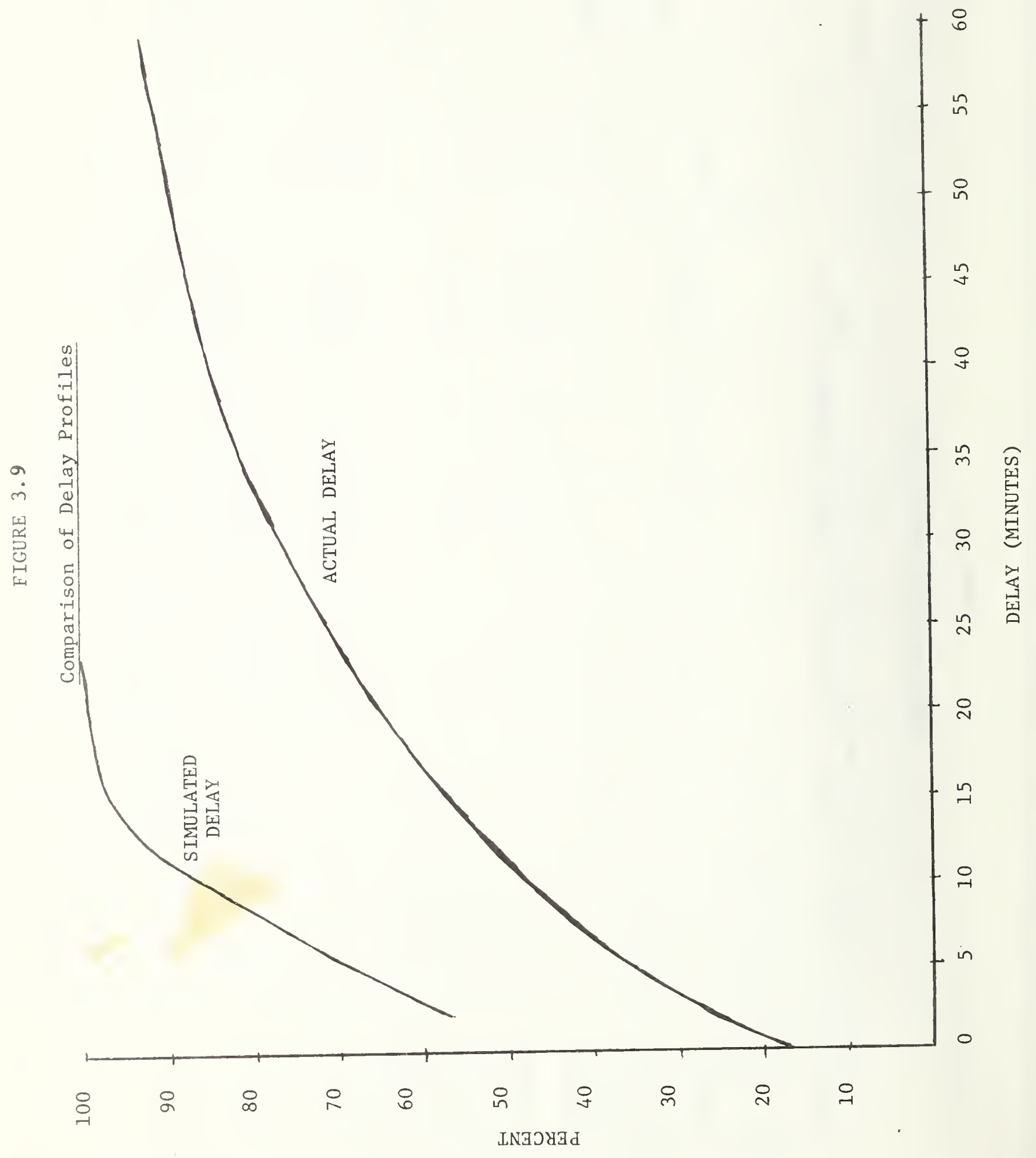


The long delays occur late in the day and landing delay peaks before takeoff delay, leading one to speculate that the takeoff delays are caused in part by delayed arrivals of an aircraft needed for a later departure. Arrival delay, computed as scheduled minus actual arrival time, clearly includes all delays occurring during the whole flight, whether caused by air traffic control (ATC) factors or something else (equipment malfunction, for example). Takeoff delay will not contain ATC delays from other sectors for this flight, but may be affected by delays to an earlier flight using the same aircraft, and may also include (non-ATC) delays due to equipment, crew and gate problems. Thus even before the simulation was run, there was doubt as to the likelihood of any agreement of the actual delays with the simulation output delays, which represent ATC delays only in the LGA terminal area. Once the simulation output became available, these fears were realized as displayed in Figure 3.9.

Although the delay profiles were quite different, their "shapes" appear similar; that is, as delay varies over the day the actual and the DELCAP-computed delays peak or fall at the same times. To test this hypothesis, i.e. that the distributions have the same general shape, the number of flights actually delayed excessively in each hour are compared in Table 3.4 with the corresponding number of flights with excessive modelcomputed delays. For the actual delay data excessive delay is taken to mean more than 15 minutes; for the simulated flights delays of 5 minutes or more were considered excessive since few flights were delayed in DELCAP by more than 15 minutes. Observations in the two columns were ranked separately, and these rankings compared by hour using the Spearman rank correlation coefficient, * whose value was .725, significant at the .001 level. This means that the probability of getting such agreement of two rankings by chance alone is less than .001. Clearly some correlation between the two distributions is to be expected since they both depend on the same traffic input, but the level of significance is high enough to indicate greater agreement than one would expect from this fact alone.

Although, as the discussion above indicates, the LGA exercise has shown the inadequacy of the particular data base used, it has been included in this report because that type of data base is the one most often suggested for delay validation and the one most obvious to those not directly involved in modeling. Elucidation of the problems associated with this approach will perhaps aid others involved in similar efforts by providing a concrete example of the difficulties. Since the "scheduled versus actual operation time" data base is inadequate to validate the DELCAP delay calculations, we will include below a description of a data base, together with directions for its collection, which we believe would

*For a further explanation of this statistic and its use see Sidney Siegel, Nonparametric Statistics for the Behavioral Sciences, McGraw-Hill, New York, 1956, pp. 202-213. 
TABLE 3.4

Number of Flights Delayed Excessively in Each Hour

\begin{tabular}{|c|c|c|}
\hline & NUMBER & NUMBER \\
\hline HOUR & ACTUALLY DELAYED & DELAYED IN DELCAP \\
\hline 1 & 47 & 25 \\
\hline 2 & 47 & 20 \\
\hline 3 & 18 & 1 \\
\hline 4 & 1 & 0 \\
\hline 5 & 4 & 0 \\
\hline 6 & 1 & 0 \\
\hline 7 & 0 & 0 \\
\hline 8 & 1 & 0 \\
\hline 9 & 0 & 0 \\
\hline 10 & 0 & 0 \\
\hline 11 & 0 & 0 \\
\hline 12 & 0 & 12 \\
\hline 13 & 3 & 28 \\
\hline 14 & 16 & 50 \\
\hline 15 & 15 & 33 \\
\hline 16 & 3 & 13 \\
\hline 17 & 6 & 11 \\
\hline 18 & 7 & 5 \\
\hline 19 & 7 & 6 \\
\hline 20 & 11 & 30 \\
\hline 21 & 20 & 57 \\
\hline 22 & 34 & 68 \\
\hline 23 & 37 & 31 \\
\hline 24 & 44 & 17 \\
\hline
\end{tabular}


be adequate for that task. The internal trace output can be used to better understand the internal operation of DELCAP, and thus acts as a beginning delay validation, but in the absence of the type of data base described below the validity of delays calculated by DELCAP is not yet demonstrated. It should be remembered, however, that DELCAP throughput output has been validated for use in setting engineered performance standards by the exercises reported above in Section 2.

\subsection{Data Required for DELCAP Delay Validation}

The delay measured by the DELCAP model includes (as intended) only that delay incurred by an aircraft in the terminal area being modeled, and incurred because of separations required between aircraft. The delay is calculated as the difference between the minimum time for an aircraft to execute the maneuver in question ( $f l y$ from handoff to the outer marker, make its final approach, land, and exit the runway -- or request clearance, exit from the gate, taxi to the departure runway, start its roll and liftoff) and the time it actually takes in the presence of other aircraft.

Instead of scheduled arrival and departure times, the model needs actual handoff and departure-request times. Using these will overcome the problem of including delays occurring elsewhere, by capturing just that portion of a flight arising within the terminal area in question. The actual handoff times will spread out the arrivals from the artificially bunched scheduled arrival times, thus reflecting the effect of the ATC system in smoothing out schedule bunching. The use of gate-departure request time will avoid contaminating the analysis with the results of late equipment arrivals, equipment problems and other non-ATC-caused delay factors causing late departure requests.

The actual handoff and gate request times could be obtained by stationing people in the tower and monitoring the appropriate positions, recording the times and flight numbers. It would also be necessary to record actual touchdown and start-of-roll times for each flight. These data could be obtained in a similar manner from the tower in good weather, if the tower is situated so that the runway is visible. Monitoring the appropriate approach or departure position would provide the flight ID, but visual recording of touchdown and start-of-roll time would be required. These data could in principle be obtained as part of some other airport data collection effort.

Such data would allow an analysis of terminal-area ATC-specific delays, and comparison of the delays output by the model with actual delay of the type the outputs are supposed to represent. (However, one major risk of discrepancy remains. Path-stretching procedures may be used by facilities without the additional flying time contributing to facility-computed delay, while that time would contribute to DELCAP-calculated delays. We emphasize again the necessity for comparisons based on the same definition and measure of "delay".) 
The analysis would focus on the comparison of DELCAP delays with delays calculated as the difference between the actual operation time (handoff to touchdown, or departure-request to roll) and a minimum time for that operation. Ideally, this input data set would allow a flight-by-flight comparison (using DELCAP's detailed trace procedure) of actual and simulated events. In addition, comparison of delay profiles could be used to assess overall performance. It is this latter that is most critical for future application of the model, and discrepancies in individual flight behavior are less important than is absence of overall bias or other systematic errors.

If DELCAP-computed delays are to be used in further analyses of the ATC system, there seems no choice but to evaluate these delay outputs using data obtained in the manner outlined above. Such a procedure is not necessary for further use of the model's throughput values, since the exercises reported in Section 2 have demonstrated the validity of that output for use in the engineered performance standard program. 


\section{CONCLUSIONS}

The DELCAP simulation model is an existing aralysis tool which has proven useful in aiding the setting of engineered performance standards. It has been operated both on the UNIVAC 1108 at NBS and on a CDC computer chosen by the FAA, and has been run both by its designers at NBS and by FAA personnel.

We have reported in Section 2 the results of a validation of DELCAPproduced throughput levels for use in FAA's EPS program. This analysis included an examination of DELCAP outputs for five different configurations (a single runway, two pairs of intersecting runways with different placements of the intersection, a pair of close parallel runways, and close parallels with a crossing runway) representative of the configurations most commonly found at major terminals*, and for three or four operating policies for each configuration. The tests included three arrival/departure mixes, and the operating policies were chosen to apply to the appropriate mixes. Each configuration and policy was run on each of three different aircraft-type mixes, distinguished primarily by the fraction of heavy aircraft in the mix and ranging from 5 percent to 50 percent heavies. Comparison of the model results with FAA-computed values at 5 airports, covering 7 configuration/policy combinations, was carried out. The DELCAP values were within 5 to 6 percent of the FAA-computed values in all cases but one, and were within 10 percent in that case. Thus the DELCAP model has been accepted as a good substitute for the manual procedure developed by the FAA, and because of its ease of use and flexibility, it can extend and enhance the FAA's analyses in the program.

The IGA exercise reported in Section 3 demonstrated the model's ability to simulate actual scheduled traffic together with randomly generated general aviation traffic and to measure delays from these operations. Inasmuch as the data presently available are insufficient to isolate delay occurring in the portion of the ATC system DELCAP was designed to model, we are unable to validate DELCAP's delay outputs without a further data collection effort. Such an effort, involving collection in a terminal area of handoff and request-to-depart times as well as actual operation times, is described in Section 3. The "delay validation" exercise has highlighted the importance of insuring that definitions of delay are the same, since there are many different definitions of this complex concept. Although DELCAP's delay values could not be validated because of these data problems, model output agreed well with facility estimations of delay and the time distributions of delay (actual versus DELCAP) were similar. These results give a preliminary indication that DELCAP-computed delays may indeed be useful for analyses, an indication which can only be checked by further efforts.

The exercises reported in Section 2 indicate that the DELCAP model is most sensitive to operating policies. Since different operating policies are optimal for different arrival/departure ratios, this factor also greatly affects model output. The model is also quite sensitive to runway *We note again that wide parallels are effectively two independent single runways. 
configuration, particularly to the number and the independence (or interdependence) of the runways, but the location of an intersection and the difference between close parallels and an intersecting pair of runways have only minor effect on throughput. Aircraft-type mix has less effect on throughput than do operating policy and major configuration differences, but it is still an important factor. Separations, too, have an effect on the throughput, but reduction of all separations to three miles or less (for a dual-use single runway) has less effect than one might expect. (Despite the reduction in minimum inter-landing separation, landing aircraft must be separated by more than three miles in order for takeoffs to occur between landings.) Other factors affecting sensitivity include approach speeds and runway occupancy times, but for the ranges occurring at the busier airports, the model is less sensitive to these than to the other factors given above.

DELCAP is a tool whose usefulness and validity have been demonstrated for application in the Engineered Performance Standards Program. It may also be useful for other analyses, but care should be exercised that the model is appropriate and that the validations like those described in this report be performed and include the types of scenarios to be represented for that application. In order to use the delay figures output by DELCAP, further validation -- requiring a special data collection effort such as that suggested in Section 3.6 -- will be necessary. Preliminary indications from the LGA exercise reported above, suggest that such an effort would be successful. 


\section{REFERENCES}

1. Judith Gilsinn, with E.H. Short, W.A. Steele, D. Klavan, A Simulation Model for Estimating Airport Terminal Area Throughputs and Delays, NBS Report Number 10592, FAA Report Number FAA-RD 71-9, May 1971.

2. Judith F. Gilsinn, Validation of Maximum Airport Throughput Levels Estimated by the DELCAP Simulation Mode1, NBS Report Number NBS-IR 75-638, FAA Report Number FAA-RD 75-66, January 1975.

3. Official Airline Guide, North American Edition, Reuben H. Donnelly Corporation, Oak Brook, Illinois 60521.

4. Analysis of a Capacity Concept for Runway and Final-Approach Path Airspace, NBS Report Number 10111, FAA Report Number RD-69-47, November 1969.

5. A.J. Goldman and W.A. Steele with W.A. Horn, Continued Analysis of a Capacity Concept for Runway and Final-Approach Path Airspace, NBS Report Number 10589, Apri1 1971.

6. W.A. Horn, Extension of a Capacity Concept to Dual-Use Runways and Multi-Runway Configurations, NBS Report Number 10593, 1971.

7. A.J. Goldman, A Capacity Concept for Runway and Final Approach Path Airspace, Navigation 17, pp. 253-259, 1970.

8. A. Blumstein, The Operations Capacity of a Runway used for Landings and Takeoffs, in Proc. Second Inter. Conf. on Operational Research, J. Banbury and J. Maitland (ed.), John Wiley and Sons, pp. 657-672, 1961.

9. R.M. Harris, Models for Runway Capacity Analysis, MITRE Corporation Technical Report Number MTR 4102, October 1969. 


\section{APPENDIX A}

\section{CHANGES AND ADDITIONS TO DELCAP}

During the course of the validation effort reported in this document, modifications were made to DELCAP and its preprocessor in several areas: output, separation criteria, random number generator, operating policies, changes in operating policy, and standard preprocessor inputs. Several criteria were used in deciding which of a number of plausible changes should be implemented, and first among these was the preservation of the DELCAP design philosophy, that the model should remain easy and inexpensive to operate. A second factor was the benefit expected to accrue and the priority of need for that change in the Engineered Performance Standards Program. The changes chosen for implementation are described below.

\section{A. 1 Modifications in Output}

DELCAP is expected to operate under two scenarios: one to compute airport maximum throughput (capacity) and the second to compute delay resulting from a particular demand profile. Since delay output would be meaningless under the first scenario, the user now has the option of suppressing delay output for runs under this scenario. Current output formats have been modified so that the number of characters per line is less than 72, permitting output to fit on most terminals. Output now consists of actual throughputs and average delay per aircraft for each hour, separately for landings, takeoffs and total operations, separately by runway. Summary statistics at the end of a run provide for each runway -- separately for landings, takeoffs and total operations -- the total throughput for the run, average hourly throughput, average total hourly delay, and the delay profile. Illustrative preprocessor and simulation outputs are shown in Figures A.1 and A.2.

In addition to throughput and delay information, DELCAP prints the final random number seed for use in subsequent runs. (See below for a more complete description of the random number generation process.)

Average hourly statistics (throughput or delay) are computed for each runway based on the time period within that hour during which the runway operating policy handles the operation in question. It should be noted that when periods of low traffic levels are averaged with busy periods, average throughput levels may appear much lower than customary throughput levels. In this case, hourly throughputs may be more appropriate and the user may wish to compute (off-line) separate average throughput levels for different time periods. The delay profile appears at the end of simulation output whenever delay output is called for. The profile shows the number of aircraft in each delay interval for each hour of the day. Delay is recorded for each landing at touchdown and for each takeoff at start of roll, so that the delay recorded to aircraft in a particular hour may include delays occurring in a previous hour. The figures thus describe 
THIS SIMULATION RUNS FROM 2.00 TO 22.00

AIRCRAFT DESCRIPTION

TYPE

SPEEDS (KNOTS)

LANDING

LIFTOFF

124.

119.

120 .

3

1

2

TRAFFIC DESCRIPTION

TYPE

LANDING

$M I X$

TAKEOFF

$M I X$

1

5.

5.

2

3

17.

17.

78 .

78.

378.78 .

AIRPORT CONFIGURATION

RUNWAY OCCUPANCY (SECONDS)

LANDING

TAKEOFF

55.

33.

40.

27.

50 .

$3 ?$.

NUWHER OF RUNWAYS $=2$

RUNWAY 1 (15) - OPERATED WITH RUNWAYS 2

OPERATION SEQUENCE

DEPAFTT ON 1 ARPIVE UN 2

RUNWAY 2 (18, - OPERATEO WITH RUNWAYS 1

OPERATION SEOUENCE

DEPART ON 1 ARRIVE ON?

RUNWAYS 15 AND 13. INTERSECT AT A POINT 2000. FEET FROM THE END OF RUIINAY 15 AND 2000. FFET FROM THE END OF RUNWAY 18 .

RUNWAYS 15 AND 18 ARE SEMI-DEPENDENT -

SIMULTANEOUS ARRIVALS ARE PROHIBITEN 
Sample Preprocessor Output (Cont'd)

FRACTION OF LANDINGS OF EACH TYPE ON EACH RUNWAY

$\begin{array}{ccc}\text { TYPE RUNATHY } & 1(15) & 2(19) \\ 1 & .0000 & 1.0000 \\ 2 & .0000 & 1.0000 \\ 3 & .0000 & 1.0000\end{array}$

FRACTION UF TAKEOFFS OF EACH TYPE ON EACH PUMWAY

$\begin{array}{ccc}\text { TYPE RUPHAY } & 1(15) & 2(18) \\ 1 & 1.0000 & \\ 2 & 1.0000 & .0000 \\ 3 & 1.0000 & .0000\end{array}$


HOURLY THPOIIGHPUT

HOUR RUI!AY

\begin{tabular}{|c|c|c|c|c|}
\hline \multirow[t]{2}{*}{3} & i & 0 & 35 & 36 \\
\hline & 2 & 37 & 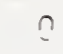 & 37 \\
\hline \multirow[t]{2}{*}{4} & 1 & 0 & 30 & 30 \\
\hline & 2 & 30 & $?$ & 30 \\
\hline \multirow[t]{2}{*}{5} & 1 & 0 & $3 R$ & 38 \\
\hline & 2 & 37 & 0 & 37 \\
\hline \multirow{2}{*}{0} & 1 & 0 & 30 & 30 \\
\hline & 2 & 30 & c & 30 \\
\hline \multirow[t]{2}{*}{7} & 1 & $n$ & 23 & 28 \\
\hline & 2 & 20 & ? & 29 \\
\hline \multirow[t]{2}{*}{8} & 1 & 0 & 37 & 37 \\
\hline & 2 & 36 & ก & 36 \\
\hline \multirow[t]{2}{*}{9} & 1 & $C$ & 35 & 35 \\
\hline & 2 & 35 & 2 & 35 \\
\hline \multirow[t]{2}{*}{10} & 1 & 0 & 37 & 37 \\
\hline & $\bar{c}$ & 37 & 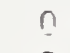 & 37 \\
\hline \multirow[t]{2}{*}{11} & 1 & 0 & $2^{2}$ & 20 \\
\hline & 2 & 26 & 9 & 26 \\
\hline \multirow[t]{2}{*}{12} & 1 & 0 & 31 & 31 \\
\hline & 2 & 31 & $?$ & 31 \\
\hline \multirow[t]{2}{*}{13} & 1 & $c$ & 37 & 37 \\
\hline & 2 & 37 & 7 & 37 \\
\hline \multirow[t]{2}{*}{14} & i & 0 & 37 & 37 \\
\hline & 2 & 37 & ר & 37 \\
\hline \multirow[t]{2}{*}{15} & 1 & 0 & $3 t$ & 36 \\
\hline & 2 & 37 & 0 & 37 \\
\hline \multirow[t]{2}{*}{15} & 1 & 0 & 32 & $3 \Omega$ \\
\hline & 2 & 37 & 0 & 37 \\
\hline \multirow[t]{2}{*}{17} & 1 & 0 & 30 & 30 \\
\hline & $\ddot{c}$ & 39 & $\cap$ & $3 \pi$ \\
\hline \multirow[t]{2}{*}{$1 \varepsilon$} & 1 & 11 & 31 & 31 \\
\hline & 2 & 31 & 0 & 31 \\
\hline \multirow[t]{2}{*}{ Iy } & 1 & 0 & 34 & 34 \\
\hline & 2 & 34 & 0 & 34 \\
\hline & 1 & 0 & 36 & 36 \\
\hline & 2 & 36 & 7 & 36 \\
\hline & 1 & 0 & 39 & 38 \\
\hline & 2 & 38 & 0 & 32 \\
\hline & 1 & 0 & 33 & 33 \\
\hline & 2 & 36 & $?$ & 36 \\
\hline
\end{tabular}

HOURI.Y DFLAY PER AIRCRAFT LANDINGS TAKFOFFS ALL

\begin{tabular}{|c|c|c|}
\hline 0 . & 3.9 & 3.9 \\
\hline 3.4 & 0. & 3.4 \\
\hline 0. & 2.4 & 8.4 \\
\hline 2.4 & $n$. & $? .4$ \\
\hline 0. & 5.4 & 5.4 \\
\hline 4.0 & $n \cdot$ & 4.9 \\
\hline 0. & 14.6 & 14.6 \\
\hline 2.5 & 0. & $? .5$ \\
\hline 0. & 29.5 & 20.5 \\
\hline 3.7 & $n$ & 3.7 \\
\hline 0. & 44.6 & 44.6 \\
\hline 4.0 & $\cap$. & 4.0 \\
\hline 0. & 41.2 & 41.2 \\
\hline 7.0 & 0 & 7.0 \\
\hline 0. & 33.1 & 23.1 \\
\hline 6.1 & $n$. & 6.1 \\
\hline 0. & 27.2 & 27.2 \\
\hline 3.9 & 0. & 3.0 \\
\hline C. & 41.8 & 41.8 \\
\hline 4.0 & $n$ & 4.0 \\
\hline 0. & 47.3 & 47.3 \\
\hline 3.2 & $n$. & 13.2 \\
\hline 0. & 44.5 & 44.5 \\
\hline ?. & $n$ & 20.9 \\
\hline n. & 30.6 & 29.6 \\
\hline 6.3 & 0. & 26.3 \\
\hline 0 & 36.0 & 36.0 \\
\hline 0.5 & 0 & 19.5 \\
\hline$n$. & 34.5 & 34.5 \\
\hline 10.0 & 0. & 10.9 \\
\hline 0. & 24.2 & 24.2 \\
\hline 13.4 & 0. & 13.4 \\
\hline 0 & 36.1 & 36.1 \\
\hline 7.9 & 0. & 7.9 \\
\hline 0. & $2 n .6$ & 20.6 \\
\hline 2.1 & 0 & 12.1 \\
\hline 0. & R.? & 9.2 \\
\hline 5.1 & $n$. & 15.1 \\
\hline$\stackrel{n}{n}$ & 2.7 & 2.7 \\
\hline 7.5 & 0. & 17.6 \\
\hline
\end{tabular}

FIN:AL RANLOM NUMBER SEEN 360575540052 
SUMIMAKY REPORT FOR THIS RIIN

TOTAL THROUGHPUT
RUNWAY
OPERATIOIS PERFORMED
LANDINGS
1
2

AVERAGE HOURLY THROUGHPUT

\begin{tabular}{cccc} 
RUPWAY & \multicolumn{3}{c}{ OPERATIO.IS PERFORMED } \\
& LANDINGS & TAKF.OFFS & TOTAL \\
1 & 0. & 34.5 & 34.5 \\
2 & 34.5 & 0.5 & 2.4 .5 \\
TOTAL & 34.5 & 34.5 & 69.5
\end{tabular}

AVERAGE HOURLY DELAY
RUIWAY
LANDINGS TAKEOFFS
\begin{tabular}{cccr}
\multicolumn{4}{c}{ TOTAL } \\
1 & 0. & 915.4 & 946.4 \\
C & 374.4 & 0.0 & 374.4 \\
TCTAL & 374.4 & 046.4 & 1320.8
\end{tabular}




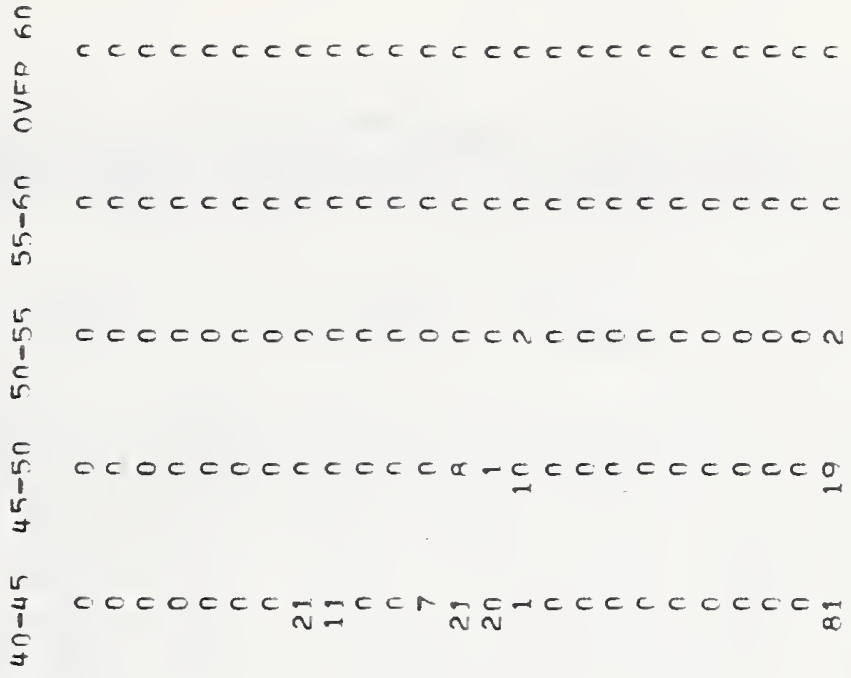

至 旁

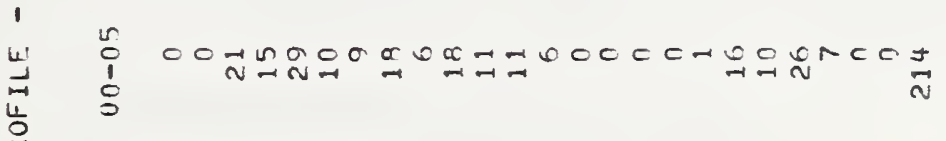


the delay experienced by operations occurring (touching down or starting ro11) in the stated hour, not the delay actually experienced that hour or the delay experienced by aircraft scheduled to land or take off that hour.

\section{A. 2 Changes in Separation Criteria}

With the advent of heavy aircraft (greater than $300,0001 \mathrm{bs}$. gross weight), wake turbulence problems have led to the imposition of separation rules requiring 5 mile separation for all non-heavy aircraft landing following a heavy, and 4 mile separation for a heavy following a heavy. All other aircraft combinations must be separated by 3 miles. Any non-heavy taking off behind a heavy must wait for two minutes after the heavy lifts off. Other takeoff separations are approximated in DELCAP by requiring that the second aircraft wait 20 seconds after the first lifts off. This eliminates all references to whether aircraft diverge or not and all necessity for treating departure paths. Other landing and takeoff separations may be input if it is so desired, but the revised DELCAP allows separation to depend only on the types of aircraft involved.

\section{A.3 Improved Random Number Generator}

Early test runs of DELCAP indicated that the random number generator available in the SIMSCRIPT system did not produce a sequence of numbers which were statistically "random" to a satisfactory degree. This has been remedied with the inclusion of a random number generator obtained from the NBS Statistical Engineering Laboratory. This generator requires a starting value (referred to as the "seed"), which is modified each time a random number is calculated. The final seed is printed out by DELCAP and can be used to start other runs. The sequence of random numbers produced depends entirely on the seed, so that runs can be replicated by using the same seed and on the other hand different traffic samples can be obtained by using different seeds. The seed is input and output as a 12 digit octal number.

\section{A.4 Modifications in Operating Policy}

The initial version of DELCAP allowed 4 different operating policies: landings only, takeoffs only, mixed operations where landings take precedence, and mixed operations in which landings and takeoffs alternate. To allow a more flexible sequencing procedure DELCAP was modified to let the user input the desired operation sequence. The user may provide any sequence of operations (of length up to 20), and this sequence will be repeated for the duration of the run. 
In the earlier versions of the DELCAP model, operating policies were strategies for operating a single runway only. In the course of the "throughput validation" effort, it became evident [2] that allowing independent sequencing and generation of aircraft on close parallels or intersecting runways unduly favored takeoffs over landings, since the average minimum time between takeoffs is less than that between landings. This led to unrealistically high takeoff throughputs and also to a degradation of the landing throughput, because of the interference by takeoffs with the landings. In discussing these problems with knowledgeable authorities at the FAA, it became clear that in most control situations a pair of close parallels or intersecting runways would be operated cooperatively, with a sequence of operations applying to the pair. The most common example involves either parallels or intersecting runways, operated with one of the pair reserved exclusively for landings and the second for takeoffs. During periods when the number of desired arrivals and departures are approximately equal and traffic is heavy, landings will be spaced far enough apart to allow a takeoff to occur in between successive landings. In practice this means landings are spaced only slightly further apart than the minimum. Takeoffs will be alternated with landings by clearing an aircraft for takeoff as soon as the previous landing has passed the intersection (when the runways intersect) or as soon as the landing touches down (for close parallels). To accommodate a higher volume of takeoffs than landings, landings are spaced far enough apart that two (or more) takeoffs could occur between successive landings.

The DELCAP model has been modified to accomodate such policies. (See Appendix B for a description of the new version of event NXTOP, in which the bulk of the modifications occur.) In earlier DELCAP versions, a policy was specified for each runway by indicating the operation sequence for that runway. The modified version now requires that the user specify the number of the policy applicable to that runway. Then he must specify separately the policy itself in the form of two sequences, the first giving the operation sequence and the second giving the associated runway sequence. Therefore the $i-t h$ entry in the first sequence is the $i-t h$ operation and the $i-t h$ entry in the second sequence is the runway on which that operation is to occur. The number of operating policies provided may not equal the number of runways; it may be less if one policy applies to several runways; it may be more if policies are changed during the course of a run.

An example of the four policies used in the LaGuardia run reported in Section 3 is given in Table A.1. Policies 1 and 4 use only one runway, on which operations are alternated. Policies 2 and 3 both use two singleoperation runways, with an operation on one alternating with an operation on the second. For instance for policy 3, takeoffs (operation 1) on runway 4 alternate with landings (operations) on runway 3. 
TABLE A.1

\section{Sample Operating Policies}

POLICY

NUMBER

1

2

3

4

\author{
SEQUENCE OF \\ OPERATIONS AND RUNWAYS
}

12

33

12

23

$1 \quad 2$

43

$1 \quad 2$

11

With the inclusion of this additional flexibility of operating policy, the user is now required to specify completely the set of policies. for any run, including the trivial sequence of operations having a single 1 for takeoffs only or a single 2 for landings only, together with the runway sequence whether or not only one runway is involved. This additional input requirement is a comparatively small price to pay for the extra flexibility and realism conferred by the more general operating policy approach. The preprocessor checks that the policy, specified in its input as applying to a given runway, can properly apply to it. It will not check, however, that another policy also affects this runway, since this may happen when policies change. Neither will it check that policy changes (after the initial policies) correctly apply to the runway they are associated with. This latter check is not made because the preprocessor does not have among its inputs the policy changes associated with each runway, since such changes are treated by the simulation as exogenous events.* Care must therefore be exercised by the user to ensure consistency for his input policies and policy changes initiated during a run.

*The alternative is to complicate the simulation itself by adding consistency checking to the simulation code. 


\section{A.5 Changing Operating Policy During a Computer Run}

In earlier versions of the DELCAP simulation, operating policies specified at the start of the run for each runway remained in force throughout the entire run. This approach was unacceptable for the LaGuardia exercise described in Section 3, since the operating policy in force changed several times during the day, and it was desired to include the effects of such changes on aircraft delay.

The main difficulty in incorporating the ability to change operating policy during a run lay in deciding how best to represent such changes. They can be classified into 3 categories:

1. use a runway surface not now being used,

2. change the sequence of operations on a runway now being used,

3. change the direction of operation of a runway now being used. Any combination of these can also occur as a policy change.

In the first two cases little additional delay results from the change, unless it must be made so suddenly that established queues must be moved. It is assumed by the model that changes are not of this sudden type. Operations will occur on a new runway as soon as the first operation designated for that runway can take place under proper separation rules. Policy shifts involving sequence changes (including those from pure operations -- of landings or takeoffs only -- to mixed operations, or the reverse) are allowed to occur as soon as the last of the operations waiting (in queues) at the time the change is called-for has occurred. This is done to avoid difficulties arising because a policy may affect more than one runway. In practice, since operations are generated some time before their occurrence (touchdown or roll) on the runway, this extra time period required before effecting a policy change results in very little delay.

Additional delay does occur, however, for case 3 above. Whenever the runway whose direction is changed previously handled takeoffs, and is to handle landings after the direction change (it may or may not handle landings before and/or takeoffs after), it will be necessary to clear the takeoff queue before effecting the policy change, and also to allow additional time for the last takeoff to clear the final approach path before the first landing under the new policy can even start its approach. Since any runwaydirection change may require moving queues around and establishing new approach patterns, an arbitrary time delay is required before initiation of a policy change whenever a change of runway direction is involved, and the model thus requires a fixed (input) time period between the last operation under the old policy and the first under the new.

Each policy change necessitates also that the distribution of traffic by runway be changed to agree with the new operating policies. (The program does not check that the two agree, so the user must be careful in providing input.) Policy change is handled by the DELCAP model as an exogenous event $\mathrm{CHGOP}$, which reads the new policy number for each runway and the new traffic distribution by runway. The user must also specify for each runway whether or not the new policy involves a direction change on that runway. All policies themselves are input at the beginning of the 
run, rather than with each change, and the user is responsible for consistency here also. Policy change is accomplished in CHGOP, whenever the policy change can occur immediately. In cases which require a delay, either to clear operations waiting or previously scheduled for the runway, or to effect a change of direction, the policy change occurs in CDIR. Descriptions of these routines are given in Appendix B, and input formats for the data required for a policy change appear in Appendix D.

\section{A.6 New Preprocessor Standard Values}

The preprocessor program has been designed to provide standard input values for each of six input categories. The user may elect to provide his own input or to accept the standard values, and indicate this decision by an option (non-blank characters if the standard is to be used, blanks for user provided values) on the preprocessor parameter card, the second preprocessor input card (see Appendix D for its format). Whereas the original version of the preprocessor was designed to have an input tape with standard input for several major airports, this tape is no longer referred to in the program and standard input is now provided internally through the use of the DATA statement.

Standard input for data group 1, aircraft type data, is shown at the top of the Sample Preprocessor Output in Figure A.1. The three standard aircraft types are:

1. heavy aircraft

2. light (piston) aircraft

3. other aircraft: larger piston aircraft and most jets.

The standard input for data group 2, aircraft type mix, appears below the aircraft type characteristics in Figure A.1. Standard input for data group 3, the departure and arrival rates, is set at 200 takeoffs per hour and 100 landings per hour, values which would saturate IFR operations at any large airport. These values are thus appropriate for throughput runs but not delay runs. To obtain realistic delay estimates, the user must supply realistic traffic levels.

Standard separations, data group 4, are those now required by FAA rules: 3 miles behind a non-heavy, 4 miles for a heavy behind a heavy, and 5 miles for a non-heavy behind a heavy for landings; and for takeoffs 20 seconds more than the runway occupancy time behind a non-heavy, 2 minutes for a heavy behind a heavy, and 2 minutes plus the runway occupancy time for a non-heavy behind a heavy. (The takeoff time separations are approximations involving several constraining rules.) Standard input for data group 5, the runway and operating policy data, specifies a single runway operated with landings and takeoffs alternated. The distance to the outer marker is 5 miles and the times to fly from handoff to the outer marker are 10, 13, and 10 minutes for the three aircraft types respectively. The standard input data for data group 6, the distribution of runway usage, have all aircraft using the single runway. 
The changes described above have enhanced model capability and allowed i.t to reflect more accurately the sitatuion being simulated, without changing the basic philosophy of the DELCAP model. DELCAP was designed to be limited in scope to the calculation of airport runway throughput and the delays caused by terminal airside traffic. The design concentrated particularly on enabling the user to describe those elements of the terminal area which have primary impact on capacity and delay, without requiring him to provide excessive detail in input data. To ensure that DELCAP remains an easily used, convenient planning tool, candidate changes have all been examined against these criteria and only those meeting them have been implemented. 
APPENDIX B

\section{DESCRIPTIONS AND FLOWCHARTS OF SIMULATION EVENTS}

Figure B.1 gives a general "flowchart" of the DELCAP simulation model routines. The word "flowchart" is somewhat of a misnomer in the context of a SIMSCRIPT model. The diagram indicates which event routines occur as a result of which other routines, but it does not give the order in which they are actually executed, since this is chronological.

Events GEN and EXGEN create flights, which are the units that move through the various events in the model. EXGEN is an exogenous event which occurs at times designated for the arrival into the system of specific flights. GEN creates flights in a stochastic manner. Stochastically generated flights are assigned an aircraft type and a landing or takeoff runway by the two functions PTYPE and PRWAY. Flights are constantly entering the system while other events are happening. GEN schedules the next occurrence of itself according to a Poisson process, while the next specific flight (if any are left) for EXGEN is always available. The event NXTOP finds the next operation (landing or takeoff) which is to occur on a particular runway. It is scheduled in one of two cases: (1) if the queue is empty when the current flight is filed in it, or (2) when the current flight has either begun to fly the final approach path to land or has left its gate to take off. Condition (1) is detected in GEN or EXGEN, and condition (2) in LAND or TOFF. NXTOP then schedules the next LAND or TOFF at the time the runway and/or final-approach path is free, as determined by the function FREER. Since there is a time gap between NXTOP and TOFF or LAND during which landings or takeoffs on other runways may have created new tieups for "this" runway, LAND and TOFF again determine the first time the runway is free (from FREER). Then the flight may land or depart, which in the DELCAP model implies tying up the appropriate points for a period of time sufficient to maintain the required separations. LAND or TOFF then reschedules NXTOP, and the cycle continues. When a tieup is no longer in force, the routine FTIEUP destroys it.

Several routines do not appear in this 1ist, since they do not affect each flight. The BEGIN event (see Figure B.2) starts the simulation, and schedules the event ENDS which prints the simulation output and stops execution. The routine CHOUR (see Figure B.3) updates the current hour for output of delay and throughput, and reschedules GEN for the Poisson parameter for the new hour. The routine PRINT records the delay and throughput information at touchdown for landings, and at start-of-roll for takeoffs.

The exogenous event CHGOP reads the characteristics of a new policy and initiates the changeover if that can occur immediately. Otherwise CHGOP or NXTOP initiates CDIR when the changeover should occur. CDIR also handles the change of direction of a runway. The following sections will include descriptions of the events in Figure B.1, as well as CHGOP and CDIR. 


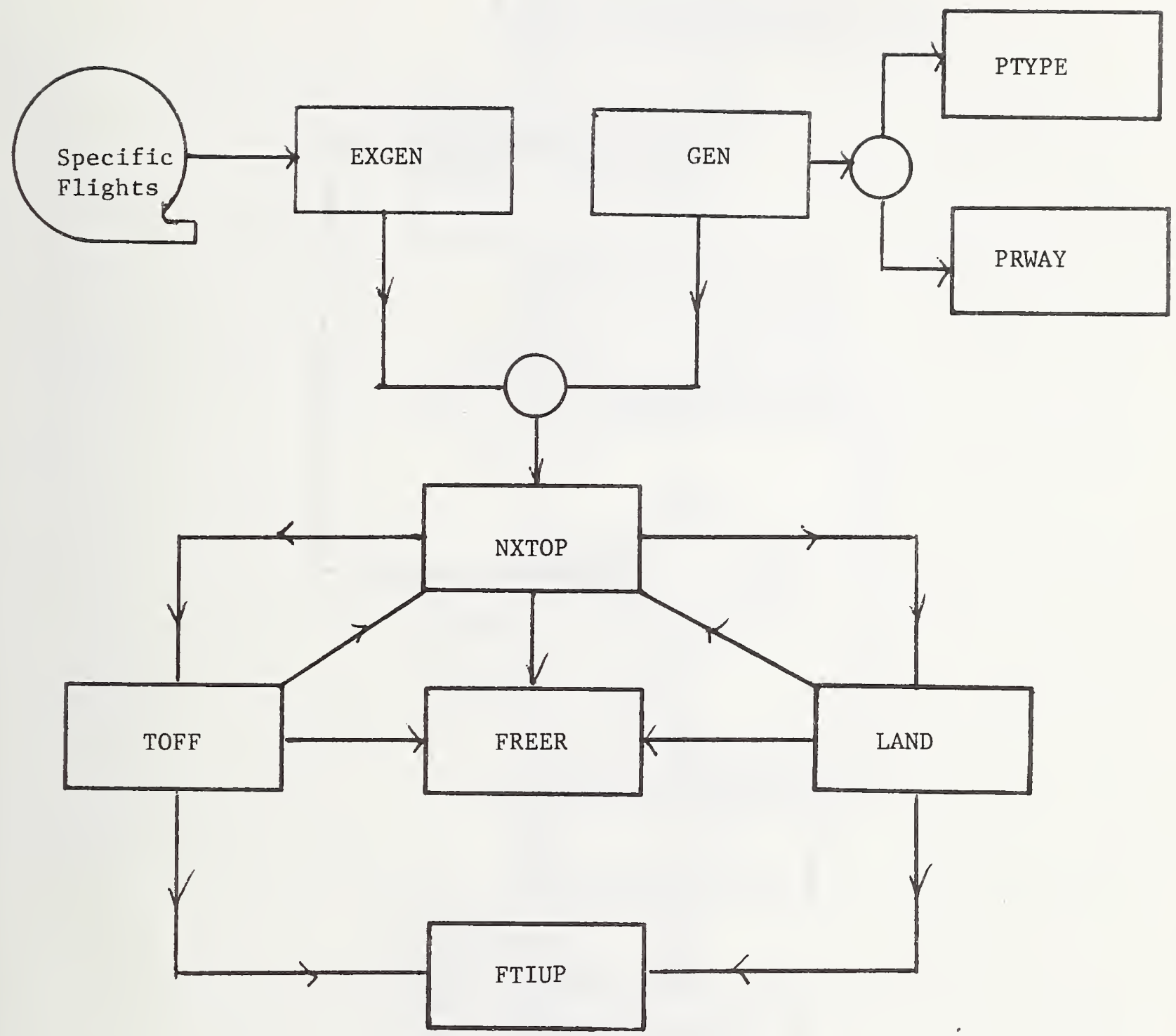

FIGURE B.I

Flowchart of the DELCAP Simulation Routines 


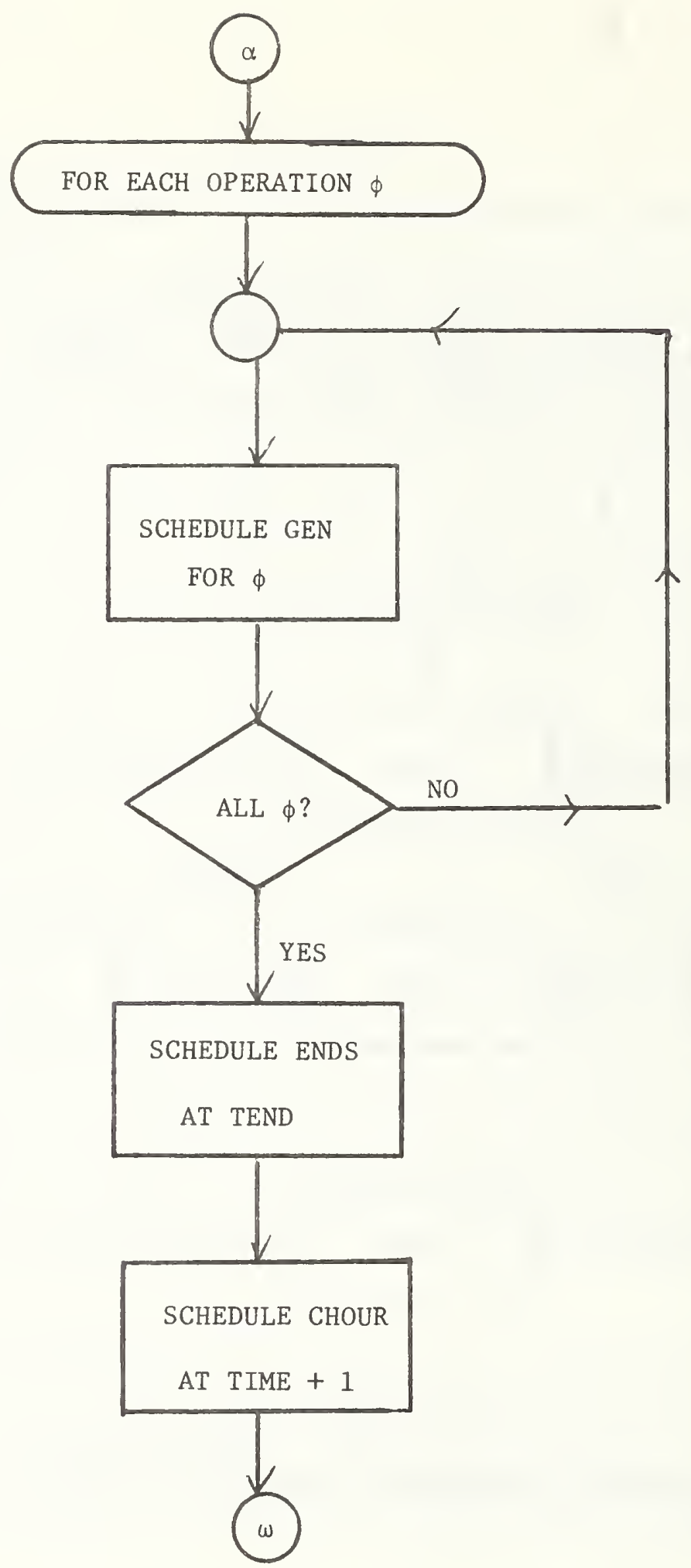

FIGURE B.2

Flowchart of Event BEGIN 


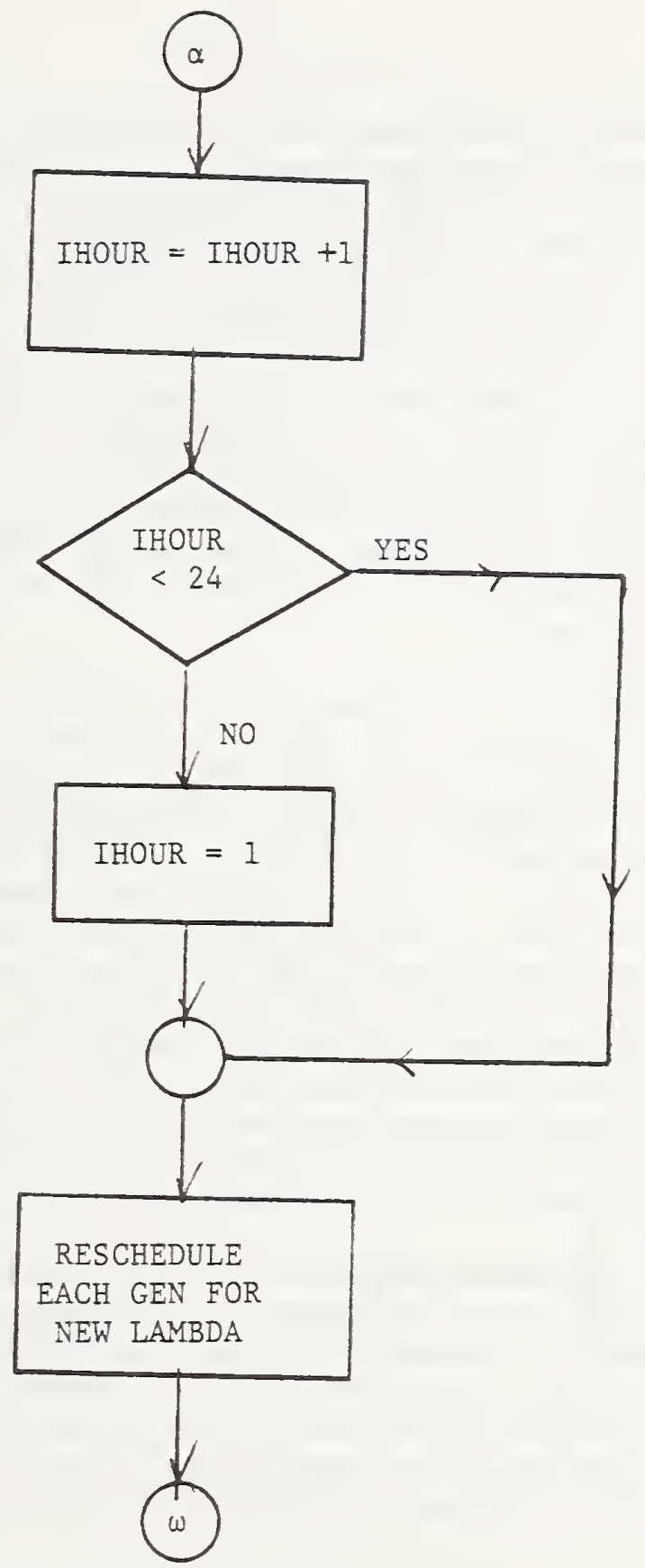

FIGURE B. 3

Flowchart of Event CHOUR 


\section{B.1 Event EXGEN}

This event creates exogenously-determined flights provided by the user. It, or the stochastic generation process or both, may be used for a particular run. When inputting the information for the routine EXGEN, the user must supply for each flight: the hour, minute, and second of entrance into the system, whether this flight is a takeoff or a landing, the runway used for takeoff or landing, and the aircraft type. The SIMSCRIPT system programs read these flights one at a time at the proper simulated time. Therefore, there is no limit on the total number of flights as long as the number simultaneously active (including both those generated by EXGEN and those produced by GEN) is sufficiently small to fit in core. (For a simulation run with 20 runways, 100 aircraft types, and 10 departure paths, there could be about 6,000 flights active at any given time. This, which is permitted in the present model, is far beyond the capacity of any existing airport to handle.)

Figure B. 4 provides a flowchart for the EXGEN event routine. For a landing, the array TIN stores the time the current flight could (in the absence of other traffic) first cross the outer marker after flying from its handoff point. A takeoff's flight plan becomes active about 13 to 15 minutes before its scheduled departure. In the model this time period is divided into two segments, so that takeoffs are scheduled about the same time before start of roll as landings are before touchdown. The first of these time segments (about 10 minutes), which may be thought of as representing the time between when the flight plan becomes active and when the aircraft is cleared to leave its gate, is added to the current time and stored in TIN. (The second segment, about 5 minutes, may be thought of as representing a time interval between when the aircraft is ready to leave its gate and when it could start its roll down the runway; it will be described in greater detail in the section on the TOFF routine.)

After calculating the appropriate TIN, the EXGEN routine files the newly generated flight into the appropriate queue. There are two queues for each runway, one for landing aircraft, the other for takeoffs. The queues are organized in a first-in-first-out manner. This means there is no sequencing by aircraft type; when a slow aircraft precedes a faster one, the latter is not permitted to overtake the former, even if it could reach the outer marker first without thereby delaying the slower plane.

Each flight must remain in the queue until its TIN. Filing flights into the queue about 10 minutes before they could actually cross the outer marker or leave a gate provides a means for identifying the aircraft type of the flight that follows the current flight. This allows calculation of the proper tieup time to ensure that two aircraft remain separated by the required distance. This distance depends on the speeds of both aircraft involved, and so cannot be calculated until the type of the second plane has been determined. 


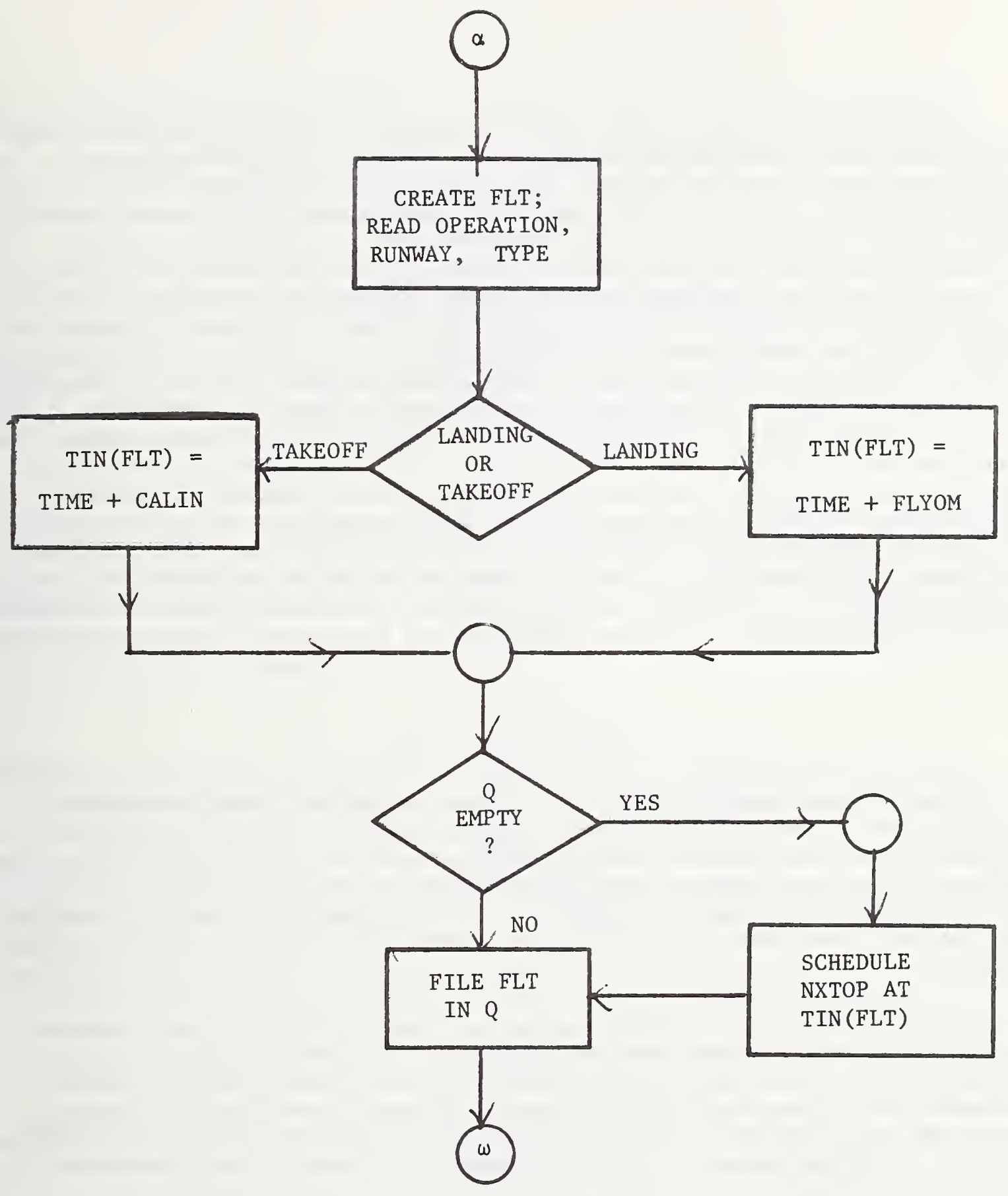

FIGURE B.4

Flowchart of Event EXGEN 
If the queue was empty before the present flight was added to it, the NXTOP routine is scheduled to occur at TIN, which is the first instant when this flight could be removed from its queue. The NXTOP routine, which schedules the next operation (landing or takeoff) for a particular runway, thus occurs in one of two circumstances: either (1) a landing or takeoff has just occurred, or (2) the runway has been idle but there is now a new flight available for it. Case (1) will be described later in conjunction with the NXTOP, LAND and TOFF routines. In case (2), which is detected in the EXGEN routine, the appropriate queue will have been empty before the flight was filed in it. Therefore the NXTOP routine is scheduled for when the flight is first available to land or take off. However, an earlier NXTOP may have been scheduled in LAND or TOFF, since the other queue may not be empty. In this situation, NXTOP is scheduled, but when it occurs the next operation will already be defined (NEXT $\neq 0$ ) and the NXTOP routine will be terminated. This means that NXTOP may be scheduled more often than necessary. The programming alternative was the coding of a much more complicated set of tests to ensure that NXTOP is scheduled only when necessary. This did not seem warranted, in view of the lack of computerstorage problems and the logical simplicity of the current test.

\section{B.2 Event GEN}

This event generates flights in a Poisson manner. Landings and takeoffs are generated separately, from two different sets of Poisson parameters. This routine is first scheduled by the BEGIN routine. BEGIN schedules two GEN's, one to create a landing flight and one to create a takeoff. From then on, the GEN routine schedules the next occurrence of itself. Therefore, within GEN we wish to sample from the Poisson distribution to reschedule GEN for the next entry ("arrival") of another aircraft into the simulated system.

The procedure used in the computer for sampling from a distribution is based on the fact that the range of any cumulative distribution is uniformly distributed over the interval $[0,1]$. In the case here, we have assumed Poisson generation, so the probability of an arrival in a time period of length dt is $\mu d t$ (plus comparatively infinitesimal terms), where $\mu$ is the expected number of arrivals per unit of time. Then the probability $q(T)$ that the next arrival will occur in at most $T$ units of time is

$$
q(T)=\operatorname{prob}(t \leq T)=1-e^{-\mu T} \text {. }
$$

Since $q$ is a cumulative distribution, its range is uniformly distributed over the interval $[0,1]$. We therefore employ a standard computer subroutine to choose a random number $R$ from this uniform distribution, and then find the $T$ for which $q(T)=R$, namely

$$
T=-\lambda \ln (1-R)
$$

where $\lambda=1 / \mu$. The next instance of GEN is scheduled to occur in $\mathrm{T}$ time units. (Note that our time unit for the simulation is the hour, so $\lambda$ is 
the reciprocal of the number of arrivals per hour.) Input to the simulation contains two sets of values for $\lambda$ for each hour of the day, one for landings and one for takeoffs. As noted earlier, on the hour, each hour, the next GENs, one for a landing and one for a rakeoff, are resoheduled according to the $\lambda$ for the appropriate hour.

In the event EXGEN, the type and the runway are provided as part of the input. In the stochastic version GEN, however, these three items are obtained by sampling from the appropriate distributions. The simulation is provided (by the preprocessor) with the cumulative distributions of (1) type of aircraft, one for landings and one for departures, and (2) runway use by each type of aircraft for landings and also for departures. The two functions PTYPE and PRWAY perform the sampling processes.

Figure B.5 provides a flowchart of the GEN routine. After rescheduling the GEN routine for the next landing or next departure (depending on the current operation), and sampling to obtain a type and runway for the current flight, the remainder of the routine is the same as for the EXGEN routine. The appropriate value of TIN is calculated, the flight is filed in its proper queue, and if the queue was empty before this flight was filed in it then the NXTOP routine is scheduled at TIN.

\section{B. 3 Event NXTOP}

This event finds the next operation, landing or takeoff, which will be scheduled to occur on a runway. Figure B.6 is a flowchart of this routine. Because of the new more sophisticated operating policies to be simulated, this routine has required significant changes from the original version of DELCAP. A search is made, starting with the next position (stored in LAST) in the policy sequence applying to this runway, for the first flight which can be scheduled immediately under this policy. If no flight can occur immediately, the search continues through the policy to determine the flight which will be available soonest, and LAND or TOFF is scheduled for that flight. In addition to determining the next operation to be scheduled under the policy, the NXTOP routine also recognizes when a change in policy, which is not initiated by CHGOP, must occur. If the next flight to be scheduled is the last flight in the queue at the time the policy change was requested in CHGOP (i.e. if the current flight $F L T=Q F(k, i))$, then the $Q F^{\prime} s$ for the other runway, operation combinations for this policy are checked. If all QF's are zero, the policy changeover is scheduled to occur when the current flight either starts its approach or leaves its gate. This is accomplished by scheduling CDIR at the (same) time for which the LAND or TOFF routine was scheduled. 


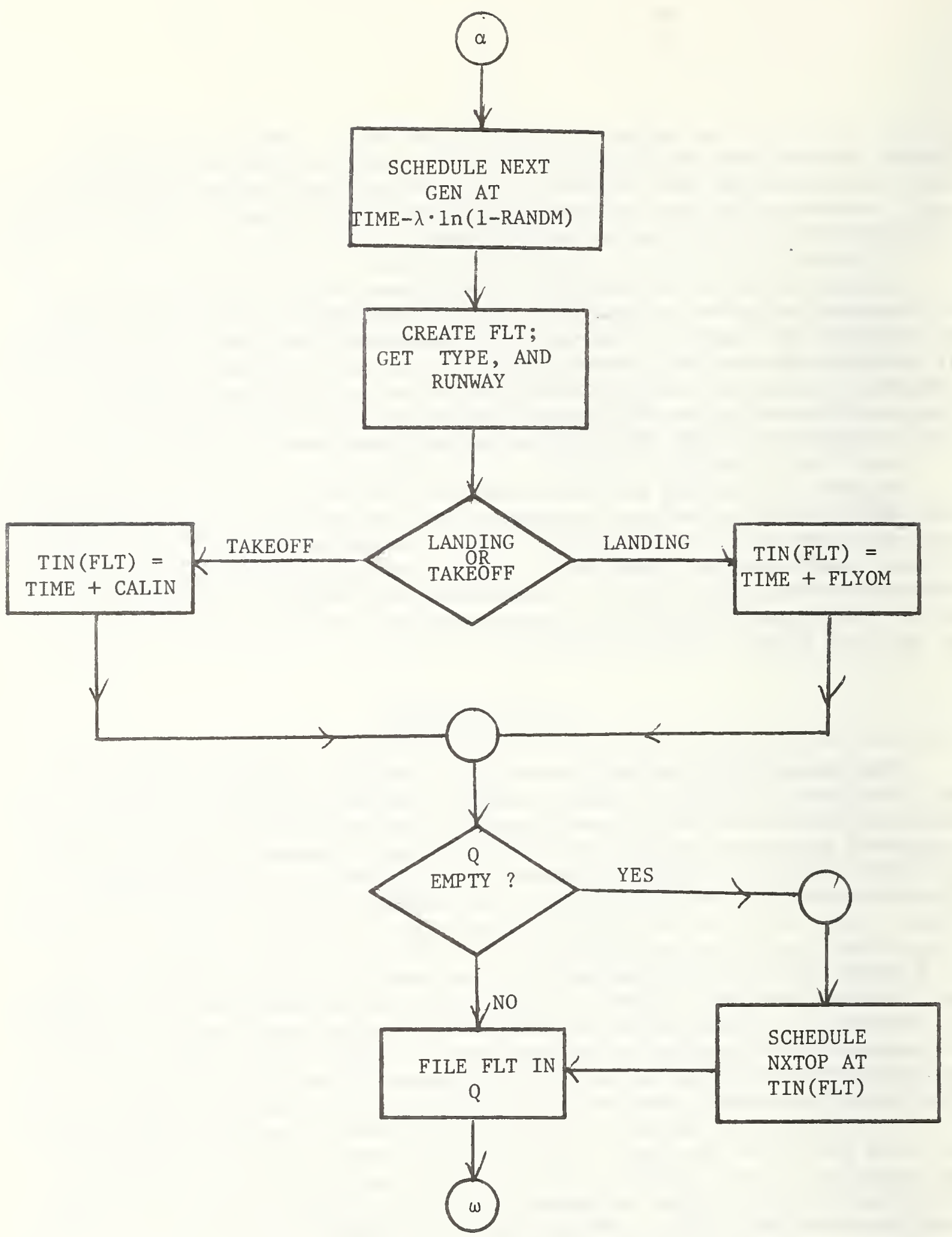

FIGURE B. 5

Flowchart of Event GEN 


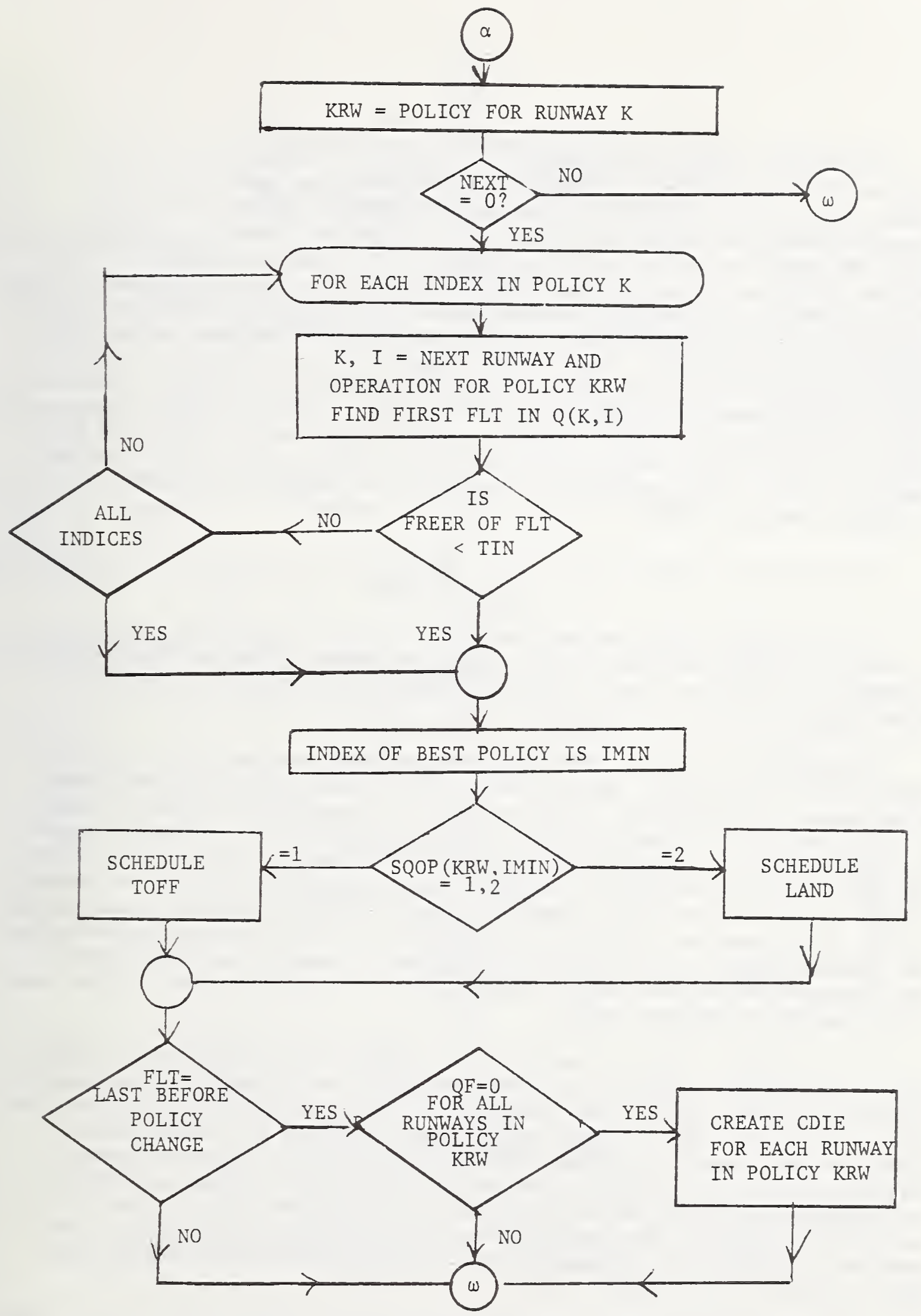

FIGURE B. 6

Flowchart of Event NXTOP 
The NXTOP routine is scheduled in one of two instances: (1) the LAND or TOFF routine has occurred, or (2) a queue was empty and a new flight has just been filed. In the second instance, NXTOP is scheduled for the time TIN at which the flight could first be scheduled. However, since the other queue for the runway need not be empty or a LAND or TOFF routine could just have occurred, another NXTOP may already be scheduled for this runway. To avoid error because of having several NXTOPs scheduled at once, an array NEXT with an entry for each runway has been introduced. Originally it is zeroed. When a next operation for a runway has been found by NXTOP, NEXT is set equal to 1 (for a takeoff) or 2 (for a landing). Then NEXT is zeroed in the LAND or TOFF routine. Therefore NEXT is nonzero precisely when a LAND or TOFF is scheduled but has not yet occurred. NXTOP proceeds to find a next operation for a runway only if NEXT for that runway is zero. This condition is tested at the beginning of NXTOP, and if NEXT is non-zero NXTOP is immediately terminated.

\section{B. 4 Function FREER}

This function finds the earliest time a particular flight can land or take off without violating the separation rules. FREER is first called in NXTOP, to find the time at which the LAND or TOFF routine should be scheduled.

There may be a gap between the time the NXTOP routine occurs and the time LAND or TOFF occurs, during which other flights might add new tieups which require postponement of the operation in question. Therefore FREER is called again from LAND or TOFF, to determine when the landing or takeoff may actually occur. Figure B.7 contains a flowchart of the function FREER. The left-hand side refers to landings, the upper right-hand side to takeoffs and the lower portion of the chart to both. $T$ is the maximum of $T I N$ and the current time, used to single out for examination only those tieups affecting the current flight. The array TR is created to contain the time (TMAX) each tieup affecting the flight will no longer be in force, and $\mathrm{J}$ is a count of the number of entries in TR.

For landings, both the set of tieups (OMTI) associated with the outer marker and the set (THTI) associated with the runway threshold are examined. The time of tieups in THTI is translated to the outer marker by subtracting off the amount of time it takes the current flight to fly from the outer marker to the runway threshold; this reflects the fact that the runway threshold need only be free as the current flight gets there, not before. For takeoffs, only the set of tieups (ERTI) associated with the end of the runway are examined. The time of these is translated to the gate by subtracting off TDMIN, since takeoffs are scheduled before they leave their gates to taxi to the runway.

If there are no tieups affecting the current flight (i.e. $J=0$ ), FREER is set equal to $\mathrm{T}$. If only one tieup affects the current flight (i.e., $J=1$ ), then TR (1) will contain the time at which that tieup will no longer impede the start of the landing or takeoff procedure, and so FREER is set equal to 
it. If several tieups affect the current flight, FREER is set equal to the maximum of the TR's.

It should be clear from the previous description that this routine does not attempt to fit a flight in between two others, even if the gap between the two is wide enough. To do so would require a great deal more coding. The crux of the difficulty is how wide a gap is "wide enough". The tieups occurring as a result of the inserted flight must not affect any previously scheduled flight. This means that all the tieups which LAND or TOFF would create must be examined to see if they would interfere with a landing or takeoff already scheduled or in progress. This is similar to performing the whole of the LAND or TOFF routine, and involves the additional burden of identifying the flight which is being interfered with. (It is no longer just the first in a queue.) Therefore the simpler procedure, of waiting until the last tieup is no longer in force, was used in the DELCAP simulation.

One further difficulty can arise when a slow landing follows (i.e. lands later than) a fast takeoff. NXTOP is called as soon as the takeoff leaves its gate. The landing therefore is not permitted to cross the outer marker before then, since FREER is at least $T$ which in turn is at least the current time of NXTOP. However, if the landing is slow enough it could in principle be scheduled earlier, and the takeoff would still be able to precede it while maintaining the required separation. Therefore, although the sequence of operations on the runway must be a takeoff followed by a landing, the sequence of routines should really be LAND followed by TOFF. This difficulty has not been resolved, but in sample debugging runs it occurred only about 2 to $3 \%$ of the time, and added only about 30 seconds extra delay at each occurrence. Therefore it does not seem to affect the DELCAP results by a significant amount.

\section{B.5 Event LAND}

The primary purpose of both the LAND and TOFF routines is to tie up the appropriate points in order to ensure that following flights remain properly separated from the current landing or takeoff. Figure B. 8 is a flowchart of LAND. LAND removes the first flight from the landing queue for the appropriate runway. Then it calls FREER to find when the runway and final approach path are first free so that this flight may cross the outer marker.

The separation rules which apply to a landing, and their implementation, are discussed below:

(1) No two aircraft may occupy the same runway at the same time. This rule is implemented by tying up the runway threshold (for landings) or the end of the runway (for takeoffs) for the time the current landing will occupy the runway.

(2) Two landings must be separated by a minimum distance (called SEPLL, in DELCAP) and depending on the two aircraft types involved. We assume a constant nominal final-approach speed, depending on aircraft type. Therefore, the point at which two landings are closest while always main- 


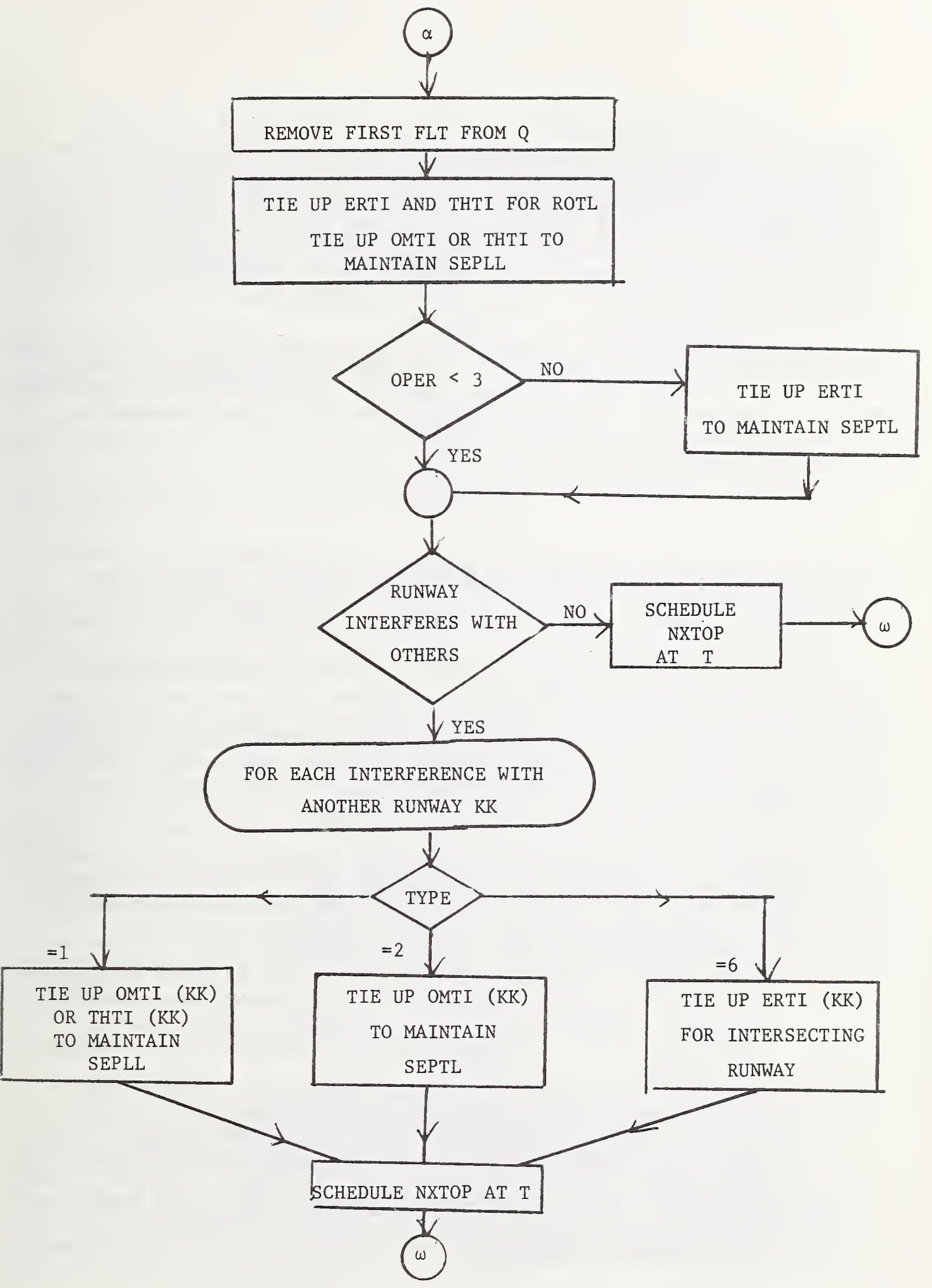

FIGURE B. 8

Flowchart of the Event LAND 
taining the required separation depends on the relative speeds of the two planes. If the first (of aircraft type $i$ ) is faster, they will be closest when the first crosses the outer marker. In this case the outer marker is tied up for the time it will take the second (of aircraft type $j$ ) to fly SEPLL $(i, j)$. If the second is faster, the two planes will be closest when the first just touches down. In this case the runway threshold is tied up from touchdown of the first until that time plus the time for the second to fly SEPLL $(i, j)$.

(3) A landing must be separated from a preceding takeoff by a required distance (called SEPTL in DELCAP). The standard present value for SEPTL is 2 miles. As noted above, the final-approach speed is treated as constant. Under the assumption of a single constant acceleration for a takeoff on the ground and in the vicinity of the airport, the distance the landing must be from the takeoff when the latter starts its roll is

$$
\mathrm{SEPTL}+0.5 \mathrm{v}^{2} \cdot \mathrm{ROTT} / \mathrm{S} \text {, }
$$

where $\mathrm{V}$ is the speed of the landing, $\mathrm{S}$ is the liftoff speed of the takeoff, and ROTT is the runway occupancy time for the takeoff. (This formula is derived in Appendix $F$ of [4].) The end of the runway is therefore tied up from the time the landing passes this point until touchdown time.

Tying up a point is accomplished in the simulation by creating a temporary entity called a TIEUP, with attributes TMIN, the time the tieup goes into force, and TMAX, the time the tieup is no longer in force. The TIEUPs are filed in one of the sets OMTI, THTI, or ERTI, which are scanned in FREER to decide when the runway and final approach path airspace are free. Once the TIEUP is no longer in force, it is removed by the FTIUP routine which is scheduled in LAND as the TIEUP is created.

In addition to tying up points on the same runway, points on interfering runways must be tied up. Two arrays RPT and TPT control these interferences in the DELCAP simulation. For each runway and interference, RPT contains the runway being interfered with, and TPT contains the type of interference. There are six types of interference:

1 Landings on one runway must be separated from landings on the other runway by SEPLL, depending on the aircraft types involved.

2 Landings on the one runway must be separated from preceding takeoffs on the other runway in the same manner as that described in (3) above.

3 Takeoffs on the one runway must be separated from following landings on the other as described in (3) above.

4 Takeoffs on the one runway must be separated from takeoffs on the other runway by the same separation as takeoffs on the same runway.

5 Takeoffs on the two runways are separated by the times in the array SEP2.

6 The two runways intersect. 
Types 1, 2, and 6 apply to landings. Tieups for interference types 1 and 2 are computed in a manner similar to (2) and (3) above. For intersecting runways, a takeoff or landing on another runway may not be on the runway between the time the current landing touches down and the time it passes the intersection or turns off, whichever occurs first. The time for an aircraft to travel from touchdown to an intersection a distance $D$ from the end of the runway is

$$
(1 / A)\left(-v+v^{2}+2 A D\right)
$$

where $\mathrm{V}$ is the landing speed and $\mathrm{A}$ is the acceleration of the landing. We assume $A$ is constant, so

$$
A=\left(v_{1}-v\right) / \text { ROTL }<0,
$$

where $v_{1}$ is the turnoff speed of the landing, $v$ is the final approach speed, and ROTL is the runway occupancy time. This formula is derived in Appendix $G$ of [4].

The RPT and TPT lists are scanned, and appropriate tieups are initiated to maintain required separation between the current landing and operations on other runways. As each tieup is created, it is filed into the set for the point being tied up. At this same time, an ETIUP is scheduled to destroy the tieup once it is no longer in force.

Once all the necessary tieups have been created, the LAND routine sets NEXT $=0$ and schedules NXTOP for the time the current landing crosses the outer marker. Then the delay to this flight is calculated as the difference between the time it crosses the outer marker, and TIN (which is the first time it could cross the outer marker were there no other aircraft present). The PRINT routine is scheduled at the touchdown time for this landing. PRINT adds the delay to this flight to the total delay, and increments the number of landings for the correct hour. Since all tieups to maintain separation from this landing have been created and since the delay for this flight has been calculated, the flight is no longer needed, so it is destroyed. This completes our description of the landing routine. The takeoff routine performs similar tasks related to takeoffs.

\section{B. 6 Event TOFF}

Figure B.9 is a flowchart of the TOFF routine. Much of it is similar to the LAND subroutine. The first flight is removed from the landing queue and FREER is called to ascertain the first time the flight can taxi to takeoff. Tieups are created to maintain separation, both on the same runway and on others where there is interference. NXTOP is scheduled for the time specified by FREER, the delay is calculated, and the flight is destroyed. Thus the overall structure of TOFF is similar to that of LAND. 


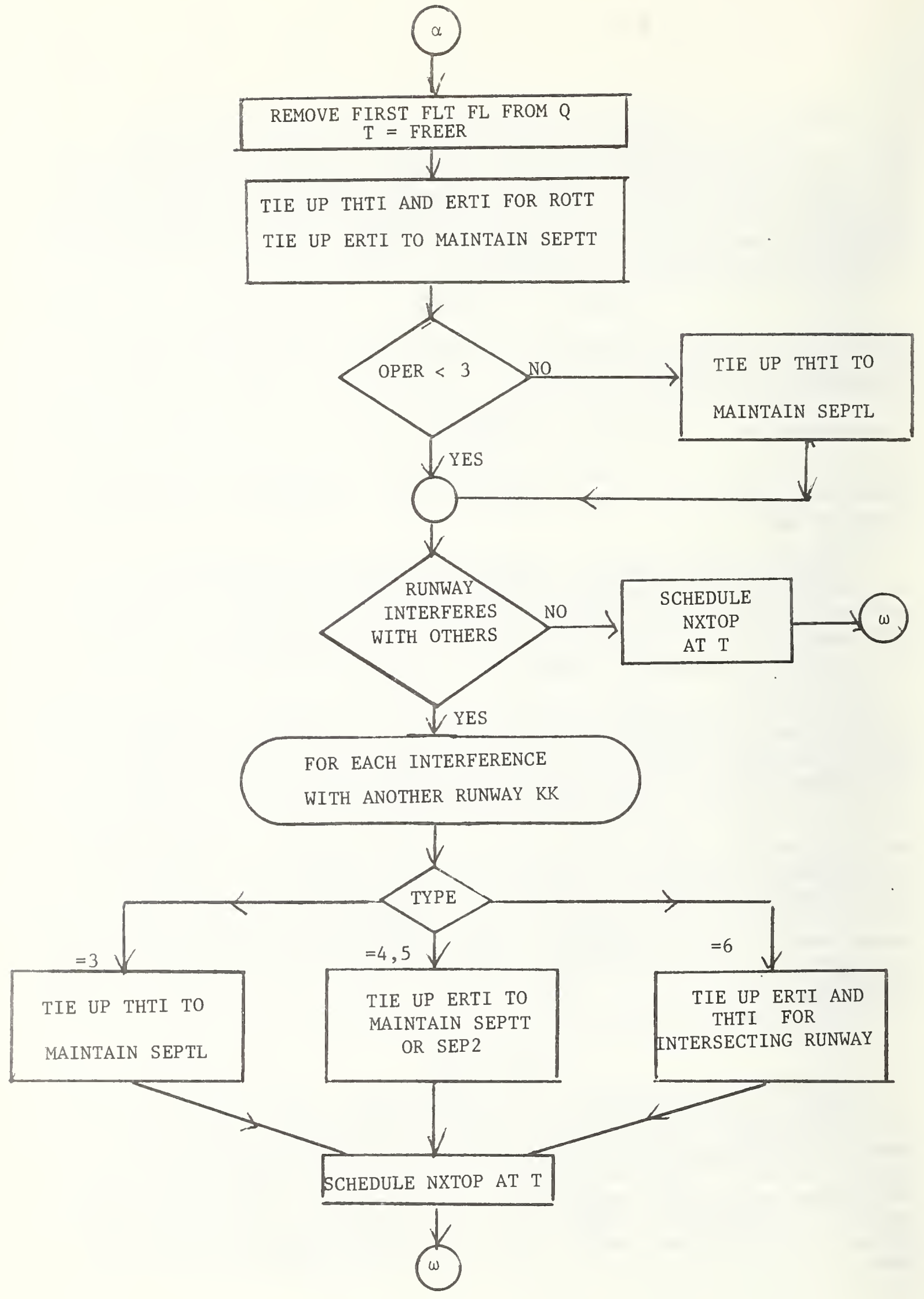

FIGURE B. 9 
Takeoffs, however, are special in one way. They enter the system several minutes before scheduled takeoff and the TOFF routine occurs later still before takeoff. The reason for this early scheduling of takeoffs can best be described here, in the context of the TOFF routine. Takeoffs are scheduled early so that their scheduling can be compatible with that of landings. Landings need to be scheduled before touchdown, since they must be properly separated from other operations along the whole of the final approach path. If takeoffs were scheduled only at start-of-roll, a following landing could be scheduled no earlier than that start-of-roll. In other words, the following landing could not cross the outer marker until the preceding takeoff had started its roll. It would greatly complicate the model if landings and takeoffs for one runway were scheduled in an order different from that in which they occur in LAND and TOFF. By scheduling takeoffs early, landings and takeoffs can be treated in the same manner. As noted above, there is still a residual difficulty when a very slow landing follows a fast takeoff, but for the most part, scheduling takeoffs early permits proper sequencing and scheduling on a dual-use runway.

One may still ask, "Why generate takeoffs so early?" It is necessary to generate takeoffs at least 3 to 5 minutes (depending on the separation rules) before they are scheduled by TOFF. When calculating the tieup duration needed to maintain separation from following aircraft, it is necessary to know the type of the following aircraft. Therefore takeoffs have to be generated as far ahead (in time) of scheduling in TOFF as the greatest time separation required between aircraft.

The careful reader may wish to inquire whether this procedure is indeed not too artificial. We note in response that these time intervals can be interpreted in terms of real events. The time between flight generation and scheduling of TOFF may be thought of as the minimum time ahead of departure at which a flight plan can be filed. Such a minimum time is in fact required at the more congested airports, and as more terminals become congested this practice will become more widespread. Also, with the addition of computer processing of flight plans, a minimum filing time is quite likely. The time between scheduling and start-of-roll may be thought of as the time for the aircraft to leave its gate, taxi to the runway, and complete final checkout. In the model, queuing for takeoff would then occur before leaving the gate, although at most terminals gate space is limited and there are parking ramps for waiting. This is another instance of a situation in which we are interested in the length of a time interval but not in where the aircraft is during that interval. We would be interested in where the aircraft actually is only if this were to affect whether the aircraft could turn onto the runway when the runway is free. The DELCAP model does not include any ground operations, and therefore, the delay figures do not include delays incurred during ground operations. Future model modifications might address this additional source of delay. 
To return to our discussion of the TOFF routine, we will now describe the separation rules applying to a takeoff, and their implementation.

(1) No two aircraft may simultaneously occupy the same runway. This rule is implemented in the same manner as it was in LAND. The runway threshold and the end of the runway are tied up from start-of-roll to liftoff.

(2) Separation between departing aircraft depends on the types of aircraft involved, since under current rules extra time is required for aircraft departing behind a heavy, and this time is less if the following aircraft is also a heavy than if it is not. Separation times are stored in the array SEPTT, which is a two-dimensional array depending on the aircraft types involved.

(3) A takeoff must be separated from a succeeding landing. The process here in TOFF is similar to that described for separation (3) of LAND. The runway threshold is tied up from start of roll until that time plus

$$
(1 / \mathrm{S})\left(\mathrm{SEPTL}+0.5 \mathrm{v}^{2} \mathrm{ROTT} / \mathrm{S}\right)
$$

where $\mathrm{V}$ is the landing speed, $\mathrm{S}$ is the liftoff speed of the takeoff, and ROTT is the runway occupancy time of the takeoff.

Each tieup created is filed in the appropriate set ERTI, for the end of the runway, or THTI for the runway threshold. Along with each tieup, the routine FTIUP is scheduled for when the tieup is no longer in force.

TOFF also ties up points on interfering runways in order to ensure that the required separation from the current takeoff is maintained. Of the six types of interference listed in the description of the LAND routine, four pertain to takeoffs:

3. Takeoffs on one runway must be separated from following landings on the other runway.

4. Takeoffs on one runway must be separated from takeoffs on the other runway by the same time as takeoffs on the same runway.

5. Takeoffs on the two runways must be separated by the times in the array SEP2.

6. The two runways intersect.

Tieups for types 3 and 4 for different runways are computed in the same manner as separations (3) and (2) above for one runway. Tieups for type 5 are computed in a manner similar to that of separation (2) above, except that a second array SEP2 is used instead of SEPTT. SEP2 contains time separations required between aircraft on different runways. Type 6 is handled for takeoffs in the same manner as for landings. The threshold and end of the second runway are tied up from the time the takeoff starts its roll until it has passed the intersection.

The remainder of the takeoff routine is the same as the landing routine. NXTOP and PRINT are scheduled, delay is calculated, and the flight is destroyed. 


\section{B.7 Event FTIUP}

This event destroys a tieup as soon as it is no longer in force. A flow chart appears as Figure B.10. These "erasures" free computer storage for new flights and tieups, and make searching the sets in FREER easier. Since the sets OMTI, THTI, and ERTI are ordered by TMAX (the time the tieup is no longer in force), FTIUP only needs to remove and destroy the first tieup in the appropriate set.

\section{B. 8 Event CHGOP}

This event, whose flowchart appears as Figure B.11, reads the new policy to be used for each runway together with the new runway usage, distributions, and initiates policy changeovers whenever the changeover can occur immediately. The array $\mathrm{QF}(k, i)$ indicates for each runway and operation the status of the runway for changing policy. CHGOP sets up $\mathrm{QF}$ so that $\mathrm{QF}=0$ if either the queue for that runway and operation is empty or if the runway was not used under the previous set of policies. If, on the other hand, the runway was previously used and has aircraft in its queue, QF for that runway and operation is set equal to the last flight in that queue.

The old policy for a runway is stored in the array INDX and the new policy in TNDX. Changing the policy consists of replacing INDX with TNDX and setting TNDX to be zero. The change can occur only when all the $\mathrm{QF}^{\prime}$ 's for all runway/operation combinations in the policy are zero. However, if the policy change involves a change in direction of a runway, it cannot be initiated immediately, and in this case the routine CDIR which handles runway direction changes is scheduled at the current time. If any QF's are non-zero then the policy change is initiated by NXTOP, which detects when the next aircraft scheduled is the flight stored in $Q F$, and calls CDIR to initiate the policy change.

\section{B. 9 Event CDIR}

Figure B.12 is a flowchart of event CDIR. This event also initiates policy changes, and can be scheduled either from CHGOP or NXTOP. It first tests if a runway-direction change is involved in the policy change. If that is so, the changeover must be deferred for a time (AFIN(k)). To accomplish this, CDIR is rescheduled after a lapse of AFIN, and CHGD is zeroed so that when CDIR is next entered the change will not be further deferred. When CHGD is zero, CDIR changes INDX to be TNDX and zeroes TNDX, thus actuating the changeover. 


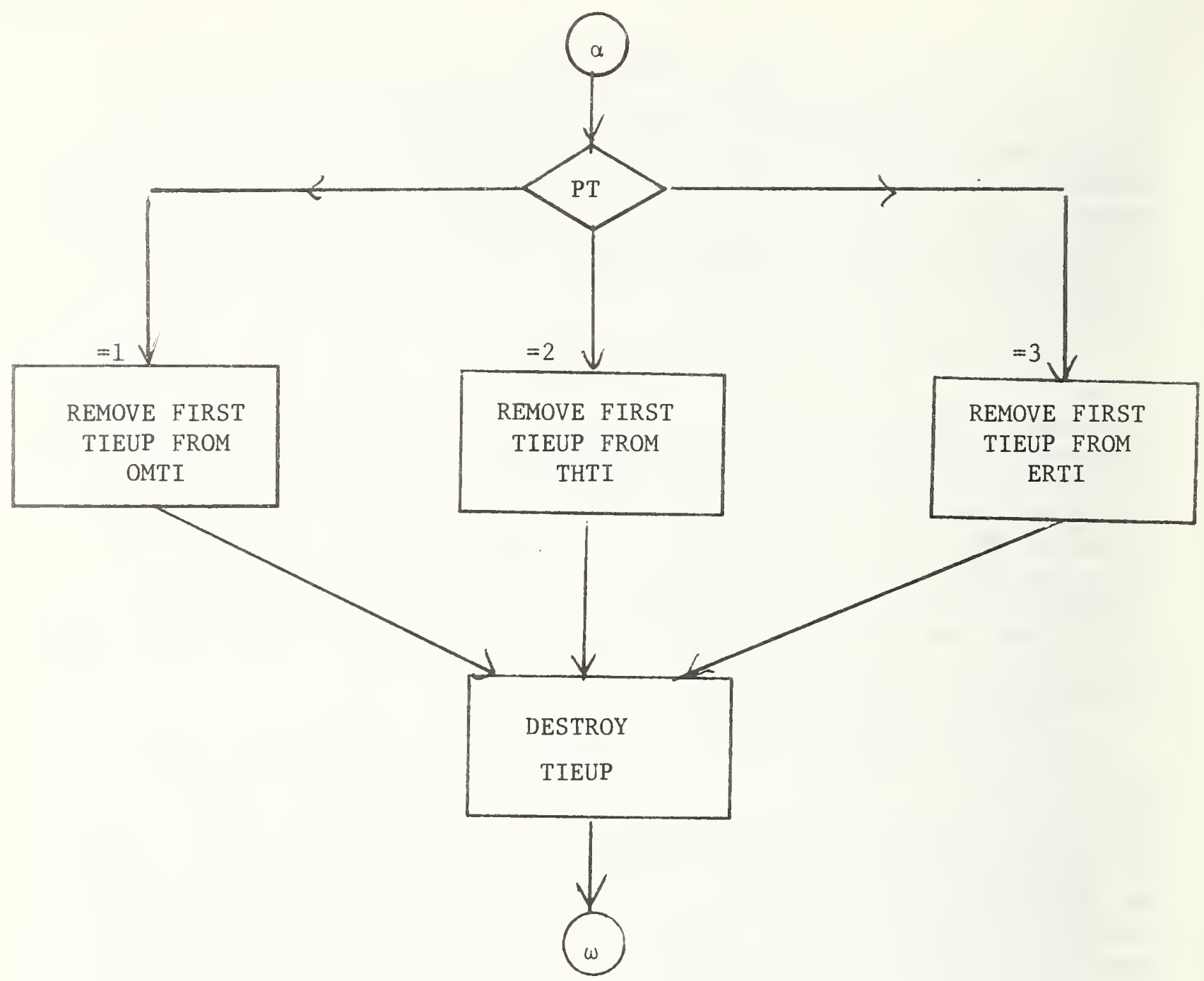

FIGURE B. 10

Flowchart of Event FTIUP 


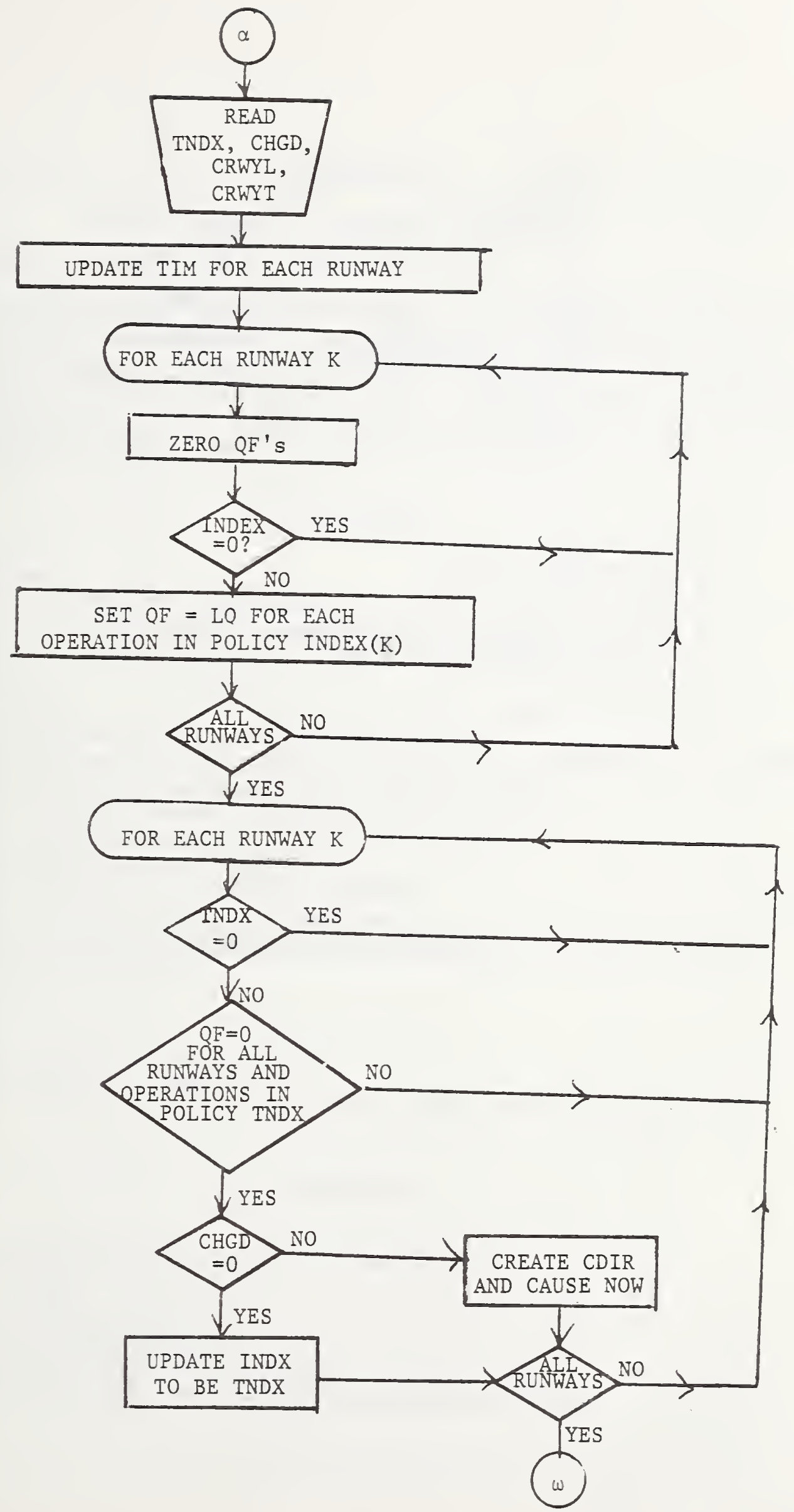

FIGURE B.11

Flowchart of Event CHGOP 


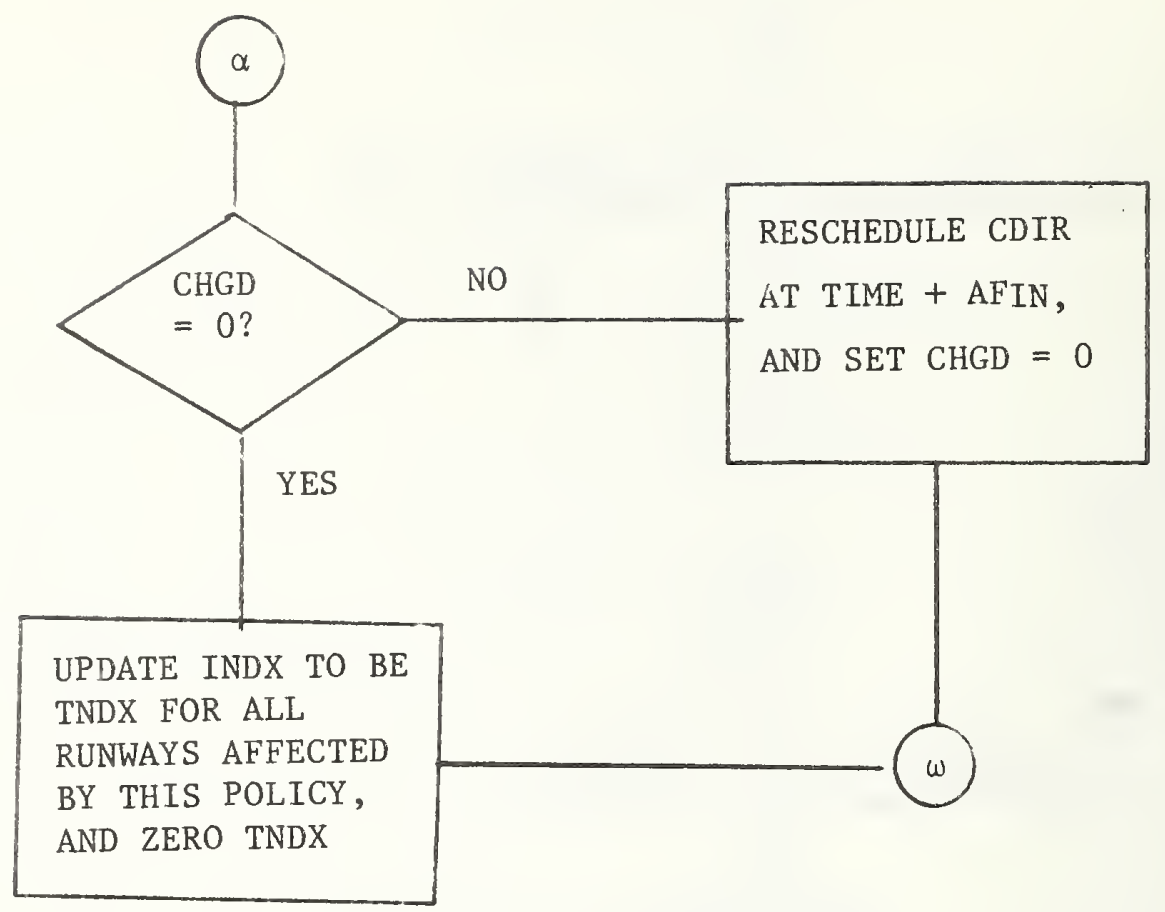

FIGURE B. 12

Flowchart of Event CDIR 


\section{APPENDIX C \\ MODEL ELEMENTS: ROUTINES, VARIABLES \\ AND ARRAYS, ENTITIES, AND SETS}

This appendix is divided into two parts. The first lists each of the model's routines, corresponding to events and functions, and provides a phrase describing what each does. The second section lists the names and descriptions of variables used in the model. The variables are listed under the SIMSCRIPT headings of: entities, arrays, attributes of event notices, temporary entities, attributes of temporary entities, and sets.

\section{C.I Routines}

Exogenous Events

1. BEGIN - starts the simulation

2. EXGEN - creates explicitly generated flights

3. CHGOP - initiates an operating policy change

Endogenous Events

1. GEN - creates flights in a Poisson manner

2. NXTOP - finds the next operation (landing or takeoff) for a runway

3. LAND - creates tieups resulting from a landing

4. TOFF - creates tieups resulting from a takeoff

5. FTIUP - destroys tieups no longer in force

6. ENDS - prints final output

7. CHOUR - updates current hour

8. PRINT - records delay and throughput

9. CDIR - accomplishes policy changes, taking into account runwaydirection changes

Functions

1. PTYPE - picks an aircraft type

2. PRWAY - picks a runway

3. FREER - finds the first time the current operation can proceed

\section{2 Variables}

Entities

1. 0 - operation (1) takeoff, (2) landing

2. $\mathrm{RW}$ - runway

3. TYP - aircraft type

4. DX - operating policy

5. H - hour

6. SLOT - positions for printing the delay profile 
Variables and Arrays

1. LAMBD(0) - Poisson distribution parameter, the average time (in hours) between operations

2. OPER(RW) - operationa1 procedure

(1) takeoffs only

(2) landings only

(3) dual use, alternate operations

(4) dual use, landings take precedence

(5) dual use, operation sequence user-provided

(6) more than one runway operated together, operation/runway sequence user-provided

3. DOM(RW) - distance from the outer marker to the runway threshold

4. NPT(RW) - greater than zero if the runway RW interferes with others

5. FLYOM(TYP) - time to fly from handoff to the outer marker

6. SQRW(DX, NSQRW(DX)) - sequence of runways used for policy DX

7. VLAND (TYP) - landing speed

8. VTOFF(TYP) - liftoff speed

9. ROTL(TYP) - runway occupancy time on landing

10. ROTT(TYP) - runway occupancy time on takeoff

11. VTAXI - turnoff speed for landings

12. DAFIX - distance from departure/arrival fix to the runway threshold

13. SEPLL (TYP $i$, TYP $_{j}$ ) - interlanding separation required between a TYP aircraft ${ }^{1}$ and ${ }^{j}$ following TYP $_{j}$ aircraft

14. SEPTL - separation required between a takeoff and following landing

15. CALIN - minimum time between the generation of a takeoff and clearance to leave its gate

16. CTYPE (0, TYPE) - cumulative distribution of aircraft mix

17. CRWYT(RW, TYP) - cumulative distribution of runway use for takeoff

18. CRWYL(RW, TYP) - cumulative distribution of runway use for landing

19. SQOP(DX, NSQOP(DX)) - operation sequence for policy DX

20. NEXT(DX) - is 0 if the next operation has not been scheduled, nonzero otherwise

21. LAST(DX) - index of latest operation used in the sequence for policy DX

22. DINT $\left(R W_{i}, R W_{j}\right)$ - distance from the end of $\mathrm{RW}_{i}$ to its intersection with $R W^{1}$

23. TPT(RW, $\left.{ }^{\mathrm{NTPT}}(\mathrm{RW})\right)$ - type of tieup caused by an operation on runway RW

(1) to maintain interlanding separation

(2) to maintain a landing separated from a preceding departure

(3) to maintain a departure separated from a following landing

(4) to maintain departure separation between completely dependent runways using the separations in SEPTT

(5) to maintain departure separation on semi-dependent runways using the separations in SEP2

(6) to maintain separation on intersecting runways

24. RPT(RW, NRPT(RW)) - runway tied up as a result of an operation on RW. Noce that RPT and TPT together describe the interference between runways; RPT tells which runway is interfered with and TPT tells how.

25. TDMIN(RW) - minimum time between a takeoff's leaving its gate and starting its roll

26. SEPTT $\left(\mathrm{TYP}_{i}, \mathrm{TYP}_{j}\right)$ - minimum time separation between a takeoff of type $\mathrm{TYP}_{i}$ and a following takeoff of $\mathrm{TYP}_{j}$ 
27. SEP2(TYP, $\left.\operatorname{TYP}_{j}\right)$ - similar to SEPTT for a takeoff on one runway following a takeoff on another runway

28. IHOUR - current hour

29. NARR(H) - number of landings generated

30. NDEP(H) - number of takeoffs generated

31. NLAND $(\mathrm{H})$ - number of landings performed

32. NTOFF(H) - number of takeoffs performed

33. DELT $(\mathrm{H})$ - total takeoff delay

34. DELL $(\mathrm{H})$ - total landing delay

35. TBEG - time the accounting for delay starts

36. TEND - time the simulation ends

37. GENN(0) - the identity of the GEN currently scheduled for operation 0

38. TDRW $(R W, 0)$ - total delay for operation type 0 on runway $R W$

39. HDRW $(R W, 0)$ - hourly delay for operation type 0 on runway $R W$

40. TNRW $(R W, 0)$ - total number of operations of type 0 on runway $R W$

41. HNRW $(R W, 0)$ - hourly number of operations of type 0 on runway $R W$

42. INITR - random number seed

43. CAP - is 0 for only throughput printout, 1 for both delay and throughput

44. $\operatorname{INDX}(\mathrm{RW})$ - policy used for runway $\mathrm{RW}$

45. TNDX(RW) - policy RW will use as soon as the changeover can be effected

46. CHGD (RW) - is 1 if the new policy for RW involved a change in direction from the previous policy, 0 if not

47. AFIN(RW) - the time required for a runway direction change

48. $\mathrm{QF}(\mathrm{RW}, 0)$ - used when a policy is being changed; is 0 if this runway can accept a new policy, and otherwise is the last FLT, in the queue for operation 0 on runway $\mathrm{RW}$, which is to occur before the policy change

49. NDLAY(H,SLOT) - the number of aircraft in hour $\mathrm{H}$ delayed between SLOT*(INC-2) and SLOT*(INC-1) minutes. (The last position contains all delayed over (NSLOT-2)*INC minutes, and the first position all occurring early or on time.)

50. INC - interval-1ength for the delay profile

51. IDT(SLOT) - daily totals of NDLAY

52. DTIM - time of latest policy change

53. TIM(RW,O) - length of time period during which runway $R W$ handled operation 0 .

Attributes of Event Notices

1. RWAY - runway

2. OP - operation

3. PT - point tied up

(1) outer marker

(2) runway threshold

(3) end of the runway

4. DLAY - delay for the current flight

Temporary Entities

1. FLT - flight

2. TIEUP 
Attributes of Temporary Entities

1. TYPE(FLT) - aircraft type

2. TIN(FLT) - first time FLT can cross outer marker or leave its gate

3. TMIN(TIEUP) - beginning of tieup interval

4. TMAX(TIEUP) - end of tieup interval

Sets

1. $Q(R W, 0)$ - landing and takeoff queues

2. OMTI(RW) - tieups in force at the outer marker

3. THTI(RW) - tieups in force at the runway threshold

4. ERTI(RW) - tieups in force at the end of the runway 


\section{APPENDIX D \\ REVISED INPUT FORMATS}

D.1 Revised Preprocessor Input Formats

\begin{tabular}{|c|c|c|c|c|}
\hline $\begin{array}{l}\text { Card } \\
\text { No. }\end{array}$ & $\begin{array}{l}\text { Column } \\
\text { Nos. }\end{array}$ & Variable & $\begin{array}{l}\text { No. Decimal } \\
\text { P1aces }\end{array}$ & $\begin{array}{l}\text { FORTRAN } \\
\text { Format }\end{array}$ \\
\hline \multirow[t]{2}{*}{1} & $1-7$ & $\begin{array}{l}\text { TBEG - beginning of } \\
\text { simulation }\end{array}$ & 2 & F7.2 \\
\hline & $8-14$ & TEND - end of simulation & 2 & F7.2 \\
\hline \multirow[t]{3}{*}{2} & $1-18$ & INPUT $(1-6), 3$ columns & - & $6 \mathrm{~A} 3$ \\
\hline & 19 & $\begin{array}{l}\text { print indicator } \\
(0=\text { throughput } \\
1=\text { both delay and } \\
\text { throughput })\end{array}$ & - & I1 \\
\hline & $20-31$ & random number seed & - & 012 \\
\hline \multicolumn{5}{|l|}{ GROUP I } \\
\hline \multirow{5}{*}{$\begin{array}{l}\text { one per } \\
\text { type }\end{array}$} & $1-3$ & number of type $(\leq 10)$ & 0 & I3 \\
\hline & $4-10$ & aver. landing speed (knots) & 2 & F7. 2 \\
\hline & $11-17$ & aver. takeoff speed (knots) & 2 & F7. 2 \\
\hline & $18-24$ & $\begin{array}{l}\text { aver. runway occupancy } \\
\text { time - landing - (seconds) }\end{array}$ & 2 & F7. 2 \\
\hline & $25-31$ & $\begin{array}{l}\text { aver. runway occupancy } \\
\text { time - takeoff - (seconds) }\end{array}$ & 2 & F7. 2 \\
\hline 非types +1 & & end-of-file & & \\
\hline 非types +2 & $1-7$ & $\begin{array}{l}\text { aver. turn-off speed, } \\
\text { a11 types }\end{array}$ & 2 & F7.2 \\
\hline
\end{tabular}




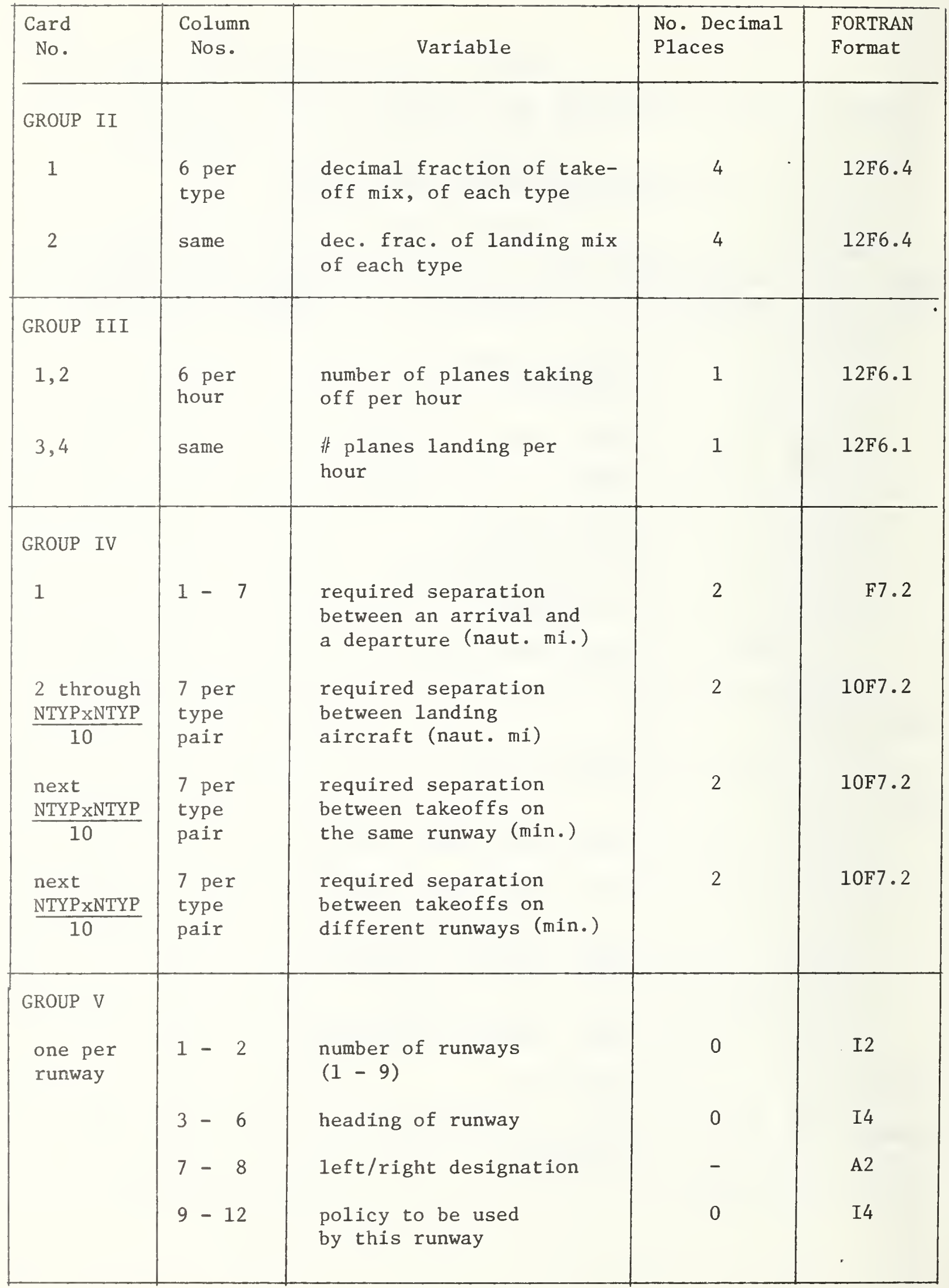




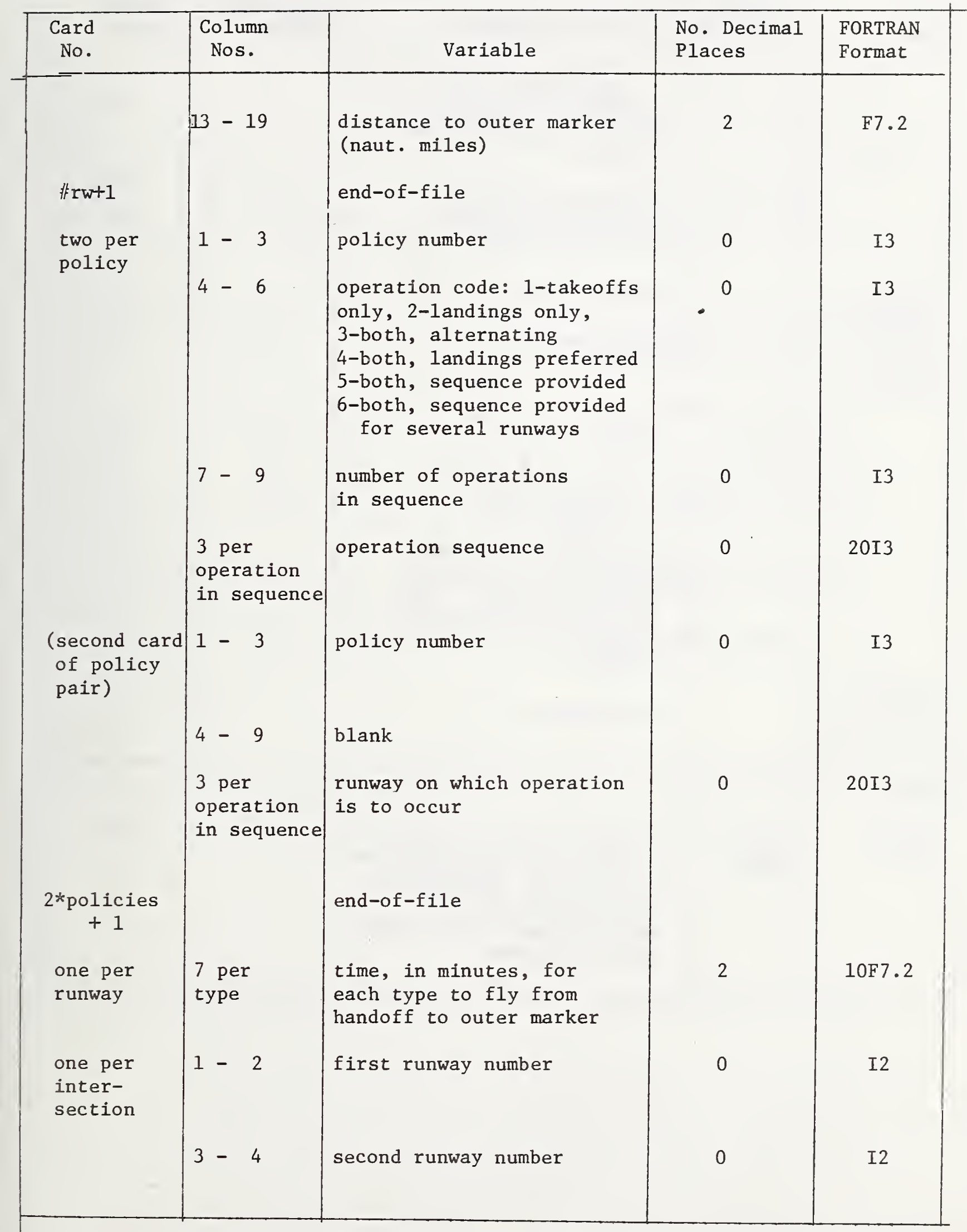




\begin{tabular}{|c|c|c|c|c|}
\hline $\begin{array}{l}\text { Card } \\
\text { Nos. }\end{array}$ & $\begin{array}{l}\text { Column } \\
\text { Nos. }\end{array}$ & Variable & $\begin{array}{l}\text { No. Decimal } \\
\text { Places }\end{array}$ & $\begin{array}{l}\text { FORTRAN } \\
\text { Format }\end{array}$ \\
\hline $\begin{array}{l}\text { 非inter- } \\
\text { sections }+1 \\
\text { one per } \\
\text { inter- } \\
\text { ference } \\
\\
\text { inter- } \\
\text { ferences }+1\end{array}$ & $\begin{array}{l}5-12 \\
3-20 \\
1-2 \\
3-4 \\
5-6\end{array}$ & $\begin{array}{l}\text { distance from end of } \\
\text { first RW to intersection } \\
\text { (feet) } \\
\text { distance from end of } \\
\text { second RW to inter- } \\
\text { section (feet) } \\
\text { end-of-file } \\
\text { first runway } \\
\text { second runway } \\
\text { interference code: } \\
1 \text { - simultaneous } \\
\text { departures } \\
\text { are permitted, given } \\
\text { divergence, but arr/arr } \\
\text { is prohibited, } 2 \text { - all } \\
\text { simultaneous operations } \\
\text { prohibited. } \\
\text { end-of-file }\end{array}$ & $\begin{array}{l}0 \\
0\end{array}$ & $\begin{array}{l}\text { F8.0 } \\
\text { F8. } 0\end{array}$ \\
\hline $\begin{array}{l}\text { GROUP VI } \\
\text { one per } \\
\text { type }\end{array}$ & $\begin{array}{l}6 \text { per } \\
\text { runway }\end{array}$ & $\begin{array}{l}\text { decimal fraction of all } \\
\text { takeoffs of type which use } \\
\text { each runway, followed by } \\
\text { decimal fraction of } \\
\text { all landings of type which } \\
\text { use each runway }\end{array}$ & 4 & $12 \mathrm{~F} 6.4$ \\
\hline
\end{tabular}




\section{D.2 Revised Input Formats for Exogenous Events}

\section{D.2.1 FLIGHT GENERATION}

\begin{tabular}{|c|c|c|}
\hline $\begin{array}{c}\text { CARD } \\
\text { No. }\end{array}$ & COLUMNS & CONTAIN \\
\hline 1 & $\begin{array}{r}3 \\
6-7 \\
9-10 \\
11-12 \\
13-14 \\
15-16 \\
17-18\end{array}$ & $\begin{array}{l}\text { the number } 2 \\
\text { the hour the flight enters } \\
\text { the system } \\
\text { the minute of that hour } \\
\text { the second of that minute } \\
1 \text { if flight is a takeoff, } \\
2 \text { if a landing } \\
\text { the runway to be used by } \\
\text { this flight } \\
\text { the aircraft type for this } \\
\text { flight }\end{array}$ \\
\hline
\end{tabular}




\section{D.2.2 POLICY CHANGE}

\begin{tabular}{|c|c|c|}
\hline $\begin{array}{c}\text { CARD } \\
\text { NO. }\end{array}$ & COLUMNS & CONTAIN \\
\hline 1 & $\begin{array}{r}3 \\
6-7 \\
9-10 \\
11-12\end{array}$ & $\begin{array}{l}\text { the number } 3 \\
\text { the hour the policy change } \\
\text { is to be initiated } \\
\text { the minute of that hour } \\
\text { the second of that minute }\end{array}$ \\
\hline $\begin{array}{l}\text { for each } \\
\text { runway }\end{array}$ & $\begin{array}{l}3-4 \\
5-6\end{array}$ & $\begin{array}{l}\text { new policy number to be used } \\
1 \text { if the runway direction is } \\
\text { changed, } 0 \text { otherwise }\end{array}$ \\
\hline $\begin{array}{l}\text { for each } \\
\text { runway } \\
\text { and type }\end{array}$ & $\begin{array}{l}5-11 \\
(4 \text { decimal places }) \\
12-18\end{array}$ & $\begin{array}{l}\text { CRWYT } \\
\text { CRWYL }\end{array}$ \\
\hline
\end{tabular}




\section{PROGRAM LISTINGS}

\section{E.1 Listing of the Preprocessor}

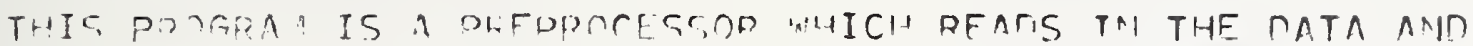
FUTC IT TATR PROPFR FOP. FAT IISE BY THE STMII.ATION PROGRAM.

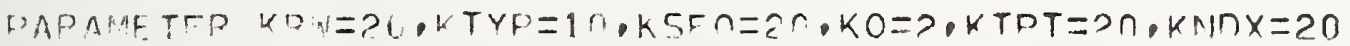

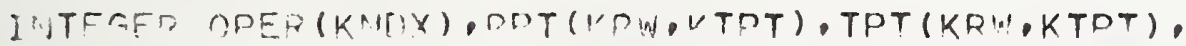

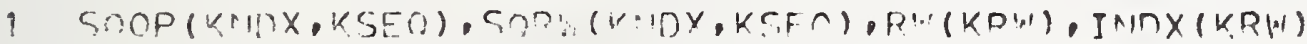

EAL L I IRI) (KO, 24)

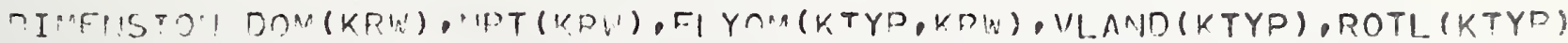

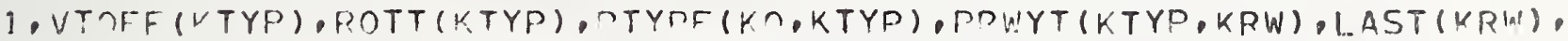

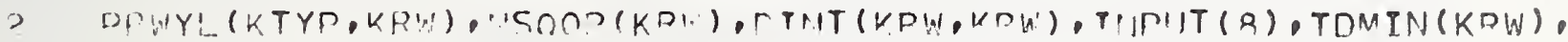

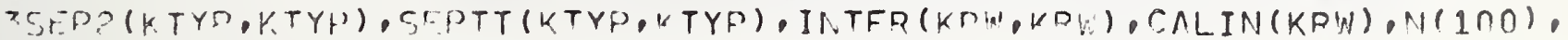

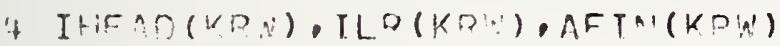

'I WFI:STA:" GFPLL (HYP,VTYP)

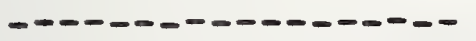

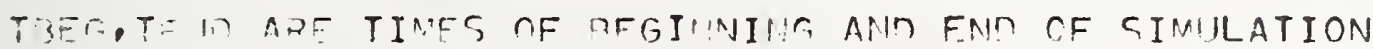

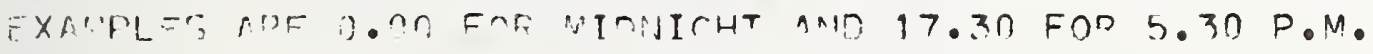

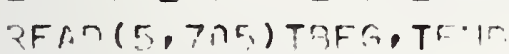

$7 \cap 5$ FOUAT (1กF7.?)

IRTTE $(6,5, n)$ THFG. TFH In

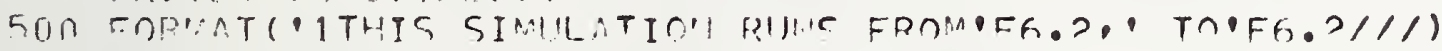

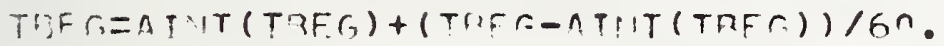

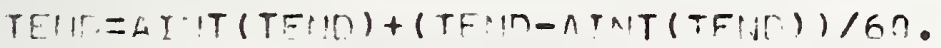

TF (TPES.GT. . . ) Gí Tr 1

Ti2f R:=Tr.rst?

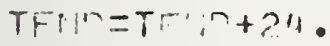

1 IF $(T F: . I F \cdot T F(3)$ TFM $=T F N T+24$.

Iisf $r=T r r-1$.

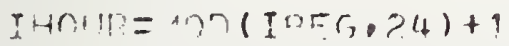

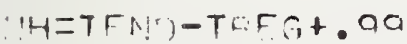

$\because 1)=-1$

IF $($ H.t. T. T. 24) GO Th?

$I I=1$.

$J J=24$

SO Tí. 't

$I I=T+i r i\}$

$I F I: U=T E \cdot 17-)$.

$J J=N \cap T(T F M, 24)+1$

IF (JU.LT.TT) :Ir, $=1,1$

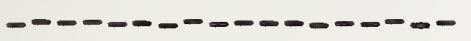

INPITIT) - LFAVE ILAK TF TTH DATA GROIP WTII RF SIPPI.IET BY USER AMYTHTINE, FLGT TLL CALIGE PPOGDAN TO SIIPPLY STANIDARD DATA

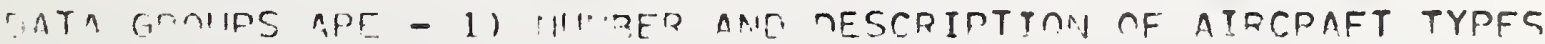
2) ATV OF ATPERAFT TYPFS

2) LAMIIIS AAIO TAKFOFF DATFS, RY HOUR

14) SFIARATTOI DEQ!ITRFMFPTTC 
5) DESCRIPTION OF AIRPORT AND ITS OPERATION

6) FRACTIOM OF TYDFS IISING EACH RUNWAY AND DFPARTURE PATH

TCAP - FLAG $115 E D$ TO CONTROL PRINTINA OF MELAY OUTPUT ( 0 = ONLY THOOUGHPUT, 1 = BOTH THROIGHPIST AND DELAY)

INITR - IHITIAL RANIOAM MIMPER SFFD (12 OCTAL DIGITS)

PEAT $(5,730)$ (INPUTT (T), T $=1,6)$, ICAP, TN!TTP

FORMAT $(6 A 3,11.01 ?)$

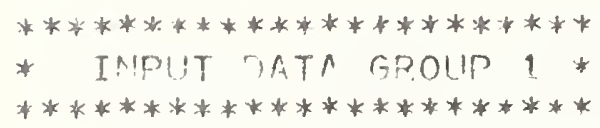

ITYPF - IIMCZFP OF TVPFS

UTOFF(I) - TAKFOFF SPFFM OF TYPF I, IN KNOTS

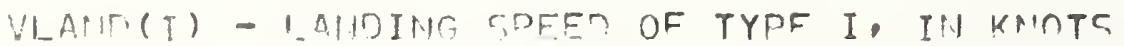

?OTI (I) - RIJNWAY NCCIPAIICY TIMF OI I ANIDINGS FOR TYPE I, IN SFCONAS

DOTT (I) - SAME FOF TAKEOFFS

VTAXI - AVERAGE TIIRMOOFF SPEFI FOR ALL. TYDES

\section{IF (TUPHT (1).EO. U) GO TO $=$}

STAMIAPT TYPF INPUT: TYPE, - HFAVV AIRCPAFT

TYDE ? - SAALL PROP ATRCRAFT

TYPE $\approx-$ CATEAORY $\cap=5$

TATA FUD" VALIIES ORTATNED AT JFY

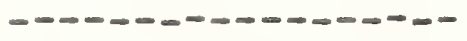

MATA ITYOE/Z/VTAXT/2O./

IATA (UAM (I), VTOFE (T), DOT! (I),DOTT (I), T=1,3)/

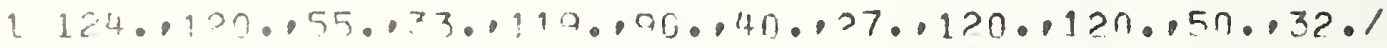

(6) 10.97

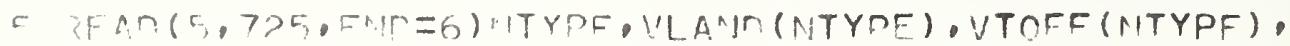

1

725 FURPAT ( $23.457 . ?)$

sin $\tan r$

6 WEAD(E, TOF) VTAXI

iी $7 \quad I=1$. ITYPE

OTI. (I) = POTL (I) / 36n?.

7 : $: 0 T T(I)=\cap O T T(I) / 3 F n r$.

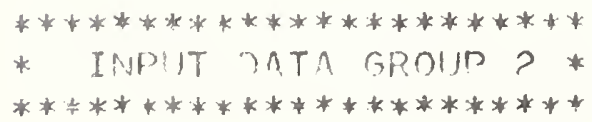

PTYPF (1.I) - THF FDACYIOA: OF TOTAL TAKEOFFS WHICL ARE OF TYPF I

PTYPF (?.T) - SAME FOD LAMDINIGS

IF (IS:P!IT(') . FO. 1) GO TO 15

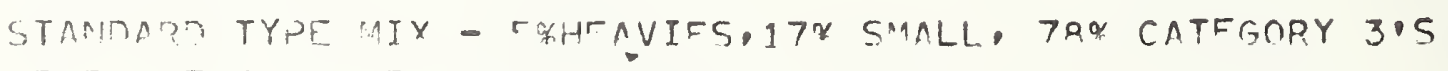

DATA $((D T Y P=(I, J), J=1,3), I=1.2) / .05 \cdot .22 .1 .0 .05 \cdot .22 .1 .0 /$

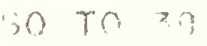

15, 10 16: $r=1, \hat{\imath}$

KEAD $(5,710)(D T Y P F(Y, 1), . J=1$, P!TYPE) 
II FOFMAT (1?F5.4)

1E CORTINUIF

DO $25 \quad I=1,2$

120 20 J

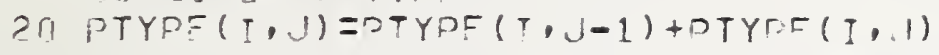

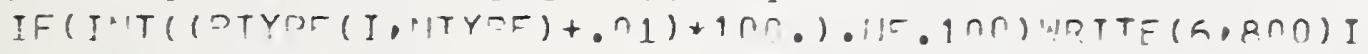

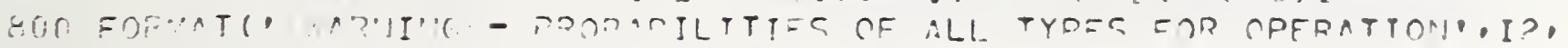

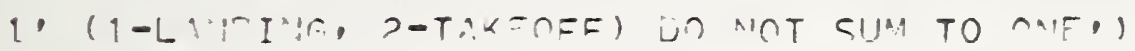

25 CO:ITI::IE

* IIIPI!T TATL GPOUP $3 *$

$* * * * * * * * * * * * * * * * * * *+* * *$

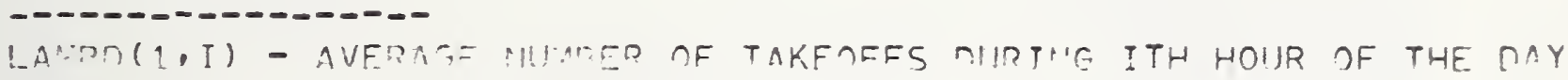

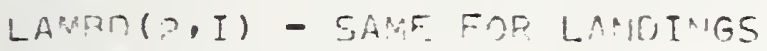

30 IF (T'PPIT (3).5O, 1) GO TO Z5

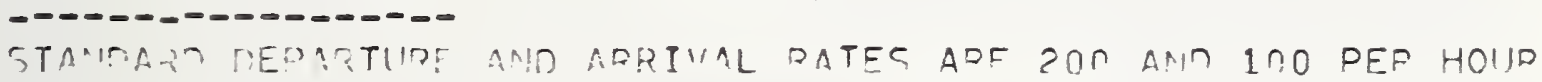

PFGPFCTTYELY (FO2, IGF TM CARACTTY DIINS)

$9021 \quad r=1,24$

$\operatorname{Lin}(1, I)=1.1200$.

$\operatorname{LA} \cos (2, I)=1 \cdot \cos \left(r_{1}\right.$

31 COP:T1,1:-

CIO TO : ?

35 If (ni . GT. . I) Gn TO 2 ?

20 36, $I=1$, ?

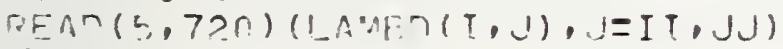

720 FOPA $⿻$ T (12F6.1)

20 $25 \quad 1=1,214$

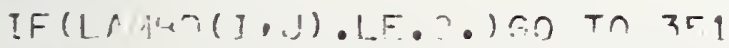

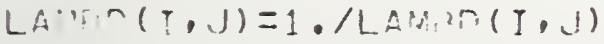

CO TO

$\therefore 2,1$ LA $(T, 1)=0.000$

za CONT II!!I=

co Tr in

2.7 190 $20 \quad T=1$, ?

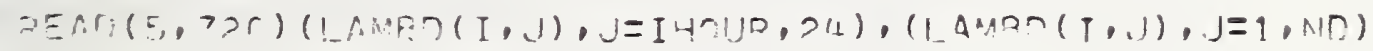

ro $30 . j=1,214$

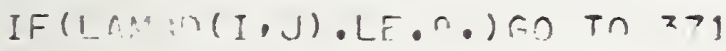

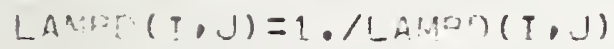

go To to

Z71 LANTR $(T, 1)=3.999$

$32^{2}$ COITIHIE

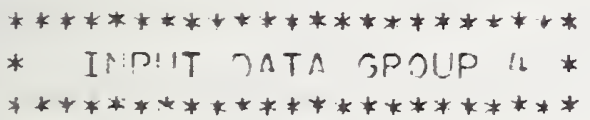

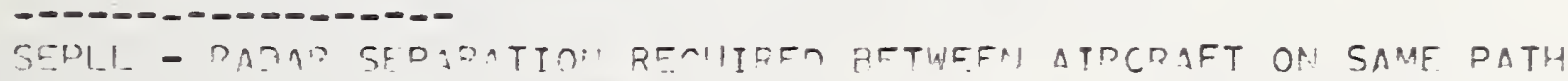

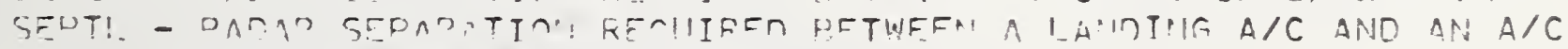

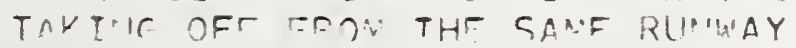

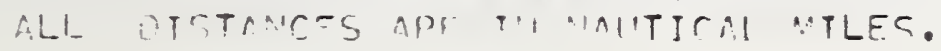


SEP? - TIME SEPARATION DEOIIPER BETEEFM! AIPCRAFT DEPARTTNG ON NIFFFPFIT DIIHIMYYS

40 IF (THPIT(14).FO." ") GO TO 45

DAFT $X=4$.

- - - - - - - - - - - - - -

STAMDADT SEPAPATIOR. TFAITREMENTC

SEPTL $=?$.

$5041 \quad 1=1.4$ TYPE.

SEUI_I. $(1,1)=5$.

TO $111=2, R, T Y P E$

SEPLI $(I \cdot U)=3$.

SEN! $1,(1,1)=i t$.

$7014 \mathrm{C} \quad \mathrm{T}=1$, 1 TYPF

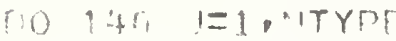

SEPTT $(T, J)=30.13630 .+P \cap T T(T)$

$14: 0$

JEP $P(I, U)=D 2 T T(I)$

in $14 \cdot 11,1=?$, ITYFF

141

SFPTT $(1,1)=2 . / 6 R \cdot+20 T T(1)$

SEHTT $(9,1)=? \cdot 161$.

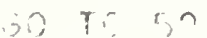

PEAR: $(9,7 \cap 5)$ T,FRTI

KEFAO $(5,7 \cap 5) \quad((C, E T) L(I, J) \cdot I=1$, P TYPE $), J=1,0.1 T Y P E)$

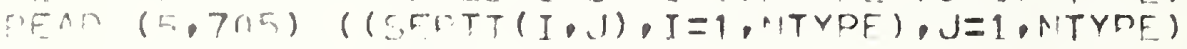

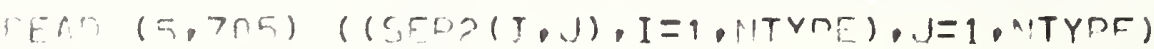

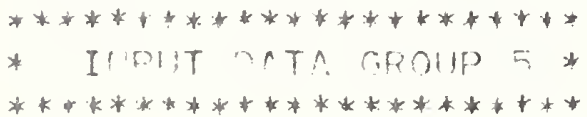

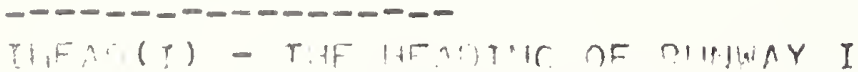

ILO(P) - FO? PAIAILFL DINWAYC, THE I.FFT OP DPGHT DFSIGNATION

FOR :

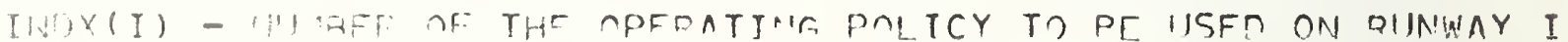

MPFP( (I) - NDFBATIAS COCF FOR POLTCY MIIMAFE .I

SOYP(U,") - SFIJIF CE OF APFPATIDUS TOR DALISY J 1 = TAKFOFF. $?=$ LAMUI). THF SFOIFICF IS DFPFATFO OVER ANI OVFR.

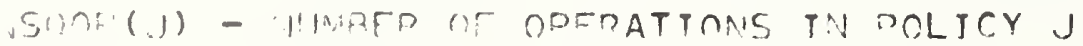

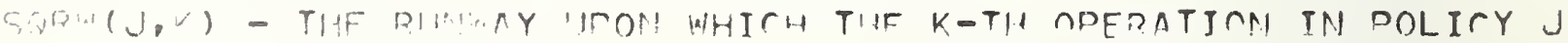
is To ñCUP.

COMES, AOF 1- TAKFCFF, MILY, ?- LAAIINGS MNLY

3-MIIAL I'SE, MLTTPNATTNG NPFRATIONS

I- IIIAL IISF, I ANחTWEC TAKF PRFCFDENCE

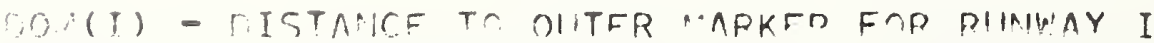

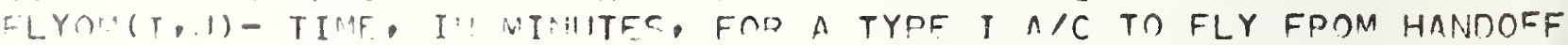
TO OIITFE MAPKFR OF DU:AMY J

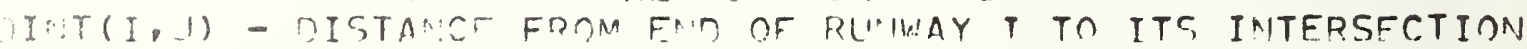
WITHI OI1 'SAY Je TM! FFFT

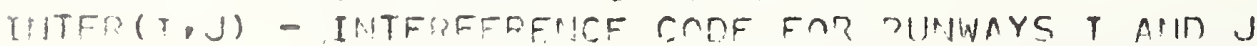
COIJFS IPF 1-1 AAMTMIRS MAI T AUI J JMITFRFFPF AND "UST MF SFPADATFN, RIJT SIMIULTANFOIS

TAKFAFFS ARF DFPATTTEN IF THFY DIVERGF. D- MI STMALTANFNI! ONEPATIONS PFRMITTFN

IF IF THFD, COMPLFTE IMAFPFMCFMCE IS ASSUMFN. 
50 IF(I IPUIT(5).FO.' 1) SO TO $=5$

STADOARA MATA IS FOO SIUELE RUMMAY WITH ALTFDINATING OPERATIONS

- - - - - - - - - - - - - -

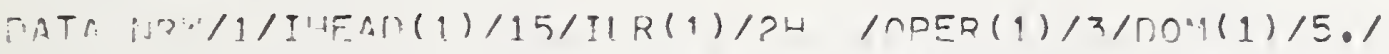

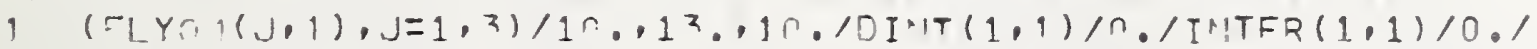

?. $: I ! / 2 /(\operatorname{son}(1, I), T=1,1 \cap) / 9,2,0 * 0 /(5 Q R \operatorname{lo}(1, T), I=1,10) / 1,1,8 * n /$

$3 \quad$ I $\cap C T(1) / 1 /[1,7 \times(1) / 1 / \cdots n \times / 1 /$

go to i?

$55 \quad \therefore+2 y=n$

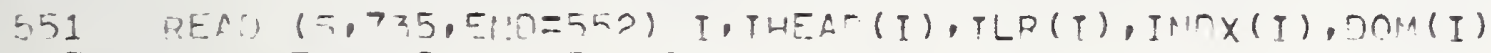

735 FOPI:A T? T? $4, A ?, I 4, F 7.2)$

$\because R:=1.1 F:+1$

50 Tr 5.51

$552 \quad: 0553 \quad I=1,<\cdot 1[X$

$\operatorname{LAST}(I)=1$

JPFP(I) =?

iैivi $x=\mathrm{l}$

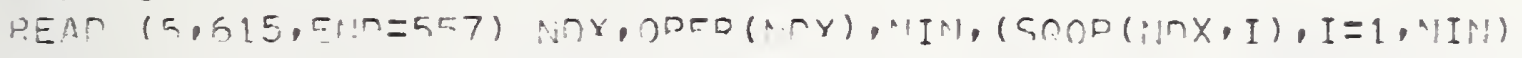

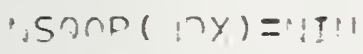

LOR:T $(2313)$

PEAr: $(5,516) \quad(\operatorname{Son}:(\sin x, T), I=1,:: 1 \times 1)$

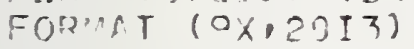

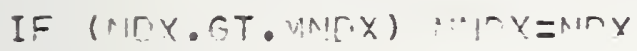

sO Tก 5,54

557 30 5.56 $k=1$, "iph

$I=I \ln x(k)$

IF $(I . F), n)$ GO TO 556

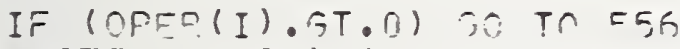

-RITF $(6,50) \quad I,$,

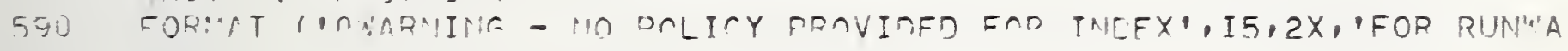
$1 Y, I$ ( I)

556

COP:TIN:T

SO $55 \quad T=1$. MR:

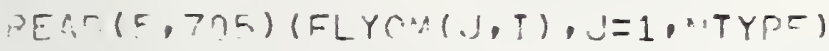

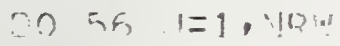

$[I, I T(I, J)=0$.

IISTFE: $(T, J)=3$.

5r, COP TI!.:

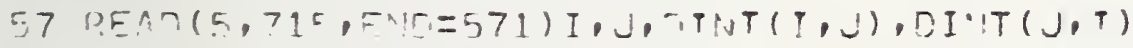

715 FODN1T( T?, 2ER, (:)

S? Tก 57

571 KEA[; $(5,7 ? \cap, F ! J=570) !$ J THTFQ(I, J)

7กח FORAMT(1)I?)

(5) TC 5,71

572 ก0 $50 \quad T=1, ? \cdot 101.1$

กO $58 \quad 1=1$. NTYPE

5a FLYO: (J,I) =FLYGM(J,I)/5?.

$505,0 \quad J=1, A ! 0,0$

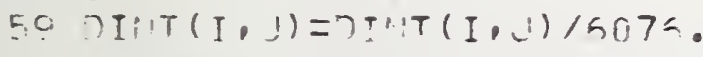

: 10 GO $i=1,1.10 \cdot 1$

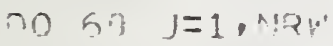

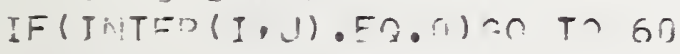

I'ITFD ( I, I ) =T:TEP $(T, 1)$

60 COITI:1:-

fo or. $I=1,1 ! \mathrm{g}:$

$\alpha=r$.

in $x=1, x=1, \ln$ 
IF(INTFR $(I, U)$ EOO.ก)GO TO 80

$I I=I N ! n \times(I)$

II $=4$

IF (I1.NF.0) II TOPFR (I1)

$J 1=I N ! D \times(J)$

$J J=4$

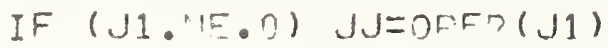

IF (TI.LT.2.2K.U.LT.?) 60 Tก 65

$k=k+1$

PPT $\left(T_{0}:<\right)=J$

$T P T(I \circ K)=1$

65

IF (II.F.O.2.OP.JJ.F..?) 50 TO 70

$k=k+1$

$\operatorname{PPT}\left(T_{0}: K\right)=J$

TPT $\left(I_{0}, P\right)=4$

IF (INTTF? $(T, 1) \cdot F \cap, 1) T D T(T, K)=5$

70 IF (II.rn.2.OP.UJ.FA.1) s0 TO 75

$k=k+?$

$\operatorname{RPT}(\mathrm{T}, \mathrm{PP})=\mathrm{J}$

$\operatorname{TPT}(T, Y)=3$

75 IF (II.F..1.OR.JU.F..2) s0 to Bn

$K=K+1$

$\operatorname{RPT}(T, K)=J$

$\operatorname{TPT}(I, /)=$ ?

AO CONTINIE.

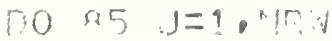

IF (OTM (T.J) .LE.0.) SO TO 85

$x=r+1$

$R P T(I, k)=J$

$\operatorname{TPT}(T, M)=h$

2.5 COATIHII

$\operatorname{PPT}(I)=K$

$k=k+1$

r.o $26:=k, k$, Thy

DPT $\left(T_{0}:\right)=6$

$\operatorname{TPT}(T, 1)=0$

se COPTIPU:

$90 \operatorname{con} 1 T T N 1=$

C

C.

$* * * * * * * * * * * * * * * * * * * * * * *$
$*$ IIDUT กАTA GROUP 万*
$* * * * * * * * * * * * * * * * * * * * * * *$

C

$* * * * * * * * * * * * * * * * * * * * * \star$

-

PRINYT(I.J) - THE FRACTIOM OF ALL TAKEDFFS DF TYPE I A/C AHICH ISF PII!!'WY J

PRIAYL $(T, 1)$ - THE SAME FOP LMADINGS

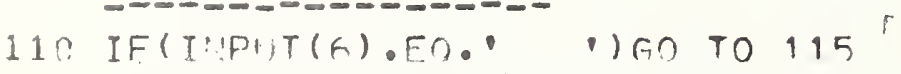

STAMDADT DUNWAY ISSARE HAS MIL ITDCRAFT OPFRATIONS ON RUAWAY 1

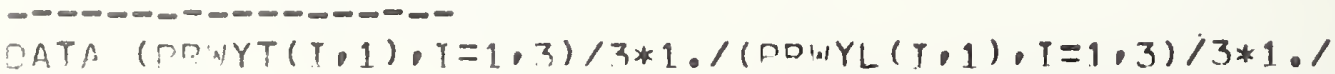

GO TC 115

$115: 10120 \quad 1=1.1 T Y$ TPE.

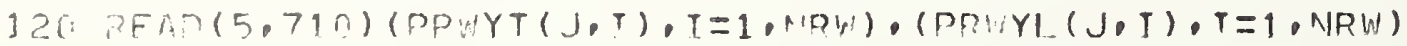

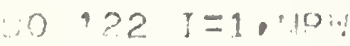

$T 1=T \cdot(Y Y(T)$ 
$1 J=1, \cap T Y P F)$

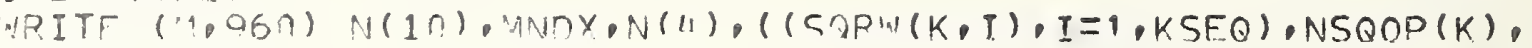

$1 \quad k=1, \sin (7 x)$

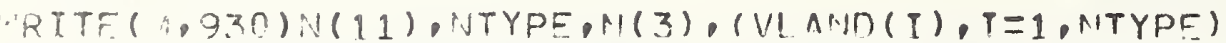

WRITE $(1,030)$ M (12), NTYPE, M( 3$),(V T \cap F F(I), I=1, N T Y P E)$

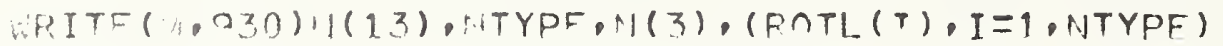

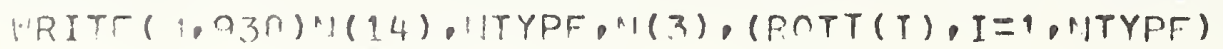

VRTF $(, 910) N(15), V T A X T$

RIT' $(1,919) 11(16) \cdot 11(2)$

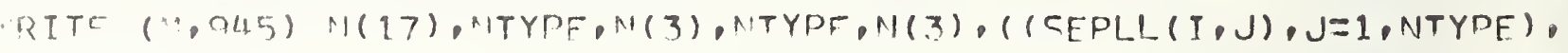
$T=1,(T Y P E)$

ARITF(:.910)N(19), TEFTL

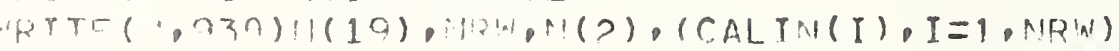

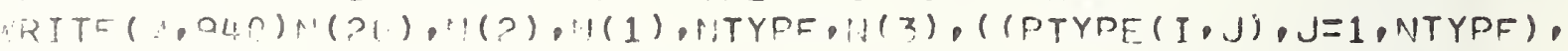

$1:=1 \cdot 21$

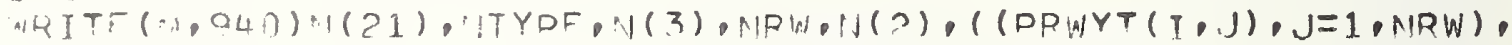

$1[=1, \cdot(T Y \cap))$

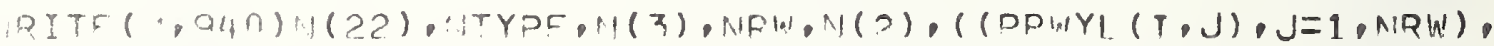

$11=1 .(T Y U E)$

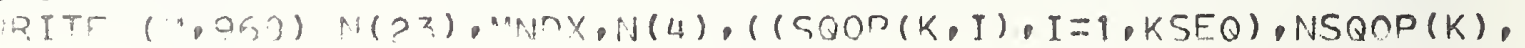

$1 \quad k=1, \ldots \ln (x)$

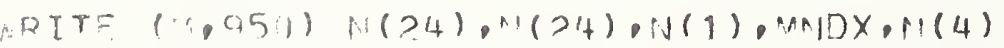

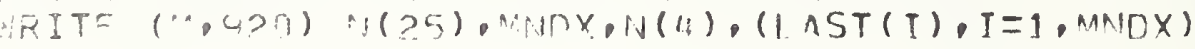

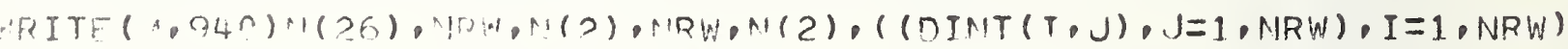

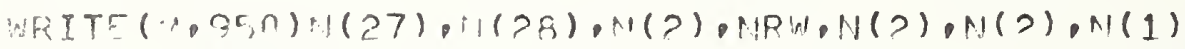

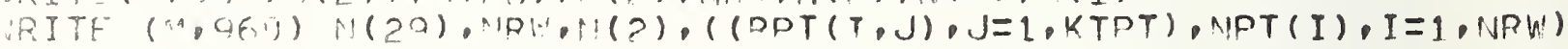

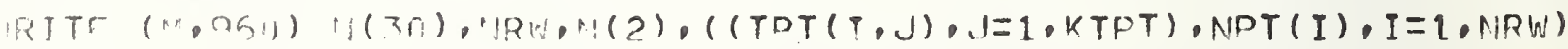

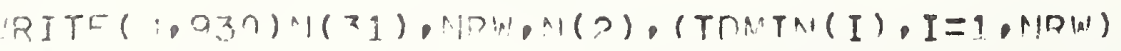

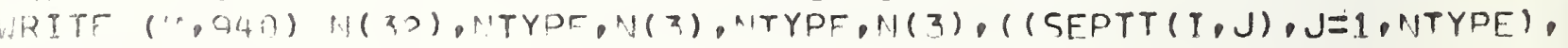

1. $I=1,(T Y P F)$

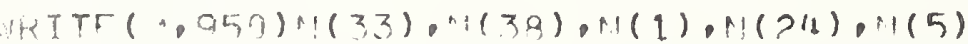

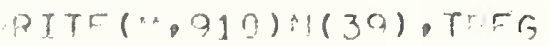

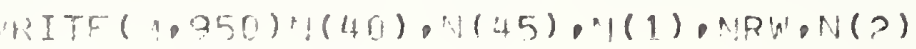

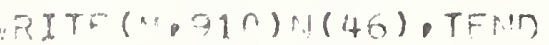

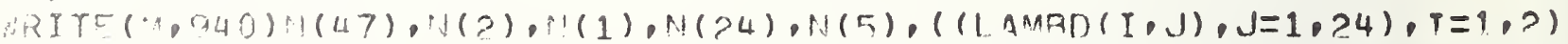

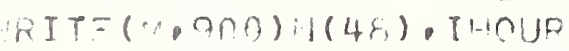

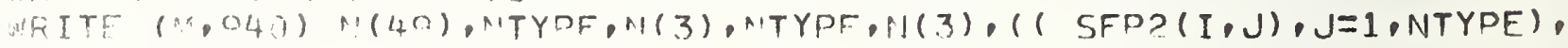
$1 \quad I=1, \cdots Y Y P E)$

ARTTF $(4,050)$ V $(50), 3(50), M(1), n(?), N(1)$

WRITT $(1,959) \quad M(51), 1(54), N(2), A P W \cdot M(2), M(2), N(1)$

URTTF (1,055) N!(55), INTTP

PITF $(", 90)$.$) N(55), TCAD$

URITE (

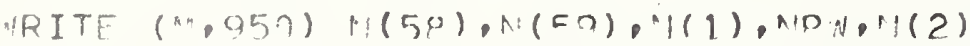

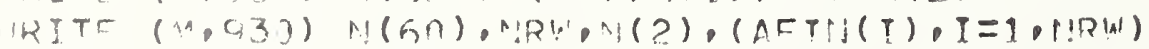

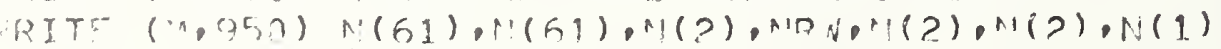

WiRITR (1.900) N(62) , ! (111)

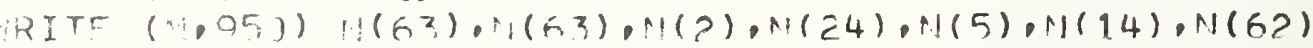

URTT (".,917) N(164), VINC.

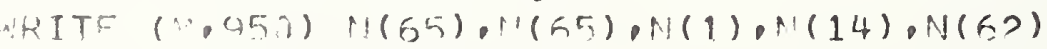

WRITF (", 910$) \quad 11(65)$, TPES,

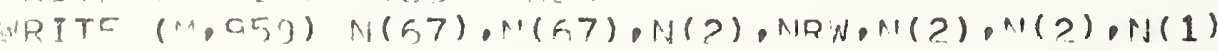

WRITE $(\cdots, 070)$

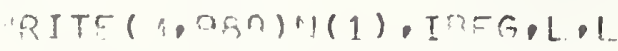

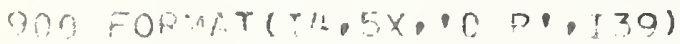

a

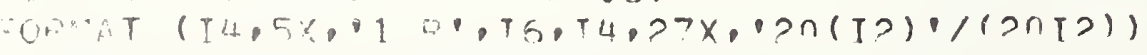

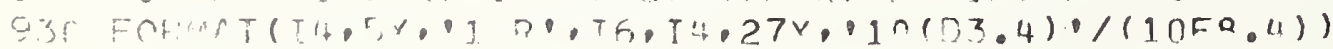




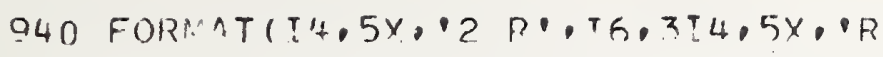

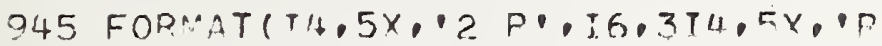

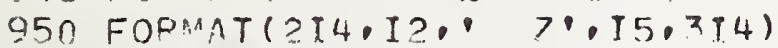

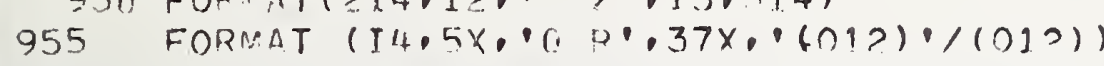

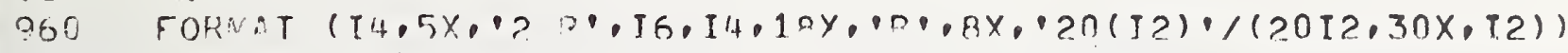

970 FORNAT(', )

C
C
C
C
C

gan FOFMAT(T3, [1, I3, T?)

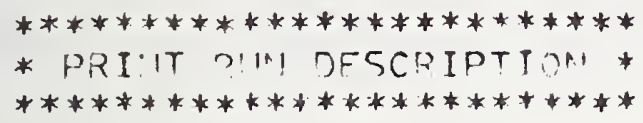

. Kर ITF $(6,5,5)$

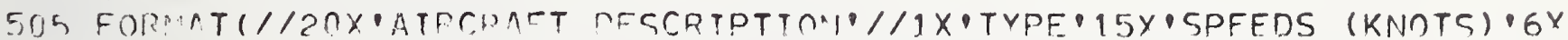

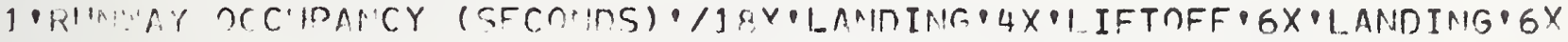

PTAKFOEF / / )

CO $1 \mathrm{FG} \quad \mathrm{T}=1$, MTYPF

QROTL=2רTL $(Y) * 36 ? \%$.

FROTT=२TTT $(I) * 3600$.

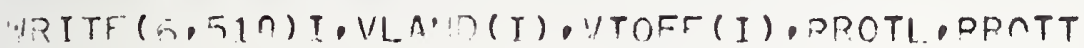

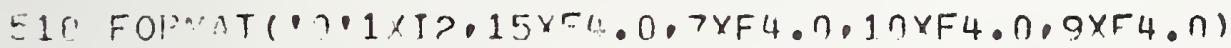

160 CONTIN, IT

WRTF $(F, 511)$

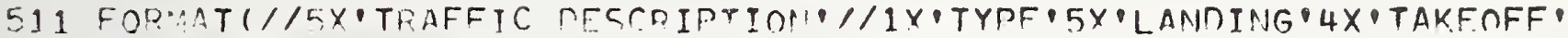

$1 / 12 \times \cdot M Y P X \cdot 1 X \cdot / /)$

$A=P T Y P T(? .1) * 9 \Gamma 0$.

$B=P T Y P E(1,1) * 1 \cap 0$

URTTF $(\kappa, 515) 川(1), n, \pi$

515 FORMAT $(? \times I 2.2(7 \times F \| . n) /)$

$10165 \quad I=2 \cdot ! ! T Y D F$

$n=($ OTYOE $(?, T)-P T Y P F(2, I-1)) * 1 \cap n$.

P=(DTYDR (1. I)-DTYMF (1.I-1) $* 10 n$.

URTTE $(5,515)$ I.A.A

16, COMTI:H!)

.RTTF(f, 5? )

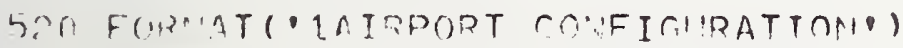

PTT: $(\because, 5,5,5) ! 1 !)$ in

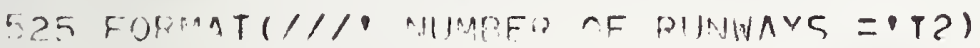

$10190 \quad r=1.10 \mathrm{~m}:$

$I=I ! D \times(T)$

IF $(I I$.$) ? n$

$J=n P F . R(I T)$

G) TO $\left(17 n \cdot 175 \cdot 19 A_{1}, 95.186,196\right) \cdot 1$

170 IRITF $(6,53 \cap)$ I. JWFAD(I), TL.R (T)

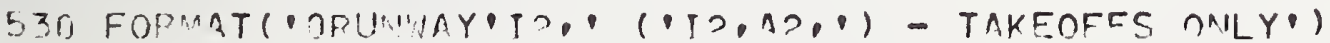

G) Tก 197

175, URITF $(5,535)$ I. IHFAn(I):TIR (T)

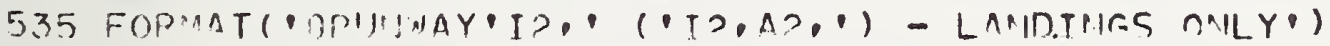

50 TO 100

IRS: $1: R I T E(G, 5 \& \cap) I, I H F \cap D(T), T L R(T)$

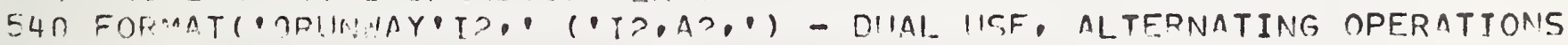
1.)

so $T O 1,20$

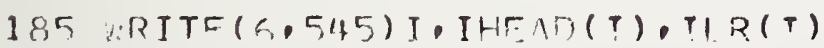

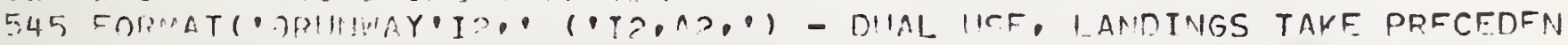
$1(F$,

rin $\operatorname{tol} 1 \operatorname{lin}$

$196 \quad$ : [1! = $(5) \cap 6(T:)$ 
DO $189 \mathrm{~J}=1$. WIN

$J J=5000(I I, J)$

GO TO $(107.188)$. JJ

187

SROP $(I I, J)=$ "REPART'

SO TO 130

$1385,5 Q O D(I T, J)=$ ARRIVF-

189 CONTIM!IF

IF (OPFI (II) . GT.5) in $T \cap 191$

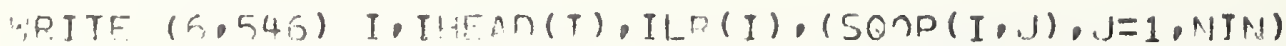

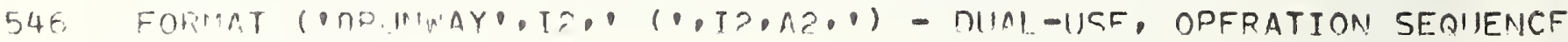
$1-\operatorname{lo}(2 \times, 10(A,, L X)))$

(i) in 1 in

$191 \quad 1 I^{1}=0$

$70134 \quad 1=1,111 ! !$

IF $(5,6 ? \cdot(I I, J)$. EO. I) GO TO 104

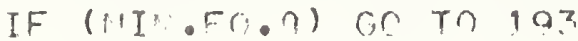

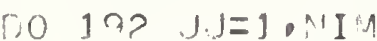

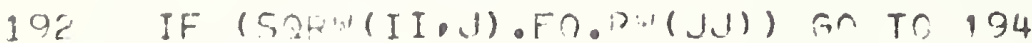

193 मI $n=! I I n+1$

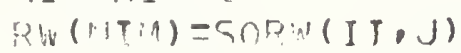

194 CONTINHI:

IF $(N I * .5 T \cdot 0)$ an Tn 136

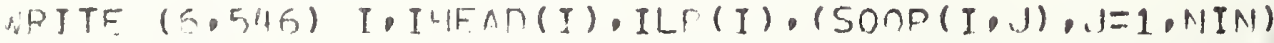

SO T? 10 ?

136 URITE $(5,547)$ I,THFAM(T),ILD(T), (RW (J),JEI,NTM)

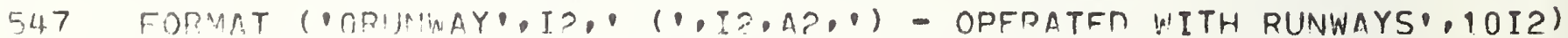

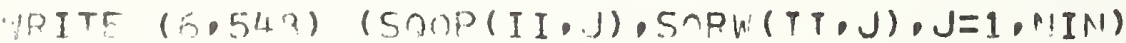

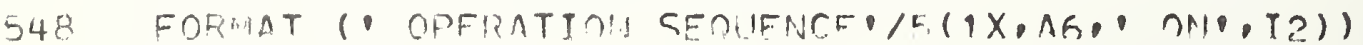

$11013\{\quad J=1$, MIN

TF $(S O A N(I I, J)$. FO. ARRTYFO $) \operatorname{SOOF}(I I, J)=$ ?

199 IF $(S C O D(I I, J) \cdot E R$ ONFPART? $\operatorname{SOCD}(I I, J)=1$

C) 10100

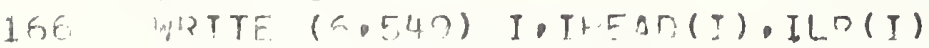

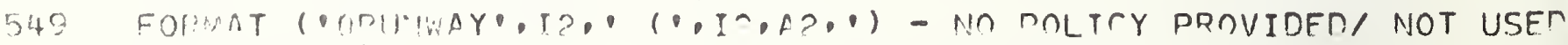
1 INITTALI.YU

$100 \operatorname{con} 1 \mathrm{THN}$

$90105 \quad r=1 \cdot 12$.

$100105 \quad J=1 \cdot \cdot 10$,

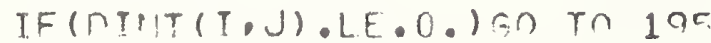

$A=D \operatorname{INT}(T, J) * 6076$.

$B=D T H(1, I) * 6076$.

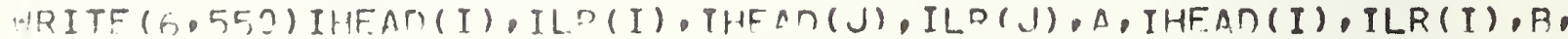

$1 \operatorname{IHE} A \cap(, 1), \operatorname{IL}(\mathrm{H})$

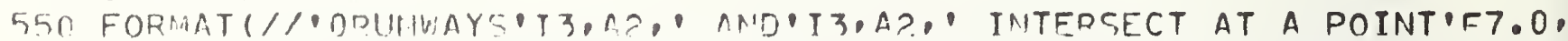

1. FFET EFOM THE./ FIIO OF RIIMIAYII,A2, ANMIF7.0, FEET FROM THF

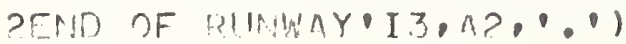

195 COI!T JPHIF

I I $=\ln \ln -1$.

ro $215 \quad T=1, I I$

$\mathrm{J} J=\mathrm{J}+1$

$10 ? 15 \quad 1=J J \cdot$ NP:A

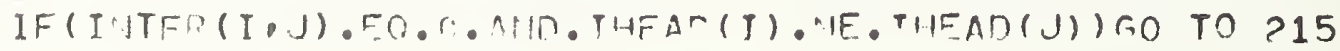

$L=J ! T F R([, J)+1$

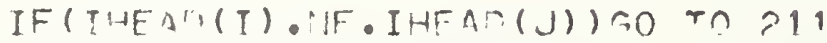

SO TO(20). $2(15,210) \cdot 1$

$20 \Gamma_{\text {NRITR }}(5,555)$ IHFAT(I) OIL?(I), IHFAN(J),ILP(J)

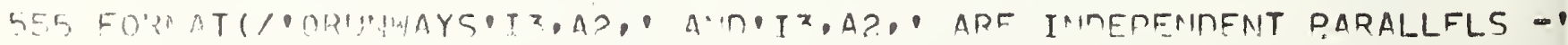

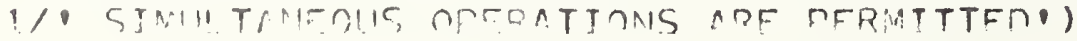


60 Tก 215

205 IRITE $(5,560)$ THEAD (I), ILD(I), THFAN (J), ILP(J)

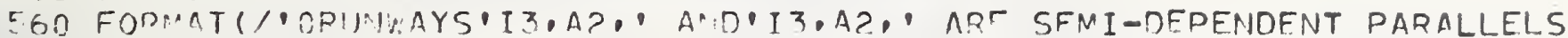

$1-1 /$ ST NULTAMEOIJ; ADRTVALS APF DROHIRITFMP)

SO TO 215

210 MRITF(

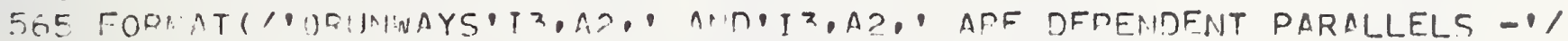

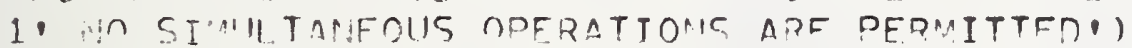

,0 TO

211 GO. TO $=15,212,213) \cdot 1$

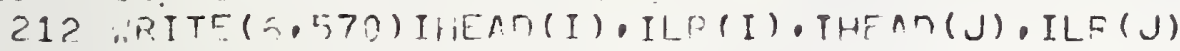

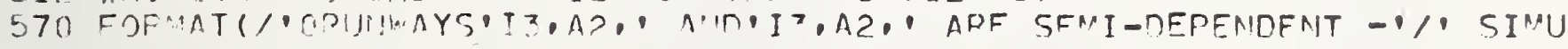
ILTMIEOIS ARRTVALS AOF OOAHTOTTEO')

Go t? $P: 5$

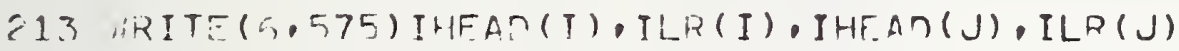

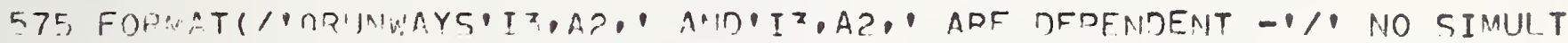
I LNE (UIS TPERATIO!IS ALF PFRMITTE[:")

2.15 (1)I!TIII:

ro

$J=\wedge \operatorname{lsin}$

1401 DRWYL $(I, J)=O R Y Y L(T, J)-P D 1.1,(T, J-1)$

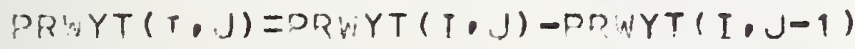

$J=J-1$

IF (1.R.T.1) G0 Tn 14.1

402 CONTIN J

VRITE $(6, \| 14)$

440 FORNAT 1'1 FOACTIOM OF I.ANOTIIGS OF FACH TYPF ON! FACH PUNWAYM///1

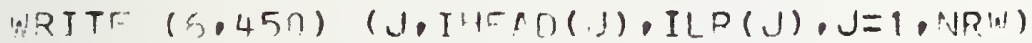

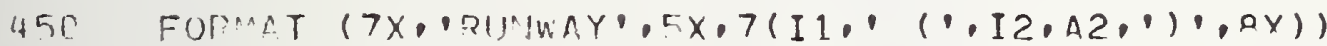

ARITF. $(5,051)$

G51 FOPIT $\left(2 x_{0}\right.$ 'TYME'//)

in $14,33 \quad I=1,1 T Y P F$

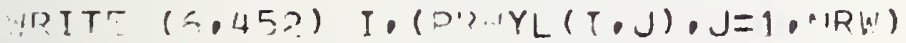

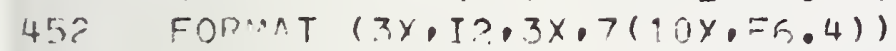

tr.3 COR:TINIS

NRIT: $(6: 453)$

453 FI) LAT $(101 / 1 /)$

IRIT: $(5.454)$

454 GORAAT (1O FRACTIO:U OF TAKFNEFS AF FACH TYPF OH FACH RUNWAYM///)

:PRTTF $(6,450)(1, \operatorname{IHT} \Delta \cap(J), I 18(J), J=1$, NPW)

UR ITF $(5,951)$

O) $404 \quad I=1$. ITYPE

RITF $(0, .452) \quad I,(D R Y Y T(I, J), J=1, N R W)$

HOL COITINIUE

¿TOP

FNI 


\section{E.2 Listing of the DELCAP Simulation}

$+N$ GEN 4

$+N$ NXTOP4

+N LAND 4

+ N TOFF 4

+1 CIIR 4

$+\uparrow$ : FTIUP:

+1 p? TR. TT

$+Y F ! T \quad 4$

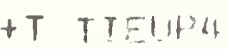

$+P$ F:IS ?

ti CUDUR?

\section{RUIAY 31 ? I 10 F}

N OP $32 ?$ I $2 R W$

3TYP F

$4 \cap X \quad F$

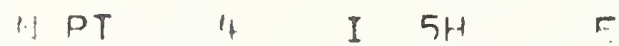

T TYPF 1 I GOPFR 1

$\therefore$ MLAY 4 F $7 D C M \quad 1$

T TIN 3 F AIFT,

GFLYก iv?

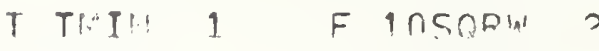

T TinV? F 1 IVLAMB 1

1) VTATF 1

13 BPOT

LPOTT

$+50 \quad 11$

T PCONTT I 3

T SOMTI 4

T PTHTI 3

$T$ STHTI 4

$T$ DEPTI 3

$T$ SERTI 4
Q $2 F$

PTYPEI

PRWAYI

FREERF

17CEPIL? F

IPSFDTL $\cap$ C

IOCNTNI F

ONCTYDE? F

ग1CFWYT? F

गPCPWYL $2 F$

כ3दिOR ? T

DUNEXT 1 T

OSLAST 1 T

ORIINAT?

गTFE ?

PLO? ?

OARFT $?$

XITFT $?$ T

agTRAT 1 E

ZSSFPTT? F

Z3NADR 1

ZLNOED 1 T

25NLAND 1 T

E ENTAFF 1 T

XTRFIT 1 F

XRกEII 1 F

IOTFEG $\cap$ F

I UAFCUTI ?

I $111.0^{A} T I, T$

I IIPFTHTI 1

I $113 \mathrm{LTHTI}$ I I

I 14 FERTI 1

I 115 LEPTI 1

46.TFAI $?$ F

$47 L A M O D ? F$

4QIHOIR $?$ T

"OSFID? F

EOEFNMI 1

EITTDW 3 E

CMTT1 RTMAX L

THTII RTMAX L.

ERTI1 RTMAX L 


\begin{tabular}{|c|c|}
\hline $53 T^{\circ} \cdot 0.1$ & 5 \\
\hline C $4 \mathrm{~W} \cdot \mathrm{R} ! \mathrm{O}^{\circ}$ & 2 \\
\hline$=E, T$ ITR & r \\
\hline $5 \in C 1 .=$ & $r$ \\
\hline C7IA & 1 \\
\hline Е & 1 \\
\hline caction & 1 \\
\hline F.ODF I:I & 9 \\
\hline FICF & $?$ \\
\hline G.2SLOT & ᄃ \\
\hline K3AILAY & $?$ \\
\hline $64 I * C$ & n \\
\hline GEITT & 1 \\
\hline GSCTT:A & ? \\
\hline F PTIM & 2 \\
\hline
\end{tabular}

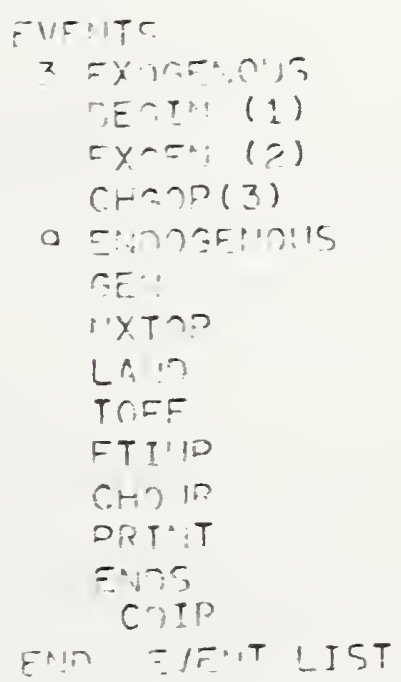




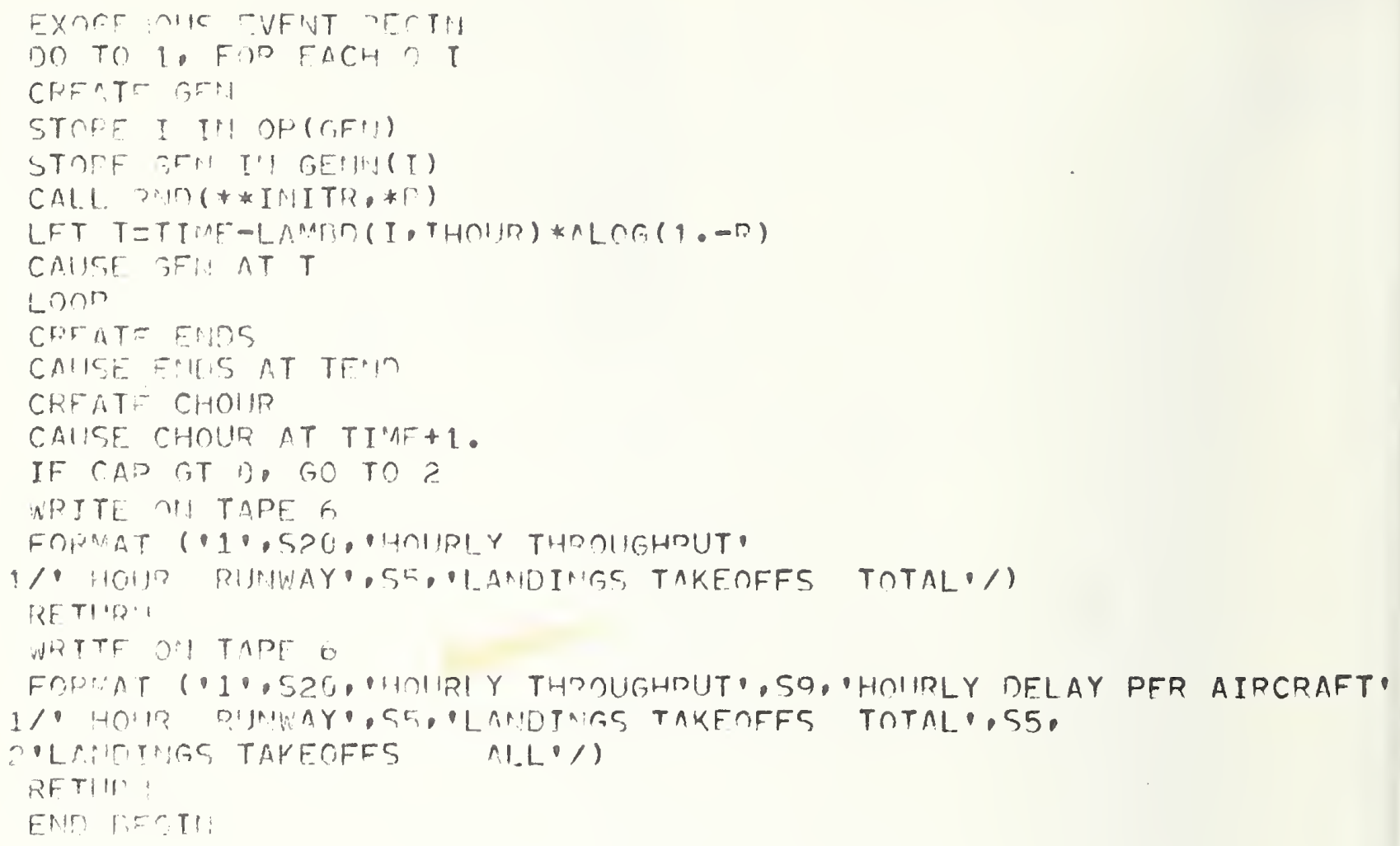


EIIOSGEMOIS FVEIT SEU

GF: 3ERERATES LANTINGS ANIN TAKFOFFC, AND

ASSIG:S ATTPIRITES TO THEM.

OP(GE:I) IS 1 - TAKFAFF, OR ?-LAMOIMG

STORE PP(GF:I) IN I

GFA SCIFIIIISS ITSFIF TO OCCUP ARAIM AFTFP A TIMF IAITERVAL

OEDFI:IA'S OI: TIIF RATF OE ORERATTON.

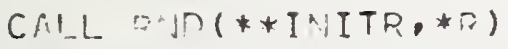

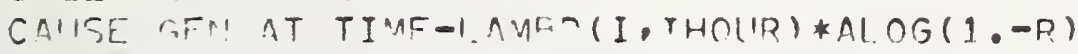

CDFAT $=$ FLT

LFT ITEPTYDE (I)

STORE TT IN TYPF (FL T)

$L F T K=O R: A Y(I, I T)$

GO TO $(9,2), I$

TIN(F!T) IS THE TINE A FLTGHT TS AVAILAPLF TO REGIN FIMIAL

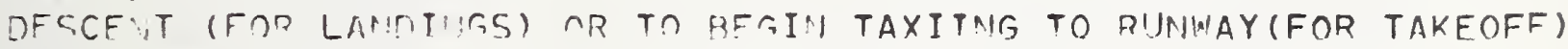

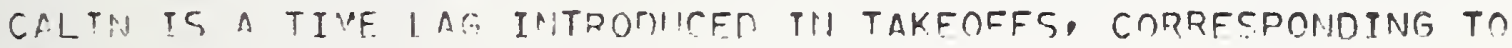

FLYOA - THE TTAF A I.ANINIHG TAKFC TO FLY FRAM

HADINCFF TO THE OUTFR MARKFO.

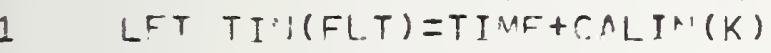

GN TO ?

LFT TI'H(FLT) $=T I$ In F $+F L Y O M(I T, K)$

IF $\cap(K, I)$ IS IOT FPPY, GO TO 4

CDFATF MXTOD

LFT R:AY $(1, Y X T C P)=$

CAIISF :YTOP AT TIN(FLT)

Q(K,I) - IS THE MIFIF OF DI $\triangle A F S$ WATTIAG TO TAKEOFF $(I=1)$,

OR I.A:D(I=D) OR, PUPIWAY K.

FILF FLT I'I $O(K, I)$

RETIIR'!

Eirl' G.:"!

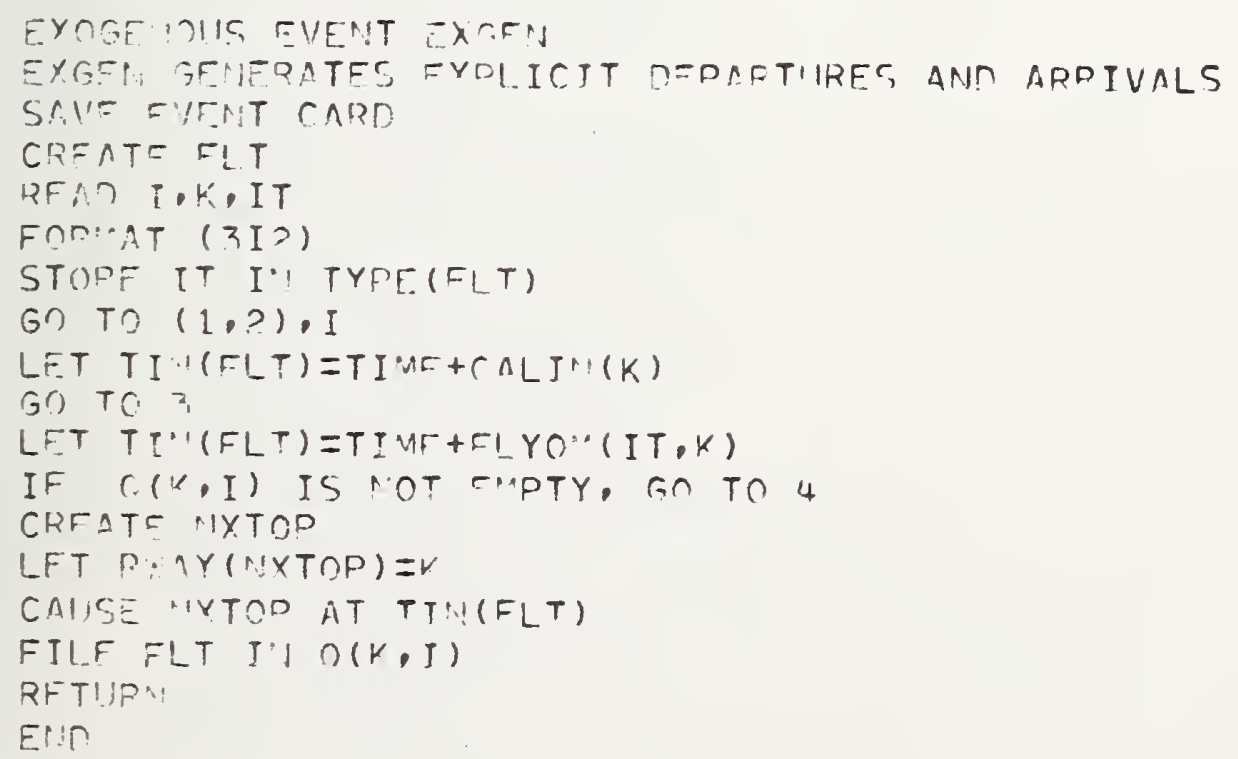


FIIPITITII PTYPF(I)

C PTYPF CHOOSES AN NTPCDAET TYPF FOR FACH FLTAHT ACCORNING TO

C CTYPE - THF CIMMATIVF IISTDIRITIOA OF A/C TYPES IN THE MIX. CMIL J"ID) (* IMITR, *D)

ON TO 1, FOR EACH TYP :

IF L LF CTYPE(I, I), GO TO?

$1 \operatorname{lonp}$

$\hat{\imath} \quad$ LFT PTVIFE=1

DFT'AR:A

ENT PTYPF

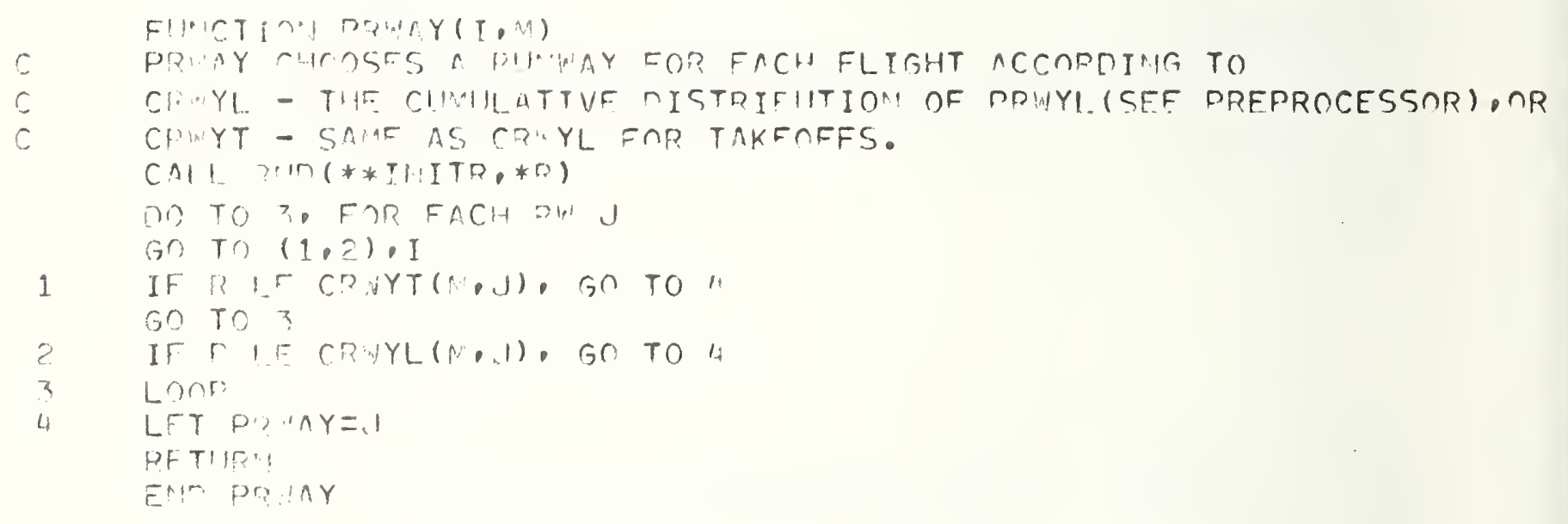


ENIOOGFUIIIS FVERT NYYTOP

DI'AFISIOI: IRIV( 20$)$

C IXTOP 7FCIDES WHTCH OPEDATIOA! WTLL RE SCHEMIILFD NEXT

C ON EAC!I DUIAMYA.

STORE DUAY (HYTOR) TP. K.

DFSTROY IIXTOP

LFT KR: $=I$ InX $(K)$

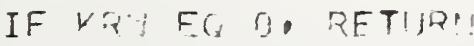

IF ME KT (KDIU) IT 10 PETIIRN

IF LATT $(K D ! !)$ GT $15 \Omega \cap P(K D, V)$, LFT LACT $(K F ! M)=1$

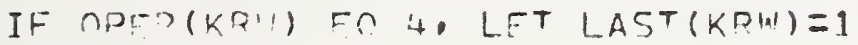

LET IT $=L \Delta S T\left(K, Q, V^{\prime}\right)$

LET IFAN =II

LET T: $=990099$

LFT I': $!:=0$

1 LET $K=S \cap F W(\%$ rian, II $)$

LFT $I=5000(\mathrm{KHAH}, \mathrm{II})$

FI', FTRST,FOR EASH FLT I'I O K, T), IF M!ONF, 90 TO?

STORE ELT II: $\mathrm{T}$

LFT T=FDEF? $(K, I, F)$

IF TING) LF T, so TO 3

IF $T$ ST Tign! SO T? ?

LFT T:O

LET I:I::=IT

STMPE $r$ I' *AIF

? $\quad$ LFT II $=I I+1$

IF I I \&T " $15 \cap 0, P(K P M), L F T$ IJ $=1$

IF II IS IF:U, GR TOI

GO TO if

3 LET I.T'i=I I

L.TT T. TET

STAME E T"1 MPF

$\cdot 6$

IF IMI $F \geqslant n, R E T I O P$

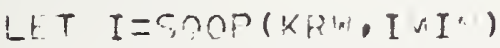

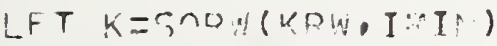

GO TO $(5,6) \cdot$ ?

5 CDFATE TOFE

STARE W IN! RIAY (TOEF)

CAIISE TOFF AT TIMI

GO TO 7

5 CREATE LA:IC

STORE \& IN DIAY (LANON)

CAISF LAR? AT TMA!

7 LET LAST (KQU) $=$ IMTN

LFT $n_{1}-V T$ T $\left.K D\right)=I M T M$

IF TAY

L.ET $K n=T M !) Y(k)$

IF , IF IF NF(K,I), PFTIION

LET $O F(K, I)=0$

LFT $1: T \%=: 152 \cap P(K P .4)$

LET ar $::=$ n 


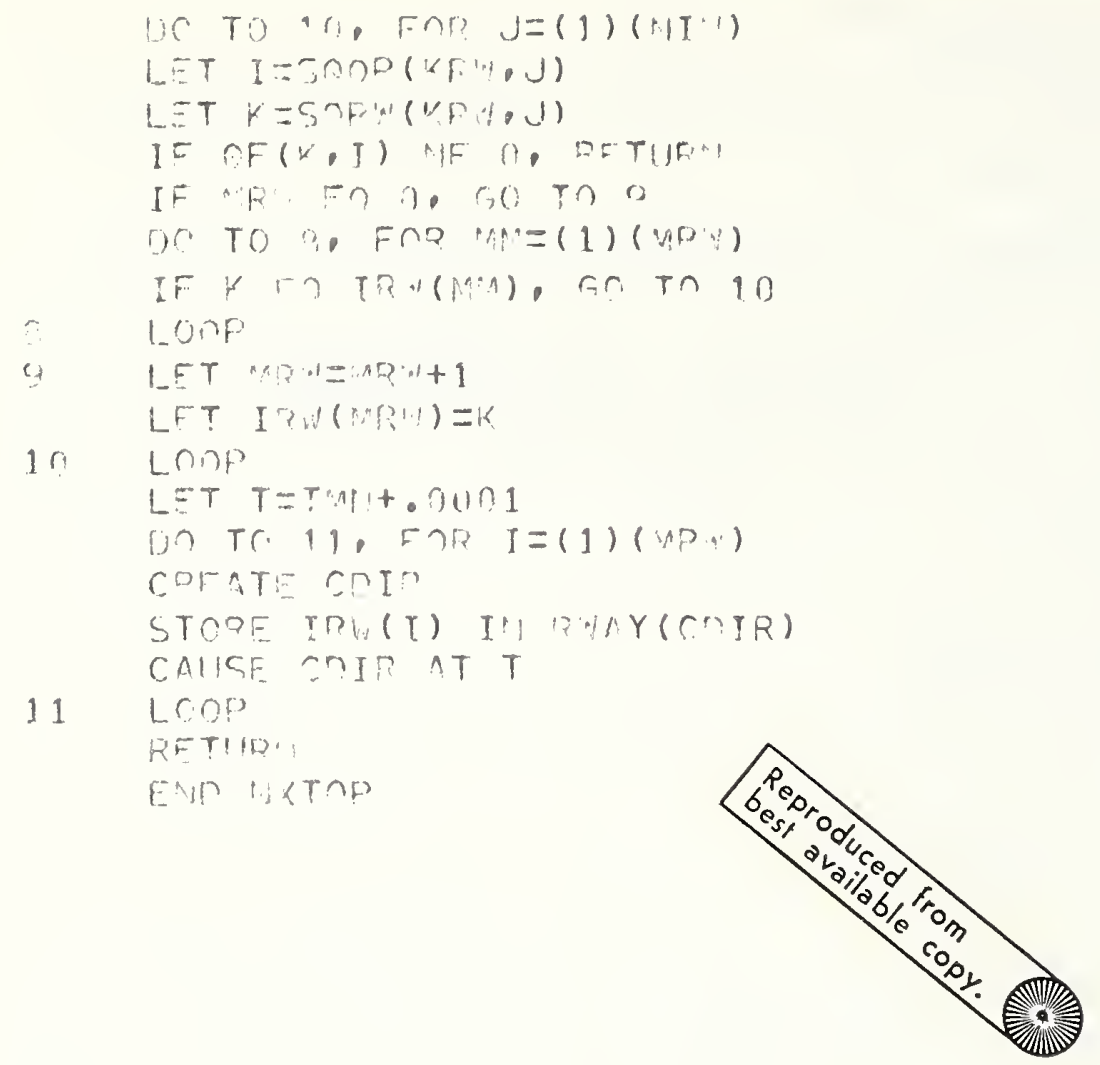


FU, ETIOH EREEP $\left(K, I, F_{L} T\right)$

FREER CALC!ULATES THF FIOST TIUE AT WHICH FI IGHT FLT CAM PERFOPM OPFOATIOH I OI: R!W AY K IITHOUT VIOLATTMG CEPARATION RULES.

DIAEIISIOH: TP( 2.5$)$

LET J J

LFT T=TI" ${ }^{\circ} E$

IF TI: (ELT) FT T, LET T=TIM(FLT)

LET $M=T Y P E(E L T)$

LFT FDEFP:T

IF I $E$ ? ?, 00 TO 4

IF T.PTI(K) IS TMPTY, DFTURM

$c$

EDTT(Y) TS THE SET OF ITIFIPS' EOR THF EIIN CF THF RUNWAY K. A TIF ID IS A TIMF IMITEOVAL NUPTMG WHICH NO TAKFOFF MAY OCCUPY

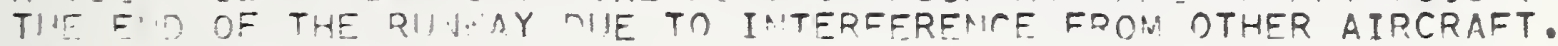

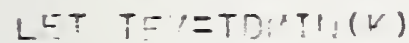

C TC:IH IS A TIS L I IMTPONUCED TNTA THF SCHEDULF OF A TAKEOFF CORPEGDOIDIUE TO THF TT"F IT TAKES A LAMIINIG TO FLY FROM THF OLTEP "ARKER TO TOICHONWN. IT "AY RE. LOOSFLY THOUGHT OF AS TAYIITIS TIUE.

DO TO 3,FOR FACH TIELIP TN FRTI $(K)$

LFT TT-TYAY (TTEYJO) - TF:A

THF E':? OF THE TYF:10, I.E. THE TIME NHFA THF FUD OF THE RUNWAY

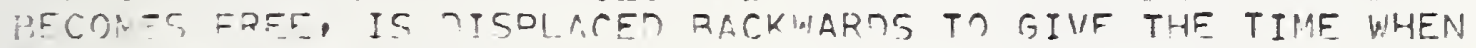

THF THK:CFE WAY DEZIN TAXI.

IF TTLST, GC TO 2

LTT J J J J I 1

LET T? $(1)=T$ T

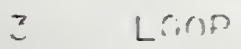

in to 13

4 IF MTI Y IS FMPTV, GO TO Q

D"TT IS THF SET OF TIFIPS FOR THE OIITER MARKER.

UN TO 5 , FOF F.ACH TIFUP IMU ONI I K

LFT TTET:AY (TTEUR)

IF TT 1.5 T , SO TO 5

$L E T \quad l=1+1$

LET $T \cap(J)=T T$

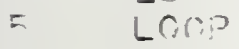

- IF THTT $(K)$ IS EMTTY, SO TO 12

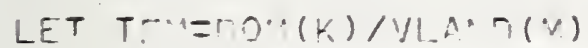

C THTI TS THE SFT OF TIEUIOS FOD THE THRFSUOLN OF THE RUNWAY. DO TO 2 , FOR EACH TIFIIO IAI THTI $(K)$

THUESHLE TIFIJOS ADE RISPLACEN DACKHARCE TO GIVE THE TIME THAT THE L:ITIHG UAY POSS THF OITFR MARKFR.

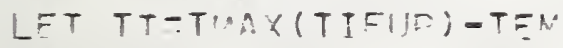

IF TT $1.5 T, S 0$ TS 0

LET $J=1+1$

LFT T $P(J)=T$ T

(4) LONO

17 IF $J=0 \cap$, RFTIJOA

LFT FEEFFETO(1)

IF J E 1, DETIID.

C FPFET TS SET HGIIIL TO TLE TUN AE THF LATEST TTEIJP, VIHEN THFRE IS

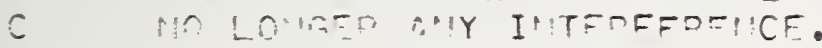

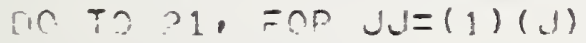

IF TH(IJ) GT FREF?, LET FREERETR(JJ)

$21 \operatorname{LOn}$

RFTIRE

Fi: FOFEW 
EMnOGE InIS FyEMT LATH

C LAPD COFTES ALL THF PTEUES MLICH

C RFGILT FFIOM AII AIRCRAFT LANITIME.

STORE PIAY (LAIII) I!' K

IF $O(K, ?)$ TS IIOT F."PTY, GN TO O

WPTTE OI! TAPE \&., TFMA.K

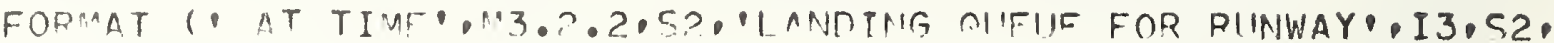

1 'TS FAPTY')

$\operatorname{ST\cap P}$

a

C

C

C

$c$

c.

C

C

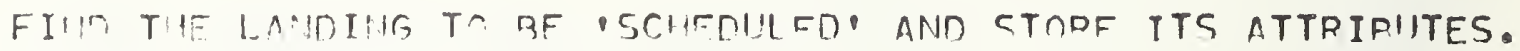
REMV FIRST FLT FFOM $\partial(K, ?)$

STOPE FIT III FI

LFT $M=T Y P E(F L)$

LFT $V=Y / L A M \cap(M)$

$L F T T=F Q E F R(K, 2, F I$.

LFT $T \cap=T+n \cap M(K) / V$

TIF UP THPESHOLI TR LAIIINC AIPRRAFT FROM TOICHDOWN TIMF UNTIL AFTFP DIPISAYY OCCIPANCY TIMF HAS ELMPSED.

CRFATF TIFIP

LET T TU T TFUP $=T^{2}$

LET T AX(TTFUP) $=T \cap+R O T L(M)$

FILF TRTUP TH THTI $(K)$

CPFAT FTRUR

STORE K I'I RWAY (FTIUF)

STARF ? IHI PT (FTI!IO)

CAISF $=$ TIIID AT THAX (TIFIIP)

TIF UT EPIO CF RUIMAYY TO DEPAPTTNG AIRCRAFT FPOM TOUCHDOWN IINTIL AFTFR DI:H!AAY OCCIJPAMCY TIUF HAC ELAPSEN.

CPTATE TIEUP

LET T;INITITI:P) $=T$ T

LFT $T \cdot A \times\left(T\right.$ TFUO) $=T^{n}+B O T L(M)$

FILF TPIIP IN ERTT(K)

CPFATE ETIIP

STORE " TU PUAY (ETTUF)

STOPE 3 III PT (FTTIIP)

CAHSE ETJINP AT TAMY (TIEIP)

FIN'T THF FOLLOWING DLAME IA! THF LANINING OIFIE

ANIT STORF ITS ATTEIRIITFS.

FIMI FIOST, FOR FACH FLT IN O(K,2), IF NMNE, GO TO 11

STARE FLT IU F

LET MN=TYPF(F)

LET SIVLAIISU (MMA)

CPEATF A TIFUP WHICH WTLL MANTAIN PROPEP RADAR SFPARATION

AFTWEF! MDPTVING ATPCPNFT.

CDENTE TJFUP

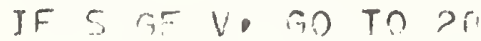

IF THE LA'IITNG SHEEN OF THF PLAME OFTNG 'SCHENULED' IS GREATER THAI: THAT OF THF EOLLOMTHG DLAME, TIF IIP THF OITER MARKFR FROM

THIF TYME THF FIPST PLANIF DASCEC THF OUTER MAPKER UNTTL

THF TIAT IT TAKFE, THE STCOHIN TA FLY THF SEPARATIOM DISTANCF

HAS EIMSER.

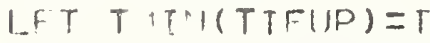

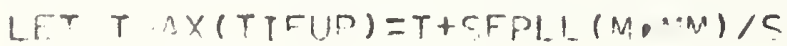

FIL.' TIEIIP TI! OMTI $(K)$

CAR ATE ETIID

STAO W II! RWAY(FTTID) 


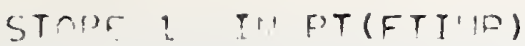

CIISE FTI!D AT TMIV(TT-1P)

Gi TC 11

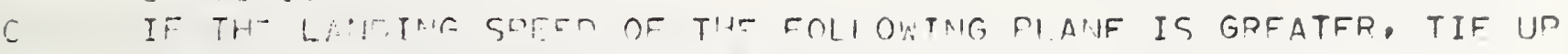

THF THOCHOLD FOMA TOUCHDOMN OF THE FIRST IATTL THE TIME IT TAKES

THE SODIT TO FLY THF STPAEATIMA PTSTAMICF HAS FLAPSED.

$\partial \cap$ LET TITH TTISUP) = Th

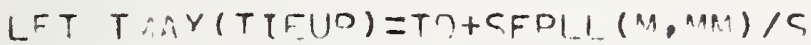

FII TTEUP IP THTT $(K)$

CPFATE FTIID

STORF * IN FINAY (FTIUP)

STORE? IN PT (FTIID)

CAISE FTIUP AT TMAY (TIF'PP)

C CPEATF A TIFUP !HICH WILL MAIMTAIN! PROPFP SFPAPATION BFTWEFA

C THTS, AMIIIIS ANO A TAKFAFF ON THE SAMF DLINWAY.

11 FIM FIRST, FOR FACH FIT IM Q $(K, 1)$, IF NONF, GO TO?

CRFATF TIEUT

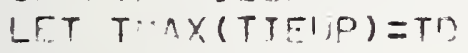

STOPE FI.T IUI F

LFT MA $=T Y P F(F)$

LFT $S=\because T O F F(M)$

I.F-T T I I!(TTFUP) $=T+(\cap 0 *(K)-(S F P T)+.5 * V * * 2 / S * D O T T(M M))) / V$

In! FI! TJElIP II! EPTI!K)

CRFATF CTIIIP

STOPE V I!! RUAY (FT JUIP)

STORE 3 T:H PT (FTIIID)

CAIISE FTIIIO AT TMXX(TIFIP)

2 IF IPT (K) EU O. GO TO 10

C NOW COFATE TIEUPS OA OTHER RUAUAYS, IF SICH INTERFERENCE EXISTS.

0 TO, OFOD $J=(1)($ P P $(K))$

CRFATE TIIIIF

C KK IS THF RIIHAY AFFECTFD.

LFT KK KIDT $(K, U)$

IT IS TIF TYDE OE TIFIP TS DF COEATFD.

TIFUP TYFES 1, ?. MMD S APDIY TO LAMDIHISS.

LET IT $=$ TF:T $(K, J)$

GO TO $(2,4,6,5,5,5)$, IT

CPEATE A TIEUF TO MINTAIV TATFOAADPIVAL SFPAPATION.

? FIUT EIOST, FOR EACH FLT TAI O(YY,?), IF NONF, GO TO 6

STROE TLT IN F

LFT iNM $=$ TYOF $(F)$

LFT $S=\operatorname{LLNMO}(\mathrm{MM})$

IF 5 , $V$, GO TO 325

LFT $T: I: \because(T$ TFUP $)=T$

LFT $T: M X(T$ TEUP $)=T+C E P L L\left(M_{A} \times A\right) / C$

LET J J $=1$

GO $T \cap 7$

325 LET TMINU(TIEUP) $=T$ ?

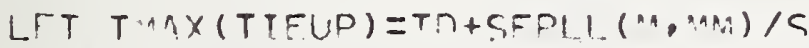

LFT $J J=$ ?

(G) TO 7

CRFATR A TIEIIP TO "AINTAIN MEPIARR SEPADATTAI.

4 LFT $T \cdot A x(T I F$ UP) $=T$ ?

425 FIM FYPST, FOP FACH FIT TM $\cong(K K, 1)$, TF NAME GO TO 6

STRPE FI.T IU: F

LET $:=$ TYPF (F)

LFT $S=V T \cap T F($ MN

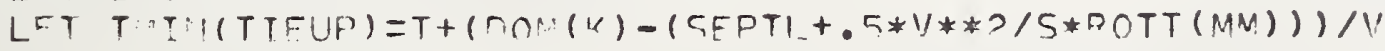


45 LET JU
GO TO 7

C TIE UP THE EIIO OF MII INTERCFCTTAG DINNWY TO TAKEOFFS AND LANDINGS

C INTIL AFTER THE LANINING DASSEC, THF INTERSFCTION!

5 LET TAIN (TIEUJ') =Tr?

LET $A=(V T A X I-V) / R O T L(N)$

LET TF $\|=.5 * A * R O T L(M) * * ?+V * D \cap T L(* A)$

C IF THE I.ANIING WLL NOT REACH THE TNTERSFCTTON,

C TIE UP UNTTL. THE LANOIIS TIDNS OFF.

IF TF' LF nIMT $(K, 0 K)$, gn TO 51

LET $R=1 * * ?+? * * * O T, T(K, K K)$

LFT TIIP $=T O+(-V+S(A R T(F)) / A$

GO TO 5 ?

51 LFT THO=Tn+ROTL $\left(x_{i}\right)$

52 LFT TA AY(TTE(JP) $=$ TIJP

FIL TIFUIC III THTI $(K K)$

CPFATE FTI!IP

STORE KK. IN RWAY (FTTUP)

STOPE $\supset$ III PT(FTIUIO)

CAIISF FTIUD AT TMAY (TIFIIP)

CPFATF TIFIIP

LET T:INT TEUP $=T$ T

LFT $T: A Y(T$ LEUP $)=T(J \cap$

LF $J . J=3$

60 TC 7

f. TFSTPOY TJTIP

GO TO ?

7 GO TS $(7 \cap 1.702 .70 .3) \cdot 1]$

701 FIIF TIFIP IU OMTI (KK)

GO TO 725 .

7n? FILE TTEIF II! TUTI(KK)

B? $\mathrm{Tr}, 70 \mathrm{C}$

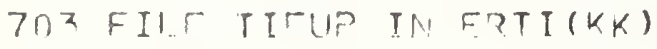

7 TI CEFATE FTIUP

STARE XK TH! RUAY(FTTUOR)

STOFE JU I I PT(FTI!ID)

CAIISF TTIIID AT TMAX (TTRIP)

G. LoOr

10 CRFAT- "WTTDO

STORE \& I'! RWAY (.IXTOP)

LFT KW=I!UY $K(K)$

LET NISYT $(K K)=0$

CDIISE IXTOP AT T

C DTFM TS THE DELAY FHCOIMTERER RY THTS LANOTING.

LET DTE" $=(T-T I N(F L)) * 6(i$.

IF. TO LS TIFGOBO TO 5 O

CREATE PRINIT

C

STMRE DATA TO HE RECORMFD AT TOICHONWN.

STORE TTFM IN MI_AY (FRTIT)

STORE K IN DWAY (PRTITT)

STR'P ? IN OP(PRINT)

CAIISE DOTUT AT TO

EA DESTFAY ELT CALLED FL

LFT L AST $(K K)=$ LAST $(\times K)+1$

DESTAOY I I In

B? TI'

Em LI'!n 
ER!IOAGR"InIIS EVEHT TAFF

TOFF CDEATES THE TTFIJDE RECIILTTMG FPOM MN ATRCPAFT TAKING DFF. STDRE DAY (TOFF) IA: K

DESTROY TOFF

IF $C(V, ?)$ IS EMPTY, GN TO 15

C FIIT TIKFOFF TO UE SCHEMULED AMIN STORE TTS ATTRIRUTES.

REIINVE FIRST FLT FRO:A $?(K, 1)$

STORE. FLT IN FL.

LFT M=TYPF. (FI_)

LFT $V=1 / T O F F(M)$

LFT TEFDFER $(K, 1, F L)$

LFT TS: $=T+T \cap M I N(K)$

c

TIF IJS THE RUNAAY TO TIKENCES AND LANMIMGS FOR DURATION OF THF

RIJHAY OCCIIOANCY TTME.

CDITE TISIJP

LFT T:IM(TIFUD) $=T$ T

LFT TIAX(TIFUP) $=T^{n}+D O T T(M)$

FILT TITIIP IH THTT (Y.)

CPEATE FTTIIP

STARE Y TN RWAY (FTIUP)

STRER $\supset$ I:! OT (FTTUP)

CMIISE FTIID AT TAANITIFIP)

CFEATE TIEIID

LET TSTIRTTEUP) $=$ TH

LIT T SAY (TIFUP) $=T$ T + ROT T (M)

FII TIFIIP III ERTI $(K)$

CPEATE FTIUP

STOPE V IMU RUAYIFTIUP)

STOPE 3 I!! DT (FTIIIO)

CAIISE FTIIP AT TAAX(TTOIP)

FII! FIPCT, FOR FACH F! I T $D(K, 1)$, IF M!OIF, GO TO 2

STRQE FLT IN! F

LET MATYMF

TIF UD THE FII OF THF DIIIUAY TO THF NIEYT TAKFOFF LONG ENOUGH

TO MAIITAIH INTED-NEPARTURF SFDARATION. THTS REPENDS ON THE

TYDFS TF TIF THO AIPCDAET.

CEFATE TIFIIP

LET T:IP:ITIFUP $)=T !$

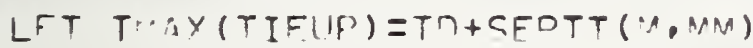

FILF TIFUIP III ERTI $(K)$

CSERTE FTIIID

STOPF K IN RUAY (FTIUP)

STORE 3 TH: DT (FTIUD)

CAIISE ETIUD AT TMAY TTTEIIP)

2. FI: FIPST, FOR FACH FLT IN $C(K, 2)$, IF MONF, GO TO 5

STIDE $=1 . T$ I $\because \mathrm{F}$

LFT $S=U L A A I M$ (TYFE (F))

C CRFATF A TIEUP TO "AMTATAIM IEP/ARR SEPARATIOH.

CRFATE TIFUP

LFT T:III(TIEUP) $=$ TO

LFT T:AX(TIFUP) $=T ?+($ SFPTL+.5*S**2/Y*ROTT(M)) /S

4 FILF TIFID IY! THTI $(K)$

CPFATF FTIIID

STADE V IA! DUAY (FT TUP)

STOPE? I:H DT (FTTIIO)

CAIISE $=T I$ IUP AT T:AY (TICIP)

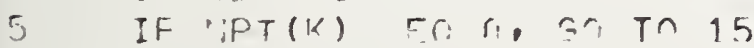


CRFATF TIEIPS OF OTHEP DUNWAYS AS REQUTRFD.

i) TO 14, FOD $J=($ I) (IIPT $(K))$

CRIATE TIEUIP

C KK - R!INIUAY AFFECTFR

LET KYORPT $(K, J)$

C IT - TYDF OE TIFIIP

C DNY TYPES 3, 4, 5, ANI 6 APPLY TO TAKEAFFS.

LET ITETPT $(K, J)$

GO TO(12,1?2,6,8,k,10), IT

C

CHFATE A TIFUP TO "ATMITAIN DPCDER OFP/ADR GFPARATTON.

a FIII FIRST,FOR EACH FI,T IN D(KK, 2), IF MONF, GO TO 12

STORE FLT IM F

LFT MAIYPE (F)

LET $S=V L A N M(M M)$

LET THIM T TEUP $=T$ Th

LET J I I ? ?

LFT THAX(TIFUP) $=T n+(S F M T L+.5 * S * 2 / 1 * R O T T(M)) / S$

se $\operatorname{TO} 13$

3 FIUT: FIPST,FOR FACH FLT IM ?(KK,1), IF MIOUF, GO TO 1 ?

STODE FLT IN $F$

LFT MPISTYPE(F)

C CRFATE A TIFUP TO VIATHTAIN PROPFR TNTFR-DFPARTIJPF SEPARATION. LET T I'P(TIEUP) $=$ T?

IF THE RIMUAYS ADE DFPEMIEIT, IISE THE SAME SEPAPATION AS FOR ONF RUIT:HAY, I.F. THOSE IN THE CFPTT ARDAY.

LFT $T A \cap \times(T I C U P)=T)+C, F P T T(\because, V M)$

IF THE PUNMAYS ALLW SIMULTANFMIS TFPARTIRFS WHEN THEY DIVERGE,

USF T.FF. SEPAPATIONS IM THE SEP? ARRAY.

IF IT E) 5,1 ET $T^{\prime \prime A V(T I C I: P)=T H+S E P 2}(M, M M)$

LFT JU $=2$

GO TC 1 ?

C

TIF UT THE FII OF MH THTERCECTTHG RIJAWAY TO ALL OPERATTONS IINTIL THF TAKEOFF PASSES THF TPITFRSFCTIOM!

10 LFT TIIITITUP) $=$ TI

LET A $=U / P O T T(M)$

LET TF A $=.5 * A * R O T T(\cdots) * * ?+V *$ OCTT(*1)

r. IF THE TAKEOFF IC MIRRARNF MFFODE DFACHTNG THF TNTERSECTION,

C TIF UP OMLY UM!TII. PIRIOARNF.

IF TE: LE OTIJT $(K, k, k)$, SO TC, 51

LFT $B=1, * * 2+?$.*A*IIT $(K, K K)$

LFT THIDET $=T+(-V+S O R T(F)) / A$

GO TO 50

51 LET TIID $=$ TO +P.OTT(N)

52. LFT TAY ITIFISP) $=T(10$

FILF TIEIIP II! THTI(KK)

CDFATF FTI!IP

STOPE KK IYI RWAY (FYIIIN)

STOPE? IN! PT (FTTUP)

CAISSE FTIUO AT TAAV TTIIIP)

CRFATF TIEHP

LFT $T: n I \because(T I F L P)=T$ T

LFT $T \cdot \cap \times(T$ IEUP $)=T 110$

LFT JJJ $=3$

GO TO 13

12 INFSTRIY TIFIP

GO TO : 4

13 GO TC $(14,121.132) \cdot 1 J$

131 FII. TT TIP I W THTT!KK) 
Gi) TO $: 35$

13? FILE TTEIID I!! FRTT(KK)

135 CFEATE ET?:D

STR,DE KK I'I RHAY (FTTUP)

STOPE JU I: PT (FTT'DP)

CAISE TTIUD AT TAAY TTEUP)

14 LOOP

15 CDEATE HXTOP

STORE $V$ TA, PWAY (UXTOP)

LET K" $=I M T X(K)$

LFT HEVT $(K K)=$ ?

CAISE :XTOP AT T

C OTFM - THE MELAY I'ICURDED EY THTS TAKEOFF

LET CITE" = (Tח-THMIII(K)-TIN $(F L)) * G 0$.

IF TP. 1.S TBEG, GO Th 5n

CDEATF ODINIT

C STOPF DLTA TO RE PECORNFD 1T THF TIME THF TAKFOFF TURNS

C OAT TO THE PIJTAAY.

STOAE DTEM II DLAY (ORI:IT)

STOFE

STADE I IM! OP(PRT'IT)

CAIISE DOIIT AT TO

SA. DESTPNY FLT CALLFN FL

LFT LAST $(K K)=$ LAST $(K K)+$ !

RF.TIIR:!

16 WDITF 2!' TAPE 5 , TIAF, K

FOP:AT ( AT TIMF', T2, 4, 52, 'TAKEOFF QUEIE FOR RUNWAY',I3,S2,

1 'IS $=$ "PTY')

STPP

EMIr) T):F 


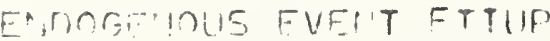

C FTIUP PFMOYFS TIFUPS FPOM THEIF SETS ANI TFSTROYS THFM WHEN

C SIMULATET, TINE PASSES, THE FND-1,TMIT OF THE TIE!JP.

STORE PDAY (ETIUP) IA K

STARE PT (FTIUPP) TH: J

DESTROY FTI!IP

GO $T O(10.20 .30) .1$

IN REMOVE FIRST TIEUD FROY OMTI $(K)$

GO TO 40

20 RFMOVE FIRST TIEUP FROM THTT(K)

GO $T C$ iी

30) RFADVE FIRST TIFIIP FROA ERTI (K)

Uח DFSTREY TIFIIP

RFTIIFI

EIST FTI'JP

ENIOAGE DUIS EVFIT DOTITT

PPIMT RECAPDS MATA ON EACH FLTGHT AT THF TTME IT ACTUALLY

TOUCHF' DOU. OP TUDIS OM! TO THF RUMWAY. AS THF CASE MAY BE.

STOPE DIAY (PRINIT) IN K

STOPE TLOY (PRINT) INI

STORE TP(PRINT) INI T

IVFSTROY PQTIT

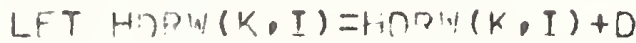

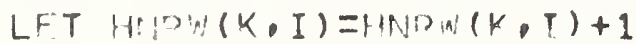

C

MTOFF MUT :HAAIN ADE THF TOTAL MIMBER OF TAKFOFFS AND LANDINGS

C DIHIMU, THIS HOIR.

C DFLT MNO DEI.L ACCUMILATE TOTAL MELAY OM TAKFOFFS AND

C LAHIIIISS RYY HOUR.

LET I I = I/IUC+1.

IF ID $O T$ T.1SLOOT, LFT IT=A.1SLOT

IF TI LF. O. LFT Iח

LFT M!ILAY (IHOHR, TO) =IINLAY (THOUR, ID ) + 1

SO $T(2.0 .20) \cdot I$

In LET MTOFF (IHOIJP) =MITOFF $($ IHOIIR $)+9$

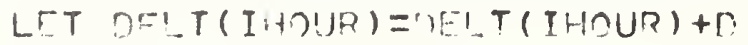

RETII:2I!

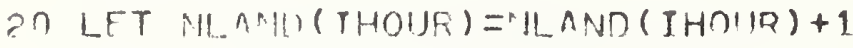

LET DFLL (IHOUR) = TELL (IHINUR) $+\Gamma$

RETIIPI!

FIIT P'T P!T 
ENIDOGEMINUS EVENT CHOIJR

LET I-TIIR =IHOUR+ I

IF IHC:IR GT MH, LFT IHOIIR=1

LET TETTME+1.

IF $T$ LF TENIO, CAIISF CHNUR AT T

DO TO 1. FOR EAC'A $\cap$ I

STORE GFMMIII) I:I GENI

CANCEL GEN

CALI. PI!I, (**INITP, *B)

CAIISE GFN AT TIME-LAMAO(I, THOUR)*ALOG(1. $-R$ )

1 LOOP

IF TIN LE TBEG, RFTURA:

LET II $=I H O ! I R-1$

DO TO 4, FOR F.ACH RW K

LFT NOSS=HNRW $(K, 1)+H N P M(K, 2)$

DO TO 10, FOP EACH O I

LFT $\operatorname{TAR}:(K, I)=\operatorname{TNCW}(K, I)+\operatorname{HNOPM}(K, T)$

12 LOOP

IF CAD RT 0, GO TO 11

IF $K$ GT 1 , Go TO ? ?

WRITE ?,1 TADE 6, II.K. INIRW $(K, ?)$, HNOW $(K, 1)$, NOPS

FONAAT (I4, I $6,54,3$ TO)

GO TO ??

20 VRTTE ר: TADE 6. K. HNRW(K.?) H HNRW $(K \cdot 1)$, NAPS

.FCRAAT $(5,16,54,3$ IO)

GO TO $?$ ?

11 LFT TOEL $=$ ?

DO TO D, FOR FACH D I

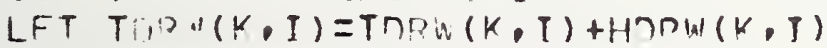

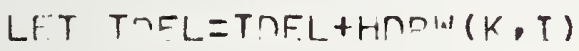

2 LONP

LET R1 $=1 / A ! D N(K, 1)$

IF $B 1$ FT $9 .$. GO TO 5

LET $D 1=$ ?

Gก TO

5 LFT O1=HTPR $(K, 1) / B$ ?

6 LET $D 2=1 \| 1$ RIM $(K, 2)$

IF $3 ?$ GT 0. . GO TO 7

LFT $D 2=$.

GO TO 12

7 LFT $D ?=4 r, R ! M(K, 2) / 3$ ?

R LFT BR= IOPS

IF 133 ST O.. GO TO 9

LFT $[; z=$ ?

GO TO $1 \cap$

a LET DI=TDEL/R3

in IF $K$ I 1, GO TO 21

WRITE ?"1 TAPF 6, IT,K, HIRW(K,?),HNRW(K, 1), NOPS, O2,D1,D3

FOPMAT $([4,16.54,3\lceil 9.53 .307 .1)$

Gก TO 2?

21 WRITE ON TADE 6, K.HNIRW(K,?), HNRW $(K, 1), N D P S, 02,01,03$

FORMAT $(54,16,54,319,53,30 ? .1)$

22 DO TO 3 , FOR EACH O I

L.ET HORW $(K, I)=0$.

$\operatorname{LFT} H^{*}: \operatorname{Non}(K, I)=0$

$3 \quad$ LONP

$4 \quad \operatorname{LOO} D$

RETIR:

ENIT $C$ HOTHE 
EXOGEDIIS EVENT CHISOP

C THIS EUFNT RFAIS THF PFH OPERATING DOLTCY AND RIHWWY PREFERFNCES ANO

C IMITIATES THF CHANGENVFR.

DO TO 1. FOR EACH Din K

REAO THDX $(K)$, CHGS(K)

FOPAAT (S?, DI? )

1 LOOP

DO TO 3. FOD EACH DU! $\mathrm{K}$

DO TO 2, FOR EACH TYP I

REAN CDEYT $(J, K)$, CR!YL $(1, K)$

FOPUAT $(5,4 \cdot ? \cap ? \cdot 14)$

2 LOOP

LOOP

If TIIT LT TREC, on TO 54

LFT TISTI:E-DTIM

00 TO 53. FOF EACH RW K

LFT KD:I=IM!OY(K)

IF KP: LF OD GO TO 5.3

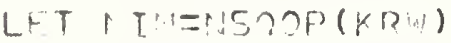

LET I $1=$ ?

LFT I?=?

DO TO 5?. FOR J $=(1)$ (NIIN)

LFT KK=SกIRA (KRW,J)

If $K K$ IE $K$, GO TH : 1

L.FT II $=500 p(K P$ W J $)$

IF II $\Gamma \cap 1, L F T \quad I 1=1$

IF II FO?

5) LOคP

If II ro ?. 60 T0 5?

$\operatorname{LFT} T_{T}(k, 1)=\operatorname{TIP}(k, 1)+T$

5e. If I? $n$ n, gO T? $=3$

LET TI: $(k, ?)=\operatorname{TIN}(K, ?)+T$

Lonn

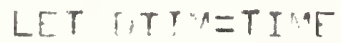

S4 OC, TO 63, FOF FAC'4 a!

LET $\cap C(K, 1)=0$

LFT GE $\left(K_{,}, 2\right)=0$

LFT I $I=[1: 7 \times(k)$

IF II Fa $n, G \cap$ TO $\therefore 3$

LET MH=:isnOP(IT)

DO TO 62, FOR $J=(1)(\mathrm{yH})$

LET KK K $=5 \cap 2 V(I I, J)$

IF KK :F $\psi$, GO TO SO

$L F T I=5)(I) P(I I, J)$

IF $\partial(\mu, T)$ IS FMPTY, GO TO K?

$\operatorname{LFT}$ SF $(K, I)=L \cap(K, I)$

6? LOOP

63 LONP 


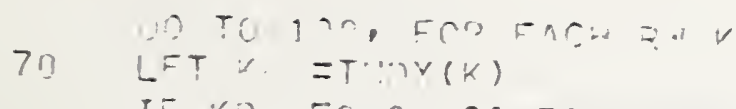

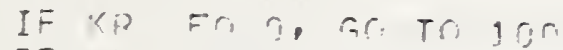

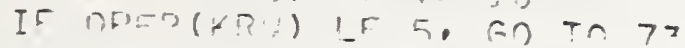

LFT :HT:=lic, OPP $(K n$,

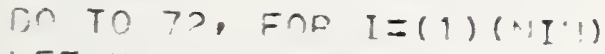

LFT KK $K=5(Y R \cdot(K H A, I)$

DO TO 7 , FOP FACH 0 II

IF $\partial F(K k, I I)$ ilf $r$, so Th, Inn

$71 \mathrm{LOOO}$

72. LOกD

73 IF $(H \cong)(K)$ ST $\mathrm{P}$, is th 00

74 LFT I: : Y $(K)=T H Y Y(K)$

$L=T \quad T \cdot \cap \times(K)=0$

in Tr 1 in

So CRFAT CLI,

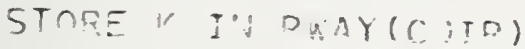

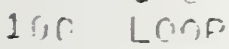

CAlIEE GTP IT TI:-

FiFTINPI

E:ir. C: $A D$ P

ElinOG:"1215 FVF'.T COTR

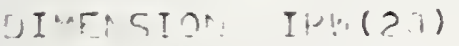

STORE JAAY (CJIR) I' K

IF $C H F)(k)$ en $[$, r, Th ?

CMISE CIP AT TI AE+AFI! (K)

LET $C:-2)(K)=0$

RF T:IR

1 UESTPOY CDID

LET $K=T+1-x(k)$

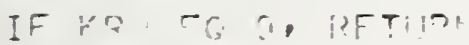

LET $\because \because=1$

LET I $(1)=K$

IF NDF (KA.) LE 4 , की Th

$L=T \quad:=15,1) \cap(K D: !)$

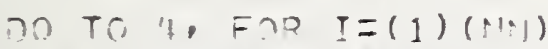

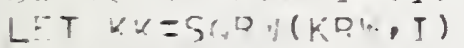

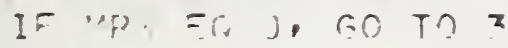

D) TO ᄀ, FD? J=(1) (MPA)

IF $x_{1}=?[2,(1)$,$) , En TC 4$

2 LCOD

$3 \quad$ LET M " = 20,1

L.ET ID:1 (1. D:U) $=K . K$

$4 \operatorname{LOn} 5$

6 Un TC5, FnT KK= (1) $(\because 2: \therefore)$

LET $K=I ? \cdot \cdot(h, K)$

$L=T \quad I:-X(K)=T M P X(K)$

LFT $T^{\prime} \cap Y(\zeta)=0$

E. LOCD

iet. Tilte,

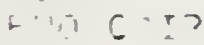




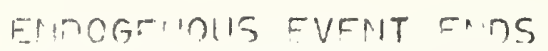

WRITF UI TAPE E. INTTD

FORMAT (10,//OFTHML RAMDOM MULMOER SEEN .012$)$

LET T=TIME-ITIM

UO TO 53, EOR FACH RH $k$

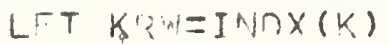

IF KF." L.E D. 60 TO 5.3

LFT MT:ISOOP (HRP)

LFT I $1=$ ?

$L F T$ I $=0=n$

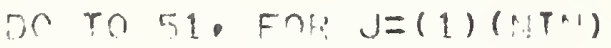

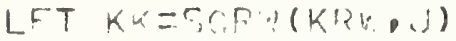

If $V k$. if $k$, nol Tn 51

LFT II $=50,0$ P (KRing J)

IF II 1 , LFT II $1=1$

IF II $5 ? ?$, LET $I ?=0$

51 LOND

IF T1 F? ?. GO TO 5

LFT TT

58 IF I2 50 , 50 TO 5 ?

LET TT: $(K, \supset)=\operatorname{TIA}(K, \supset)+T$

2.3 LOOP

WPTTE OA TANF, 6

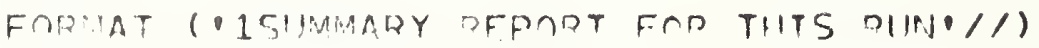

WITTE TM! TAPE E,

FOEMAT (C,5, TOTAL THROIIGHPITU/1

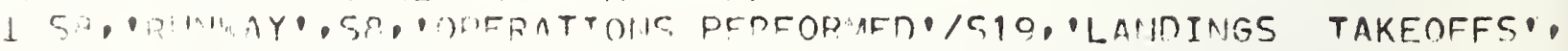

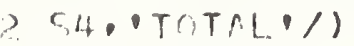

LET PI. MPIDE=?

LET MTAFF=?

DO) TO 1. FOP FACl.t OH. $k$

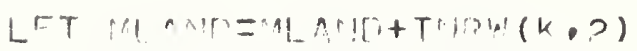

LFT MTOFF= TOFF+T:IN⿴囗十 $(K, 1)$

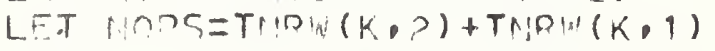

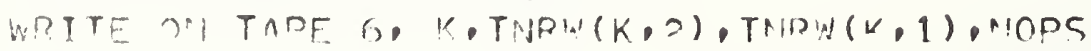

FOHAT (<19.11.5\%, 3I In)

LOOP

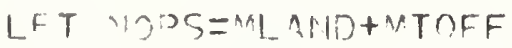

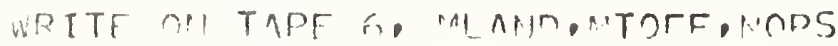

FORMAT (S9. TOTAL. * 3T1O//1)

WTP TE ON TAPE 6

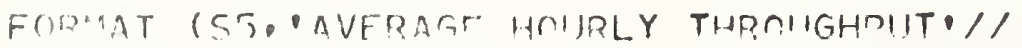

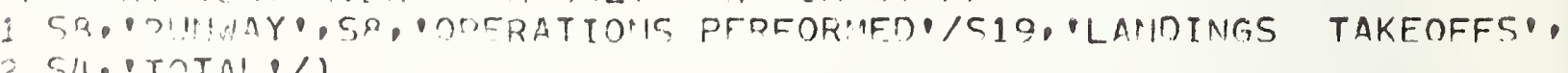

2 54, TTTAL /

LFT THI =TFPIT-TRF,

LET TLA:UIEI.

LET TIOFF=?.

DO TO ?. F.JP EACH RIS K

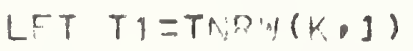

LET TINEF $=T T C F F+T 1$

IF TI $T(k, 1)$ GT 0.0 . SO TO 7

LIT T T: $=$.

GO TO

$7 \quad$ LFT T1 $1=T_{1} / T_{T}(K, 1)$

LFT T?=TH

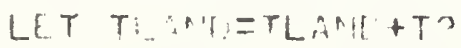

IF TI $\left(V_{0}\right)$ ) GT $\cap . n$, so TO 
LET TO=?

SC: TO in

O LET TP $=T 2 / T$ T M $(K, ?)$

10 LET TET $1+T$ ?

SRTTF. OH TAPF F, K,T?,TI,T

FODNAT (s10, I1, Gu, zחR.)

$=\quad$ LOOP

LFT TE! TLAINATTOFF) /THF

LFT TLAIDOTI_AIJI/TH?

LET TTAEF=TTOFF/THO

WEITE O: TAPE G, TLANID, TTOEE, T

FCF'A $(59$, 'TOTAL'.51, 2798.1///)

IF CAD I.E ), 5,0 TO 4

IFTTE $\cap$ I TAPF 6

FAR:AT (C5, AVFQAGE HOHIRLY DELAYO//

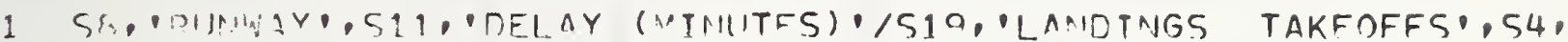
- TOT:UL, /

LFT DLA'Jn=0.

LFT DTAFF=n.

DO TO $\approx$ F FnP FACH $\cap ! ! \mathrm{V}$

LFT $T 1=T \cap Q_{1}:(K, 1)$

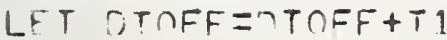

IF TI $1(K, 1)$ GT 0.0 , GO TO 11

LET TI=?.

GO TO !?

$11 \quad$ LET TI=T1/TIM $(K, 1)$

12 LET T?=TCR: $(K, ?)$

LF.T ח! $\lambda, \cap=\sim L \wedge !(?+T$ ?

If $T I \cdots(k, 2)$ GT $0 . \eta$, sก TO 13

LET TP=n.

Gก TO 14

$13 \quad L=T \quad T ?=T ? / T T \because(K, 2)$

14 LFT $T={ }^{\top} 1+T ?$

แRTT: n! TAPF מ. K,T?.T1,T

FOP:AT (51), I1. SH, RחR.1)

3 LOnP

LFT $T=(\cap I A J \cap+D T \cap F F) / T H D$

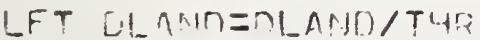

LET DTOFF=?TOFF/TH!)

WDITE O TANE F, OL AMR, OTOFF, T

FCF AAT (SO, TOTAL, , ऽ1, 3กB. 1///)

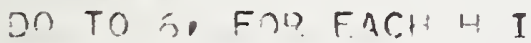

DC TO 5. FOR FACH SLOT $J$

$\operatorname{LTT} I \cap T(J)=\operatorname{IDT}(J)+\operatorname{LL} \operatorname{LY}(I,, 1)$

5 LCOD

- Lก:ก

CAIL :WITT

4 STOF

E:D E:IS 


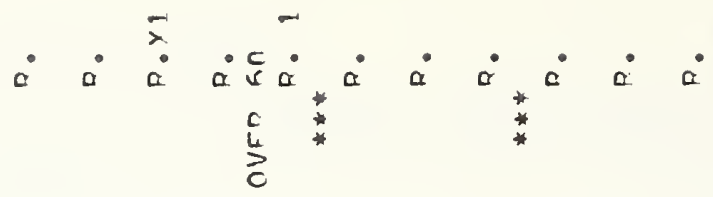

$$
\begin{aligned}
& \begin{array}{ll}
c & * \\
0 & * \\
i & *
\end{array} \\
& \begin{array}{l}
5 \\
5 \\
b \\
c \\
5
\end{array}
\end{aligned}
$$

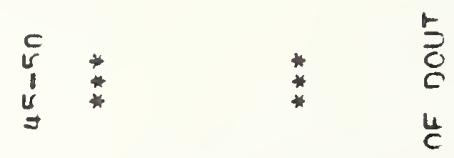

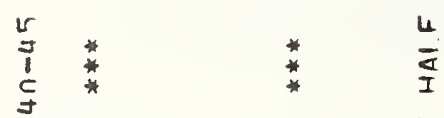

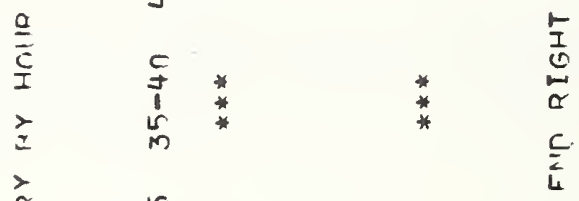

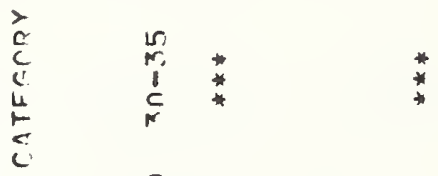

$$
\begin{aligned}
& \text { z) }
\end{aligned}
$$

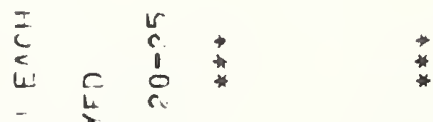

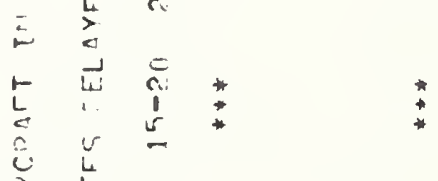

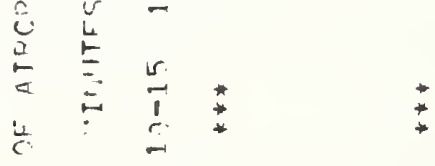

$$
\begin{aligned}
& \text { i }
\end{aligned}
$$

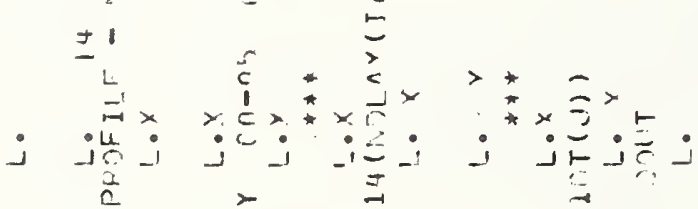

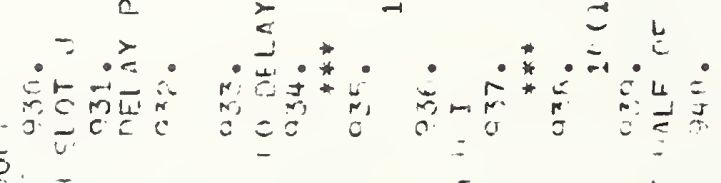

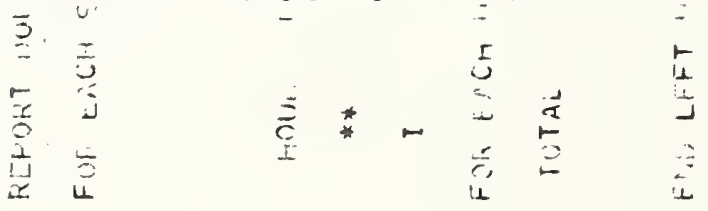


In Chapter 2 of this report we discussed a run of DELCAP using traffic schedule data from [3] together with actual runway-use information from the CATER data. These two data sources were matched, and the discrepancies noted were resolved to the extent possible. Figure F.1 records those errors, inconsistencies and mismatches which were found but could not be reconciled.

Three flights identified as TWPCK were listed among those scheduled, but were rejected because their flight identification numbers had incorrect form (correct form is two alphabetic characters followed by 3 or 4 numeric characters). We were unable to discover anything further about the identity of these flights, although it is speculated that they are TWA pilot check flights.

Three flights had a discrepancy between a scheduled aircraft type and the type actually used. Two Eastern flights scheduled for heavy aircraft actually used category 3 aircraft, and one Air New England flight scheduled for a light aircraft actually used a category 3 . In all three cases, the actual type used was input to the model.

A total of 43 flights were not matched. of this total, 24 are National flights which were scheduled but did not occur because of a strike by National employees. This left unexplained a total of six scheduled flights which did not actually occur, and 13 flights which occurred but were not among the list of those scheduled, amounting altogether to an error in less than 3 percent of all the scheduled flights.

A 1ist of all flights, arrival/departure designator, aircraft type, runway used, scheduled and actual operation time is given in Figure F.2 at the end of this appendix in order of actual operation time. All times are in Greenwich Mean Time (GMT), and since local time on October 25th was Eastern Daylight Time, one can obtain local time from GMT by subtracting 4 hours.

Several other problems in reconciling the two data sets were encountered and overcome. The schedule data, being computer output, had a fixed format: 7-character flight ID, two leading alphabetic characters, followed by a zero and 4 trailing numerics. The CATER data listed the flight ID with no extra zeroes between the alphabetic airline identifier and the numeric flight code. In addition, airline identifiers for suburban carriers are not the same in the two sources. For instance Air New England is ANE in the CATER data and NE in the schedule data, Command Airways is CMD in CATER and DD in the other, and Catskill Airways is CSK in CATER and $\mathrm{KF}$ in the schedule data. 
FIGURE F.1

\section{Inconsistencies in Two Data Sources}

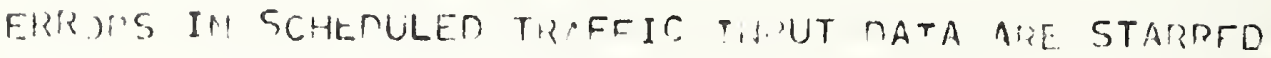

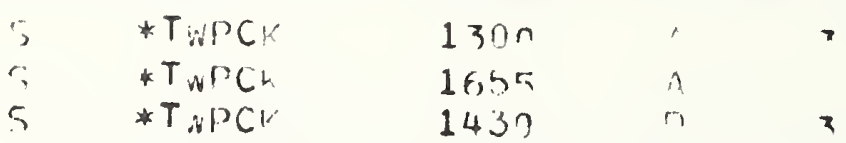

AIRCPAFT TYPF. INCOISISTENCY. SCIERUIEN TYME IN FAOFNTHFSEG.

\begin{tabular}{|c|c|c|c|c|}
\hline FAO414 & $44 ?$ & 417 & $\Lambda$ & $3(1)$ \\
\hline i. F 1448 & 1335 & $13 ? n$ & r) & $3(2)$ \\
\hline$E A \cap 011$. & $142 ?$ & $1, n n$ & 0 & $3(1)$ \\
\hline
\end{tabular}

73; SCHFUILE: ODERATIOIS RF1: UF :HTRH 30 WFIF MOT MATCHEN

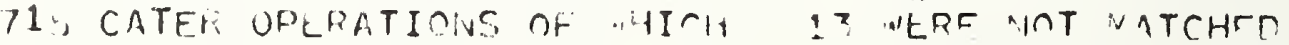


FLI; ;HTS 1:00 FUIIIN

IN TIF TCHENIILE LIATA

IH THE CATER TATA

\begin{tabular}{|c|c|c|}
\hline "A.0605 & 19 & $\therefore$ \\
\hline$\because A O B 11$ & $1 \cap n$ & T \\
\hline 141605 & 10? & $n$ \\
\hline * $1 \cap 61 c^{\prime}$ & 413 & 9 \\
\hline A060 & 417 & 1 \\
\hline 70729 & $42 n$ & r. \\
\hline A060? & 455 & $n$ \\
\hline$[00031$ & 1125 & १ \\
\hline
\end{tabular}

$\begin{array}{llll}r .20361 & 24 & A & ? \\ c .2600 & 43 & A & ?\end{array}$

31

31

$$
\wedge \text { ก. } 35 n
$$

152

31

$\begin{array}{rrrrr}E .0706 & 243 & 0 & 3 & 31 \\ F A 2435 & 255 & r & 2 & 04 \\ E .7121 & 1932 & n & 3 & 13 \\ 1.10903 & 1206 & n & 3 & 13\end{array}$

A 0143

1305

1213

: $A 0055$

1355

$\therefore A \cap 05$ S

1417

F.1012?

13110

n 3

13

१ก144 $1523 \quad 1$

U१7218

1437

13

22

A. $043 y$

1535

$\begin{array}{ll}n & 2 \\ 1 & 3\end{array}$

Aी 428

1547

$155^{n}$

$T .1032^{\circ}$

1553

$n$

13

Aก $14 \hat{i}$

1540

$155 n$

. 11446

17.5

$5 \times 7 \times 23$

1716

$A$

3

22

I $\triangle \cap 000$

1407

$\therefore$ LL 0677

1845

A 44 ?

1915

$\triangle 10021$

1027

त 40129

2ก15

MO14E

2129

215 ?

A0094

¿23?

VFค $\cap 74$

2748

$\wedge 3$

22

CP06ก1

2275

A गก0 3

2300

NF2472

.254

$n$

3

31 
Another difference between the two sets concerns the designation of the Eastern Air Shuttle flights. Each such flight appeared in the schedule data once with the symbol < as the final character in the ID. It appears in the CATER data as many times as there were sections of the flight. There were different numbering schemes in use for the shuttle flights in the two data bases, which required further hand reconciliation. Al1 of these discrepancies were identified and standard formats decided upon, using the two-letter airline code from the schedule data and a four-digit, right-justified numeric flight code. Additional sections of the air shuttle were included as scheduled when they actually occurred. Differing shuttle numbering schemes were eliminated by an arbitrary choice of one coherent scheme. The result of these efforts is the list of 702 flights in Figure F.2. 
DETAILED FLISTIT OITPIIT

FLT II) A/O TYME RIFAAY SCIFDILEN ACTHAL

TWOLES

0
$D$
A
$U$
A
L
A
D
D
A
A
U

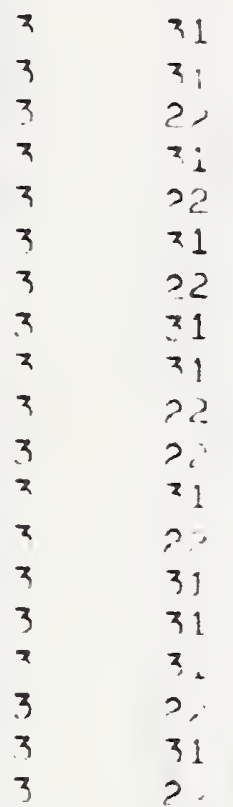

2250

AAO 350

AL 0753

AAO5:2

AL 0757

UAO4??

EAO $11: 4$

NE $1+1+2$

$A A 0>06$

UA.0.332

EA1:? 1

EAZSË

$A A O=28$

$T: 0,53$

TW0.359

OL1406

PI0053

UAO 250

$\mathrm{AAO}_{4}, 3 \mathrm{O}$

$\mathrm{TWO}_{\mathrm{W}} \mathrm{X} 3 \mathrm{3}$

2

3

EA0541

$A A O ; 11$

$A A 03 \div 1$

ALO,$\cap 1$

EA1:33

EA2 131

$E A 11 \geq 3$

UAD:3??

EA21 32

TWD346

NWD 224

EAO 3: 7

$A A 0273$

500719

UAD $7 \div 6$

AAO 20

ALO 7149

$\mathrm{NW} 0211$

DL1248

$A D O \geq 59$

$A L 0,18 B$

T.1014 1

FA2512

UAO\&?

AAO $\$ 47$

FA1 1?:5

A

U

o

U

A

D

A

$A$

U

i)

321

$3 \quad 31$

3 ?

$=31$

$3 \quad 31$

$3 \quad 21$

3 2:

3 ?

32

3 ?2

3 ??

$3 \quad 31$

$32 ?$

2 31

3 ?

320

32 ?

323

3 ?

3

$?$

3.

?.

?

71

2

ij

3

3

3

2

3

$?$

2? 255

$230 \mathrm{r}$

2? 10

2234

$233^{\circ}$

$2)^{2} \mathrm{U}$

$2=10$

2300

2.305

$2.2^{2}$

1

$2 \times 3$

$2 \times 4$ ?

2745

$2 \times 5 n$

$233 r$

2350

2347

2.355

2255

2045

2300

2.345

25

त)

25

$2.35 n$

27

2339

2ख51

$275 n$

232 .

2347

2.? 40

?

2.20

2700

2355

5

49
$2 \times 55$

$233 n$

$4 \%$

ก

$$
1
$$$$
1
$$$$
\text { ? }
$$$$
3
$$$$
4
$$

5

6

8

in

11

12 .

12

14

16

16

17
17

28

19

20

22

23

ग 4

25

26

ग6

27

27

29

30

21

32

33

34

36

36

38

38

20

39

40

41

$4 ?$

15

46 


\begin{tabular}{|c|c|c|c|c|c|}
\hline 118,0725 & u & 3 & $2 i$ & 5 & 117 \\
\hline$A A \cap ?:=7$ & 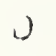 & 2 & 1 & 1 & $1+\beta$ \\
\hline$A \cap 01,4$ & $A$ & 1 & $?:$ & $2^{x}$ & 148 \\
\hline$T$ TSO 0160 & $A$ & 3 & 2 & $234 n$ & 50 \\
\hline DLOPOO & $\dot{\lambda}$ & 3 & 22 & $2.34 ?$ & 51 \\
\hline$A \Delta 0 \geq S 4$ & $A$ & 3 & 22 & 2747 & 53 \\
\hline$A A 0 \rightarrow 45$ & $H$ & 3 & 22 & $n$ & 55 \\
\hline Aम 0154 & $A$ & $\begin{array}{l}3 \\
3\end{array}$ & $? 2$ & $235 n$ & 57 \\
\hline$E \cap 11 \geq 1$ & $A$ & 3 & $2 \%$ & $4^{-}$ & 59 \\
\hline $\begin{array}{l}T=0350 \\
A A O 5,6\end{array}$ & $A$ & 3 & 22 & 32 & $1 \cap 0$ \\
\hline $\begin{array}{l}A A O \div=6 \\
A A O 4 \cap 1\end{array}$ & $A$ & 3 & 22 & $3^{n}$ & $1 \cap 1$ \\
\hline $\begin{array}{l}A A O 4 \cap 1 \\
A \cap O D \cap\end{array}$ & $u$ & 3 & 31 & ก & $1 \cap 1$ \\
\hline ANOInC & A & 3 & $2 ?$ & $2 \cap 1=$ & $1 \cap ?$ \\
\hline$E \wedge 11: 3$ & $a$ & 3 & $2 ?$ & $10 a$ & $1 \cap 6$ \\
\hline EA15:3 & $J$ & $x$ & 21 & 102 & $1 \cap \Omega$ \\
\hline$A A 0 \leq 1,2$ & $A$ & 3 & $? 2$ & 45 & 130 \\
\hline$E A 2141$ & () & 3 & $=1$ & $10 n$ & 100 \\
\hline$E A 2, ? 4$ & $A$ & 3 & 0 & 114 & 110 \\
\hline AA 0,341 & $\checkmark$ & 3 & 31 & n & 110 \\
\hline EAOSF5 & 0 & 3 & 31 & $2.34^{n}$ & $1 ! 1$ \\
\hline PIOU: & $\Lambda$ & 3 & $?=$ & 't & 111 \\
\hline$A L O \& 51$ & 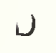 & 3 & 31 & 45 & 113 \\
\hline$E 40052$ & $A$ & 3 & $? ?$ & $23.5=$ & 113 \\
\hline DL0218 & $A$ & 3 & $\rho ?$ & 211 & 114 \\
\hline NCO $15 P$ & $\hat{H}$ & 3 & 22 & $5 n$ & 116 \\
\hline FADOOB & A & $\pi$ & $? 2$ & 31 & 117 \\
\hline UAO3:17 & U & 3 & $x_{1}$ & 55 & 190 \\
\hline$A A O,, 22$ & $A$ & 3 & $?$ & $4 ?$ & 119 \\
\hline$A \wedge 03 \Omega ?$ & $A$ & 3 & $?$ & 57 & $1 ? 0$ \\
\hline$F A 1141$ & $A$ & 3 & 2 & $14 r$ & $1 ? 1$ \\
\hline$A A 0,51$ & L & 3 & 71 & $2^{n}$ & $1 ? 1$ \\
\hline$A A 025,0$ & $A$ & 3 & $?$ & $2^{2}$ & 120 \\
\hline DL1275 & $\dot{i}$ & 3 & 31 & 100 & 123 \\
\hline$A \wedge D_{1}>0$ & 0 & 3 & 31 & 2355 & 124 \\
\hline$E A 25 \geqslant 1$ & $A$ & 3 & 22 & $5^{x}$ & $1>4$ \\
\hline $\mathrm{AAO}_{4}=\mathrm{C}$ & $\mathrm{B}$ & 3 & 31 & $3 n$ & 127 \\
\hline EAOIOO & $A$ & 3 & 0 & 24 & 127 \\
\hline USOOBI it & $A$ & 3 & $?:$ & 51 & $1 ? 9$ \\
\hline$A^{\prime} O_{1}=2$ & $A$ & 3 & 2 & $1 \%$ & $1 \geq 0$ \\
\hline DLO & U & 3 & $3 i$ & 27 & 130 \\
\hline Tw0? & $\hat{i}$ & 3 & 2 & 2340 & $1 \times 3$ \\
\hline$E A 2,32$ & $A$ & 3 & ? & 135 & 135 \\
\hline Tw1 12 ? & $A$ & 3 & 22 & $10 ?$ & 136 \\
\hline$\triangle A O D, \cap B$ & $A$ & 3 & 22 & 100 & 138 \\
\hline NWO 030 & $A$ & 3 & 39 & $10 x$ & $14 n$ \\
\hline$A A O 311$ & $u$ & 3 & 21 & $3 n$ & 140 \\
\hline$A A O 5 / 5$ & ij & 3 & 21 & 900 & $14 ?$ \\
\hline EAOUIR & $A$ & 3 & 22 & $5 n$ & $112 ?$ \\
\hline DUO 01147 & $\Lambda$ & 2 & 21 & $2 \times 2 n$ & 14.3 \\
\hline$A L 0 S: 7$ & $A$ & 3 & $?$ & $5 n$ & 143 \\
\hline$T * 0,1+6$ & $A$ & 3 & 3 & 45 & 115 \\
\hline$F \cap 25 n 1$ & $\therefore$ & 3 & $2 \ddot{c}$ & 142 & 146 \\
\hline
\end{tabular}




\begin{tabular}{|c|c|c|c|c|c|}
\hline$E A D_{1}, 16$ & A & 2 & $?:$ & $12^{5}$ & 147 \\
\hline EAट14? & j & 3 & 71 & 94. & $1: 1.2$ \\
\hline$A A O<1$ & 1) & $z$ & 21 & $3-$ & 140 \\
\hline$\triangle A O_{1} 4{ }^{\circ}$ & $A$ & 3 & $?$ & $5 n$ & $15 n$ \\
\hline$A \cap 0=56$ & $\lambda$ & 3 & 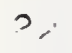 & 121 & 152 \\
\hline$E \wedge 1 \supset 11$ & 2 & 3 & $3:$ & lun & 15.3 \\
\hline$E A \cap 753$ & $\hat{A}$ & 3 & 2 & $? \times 5 ?$ & $15 x$ \\
\hline$F \cap 0 ๖ 40$ & $\dot{A}$ & 3 & $?$ & 139 & 155 \\
\hline DU0:25 & U & $?$ & $2 \%$ & 55 & 156 \\
\hline$A L O, 7,3$ & $\hat{A}$ & 2 & $2 \hat{\imath}$ & $12 r$ & 157 \\
\hline $\mathrm{T} \times \mathrm{O}+7 \mathrm{~F}$ & $A$ & 2 & 32 & $12^{7}$ & 152 \\
\hline B:HD(110) & A & 3 & 22 & 125 & 150 \\
\hline$A L O, ! 2$ & $A$ & 3 & 32 & 5 & $2 ! 1$ \\
\hline $\begin{array}{l}E A 0415 \\
E A 1] 43\end{array}$ & $\stackrel{b}{A}$ & 1 & $\begin{array}{l}3 ! \\
3 !\end{array}$ & $\begin{array}{l}101 \\
200\end{array}$ & $\begin{array}{l}2 \cap ? \\
20 ?\end{array}$ \\
\hline$T: 0: 54$ & $r_{1}$ & 3 & 2? & 132 & $2 \cap 4$ \\
\hline ACIO3.54 & H & 3 & 22 & 1411 & 2nG \\
\hline $\mathrm{APO}_{4}>\mathrm{G}$ & i) & $x$ & 31 & 115 & $2 \cap 9$ \\
\hline$E \wedge 2412$ & $\wedge$ & 3 & 22 & 200 & 279 \\
\hline PIO 125 & ن & 3 & 31 & $11 \%$ & 210 \\
\hline PIOG & $\hat{\mu}$ & 3 & 22 & 147 & 211 \\
\hline OL0.357 & u & 3 & 21 & 125 & 211 \\
\hline EA2151 & U & 3 & 31 & 200 & 213 \\
\hline$T: 0434$ & $A$ & 3 & $? 2$ & 308 & 213 \\
\hline $\mathrm{EAO}_{417}$ & i) & 3 & $3 !$ & 100 & 215 \\
\hline$A 40.325$ & U & 3 & 31 & $10 n$ & 216 \\
\hline$A A \cap B=0$ & $\dot{\mu}$ & 3 & $2 ?$ & 214 & 219 \\
\hline DLO1.8 & A & 3 & 22 & por & 293 \\
\hline$F: 23,44$ & $A$ & 3 & 21 & 2211 & $2>4$ \\
\hline$T: 05: 1$ & L & 3 & 31 & 55 & $2 ? 7$ \\
\hline$A L .05 / 1$ & 0 & 3 & 21 & 156 & 228 \\
\hline ALO>5Y & U & 3 & 31 & 205 & 230 \\
\hline$A L D \leq, 1: 7$ & 0 & 3 & 31 & $13 n$ & 234 \\
\hline$E A 1545$ & $u$ & 2 & 31 & 236 & 235 \\
\hline$A, 101=1+$ & $A$ & 2 & 31 & 220 & 230 \\
\hline$\Gamma L 0_{3}=1$ & + & 3 & 23 & $23 n$ & 24.3 \\
\hline UAO9?S & $A$ & 3 & $2:-$ & $23 x$ & 245 \\
\hline AAח & $A$ & 3 & $?$ & $14 ?$ & 247 \\
\hline EA1151 & $\dot{A}$ & 2 & $?:$ & 249 & 250 \\
\hline$E A O 1.7$ & $u$ & 3 & 3. & $12=$ & 250 \\
\hline OLO1:3 & U & 3 & $n$. & 24. & 256 \\
\hline$E A \cap B_{i j}=x$ & 1) & 2 & 74 & $11^{-}$ & $? 5 R$ \\
\hline$E A 1)_{4} ? 1$ & U U & 3 & $n_{4}$ & २1: & 311 \\
\hline$A \wedge 01311 ?$ & $A$ & 3 & 9.1 & xin & 317 \\
\hline$A L(0,3: 4$ & A & 3 & $n 4$ & $x 1: 6$ & $3>7$ \\
\hline 8,0432 & $\rightarrow$ & 3 & $\therefore$ & 246 & $41^{2}$ \\
\hline$E A D+14$ & $a$ & 3 & 32 & 417 & $44 ?$ \\
\hline$F A O+15$ & $A$ & 3 & $2 ?$ & 417 & 449 \\
\hline $0 \leq 0,74$ & $A$ & 2 & 22 & 1120 & 4LS \\
\hline 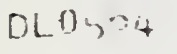 & i & $z$ & 28 & $45 \%$ & $5=2$ \\
\hline
\end{tabular}




\begin{tabular}{|c|c|c|c|c|c|}
\hline$A \wedge 0,1+?$ & $n$ & 3 & 12 & $31 r$ & $70 ?$ \\
\hline EA21:1 & 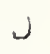 & 3 & 13 & $11 \cup n$ & 1175 \\
\hline$F \cap 14\{1$ & 0 & 3 & 13 & 11 ก & $11 \cap 7$ \\
\hline$A \cap O_{i}>1$ & i) & 3 & .3 & $110^{n}$ & 1111 \\
\hline AADitis & $u$ & 3 & 1.3 & $110 n$ & 1111 \\
\hline DL 1 y is & $u$ & 2 & 17 & 1105 & 1112 \\
\hline $\mathrm{ANO}_{4} 39$ & $D$ & 2 & 9.2 & 1100 & 1114 \\
\hline$A A \cap+41$ & u & 3 & 13 & $11 \cup 5$ & 1116 \\
\hline $\mathrm{AAO}_{4}>7$ & U & 3 & 15 & $11 u^{r}$ & 1117 \\
\hline$E A O 5,19$ & ) & 7 & 13 & 111 ? & 1110 \\
\hline DLOCOL & ') & 3 & 13 & 112 & $11>5$ \\
\hline FAOS:7 & U & 3 & 13 & $1 ! 2^{r}$ & 1127 \\
\hline$P I 0_{11} 57$ & (1) & 3 & 13 & 1437 & 1135 \\
\hline$A A O+17$ & $\theta$ & 3 & 13 & 193 & 1135 \\
\hline$A A 0,, \therefore=7$ & 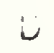 & 2 & 93 & 1130 & 1139 \\
\hline$A A O C, O Q$ & ()) & 3 & 93 & $193 n$ & 1130 \\
\hline$A A \cap 3 \cap 7$ & A & 3 & 32 & 1932 & 1142 \\
\hline EAICO1 & $\Lambda$ & 3 & 22 & 1140 & $11 / 6$ \\
\hline$E A O=: n$ & A & 3 & 22 & $115^{\circ}$ & 1140 \\
\hline$T: 0127$ & i) & 2 & 13 & $114 r$ & 1151 \\
\hline$E A 24 \cap 1$ & $A$ & 3 & $3 ?$ & $114 \mathrm{~F}$ & 1153 \\
\hline UAO 111 & !! & 3 & 93 & $114 n$ & 1153 \\
\hline DEOan? & 2 & $?$ & 32 & 1145 & 1155 \\
\hline ALOang & $\cup$ & 3 & 13 & 1145 & 1155 \\
\hline$F \cap 1+11$ & i) & 3 & 13 & 1200 & 1157 \\
\hline $\mathrm{NCO})^{\circ} 1$. & U & $x$ & 13 & 115 & 1159 \\
\hline$A A U: A$ & $A$ & 1 & 32 & $115 r$ & 1150 \\
\hline$T w 0.3113$ & $u$ & 3 & 13 & $114 \%$ & 1270 \\
\hline$E A O .351$ & L & 3 & 13 & $115 ?$ & $12 n 1$ \\
\hline$A A \| ?=2$ & $A$ & 3 & 22 & $115 ?$ & $12 \cap 3$ \\
\hline$A A O 1 \geq 5$ & $U$ & 3 & 13 & 1945 & $12 n .3$ \\
\hline $\mathrm{AAOS} \times 7$ & i & 3 & 13 & $115 r$ & 12114 \\
\hline Dlioisel & A & 3 & $2 ?$ & $115 \mathrm{~F}$ & $12 \cap 4$ \\
\hline$F \cap 21,11$ & u) & 3 & 13 & 1200 & 1207 \\
\hline$A \cap 0,10$ & in & 3 & 22 & 1201 & 1279 \\
\hline UAO4=5 & $j$ & 2 & 13 & $120 n$ & 1209 \\
\hline ALO 7166 & $A$ & 3 & 2 & $121^{n}$ & 1212 \\
\hline$E \cap 01 \cap 1$ & $u$ & 3 & 13 & 12010 & $121 ?$ \\
\hline$A A O=9$ & 0 & $x$ & 13 & $1 \hat{\imath} \cup$ & 1214 \\
\hline$K F 0_{1} \cap 7$ & $A$ & 2 & ?? & $1>15$ & 1215 \\
\hline EA1413 & i) & 3 & 13 & 1215 & 1216 \\
\hline$T w 0317$ & is & 3 & 13 & 1207 & 1217 \\
\hline OLOS. 5 & $A$ & 3 & 32 & 1213 & 1217 \\
\hline$A A 0,77$ & $A$ & 3 & $=2$ & $1 ? 1^{n}$ & 1220 \\
\hline$A A O \cap \cap G$ & $\mathrm{~L}$ & 3 & 13 & 1200 & 1220 \\
\hline$A L 07=?$ & $A$ & 3 & 22 & 1207 & $12 ? ?$ \\
\hline EA2U12 & () & 3 & 13 & 1??? & 1222 \\
\hline OLO1BB & $A$ & 2 & 22 & 1154 & 1224 \\
\hline DLOC:9 & $n$ & $x$ & $2=$ & $1 ? 11$ & 1226 \\
\hline NI 1::77 & $A$ & $?$ & $? 2$ & $1>1$ & $12 ? \Omega$ \\
\hline
\end{tabular}




\begin{tabular}{|c|c|c|c|c|c|}
\hline$\triangle A O 4=?$ & $A$ & 3 & 32 & 1216 & 1230 \\
\hline KFOL11 is & U & $?$ & 22 & $125 r$ & 1233 \\
\hline$T: 0: .6 .7$ & $\mathcal{U}$ & 2 & 13 & $1>2 n$ & 123.3 \\
\hline$T+01 \geqslant 9$ & i & 2 & 13 & 1220 & 12.33 \\
\hline$E A 0,562$ & H & 3 & 2 & 1325 & 1236 \\
\hline $\mathrm{N}: \mathrm{O}_{2} \cap 1$ & i) & 2 & 13 & $1.3 r$ & 1236 \\
\hline$A A O ., 40$ & $A$ & 3 & ?? & 1.027 & 1238 \\
\hline 000042 & 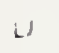 & 2 & $? ?$ & $123=$ & $12 ' 11$ \\
\hline$A H 0510$ & $U$ & 3 & 13 & $1: 3-$ & 9241 \\
\hline NE1n'1 & $\dot{A}$ & 3 & 32 & $1 ? 2^{5}$ & 1243 \\
\hline NE $14: 9$ & $A$ & 3 & 22 & 1240 & 1246 \\
\hline$E A O_{i}:=0$ & [) & 3 & 13 & 124, & 1247 \\
\hline$A A O C 75$ & U & 3 & 13 & $124^{\circ}$ & 1249 \\
\hline$A L O_{1}=3.3$ & [: & 3 & 13 & 1245 & 1250 \\
\hline$T * 0=20$ & $\therefore$ & 2 & 22 & $124 n$ & 1251 \\
\hline$N E 1, R 1$ & $\dot{\mu}$ & 3 & 22 & $123 n$ & 1252. \\
\hline$T \cdot 1046,6$ & $A$ & 3 & $P 2$ & 1,40 & 1254 \\
\hline R1:0.101 & 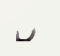 & 3 & 13 & 1240 & 1255 \\
\hline$A L 0751$ & $\dot{u}$ & $z$ & 13 & $125^{\circ}$ & 1256 \\
\hline ER2 +11 & $\therefore$ & 3 & 32 & $125=$ & 1256 \\
\hline$T: 0.515$ & L & 3 & 1.3 & $124=$ & 1257 \\
\hline$A, \cap \cap 24$ & $A$ & 3 & 22 & 1247 & 1250 \\
\hline FAO3: J & is & 2 & 13 & $122^{\circ}$ & 1301 \\
\hline Tw0112 & $\vec{A}$ & 2 & 32 & $123=$ & $13 \cap 1$ \\
\hline UNOY 0147 & $u$ & 3 & 1.3 & $125 ?$ & $13 \cap 2$ \\
\hline EA1:11 & $A$ & 3 & 22 & 1246 & $13 n 2$ \\
\hline$A L 0, \sin 2$ & 4 & 2 & 22. & 1245 & $13 \cap 4$ \\
\hline 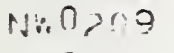 & $\dot{U}$ & $z$ & 13 & $1 ? 5^{\circ}$ & $13 \cap 4$ \\
\hline$F A, 05,33$ & $A$ & $\therefore$ & 32 & $1>4^{n}$ & 1306 \\
\hline$T: 01>7$ & $i$ & 3 & 13 & 125 & $13 \cap 7$ \\
\hline$E \cap 14=1$ & j & 3 & 13 & $130 r$ & $131 ?$ \\
\hline$A \hat{A} O=\therefore 0$ & $\therefore$ & 3 & 32 & $1.30 n$ & 1312 \\
\hline OLO $0=5$ & 5 & 3 & 13 & $125 \pi$ & 1313 \\
\hline$A=34=4$ & H & $z$ & 32 & 1309 & 1314 \\
\hline $\mathrm{AAU}_{4} ? \mathrm{~B}$ & i & 1 & 1.3 & 1245 & 1315 \\
\hline NE 1476 & $j$ & 2 & วิ & $1=0 n$ & 1316 \\
\hline$A L 0$ i 35 & $A$ & 3 & $\partial_{c}$ & $134 \%$ & 1315 \\
\hline$E A 2 \cap>1$ & J & $x$ & 13 & $1 \times 0 n$ & 1317 \\
\hline$E A 1423$ & j & 3 & 13 & $1 \geq 12$ & $131 \%$ \\
\hline DL02n: & $u$ & 3 & $! j$ & 1310 & $13 \geq 0$ \\
\hline UfIOB. & h & 3 & $2 ?$ & 1300 & 1320 \\
\hline $\mathrm{AAO}_{4} ; 2$ & 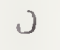 & 3 & 1.3 & $120-$ & 1321 \\
\hline$A A O=35$ & 1) & 3 & 13 & 1300 & 1321 \\
\hline$A A 0, ? 9$ & 0 & 1 & 13 & $1.20 n$ & 1322 \\
\hline EA1)13 & i & 3 & $? \bar{z}$ & 1324 & $13 \geq 4$ \\
\hline $\mathrm{NESin} 72$ & $u$ & 3 & 22 & 1315 & 1325 \\
\hline$P I O \cup 76$ & $H$ & 3 & 22 & $125 n$ & 1325 \\
\hline$A A 0577$ & $u$ & 3 & 13 & 1355 & 1327 \\
\hline$\Delta L 0 \div 42$ & $\alpha$ & 3 & 32 & $125=$ & $13 ? 8$ \\
\hline NE1 Ink? & $\checkmark$ & 3 & 32 & $1 \geq 2 n$ & $13 ? 8$ \\
\hline
\end{tabular}




\begin{tabular}{|c|c|c|c|c|c|}
\hline$E \cap D, 0,1$ & $a$ & 3 & $? ?$ & 1.315 & $13>9$ \\
\hline$A A 04+1$ & $u$ & 3 & 13 & 1200 & 1330 \\
\hline AAO & $A$ & 3 & $? ?$ & 1315 & 1333 \\
\hline NE 1 +ifa & $\because$ & 3 & 1.3 & $132^{n}$ & 1335 \\
\hline$A L 0 \div 1 \cap$ & $A$ & 3 & .2 & $1 \times 1 n$ & 1336 \\
\hline$O L 0_{177}$ & U & z & 1.3 & $132^{r}$ & 1337 \\
\hline A 0398 & A & 3 & 22 & $1^{2} 1=$ & 1338 \\
\hline TwO 3n6 & i & 3 & $? ?$ & 1327 & 1.3160 \\
\hline AAO:?? & $A$ & 3 & 32 & $13 \overline{2} n$ & 1342 \\
\hline$A \cap 0451$ & () & $x$ & 13 & $1 \times 25$ & $1.34 ?$ \\
\hline$F A 07+1$ & $U$ & 3 & 13 & $133 n$ & 13144 \\
\hline$E 1,0352$ & $\hat{A}$ & 3 & 22 & 1331 & $13+6$ \\
\hline ALO $07: 5$ & D & 3 & 13 & $133 n$ & 1316 \\
\hline$E A 2422$ & $A$ & 3 & $? ?$ & 1347 & 1347 \\
\hline EAOL, 3 & $1)$ & 3 & 13 & $1.24 i$ & 13140 \\
\hline$T x_{17}$ & L) & 3 & 13 & 1347 & 1350 \\
\hline$T: 0+06$ & 4 & 3 & 22 & 1.349 & 1350 \\
\hline$A A 0=04$ & $A$ & 3 & $? 2$ & 1343 & 1351 \\
\hline$A L 0$ it 35 & i) & 3 & 13 & 1325 & 13511 \\
\hline$E A 24: 1$ & $A$ & 3 & 32 & $1 \geq 51$ & 1355 \\
\hline EA1U,1 & $n$ & 3 & 22 & $1=5 n$ & 1357 \\
\hline$T \cdot 04>0$ & $A$ & 3 & $?=$ & $135 ?$ & 1350 \\
\hline$[Y L O, \cap B$ & $A$ & $x$ & $\therefore 2$ & 1315 & 1401 \\
\hline$A A D 36,3^{3}$ & () & 3 & 13 & 1.345 & $14 n ?$ \\
\hline Tw0.519 & $j$ & 3 & 13 & 1345 & $14 n 3$ \\
\hline$F A 14.31$ & $\dot{L}$ & $x$ & 13 & $140^{-}$ & 1405 \\
\hline $13 A 0,390$ & A & 3 & 27 & 1345 & $14 n 7$ \\
\hline AAO 0,711 & A & 3 & $? 2$ & $1 \times 47$ & 1478 \\
\hline$A L O 4+2$ & u & 3 & 13 & 1335 & $14 n 0$ \\
\hline $\mathrm{AAO}_{4}>0$ & $A$ & 3 & 32 & 1340 & 1410 \\
\hline$\triangle A O, 200$ & (1) & 3 & 13 & $140 n$ & 1411 \\
\hline A: $05: 4$ & $\lambda$ & 3 & $2 ?$ & 1405 & 1412 \\
\hline$T \wedge O_{1} 1$ & 1) & 3 & 13 & 1.345 & 1414 \\
\hline$F A 2,1 \times 1$ & 1) & 3 & 13 & 1400 & 1415 \\
\hline DL1995 & 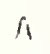 & 3 & $? ?$ & $140 n$ & 1415 \\
\hline$E A 1 \cup>3$ & $a_{4}$ & 3 & $2 \%$ & 1417 & 1417 \\
\hline A., $0 \geq 115$ & $\therefore$ & 3 & 13 & 1400 & 1417 \\
\hline AL 0405 & L & 3 & 13 & 1345 & 1419 \\
\hline $5007 ! 0$ & $A$ & $x$ & 32 & $140^{n}$ & $14 ? 1$ \\
\hline$\left.F A O_{1}\right) 11$ & i) & 3 & 13 & $140 n$ & 1422 \\
\hline$E A 1: \times 3$ & C & 3 & 13 & 1421 & 1424 \\
\hline$A A 0,3133$ & C & 3 & 13 & $140 r_{i}$ & 1426 \\
\hline PIO $117 ?$ & $U$ & 3 & 13 & 1.345 & 14.7 \\
\hline TwOuns & () & 3 & 13 & 1355 & $143 ?$ \\
\hline NhOz:I? & $A$ & 3 & 32 & 1424 & 14.33 \\
\hline DLOard & i) & 3 & 13 & $1 \geq 5$ & 1433 \\
\hline TN0.310 & $A$ & 3 & 32 & 1427 & 1434 \\
\hline$E \cap 1133$ & $A$ & 3 &, 2 & 1441 & 1441 \\
\hline$E A O_{1} \div 3$ & $U$ & 3 & 13 & 1435 & 1442 \\
\hline PIOnnt & $A$ & 3 & $=?$ & $135 n$ & 1444 \\
\hline
\end{tabular}




\begin{tabular}{|c|c|c|c|c|c|}
\hline$\triangle A 0573$ & 1 & 3 & 93 & $143 n$ & 1444 \\
\hline$A A O \div: 2$ & $A$ & 3 & $n$ & $143 n$ & 1446 \\
\hline $\mathrm{TW} 0 \supset>0$ & $A$ & 3 & 32 & 1445 & 1449 \\
\hline$E A 1: \geq 1$ & $\hat{4}$ & 3 & 22 & $144 x$ & 1450 \\
\hline$E A 0: 3(1) 2$ & $A$ & 3 & $\eta_{2}$ & 14214 & 1452 \\
\hline 440272 & $A$ & 3 & $2 ?$ & $144 x$ & 145.3 \\
\hline$E A 0543$ & L & 3 & 13 & 11145 & 1453 \\
\hline NCOOS & $A$ & 3 & 22 & $145 r$ & 1455 \\
\hline$A A O 3+9$ & 0 & 3 & 13 & $1113 n$ & 1455 \\
\hline NWO 0270 & $\therefore$ & 3 & 22 & $144 n$ & 1456 \\
\hline$T W 0 \cap 72$ & $\hat{A}$ & 3 & 22 & $145 ?$ & 1450 \\
\hline TW0.3:3 & B & 3 & 13 & 1445 & 1458 \\
\hline$A A D: 12$ & $A$ & 3 & $?$ & $14 t^{2}$ & 1450 \\
\hline$E A 2 \div 31$ & $i$ & 3 & 22 & $145 n$ & $15 \cap 2$ \\
\hline 500713 & $u$ & 3 & 13 & 1455 & $15 n 2$ \\
\hline EAO150 & $a$ & 3 & 22 & 11159 & 1504 \\
\hline EA1441 & i) & 2 & 13 & $150 n$ & 1505 \\
\hline $11 A 0: 3: 10$ & $A$ & 3 & 22 & $145 \%$ & 1.506 \\
\hline UAO $\$ 11$ & $u$ & 3 & 13 & $15 n \pi$ & $15 \cap 8$ \\
\hline PI0:172 & $A$ & 3 & 22 & 11147 & $15 \cap 8$ \\
\hline 1140459 & 0 & 3 & 13 & 1505 & 1510 \\
\hline$A A 0,98$ & $A$ & 3 & 22 & 1505 & 1510 \\
\hline$A L O 4 x 2$ & $\dot{A}$ & 3 & 22 & 1455 & 1513 \\
\hline$T: 0115$ & 0 & 3 & 13 & $150 \mathrm{or}$ & 1515 \\
\hline $4 \times 0450$ & $A$ & 3 & 22 & 1517 & 1516 \\
\hline$A A O, \backslash, 7$ & $u$ & 3 & 13 & $150 \mathrm{n}$ & 1516 \\
\hline$A \cap \cap++13$ & i) & 3 & 13 & $150 \mathrm{n}$ & 1317 \\
\hline$A A O 4 \times 3$ & i) & 3 & 13 & 1500 & 1518 \\
\hline$E A 2,141$ & 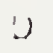 & 3 & 13 & $150 n$ & 1510 \\
\hline$A \triangle 0>21$ & $A$ & 3 & 22 & $1=1 n$ & $15 ? 1$ \\
\hline DL1) 14 & () & 3 & 13 & $1=2 n$ & 1523 \\
\hline$T=0.314$ & $\Lambda$ & 3 & 22 & 1520 & 1526 \\
\hline$A A O \perp 42$ & $A$ & 3 & 22 & 1505 & 1529 \\
\hline DLO709 & $A$ & 3 & .22 & $152 ?$ & 1530 \\
\hline$A \cap 0\{06$ & $A$ & 3 & $? 2$ & 1523 & 1.535 \\
\hline$\triangle A O 41: 2$ & $\checkmark$ & 3 & 13 & $153 n$ & 1536 \\
\hline$A \cap 046,3$ & $u$ & $x$ & 13 & $153 r$ & 1538 \\
\hline$E-20+0$ & u & 3 & 13 & $154 \circ^{\circ}$ & 1540 \\
\hline PIOOOOI & 0 & .3 & 13 & 1445 & 1541 \\
\hline$E A 111+1$ & $A$ & 3 & 22 & $154 \pi$ & $154 ?$ \\
\hline EAO1-3 & $\lambda$ & $z$ & $2 i$ & $153 ?$ & 15,5 \\
\hline UAO $3 \cap 4$ & $\hat{A}$ & 3 & .2 & 15,35 & 1547 \\
\hline$E A 0150$ & U & 3 & 13 & 1537 & 1548 \\
\hline AND 33 & u & 3 & 13 & $154 r$ & $15 / 18$ \\
\hline$T w 0124$ & $A$ & 3 & $2:$ & 15,46 & 1552 \\
\hline $0<0-176$ & $\hat{A}$ & $x$ & 22 & 1545 & 1553 \\
\hline ALO +7.3 & i) & 3 & 13 & 1545 & 1554 \\
\hline$N * 0,>7$ & U. & 2 & 13 & $154^{n}$ & 1556 \\
\hline$F A 1 \| 43$ & $d$ & 2 & 32 & $155^{-}$ & 1557 \\
\hline NA $0>15$ & (i) & 3 & 13 & $155 n$ & 1557 \\
\hline$\triangle A D 3 \cap 2$ & $A$ & 3 & 26 & $154 \Omega$ & $16 \cap 1$ \\
\hline $4 A 0 ? 73$ & $A$ & 3 & 32 & 1601 & 1602 \\
\hline$A A \cap<39$ & U & 3 & 13 & is.un & $16 \cap ?$ \\
\hline$A \cap 0 \backslash \cap 4$ & $A$ & 3 & 22 & 1545 & 1604 \\
\hline
\end{tabular}




\begin{tabular}{|c|c|c|c|c|c|}
\hline$E \cap 2+41$ & $A$ & 3 & $2 ?$ & $155^{\circ}$ & 1605 \\
\hline $\mathrm{NCO}, 53$ & 1) & 3 & 13 & 1600 & 16,76 \\
\hline$E \cap 0 \%: 1 \cap$ & 4 & 3 & 22 & 1550 & $16 \cap 8$ \\
\hline$E \hat{n}, 0,1)$ & $A$ & 3 & 22 & 15.50 & 1610 \\
\hline EA?0 51 & 0 & 3 & 13 & $160 \cap$ & 1610 \\
\hline$E A 1+c \cdot 1$ & W & 3 & 13 & $160 n$ & 1611 \\
\hline $\mathrm{EAO} O 17$ & 5 & 3 & 1.3 & Ifor & 1613 \\
\hline UAOn $1 Y$ & $U$ & 3 & 13 & $160 n$ & 1615 \\
\hline AAO 1135 & $A$ & 3 & 22 & 1600 & 1616 \\
\hline AAD 271 & U & 3 & 13 & 1600 & 1017 \\
\hline$A A \cap, \cap \cap 7$ & $\mathrm{U}$ & 3 & 13 & $160^{\circ}$ & 1619 \\
\hline$T w 0171$ & $\cup$ & 3 & 13 & 1605 & $16 ? n$ \\
\hline$\triangle A O 524$ & $A$ & 1 & 22 & $1<21$ & 1621 \\
\hline DLO7n3 & $u$ & 3 & 13 & 1617 & $162 ?$ \\
\hline$P I 0,179$ & $U$ & 3 & 13 & 1555 & 1623 \\
\hline$C L O+58$ & $A$ & 3 & $3 ?$ & 1607 & 1604 \\
\hline $1100 \times 5,5$ & ن & 3 & 13 & 1625 & $16 ? 2$ \\
\hline$E A O S: 0$ & $A$ & 3 & $2 ?$ & 1625 & 1638 \\
\hline$F \wedge 01 \cap 2$ & $\hat{A}$ & 3 & $? \varepsilon_{2}$ & $155 n$ & 1631 \\
\hline$A \cap 0.3<1$ & U & 2 & 13 & $162 n$ & 1634 \\
\hline 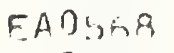 & $A$ & 3 & 2 & 1637 & 1634 \\
\hline OL0.370 & $A$ & 2 & ? & 16in & 1635 \\
\hline$E A O 163$ & L' & 3 & $1 ;$ & $1<15$ & 1636 \\
\hline UAO4 5 & i) & 3 & 13 & $16.3 n$ & 1638 \\
\hline$F=2451$ & $A$ & 3 & 22 & $1 \in 5 n$ & 1630 \\
\hline$A A O, 79$ & $U$ & 2 & 13 & $16.3 n$ & 1640 \\
\hline$T$ Two318 & $A$ & 3 & $2 ?$ & 1626 & $16: 1$ \\
\hline RivOnn2 & $n$ & 3 & 22 & $1<2 x$ & 104.3 \\
\hline$E$ En $1,1,1$ & $A$ & 2 & 22 & $164 n$ & 1616 \\
\hline NE 1447 & $\Lambda$ & 3 & 22 & 16.35 & 1648 \\
\hline $11404: 9$ & ij & 2 & 13 & $164 r$ & $165, n$ \\
\hline $0<0009$ & 0 & 3 & 13 & $164=$ & 1651 \\
\hline$A, 0 \geqslant * 1$ & U & 3 & 13 & 16,42 & 1654 \\
\hline NE $1 ; 73$ & $\Lambda$ & $x^{2}$ & 32 & $164 n$ & 1655 \\
\hline$E A O: 50$ & $A$ & 3 & 22 & $165^{a}$ & 1.657 \\
\hline$T w 05,15$ & $\dot{U}$ & 3 & 13 & 1645 & 165,8 \\
\hline$F A 0115$ & $A$ & 3 & $?_{i}$ & $170 ?$ & 1550 \\
\hline$A \cap O, \cdots, B$ & $A$ & 3 & 28 & $155 r$ & $17 n 1$ \\
\hline$A \cap 00: 5$ & 3 & 3 & 13 & $1<47$ & $170 ?$ \\
\hline$A, 1000 ?$ & $A$ & 2 & 22 & 1651 & 1778 \\
\hline$F \cap 2 \| A_{1}$ & $u$ & 3 & 13 & 1700 & $17 \cap 8$ \\
\hline $\mathrm{DLO} 45 \div 3$ & L & 3 & 13 & 170 . & 1710 \\
\hline A40.370 & h & 3 & 22 & 1700 & 1711 \\
\hline$F+2450$ & $A$ & 3 & 2 & $171^{x}$ & 171.3 \\
\hline$F \wedge 14 f, 1$ & ن & 3 & 13 & $170^{n}$ & 1714 \\
\hline$T 110.533$ & 0 & 3 & 13 & $164 \pi$ & 1715 \\
\hline$A A O 1,9$ & U & 3 & 13 & $170 n$ & 1717 \\
\hline TW01 fil & $j$ & 3 & 13 & $170 n$ & 1719 \\
\hline Trino? & $A$ & 3 & 2 & 171 & 1713 \\
\hline ALOG"in & $n$ & 3 & $\because$ & $15,5 x$ & 1700 \\
\hline
\end{tabular}




\begin{tabular}{|c|c|c|c|c|c|}
\hline$E \wedge 20 F 2$ & $\cup$ & 3 & 18 & $172^{n}$ & $17 ? ?$ \\
\hline$E A 14: 3$ & $\jmath$ & 3 & 13 & 1723 & 1723 \\
\hline$E \wedge 0545$ & L. & 3 & $1 ;$ & $165 ?$ & 1724 \\
\hline DLO 36.7 & 1 & 3 & 1.3 & $171 r$ & $17>5$ \\
\hline UAOYI" & $A$ & 3 & $? ?$ & 1721 & 1725 \\
\hline Tw03?? & $A$ & 3 & 32 & 1726 & $17 ? 8$ \\
\hline$E A \cap 151$ & ij & 3 & 13 & 1705 & 1709 \\
\hline$E A O \geqslant 19$ & $D$ & 3 & 1.3 & $1>2 n$ & $17=1$ \\
\hline $\mathrm{OLO}, \ldots 5$ & $\lambda$ & 3 & $? ?$ & 1739 & 1734 \\
\hline$A 40572$ & $A$ & 3 & $2:$ & $15.4^{-}$ & 1736 \\
\hline NE 1,53 & $A$ & 3 & 37 & $171 n$ & 1737 \\
\hline EAO7:? & ن & 3 & 13 & $173 r$ & 1720 \\
\hline $\mathrm{AAO}_{414}$ & $A$ & $?$ & 22 & $17 \hat{2}$ & $1.71+0$ \\
\hline $\mathrm{AnO}_{4} \leq \mathrm{n}$ & r. & 3 & 22 & 1731 & 1744 \\
\hline AAOUก? & $u$ & 3 & 13 & $173 n$ & 1745 \\
\hline$F \cap 245,1$ & $A$ & 3 & 32 & $175 n$ & 1746 \\
\hline$A \cap 0,5 ? 4$ & $A$ & 3 & 22 & 1744 & 1748 \\
\hline$A A 04 \cap 5$ & D & 1 & 13 & $173^{\circ}$ & 1740 \\
\hline$F, A 9536$ & $J$ & 3 & 13 & 1740 & 1751 \\
\hline $1 J A 01317$ & j & 3 & 13 & 1745 & $175 ?$ \\
\hline$A A \cup 373$ & $J$ & 3 & 13 & 1745 & 1754 \\
\hline$A A 04: 7$ & li & 3 & 13 & $173 n$ & 1756 \\
\hline$A L 0_{B 3}=7$ & $u$ & 3 & 13 & 1745 & 1757 \\
\hline $\mathrm{AAO}_{44 \mathrm{n}}$ & $A$ & 3 & $2 ?$ & $173 n$ & 1757 \\
\hline$A A O 3,35$ & $A$ & 3 & $3 ?$ & 1745 & 1758 \\
\hline$T x^{0} 0.337$ & is & 2 & $1 \geq$ & 1745 & 1750 \\
\hline T:051? & $A$ & 3 & 32 & 1740 & $18 \cap 0$ \\
\hline$E \wedge 01: 3$ & $u$ & 3 & 13 & $175^{\circ}$ & 1800 \\
\hline$T N 0436$ & $A$ & 3 & 22 & 1751 & $180 ?$ \\
\hline$E A 14>1$ & 0 & 2 & 13 & 1000 & $18 \cap 4$ \\
\hline$D L 0: 457$ & $A$ & 3 & $>2$ & $175 \%$ & $18 \cap 4$ \\
\hline$E \wedge 1 \cap G 1$ & $A$ & 3 & $? ?$ & 1737 & $18 \cap 6$ \\
\hline FA21+52 & $A$ & 3 & $3 ?$ & $18 \cup 7$ & $18 \cap 7$ \\
\hline$T W_{1} \geqslant 5$ & 0 & 3 & 1.3 & 1755 & $18 \cap 8$ \\
\hline T:40ว?? & $A$ & 3 & $?$ & 1755 & $18 \cap 9$ \\
\hline FA2071 & $u$ & 3 & 13 & lan & 1810 \\
\hline NE 1 万F 4 & i) & 3 & 13 & $175^{n}$ & 1811 \\
\hline OLO2!? & $A$ & 3 & $2 c$ & $174 \%$ & 1811 \\
\hline$E A D O P 1$ & is & 3 & 13 & 1007 & 1813 \\
\hline ALOB?S3 & $A$ & 3 & 22 & 1740 & 1813 \\
\hline$E \cap \cap,>4$ & $A$ & 3 & $2=$ & $180=$ & 1318 \\
\hline$A A O ; \leqslant 3$ & is & 3 & 13 & 1nun & 1318 \\
\hline RNOONO & $u$ & 3 & 13 & $170 n$ & 1819 \\
\hline NE $1 \cap>4$ & $n$ & 3 & 13 & 1015 & 1320 \\
\hline$A A D: 219$ & $A$ & 3 & 32 & 150 & 1820 \\
\hline EA1063 & $\Lambda$ & 3 & $2 \hat{2}$ & $1.2 ?$ & $182 ?$ \\
\hline$\triangle A O 355$ & $\mathrm{u}$ & 3 & 13 & 1oun & 1823 \\
\hline UAOSTS & $A$ & 3 & $2 ?$ & $1 \times 19$ & 1825 \\
\hline
\end{tabular}




\begin{tabular}{|c|c|c|c|c|c|}
\hline$E A 2 i / 2$ & i) & $?$ & 13 & 1025 & 1825 \\
\hline EAO063 & $A$ & 3 & .2 & 1815 & 1827 \\
\hline EA 1473 & L & 3 & 13 & 1920 & $18 ? 9$ \\
\hline$E A 1475$ & 3 & 3 & 13 & $1 \times 3 n$ & 1832 \\
\hline$A A 0431$ & $A$ & 3 & 32 & 142 & $18 \times 5$ \\
\hline$A A O \cap 17$ & 0 & 3 & 13 & 183 & 1837 \\
\hline$T \times 03.6$ & $\hat{A}$ & 3 & ?? & $1 \&: 26$ & 1839 \\
\hline$E \cap 24: 1$ & A & 3 & 3 & 1046 & 1847 \\
\hline $\mathrm{NCO}_{4}, ?$ & fi & 3 & $2 ?$ & $1 \times 4$ & 18343 \\
\hline$E A I_{\|}>1$ & $\lambda$ & 3 & $? ?$ & $10.4 n$ & 1845 \\
\hline$A A O S, 5$ & i) & 3 & 13 & $1 \times 3$. & 18117 \\
\hline EAOOIn & $A$ & 3 & 32 & $1 \times 25$ & 18147 \\
\hline$n L 0457$ & U & $z$ & $1 \overline{3}$ & $184 n$ & 1840 \\
\hline UAO3 378 & $A$ & $z$ & 22 & 1247 & 1850 \\
\hline$\triangle A D 173$ & U & 3 & 13 & $1 \times 4 r$ & 18359 \\
\hline$A \cap 0+42$ & $A$ & 3 & 22 & 1942 & 1853 \\
\hline$A L O=3,5$ & $U$ & 3 & 13 & $1 \cap 3 c$ & 1853 \\
\hline$A L \cap 75: \Omega$ & $A$ & 3 & $3 a^{2}$ & 1747 & 1855 \\
\hline (1) & $A$ & 3 & $p$ & 1042 & 1856 \\
\hline EAOG, $/ 4$ & U & 3 & 13 & 194 & 1358 \\
\hline FA247? & $A$ & 3 & 22 & $1 \cap 50$ & 1858 \\
\hline$\| A 0 ;>4$ & A & $z$ & 3 & 1046 & 1850 \\
\hline FAL:1 & $U$ & 3 & is & $100 m$ & 1900 \\
\hline$E \wedge 2: 1$ & L. & $\therefore$ & 13 & $100 r$ & $13 n 1$ \\
\hline$A \cap \cap 454$ & $A$ & 3 & 22 & 1945 & $19 \cap 1$ \\
\hline$T \times 00: 6$ & $A$ & 3 & 32 & 1045 & 1902 \\
\hline Tr0.339 & L & 3 & 13 & 1345 & 1906 \\
\hline$E \wedge 1 \cap 7 \pi$ & A & 2 & ?? & $130 \mathrm{~K}$ & 1906 \\
\hline AAO $\$ 64$ & $\dot{A}$ & 3 & $2 ?$ & $1: 13$ & $19 \cap 3$ \\
\hline $\mathrm{AAO}_{4} \times 1$ & $u$ & 3 & 13 & 1000 & 1909 \\
\hline$F \cap 2474$ & $n$ & 3 & 22 & 191 & 1910 \\
\hline$E \cap 0,3,2$ & $n$ & 3 & 22 & $185 \%$ & 1911 \\
\hline$A A 0,4 C$ & $u$ & 2 & 13 & $190^{r}$ & 1993 \\
\hline FAOU1).3 & 1 & 3 & 3 & 1.55 & 1915 \\
\hline$\triangle A O \supset \cap B$ & $A$ & 3 & $? ?$ & 1945 & 1916 \\
\hline EA14A3 & 11 & 3 & 21 & 1020 & $192 ?$ \\
\hline$E \wedge 0_{1} \cap 2$ & $A$ & 3 & $? ?$ & 1919 & 19?? \\
\hline$E A 2 \pi \because 2$ & ) & 2 & 31 & $102^{2}$ & $19 ? 3$ \\
\hline ALOSO? & $\Lambda$ & 3 & $?$ & 195 & $19 ? 4$ \\
\hline$T w 06,53$ & $?$ & 2 & 31 & inor & 1925 \\
\hline OLO 178 & $A$ & 3 & $3 ?$ & $1 \cap 1$. & 1926 \\
\hline OLO $2 ? 3$ & $\checkmark$ & 3 & $x_{1}$ & inin & 1927 \\
\hline $\operatorname{Nin} 0 \Rightarrow 22$ & $A$ & 3 & 3 & 1015. & 1908 \\
\hline An: $0: 3 \cap 1$ & $U$ & 3 & 31 & 1215 & 1920 \\
\hline$\triangle A O 3 ? 6$ & A & 3 & $?$ & 101 & 1930 \\
\hline EA2:1184 & ) & 3 & 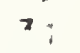 & 103 & 1931 \\
\hline TWO 330 & 4 & $z$ & $?$ & 1026 & 1933 \\
\hline ALOY:T & U & 3 & 31 & 163 . & 1. 934 \\
\hline$E \cap 2+1$ & $A$ & 3 & $?$ & 1040 & 1934 \\
\hline 831100774 & $A$ & 3 & 3 & $172 n$ & 1937 \\
\hline
\end{tabular}




\begin{tabular}{|c|c|c|c|c|c|}
\hline Tw0, & L & 3 & 21 & 1 non & 1038 \\
\hline$A \cap \cap 4: ?$ & $u$ & 3 & 21 & $1 \cap 3 n$ & 1942 \\
\hline$A \wedge O,, \neg, B$ & $A$ & 3 & $?:$ & 1935 & 1944 \\
\hline$E A 1 \cdots \cdots 1$ & $A$ & 3 & 22 & $103 n$ & 1945 \\
\hline$A f_{1} 03 r_{14}$ & A & 3 & $? ?$ & $1: 4 n$ & $195 ?$ \\
\hline 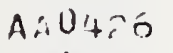 & A & 3 & $?$ & 1047 & 1953 \\
\hline$E \cap 14 \cap 3$ & 0 & 3 & 21 & 1052 & 1953 \\
\hline$T: 0475$ & $U$ & 3 & 31 & 1035 & 1955 \\
\hline$E A 24: 2$ & 4 & 3 & 2? & 1050 & 1955 \\
\hline$A A O 511$ & $U$ & 3 & 31 & 1035 & 1957 \\
\hline $\mathrm{AAO}_{4} 55$ & 1) & 3 & $z$ & $1 n 3 n$ & 1958 \\
\hline NE. $14 / 15$ & A & 3 & $P c^{2}$ & 174 & 2000 \\
\hline $\mathrm{NCO}, 155$ & U & 3 & 31 & 1040 & $20 \cap 1$ \\
\hline$E A O 7+3$ & A & 7 & $? 2$ & 1059 & 2003 \\
\hline$\left.F A 2_{1}\right)$ I & 1) & 3 & 31 & $2 n 0 r$ & 2006 \\
\hline $\operatorname{Tin} 0170$ & $A$ & 2 & 22 & $105 a$ & 2007 \\
\hline ALO5,19 & i) & 3 & $3 !$ & $104 r$ & $20 \cap 8$ \\
\hline DL 19: 7 & a & 3 & $3 \%$ & $105^{n}$ & 2010 \\
\hline$T: 03143$ & $\mathrm{C}$ & 3 & $3 i$ & 1045 & 2012 \\
\hline$P I 0030$ & $A$ & 3 & $2 ;$ & 1040 & 2012 \\
\hline UAO $\{\cap 3$ & 0 & 3 & $z:$ & $1 \cap 55$ & $201^{x}$ \\
\hline$E A 14: 1$ & 0 & 3 & 21 & $2 n \theta n$ & 2015 \\
\hline$A A \cap: 1>5$ & $\Lambda$ & 3 & $\therefore i$ & 2000 & 2015 \\
\hline FAO 16? & $U$ & 3 & $3:$ & 1055 & 2016 \\
\hline EA10.15 & $A$ & 3 & $?:$ & $2 \times 17$ & 2017 \\
\hline UAOY? 1 & U & 2 & 31 & $20 u n$ & 2018 \\
\hline$U A D+15$ & $u$ & 3 & $3:$ & $200 n$ & ?.0?ก \\
\hline$E A 2 n \cap 2$ & 0 & 3 & 3 & $2 \cap 2 !:$ & 20214 \\
\hline$A A O 536$ & $\dot{A}$ & 3 & ?. & $2 n 16$ & 2025 \\
\hline EAO.355 & u & 3 & 31 & $2 \cap 05$ & 2025 \\
\hline$T+0147$ & U & 3 & 31 & $10.5 n$ & $20 ? 7$ \\
\hline$E A 1 \div 05$ & 0 & 3 & 21 & $2 \cap 2 n$ & 2029 \\
\hline$E \wedge 1 \cap .3$ & $A$ & 3 & $\jmath \hat{\imath}$ & $2 n .37$ & 2030 \\
\hline AAOS:5 & $\checkmark$ & 3 & $3 i$ & $2 n u^{n}$ & 2031 \\
\hline$A \wedge 0175$ & D & 3 & 31 & ?nus & 20.32 \\
\hline$F A 11 \cap 1$ & $A$ & 3 & 22 & $2 n 4 n$ & $203 ?$ \\
\hline AAO3?6 & U & 3 & 31 & $105 r$ & 2032 \\
\hline$E \wedge 0,308$ & $\hat{A}$ & 3 & 23 & $2 \cap 16$ & 2035 \\
\hline EAUSU7 & $A$ & 2 & 22 & $2 n 2 a$ & 2036 \\
\hline NWDP:35 & 0 & 3 & $3 i$ & $2 n 15$ & 2032 \\
\hline UAO 753 & D) & 3 & 31 & $2 n 1 n$ & $? 03 n$ \\
\hline$T \vee 0.334$ & $A$ & 3 & $? 2$ & $2 \cap 26$ & 2041 \\
\hline$T h 0144$ & $A$ & 3 & $n_{2}$ & 1051 & 2043 \\
\hline UAO550 & H & 3 & 22 & $2 n 3 n$ & 2045 \\
\hline$E \wedge 2,11$ & 4 & 3 & 22 & $2 \cap 5 n$ & 2047 \\
\hline$E A 0: 77$ & 0 & 3 & 21 & 2015 & 201049 \\
\hline NF. 1444 & 0 & 2 & 31 & $2 n 3 n$ & 2052 \\
\hline$A A 0 ?=1$ & $A$ & 3 & $2 ?$ & 2045 & 2055 \\
\hline$U_{4 i} D, 5,51$ & $u$ & 3 & 31 & $2 n 3 n$ & 2057 \\
\hline $\mathrm{AnO}_{4} \mathrm{z}_{n}$ & $A$ & 2 & 22 & 2047 & 2057 \\
\hline
\end{tabular}




\begin{tabular}{|c|c|c|c|c|c|}
\hline$F A O H, n$ & & 3 & $?$ & $2 n 2 \pi$ & 2058 \\
\hline$E A 1$ in 3 & () & 3 & 31 & $210 r$ & 2100 \\
\hline $\mathrm{NCO} \cup 5,1$ & $A$ & 3 & $2 ?$ & $20,4 ?$ & $? 100$ \\
\hline$A A 0 \times>5$ & 1) & 3 & 31 & $20.3 n$ & 2106 \\
\hline $\mathrm{AHOH}^{2} \mathrm{C}$ & 0 & 3 & 31 & $2 \cap 3 n$ & $21 \cap 7$ \\
\hline$K F 0_{116}$ & $A$ & 2 & $2 \%$ & $2 r, 45$ & 21.07 \\
\hline FA1:193 & A & 3 & 22 & 2107 & 2100 \\
\hline DL1 UクB & 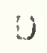 & 3 & 31 & $2 n: 4 n$ & 2130 \\
\hline DLO565 & $J$ & 3 & 31 & $2 n 4 n$ & $? 111$ \\
\hline FA2: & A & 2 & ?? & 2111 & 2111 \\
\hline$E \cap 21 \cap 1$ & ن & 3 & 31 & $21 u^{n}$ & 2112 \\
\hline$A O_{4} \cap 83$ & $\hat{A}$ & 3 & $?$ & $2 \cap 31$ & $211 ?$ \\
\hline 500.321 & $f_{1}$ & 3 & $?$ & $2 n 3 n$ & 2114 \\
\hline$\triangle A O 41 ?$ & 0 & 3 & $3 !$ & 2045 & 2116 \\
\hline OLO $1 \supset 0$ & iA & 3 & 2 & $204 a$ & 2116 \\
\hline $\operatorname{Tin} 0,347$ & U & 3 & 31 & $2 n 45$ & 2119 \\
\hline UAD5:44 & $A$ & 3 & 22 & ? ? 01 & 2113 \\
\hline EA24:4 & 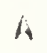 & 3 & $2 ?$ & $211 n$ & 2110 \\
\hline$T w 0>086$ & $A$ & 3 & $? ?$ & $210 \%$ & 2.120 \\
\hline 440549 & 0 & 3 & 31 & 2055 & 2123 \\
\hline$P I 0,3,3$ & 0 & 3 & $\times 1$ & $210 n$ & 2135 \\
\hline ALOSI: & $A$ & 3 & 22 & $2 \cap 43$ & $? 125$ \\
\hline 13.100105 & 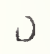 & 3 & 31 & $290 n$ & 2137 \\
\hline$A 400-5$ & D & 2 & 71 & $2 n 5 r$ & $P 1 \geq R$ \\
\hline$E A D,-3$ & u & $x$ & $2 y$ & 2105 & 2123 \\
\hline $0: 01: 1$ & $\dot{A}$ & $?$ & $p$ & $2 \times 2 r$ & 2120 \\
\hline$E \wedge 05: 4$ & $A$ & 3 & $?$ & 2042 & 2131 \\
\hline$F \wedge 15 \| 1$ & $u$ & 3 & 31 & $210 n$ & $213 ?$ \\
\hline$A F O S: B$ & $\lambda$ & 1 & $?:$ & $2 \cap 53$ & $? 13.3$ \\
\hline$T w 0.2,1$ & $\mathrm{U}$ & 3 & 31 & $2 n 5 n$ & 2135 \\
\hline$A A 93 \times 1$ & 0 & 3 & 31 & $214 n$ & $? 136$ \\
\hline NWO, $0, ?$ & $A$ & $z$ & 23 & $212^{n}$ & 2136 \\
\hline$T w 05>?$ ? & $A$ & 3 & 22 & $2 \times 47$ & 2139 \\
\hline UAOH1 4 & $A$ & 3 & ?? & 2110 & 2142 \\
\hline Tw01:3 & ט & 3 & 31 & $210 n$ & $214 ?$ \\
\hline$K F 0117$ & 0 & $?$ & 31 & $212 r$ & 2143 \\
\hline $\mathrm{ALOM}>4$ & $A$ & 3 & 22 & $2 \cap 53$ & 2143 \\
\hline FA2Sil & $\lambda$ & 3 & 22 & $215^{-}$ & 2145 \\
\hline ALO7:0 & $A$ & 3 & $? ?$ & $212 ?$ & 2147 \\
\hline ER:1:2 & $u$ & 3 & 31 & 2147 & $>148$ \\
\hline$E A 11 \cap 1$ & $A$ & 2 & 3 & 2142 & 2149 \\
\hline$F A O_{3}, 7$ & $U$ & 3 & 31 & $211=$ & 2150 \\
\hline$A A 0473$ & $A$ & 2 & $? ;$ & 2111 & $215 n$ \\
\hline DL0?2:1 & 0 & 3 & 31 & $212^{n}$ & $? 15 ?$ \\
\hline$E A 21 \cap 4$ & 3 & 3 & 31 & $215 x$ & 2153 \\
\hline$E A \perp 1: 3$ & $A$ & 3 & $2:$ & $215 x^{3}$ & 2153 \\
\hline DLn125 & $A$ & 3 & $2 \%$ & $212^{2}$ & 2155 \\
\hline$E A 0307$ & $\mathrm{D}$ & 3 & 31 & $213^{r}$ & 2156 \\
\hline PI0, 74 & $A$ & 3 & $2 \hat{\imath}$ & 2112 & 2157 \\
\hline NE 1141 & $a$ & 3 & 22 & 211 & 2202 \\
\hline
\end{tabular}




\begin{tabular}{|c|c|c|c|c|c|}
\hline$A A D^{2}=0$ & 3 & 3 & $3 i$ & $213^{-}$ & 2205 \\
\hline$A A O \sharp \therefore O$ & $\therefore$ & 3 & 22 & 2117 & $22 \cap 5$ \\
\hline EAD759 & $\lambda$ & 3 & ? & $214^{\circ}$ & 2205 \\
\hline WAOSSFA & $A$ & 2 & $\partial_{C}$ & $215 ?$ & $22 \cap A$ \\
\hline$\triangle A 0 \supset A 1$ & (i) & 2 & 31 & $212^{5}$ & 2200 \\
\hline Tพ0ว3⿻コ一 & $\dot{A}$ & 3 & $2 ?$ & $293 n$ & $22 ! 0$ \\
\hline $\operatorname{Var} \theta=9$ & 1) & 7 & 21 & 2927 & 2211 \\
\hline$A A O=70$ & $\dot{A}$ & 3 & 22 & $214 \pi$ & 2212 \\
\hline$A A O S \geq O$ & $A$ & 1 & $? ?$ & 2147 & 2213 \\
\hline TnO:0 5 & $U$ & 3 & 31 & $213 n$ & 2214 \\
\hline $0 \cup 0 \cap 46$ & L & $?$ & 31 & $2 r 5=$ & 2214 \\
\hline$T: W 0,5 ; 6$ & 4 & 3 & 28 & $215^{9}$ & 2216 \\
\hline$E+25 \cap 2$ & $h$ & 3 & ?? & $2 \hat{2} 17$ & 2217 \\
\hline NE 1,, 55 & $A$ & 3 & 32 & $214 r$ & 2219 \\
\hline$E A 1: 13$ & $U$ & 3 & 31 & $2 ? 2 n$ & $22 ? 0$ \\
\hline Aล0กบล & $A$ & 3 & 22 & $134 n$ & $? 2 ? 1$ \\
\hline$A L D>1+7$ & i & 3 & 22 & $1 \times 5 n$ & 2225 \\
\hline$E A 2111$ & ن & 3 & 31 & $220 n$ & 2276 \\
\hline NCOOF 7 & 0 & 3 & 31 & 2455 & 2230 \\
\hline 1140712 & $\hat{A}$ & 3 & $3 ?$ & $2 ? 0 n$ & 2230 \\
\hline$E A 25 \cap 74$ & $A$ & 3 & $\partial 2$ & $2 ? 3 ?$ & 2232 \\
\hline 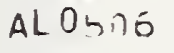 & u & 3 & 31 & $213^{n}$ & 2232 \\
\hline 500717 & $j$ & 3 & 21 & $211 n$ & 2234 \\
\hline OLO1=1 & $u$ & $x$ & 71 & $2 \cdot 4 \cap$ & 2236 \\
\hline$A A O=C$ & $A$ & $\pi$ & $2 ?$ & 2147 & 2.36 \\
\hline UAUSTד & $u$ & $x$ & $\geq 1$ & 2300 & 2237 \\
\hline $5 A 1175$ & $A$ & 3 & 2 & 2237 & 2.237 \\
\hline FAO::6,2 & $A$ & $x$ & 22 & $2 ? 17$ & 2239 \\
\hline FA1:11 & ? & 3 & 31 & $230 n$ & 2240 \\
\hline DLOOOO & $A$ & 3 & 22 & $2 ? 0^{2}$ & 2241 \\
\hline$E A .2112$. & $\mathrm{Q}$ & 3 & $=1$ & 2340 & 2242 \\
\hline $\mathrm{TWO}_{4} 56$ & $\hat{H}$ & 3 & 22 & 2147 & 2243 \\
\hline$A L 0_{1}, 7 \geq$ & U & ${ }^{2}$ & $x 1$ & 2200 & 2244 \\
\hline$T:$ П ระ1 & 1) & 3 & 31 & 2.145 & $? 245$ \\
\hline EAOSG4 & $r$ & 2 & $=2$ & $2=0=$ & 2245 \\
\hline TV: $0.44 ?$ & A & 3 & $? 2$ & $223 n$ & 2246 \\
\hline FAO & L & 3 & 71 & $220 n$ & 22147 \\
\hline EA15i5 & 0 & 3 & $3 i$ & 2247 & 2247 \\
\hline$A L 0,3 F 7$ & U & 3 & 21 & 2145 & 2240 \\
\hline$A A 0: 550$ & $A$ & 3 & $p_{i}$ & $2 ? 17$ & 2250 \\
\hline$A A 0473$ & i) & $x$ & $3 i$ & 2147 & 2251 \\
\hline$E A 1111$ & $A$ & 3 & $? ?$ & 235 & 2252 \\
\hline 020070 & $A$ & -3 & 22 & 2137 & 2254 \\
\hline$E A O_{i 1} \geqslant 4$ & A & 3 & $? \bar{c}$ & 2225 & 2255 \\
\hline UAOS6,5 & $u$ & 3 & 21 & $2>2 r$ & 2256 \\
\hline$A A 0>09$ & $A$ & 3 & $2 i$ & $2 ? 2 ?$ & 2258 \\
\hline$T w 0 / 111$ & ) & 2 & 21 & $295 r$ & 2259 \\
\hline NWO $0=33$ & ن & 3 & 21 & $2.22 n$ & $? 300$ \\
\hline $\operatorname{Tin} 05383$ & A & 3 & $?$ & $2>31$ & 2300 \\
\hline Tw0, 76 & $A$ & 3 & ?? & 2247 & $23 \cap 2$ \\
\hline
\end{tabular}




\begin{tabular}{|c|c|c|c|c|c|}
\hline$A A O 4 \times 7$ & u & 1 & 31 & $270 n$ & $23 \cap 5$ \\
\hline$A L 07383$ & $\hat{A}$ & 3 & $? ?$ & $273 n$ & 2306 \\
\hline NE $1 ;, 67$ & $A$ & 3 & 22 & $214 r$ & 2307 \\
\hline NE 147? & 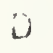 & 3 & $x 1$ & 2145 & 2308 \\
\hline PI0U52 & $A$ & 3 & $2 ?$ & 2725 & 2308 \\
\hline DL07?3 & [ & 3 & 31 & 2025 & 2310 \\
\hline EA2511 & $A$ & 3 & $?$ & $225 x$ & 2311 \\
\hline$P I 01149$ & ij & 3 & 31 & $232^{n}$ & 2311 \\
\hline TW0495 & U & 3 & $x 1$ & $2 ? 25$ & $? 313$ \\
\hline$A \operatorname{Ln} 77$ & $A$ & $x^{2}$ & $?:$ & $\ln 35$ & 2314 \\
\hline$N N_{-1443}$ & $A$ & 3 & 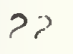 & $221 n$ & 2315 \\
\hline$A 1,04 ? 1$ & 0 & 3 & 31 & $213 n$ & 2315 \\
\hline NEI NSE & 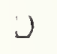 & 3 & 31 & 2015 & 3316 \\
\hline$A A O>A B$ & $A$ & 3 & 2 & $?-47$ & 2317 \\
\hline $\mathrm{CBO}_{3} \mathrm{n}$ : & $A$ & $?$ & $P \gamma$ & $2-1 n$ & 2318 \\
\hline$E A 0759$ & $U$ & 3 & 31 & $233 n$ & 2319 \\
\hline EAO:S4 & $A$ & 3 & $?$ & $215 h$ & 2320 \\
\hline$A A 01,35$ & 1) & 3 & 31 & 2955 & 2321 \\
\hline$F A 2: 14$ & $A$ & 3 & $?$ & 2320 & 2322 \\
\hline$E A D \leq 144$ & 3 & 3 & $3:$ & 2945 & 2323 \\
\hline$F \wedge 11>7$ & $\lambda$ & 3 & $2:$ & 2324 & 2324 \\
\hline EA21?1. & ij & 3 & 31 & 2300 & 2325 \\
\hline FAI,$? 3$ & () & 2 & $x_{i}$ & 2327 & 2327 \\
\hline$A A O: \triangle P A$ & $\dot{A}$ & 3 & 2 & 2347 & 2.327 \\
\hline$U A O \rightarrow ? O$ & $u$ & 3 & 31 & $2.30 n$ & 23.29 \\
\hline$E A 1 \div>1$ & ) & 3 & 31 & $230 n$ & 2320 \\
\hline TwO 355 & 1) & 3 & 31 & 2345 & $? 331$ \\
\hline$A L 0737$ & $1)$ & 3 & 31 & 1050 & 2333 \\
\hline$T N 0464$ & $A$ & 3 & $?$ & $275 a$ & 23.33 \\
\hline$O L O+112$ & $\therefore$ & 2 & 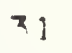 & $230 n$ & 2335 \\
\hline WwO 0,2 & $A$ & 3 & $2 ?$ & $275 r$ & .335 \\
\hline $\mathrm{ALO}_{4} 75$ & $A$ & 3 & 22 & 2255 & 2337 \\
\hline$A A O, 2,5$ & U & $x$ & 31 & $213 n$ & 2338 \\
\hline$E A 21,2$ & $\mathrm{u}$ & 3 & 31 & $2 \times 3 n$ & 2330 \\
\hline EA0.357 & $A$ & z & $? ?$ & 2305 & 2341 \\
\hline A 10531 & lj & 1 & 31 & $225 n$ & 2344 \\
\hline EA15>5 & (1) & 3 & 31 & 2345 & 2345 \\
\hline AAO156 & $A$ & 3 & $2 c$ & 2347 & 2346 \\
\hline$E A 1121$ & $A$ & 3 & 22 & 2345 & 2347 \\
\hline$A A 0139$ & i) & 3 & 31 & $233 n$ & 2348 \\
\hline $\mathrm{UAO}_{0}, \times 5$ & Uे & 3 & 31 & $2 \times 15$ & 23140 \\
\hline TW0:41 & ij & 3 & 21 & 2300 & 2351 \\
\hline 500716 & $A$ & 3 & $?$ & $2.32^{r}$ & 2351 \\
\hline$E A 2124$ & $\dot{U}$ & 3 & 21 & $2.35^{n}$ & 2352 \\
\hline NE $107 \mathrm{~B}$ & i) & 3 & $?$ & 202 & 2353 \\
\hline EAOSAS & 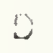 & 3 & 31 & $2 \pi 2 r$ & 2353 \\
\hline$F \cap 0.35,8$ & $A$ & 1 & $? 2$ & $2^{2} 3 n$ & 2354 \\
\hline 020971 & i & 3 & 31 & 2.245 & 2355 \\
\hline EA25:1 & is & 3 & 22 & $235 n$ & 2356 \\
\hline$A A O 2 A$ & U & 3 & 31 & $225 n$ & 2357 \\
\hline$A L 07: 3$ & $A$ & 3 & $2 ?$ & $230 r i$ & 2359 \\
\hline
\end{tabular}





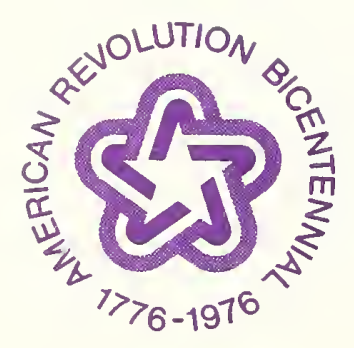

